Portland State University

PDXScholar

$1-1-2010$

\title{
Visions and Voices: An Arts-Based Qualitative Study Using Photovoice to Understand the Needs and Aspirations of Diverse Women Working in the Sex Industry
}

Moshoula Capous Desyllas

Portland State University

Follow this and additional works at: https://pdxscholar.library.pdx.edu/open_access_etds Let us know how access to this document benefits you.

\section{Recommended Citation}

Capous Desyllas, Moshoula, "Visions and Voices: An Arts-Based Qualitative Study Using Photovoice to Understand the Needs and Aspirations of Diverse Women Working in the Sex Industry" (2010).

Dissertations and Theses. Paper 23.

https://doi.org/10.15760/etd.23

This Dissertation is brought to you for free and open access. It has been accepted for inclusion in Dissertations and Theses by an authorized administrator of PDXScholar. Please contact us if we can make this document more accessible: pdxscholar@pdx.edu. 
Visions \& Voices: An Arts-Based Qualitative Study

Using Photovoice to Understand the Needs and Aspirations of Diverse Women

Working in the Sex Industry

\author{
by
}

Moshoula Capous-Desyllas

A dissertation submitted in partial fulfillment of the requirements for the degree of

Doctor of Philosophy

in

Social Work and Social Research

Dissertation Committee:

Stéphanie Wahab, Chair

Laurie Powers

Pauline Jivanjee

Julie Rosenzweig

Ann Mussey

Portland State University

(C) 2010 


\begin{abstract}
The ways in which sex workers have been studied and represented historically, socio-politically and academically do not take into account their voices, subjective experiences and participation in the process. Women working in the sex industry are seldom heard and their needs are consistently defined and represented by others. This contributes to the stereotyping and stigmatization of sex workers, while academic research is consistently being done on sex workers instead of with them.

This study uses the arts-based research method of photovoice with individuals working in the sex industry in Portland, Oregon to understand their needs and aspirations through their own artistic self-representation. Understanding sex workers' needs from their own point of view provides the opportunity for collaborative knowledge creation of important issues in order to enhance social service design and delivery, and advocate for social change. Valuing sex workers' aspirations supports the acknowledgement of individual strengths, skills, and visions.

Drawing from techniques of interpretive phenomenological analysis methods, the themes that emerge to illustrate the participants' needs and aspirations include: sustainability of the body; nourishment of the heart; fostering of the mind and soul; social justice and activism; dreams and desires; and self-empowerment and identity. The participants create meaning from their photographs through the use of self, performance, bodies, emotions, imagination, intellect, humor and story-telling. The role of intersectionality informs the sex workers' diverse experiences and their unique ways of self-expression.
\end{abstract}


The researcher uses collage as reflexivity to illustrate, contextualize and reflect her physical, emotional, and mental experiences throughout the study. The multiple art exhibits that ensue from this study allow for the artists' visions and voices to travel to a broad audience beyond academia, in order to reach influential community advocates and challenge stigma and stereotypes. This arts-based study presents the richness and complexity of alternative forms of data, invites new levels of engagement that are both cognitive and emotional, and provides creative ways through which to explore and understand the experiences of sex workers. 


\section{Dedication}

This dissertation is dedicated to the eleven artists featured in this study, who shared their lives, loves and wisdom with me. I learned so much from each one of these incredible women who trusted me to tell their stories and who continue to inspire me through their visions and voices.

* In loving memory of Rogue (1978-2010) * 


\section{Acknowledgements}

I will forever be grateful to various individuals in my life that provided strength, courage \& support throughout this journey. This dissertation would not have been completed without the participation and creativity of the amazing women who participated in this study: Alex, Bee, Crystal, Grahm, Jasmine, Lady Purfection, Merry Mag, Mouse, Rizzo, Rogue, and Sarah.

I wish to thank my community partner, Crystal Tenty, for her contribution and our collaboration on the various stages of this dissertation. I am forever grateful for her enthusiasm and commitment to this study and to sex workers' rights.

I feel deeply honored that Stephanie Wahab was willing to be a part of my dissertation journey, and I want to express my sincerest gratitude for her guidance, support and patience. Throughout the years, Stephanie continued to encourage and nurture my need to merge art, research and creative self-expression. She was a source of inspiration and an impressive role model in academia and for life. Stephanie taught me not to be afraid to push the boundaries and limits, for which I am eternally grateful.

I am particularly thankful to Laurie Powers, who shared her wisdom and expertise with me, and believed in my ability to implement this study when I struggled to find that belief in myself. Her constant support during our meetings always left me feeling energized, empowered and passionate about the possibilities.

Throughout this study, I had the constant moral support of Pauline Jivanjee, who met with me regularly to discuss my research process and experiences. I want to thank for her warmth, depth of perception and support of alternative ways of creating and representing research. 
Many thanks go to Julie Rozensweig who shared her enthusiasm for creative scholarship and continued to encourage me from the moment I entered the doctoral program. As my committee's outside member, Ann Mussey brought a penetrating curiosity and a deep, warm humanity to our discussions. I am particularly grateful to Ann who also showed her support and enthusiasm for this dissertation by attending the art exhibit.

I am eternally grateful to my editor, art show coordinator and amazing friend, Erika, for her support throughout many stages of this study. I also want to thank my peer reviewer, Diane, for her expertise and guidance throughout. My gratitude goes out to members of the DO MSW team, members of my Ph.D. Cohort and my fellow doctoral student colleagues who surrounded me with incredible support over the years.

I could not have done this without my lovely family, amazing friends and phenomenal partner, who surrounded me with love and laughter, and for always believing I would succeed in completing this dissertation. A very special thank you goes to Niko, for being by my side every step of the way. 


\section{TABLE OF CONTENTS}

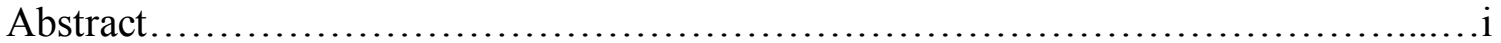

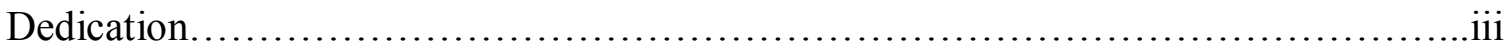

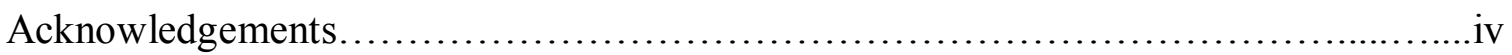

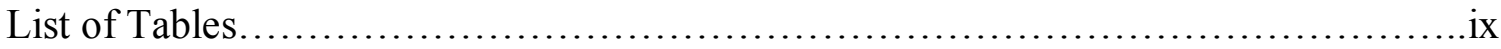

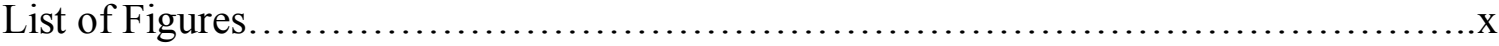

CHAPTER 1 - INTRODUCTION...............................................

Background...........................................................

Terminology \& Definitions............................................ 3

Sex Work, Prostitution, and the Sex Industry......................... 3

Feminist Perspectives on Sex Work .........................................5

Sex Work as Violence and Exploitation...............................6

Sex Work as Legitimate Work....................................8

Perspectives Outside of the Sex Work Polemic........................11

Significance of this Study................................................. 15

Relevance to Social Work.................................................... 16

CHAPTER 2 - LITERATURE REVIEW OF SEX WORKERS' NEEDS \& ASPIRATIONS......................................................20

Historical \& Socio-Political Representations of Sex Workers’ Needs \& Aspirations..........................................................20

Faith-Based Organizations.....................................20

Social Work Bodies..............................................21

Medical Professionals................................................25

Policy Makers........................................................27

Social Movements and Organizations................................31

Academic \& Research-Based Representations of Sex Workers' Needs............35

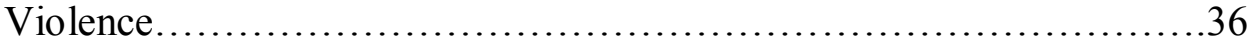

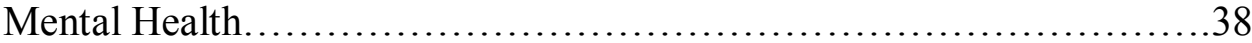

Drugs \& Alcohol.................................................... 38

HIV/AIDS........................................................... 39

Needs Assessment Studies.........................................41

Limitations of Social Science Research............................42

Creative \& Artistic Representations of Sex Workers' Needs \& Aspirations......44

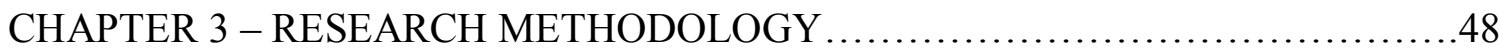

Location of Self.......................................................48

Research Questions.................................................. 50

Arts-Based Research Framework.........................................51

Art as a Way of Knowing.........................................52

Key Features of Arts-Informed Inquiry..............................53

Creative Forms of Data Representation.............................55

Use of Images in Research............................................57 
Theoretical \& Practical Framework...............................................55

Feminist Standpoint Theories...........................................59

Knowledge as partial and situated...........................60

Woman as epistemologically privileged.......................662

Limitations of theory.........................................64

Freire's (1970) Approach to Empowerment Education....................65

Education for critical consciousness.............................66

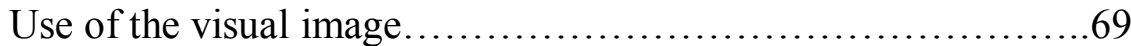

Limitations of approach....................................70

Participatory Approach to Documentary Photography....................71

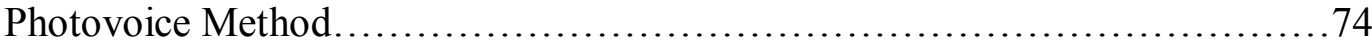

Concepts of Photovoice.............................................76

Photovoice Research Studies...........................................78

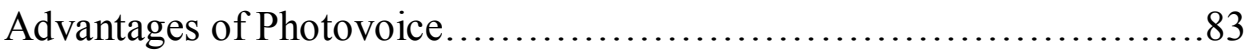

Limitations of Photovoice.......................................... 86

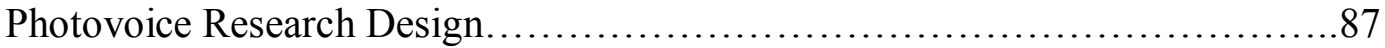

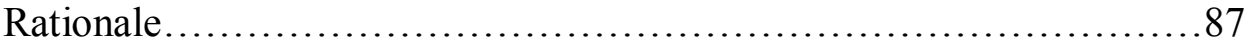

Manifestations of the Photovoice Process...............................88

I. Contextualizing the project............................... 89

Identifying the site.................................... 89

Selecting the methodology $\ldots \ldots \ldots \ldots \ldots \ldots \ldots \ldots \ldots \ldots . \ldots \ldots$

Community partnership..............................91

Community support.................................99

II. Finding the artists......................................99

Sampling and recruiting ............................99

Participant diversity...................................96

III. Orientating the artists to the tools of artistic expression........98

Conducting the photovoice trainings.....................98

Group photovoice training session.......................99

Individual photovoice training sessions..................101

Devising the initial theme for taking the photographs....102

IV. Taking the photographs and creating art....................103

Artists in the community..............................103

Unanticipated occurrences............................104

V. Individually reflecting, dialoguing and storytelling...........105

Selecting photographs for discussion....................105

Contextualizing and storytelling.......................107

VI. Communal dialoguing and sharing the artistic creations......108

Group Dialogue Sessions.............................108

Selecting photographs for art exhibit....................111

Organizing the representation of the art.................112

VII. Disseminating artistic creations to the public................114

Community art exhibits...............................114

Media coverage and attention...........................116

Audience interactions with art.........................116 
CHAPTER 4 - DATA ANALYSIS PROCEDURE...............................119

Artistic Representation of Analysis Process............................... 120

Within-Case Analysis of Individual Transcripts............................ 123

Step 1: Immersion in the data................................... 123

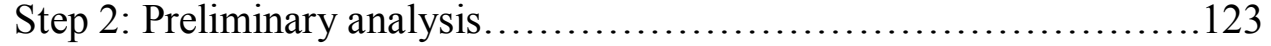

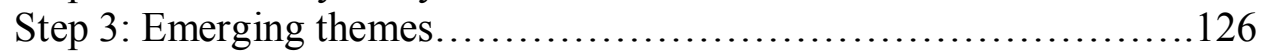

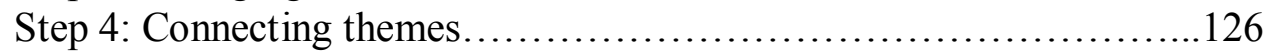

Step 5: Creating individual analysis summary.......................129

Step 6: Final categories.......................................130

(Visual) Cross-Case Comparison \& Synthesis............................. 131

Step 7: Parallel process of analysis...............................131

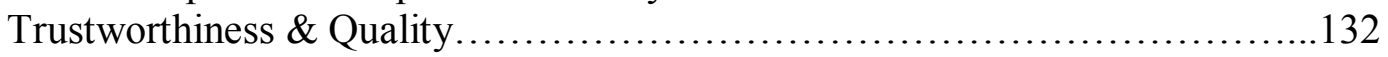

CHAPTER 5: SELF AS ARTIST/RESEARCHER .............................. 135

Reflexivity through Collage............................................ 135

Creation of Collages.................................................... 136

Collage I: Possibilities for an Outsider...............................139

Collage II: Chaotic Liberation..................................145

Collage III: The Wait, I Carry ...................................151

CHAPTER 6: PRESENTATION OF THE ARTISTS \& THE FINDINGS............155

Portraits of the Artists..................................................... 155

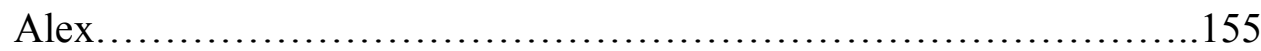

Bee.............................................................

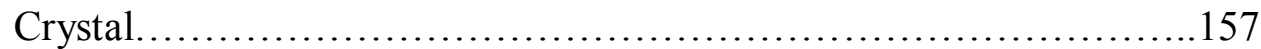

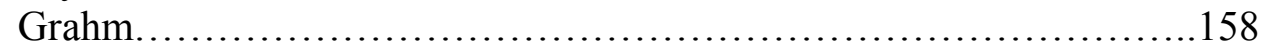

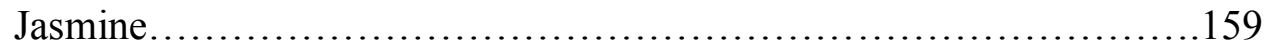

Lady Purfection................................................. 160

Merry Mag....................................................... 161

Mouse.............................................................. 162

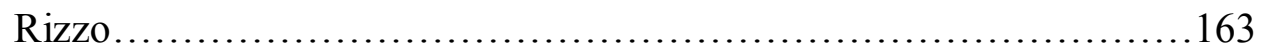

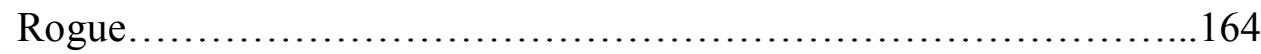

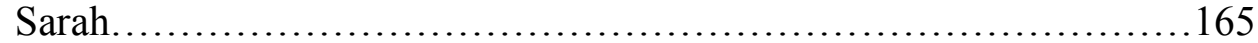

Overview of Photographs and Themes....................................... 166

Artistic Representation of Six Themes..................................... 171

Presenting the Findings............................................... 174

Sustainability of the Body.................................... 174

Resources for survival..................................... 175

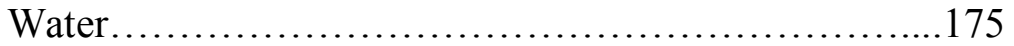

Food................................................ 176

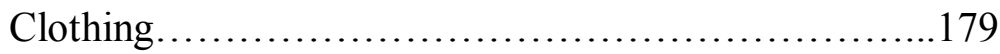

Restrooms....................................... 180

Shelter............................................ 182

viii 


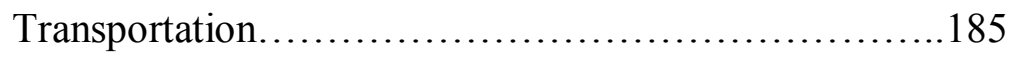

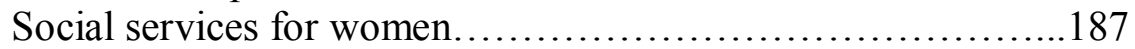

Safety and protection........................................ 188

Self care for preservation....................................192

Privacy and solitude..........................................194

Income generation....................................... 196

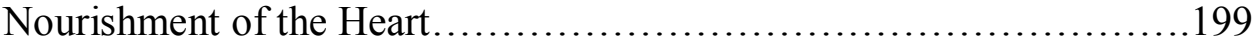

Love and romance......................................200

Family, friends and community.............................205

Family ...............................................

Friends..............................................207

Partners................................................210

Community.............................................211

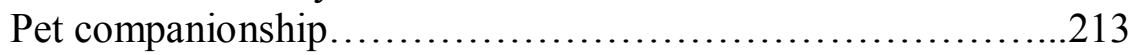

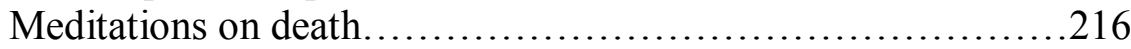

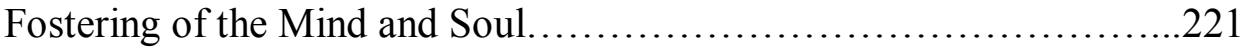

Educational endeavors....................................221

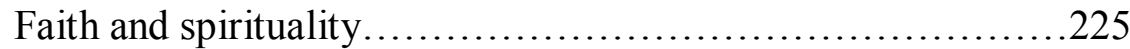

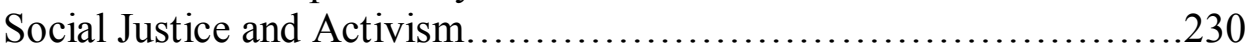

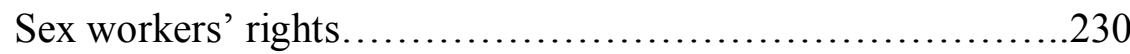

Judgment, stigma and stereotypes..........................234

Poverty and racism..........................................239

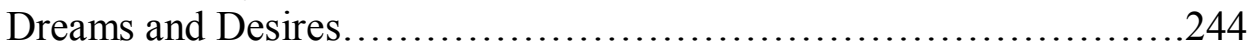

Play, fun and happiness..................................244

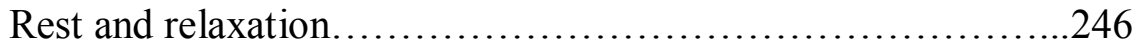

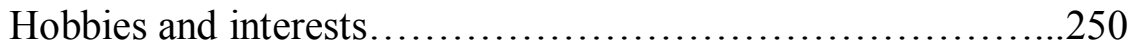

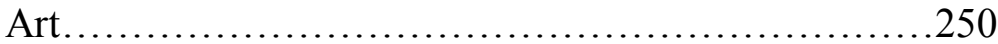

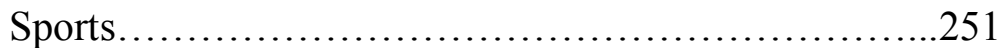

Music................................................252

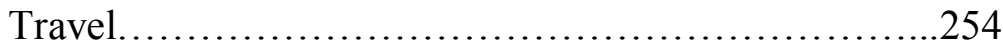

Career Interests.......................................255

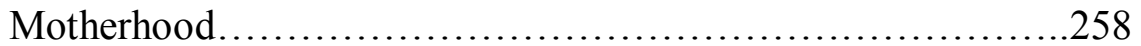

Self-Empowerment and Identity...................................261

Inner strength and personal growth.........................262

Relationship with work.................................266

Work environment and satisfaction.....................267

Sex work as art.........................................270

Work accessories..................................273

Identity and existence....................................274

Self-confidence......................................278

Respect and recognition...................................280

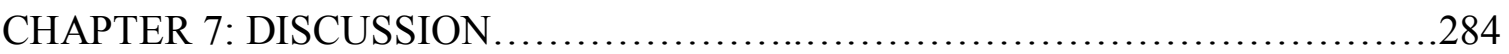

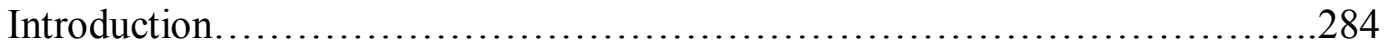

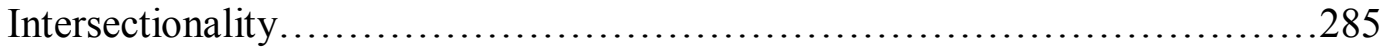


Diversity of Needs and Aspirations...............................286

Self Perceptions...............................................291

Construction of Needs and Aspirations..............................291

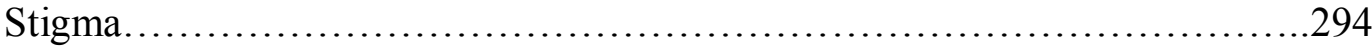

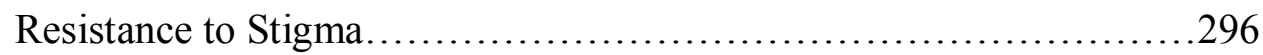

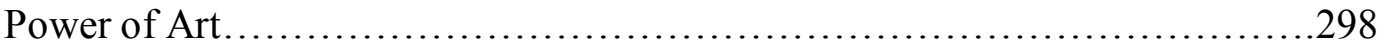

For the Artists..................................................298

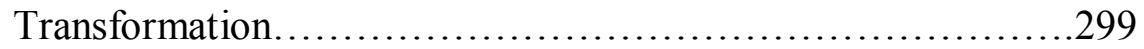

Empowerment............................................299

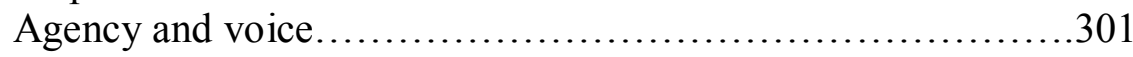

Visibility and existence.................................... 301

For the Researcher............................................302

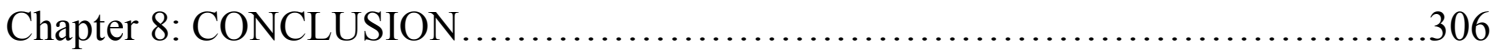

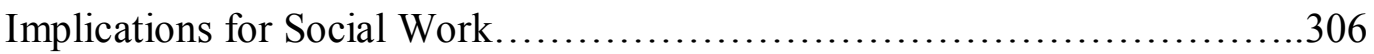

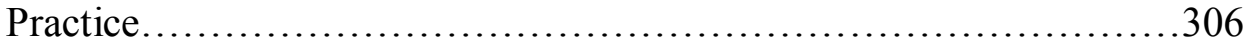

Valuing knowledge through art............................307

Service design and delivery................................308

Working towards social change........................... 312

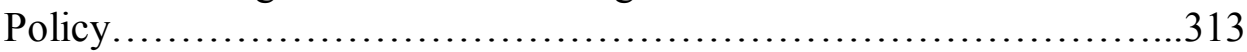

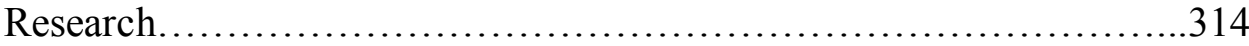

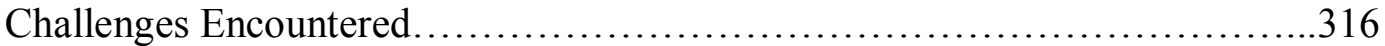

Suggestions for Future Research....................................... 319

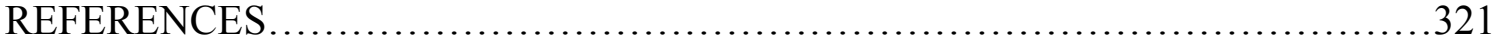

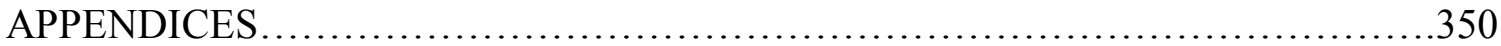

Appendix A: Recruitment Flyer.........................................350

Appendix B: Social Service Agency Recruitment Letter.....................351

Appendix C: Telephone Recruitment and Screening Script....................352

Appendix D: Consent Form........................................... 356

Appendix E: Project Summary Handout....................................359

Appendix F: Training Workshop Session Curriculum.........................360

Appendix G: Tips for Using a Camera \& Taking Photographs Successfully.....362

Appendix H: Demographic Data Form................................... 363

Appendix I: Individual Dialogue Session Questions Guide....................364

Appendix J: PSU Photo Release Form.................................. 365

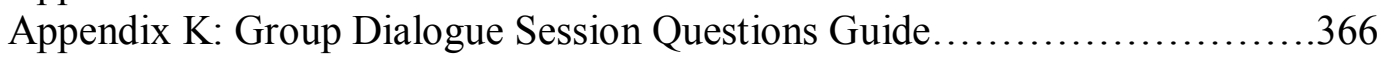

Appendix L: Participant Contact Sheet......................................368

Appendix M: Recruitment Flyer with Graphic............................. 369

Appendix N: Art Exhibit Flyer........................................ 370 


\section{LIST OF TABLES}

Table 1: Preliminary Analysis Procedure Table................................... 125

Table 2: Table of Connecting Themes......................................... 127

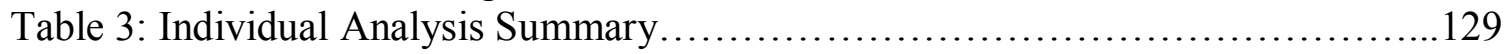

Table 4: Final Categories Table............................................ 131 


\section{LIST OF FIGURES}

Figure 1: Visual Representation of Analysis Process................................122

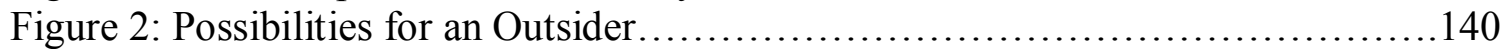

Figure 3: Chaotic Liberation.................................................... 146

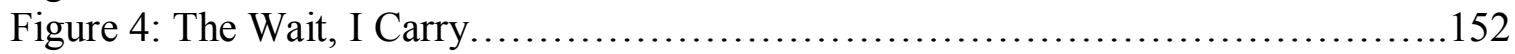

Figure 5: Continuum of Needs and Aspirations......................................169

Figure 6: Visual Representation of the Themes of Needs and Aspirations...............170

Figure 7: Untitled.............................................................. 175

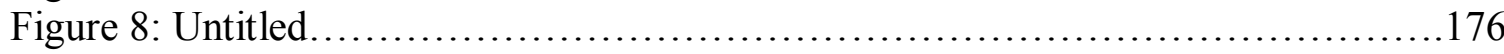

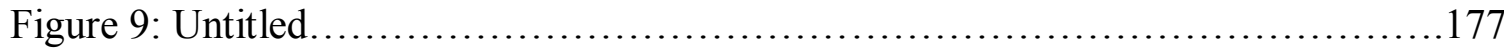

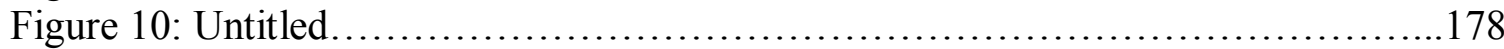

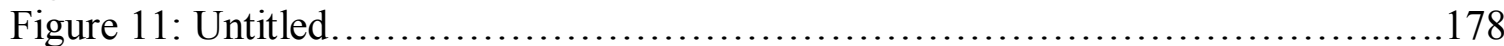

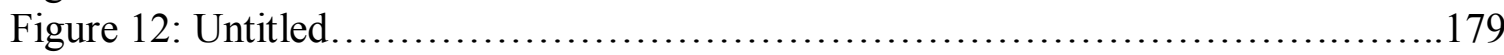

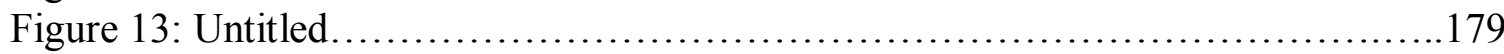

Figure 14: Shooting gallery, office, beauty salon, motel room, and also, surprisingly, just a bathroom...................................................... 180

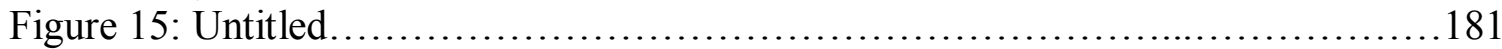

Figure 16: Our rights-basic human dignity ..................................... 181

Figure 17: Camp, Sweet Camp.................................................... 182

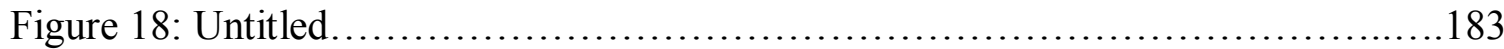

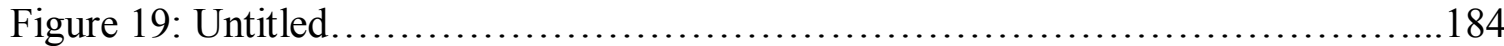

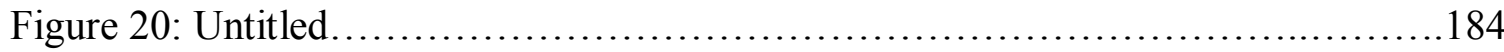

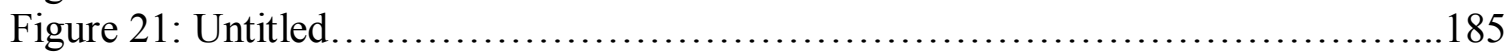

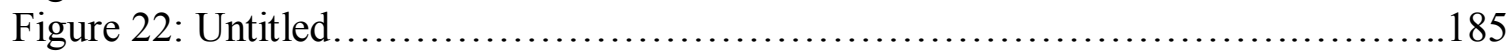

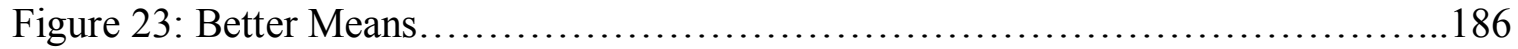

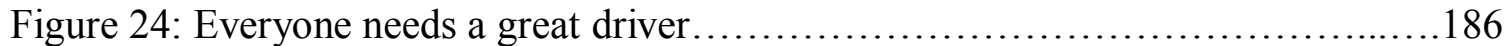

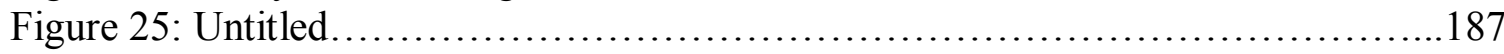

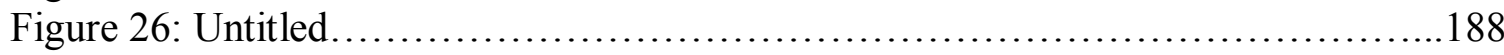

Figure 27: Sometimes Sex Work Hurts-Call the Bad Date Line. Not all People Hate

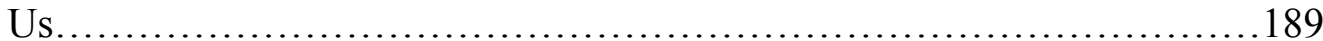

Figure 28: An angel always watching over the women working the street who are vulnerable to the utmost evil............................................. 190

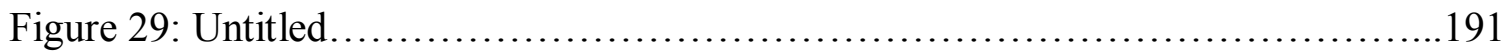

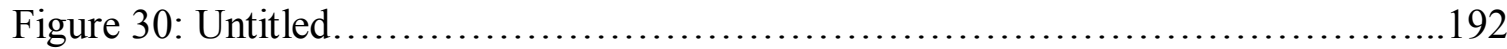

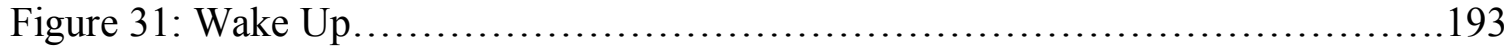

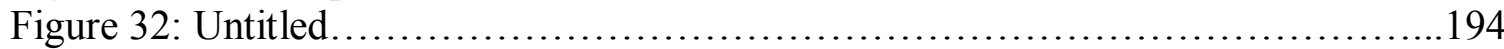

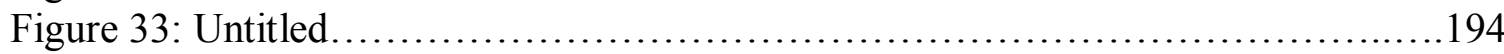

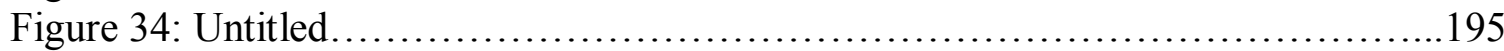

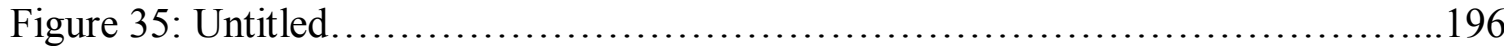

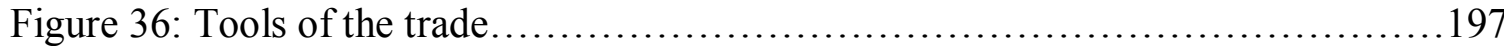

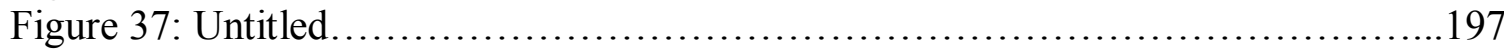

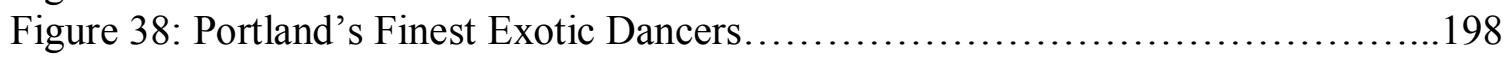

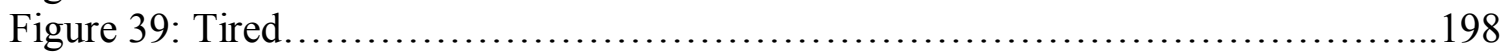

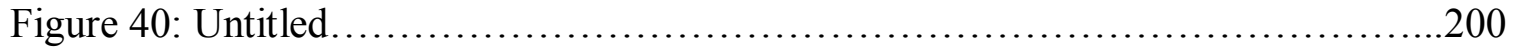




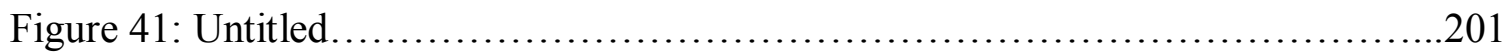

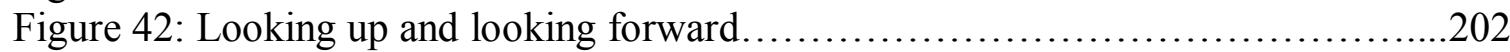

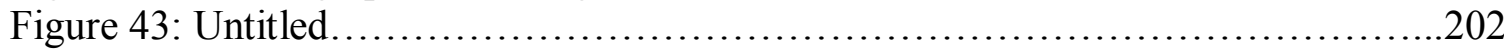

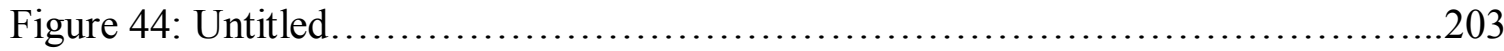

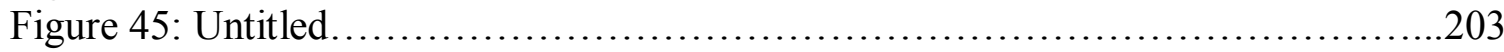

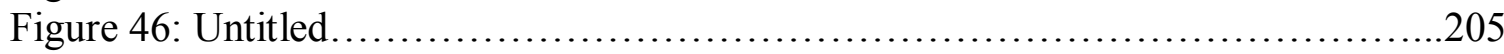

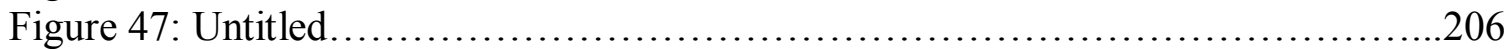

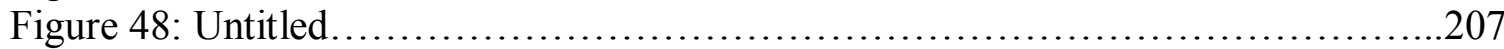

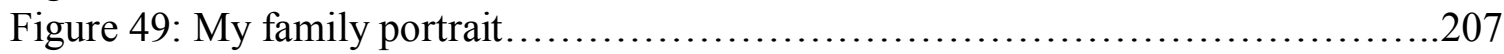

Figure 50: Untitled...................................................... 208

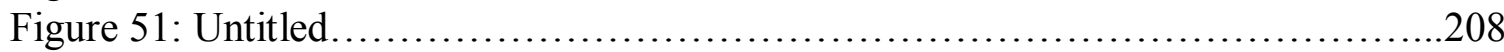

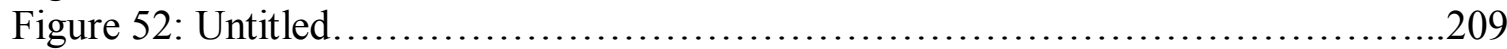

Figure 53: Untitled............................................................ 210

Figure 54: We grind. Warmth, comfort, speed naps, companionship.................210

Figure 55: Untitled.......................................................211

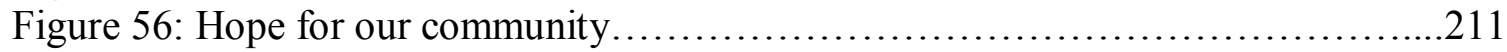

Figure 57: I can only hope my feet are matched and weathered as much as these beautiful feet from walking and doing outreach to others in poverty.........212

Figure 58: Untitled......................................................... 213

Figure 59: Cowboy: sporadic...fun, inspiration, love...never judges me for my

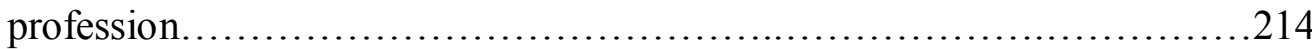

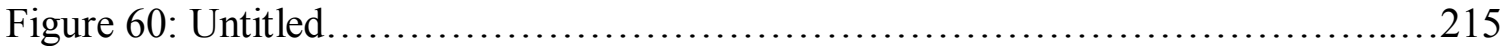

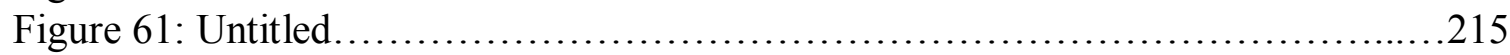

Figure 62: Untitled......................................................216

Figure 63: See you in Ho Heaven Tomorrow.....................................217

Figure 64: Eileen Wournos - you are my hero...................................218

Figure 65: A memorial sound at the trailheads in Forest Park, in remembrance of the three beautiful women violently raped and killed here.....................219

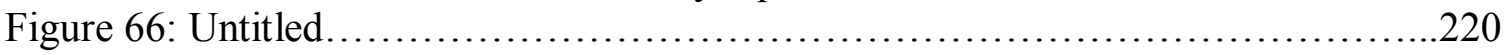

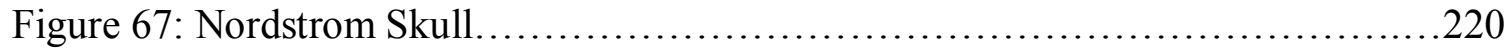

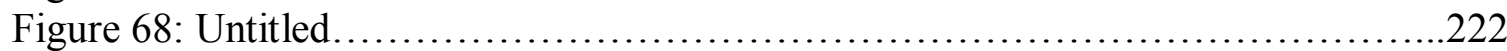

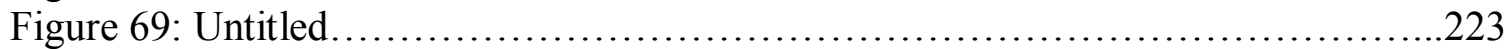

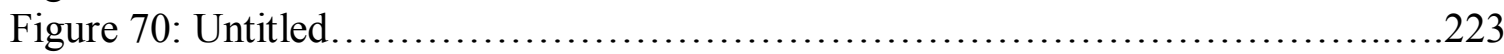

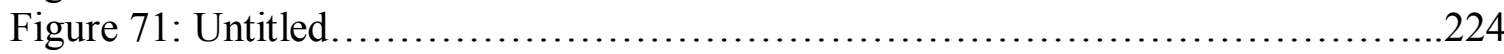

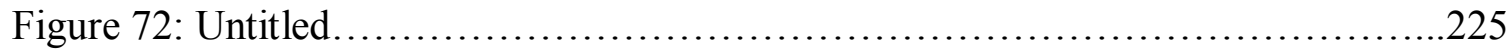

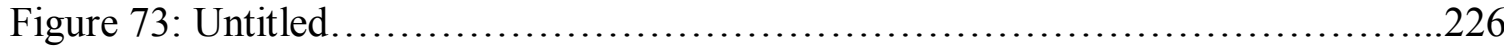

Figure 74: Being spiritual and having a good relationship with God..................226

Figure 75: My Best Friend....................................................227

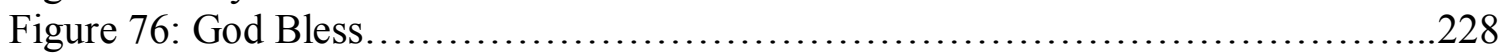

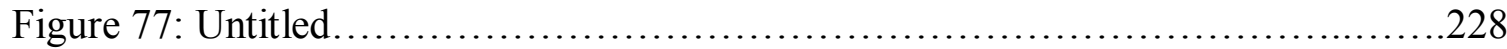

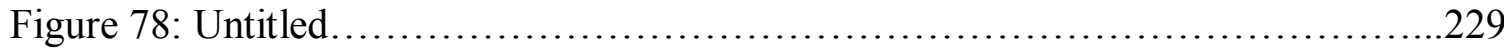

Figure 79: Untitled......................................................229

Figure 80: The three condom law: This could get YOU arrested for prostitution! .......231

Figure 81: The last legal pussy...............................................231

Figure 82: There is no shame in consensual sex work. There is shame in a society 
that would criminalize us for trying to support and protect ourselves........232

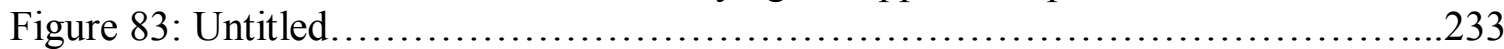

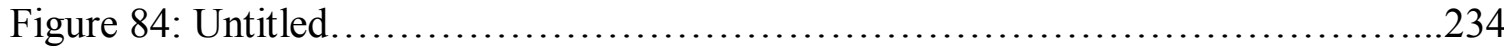

Figure 85: Collecting drinks in the dressing room...............................235

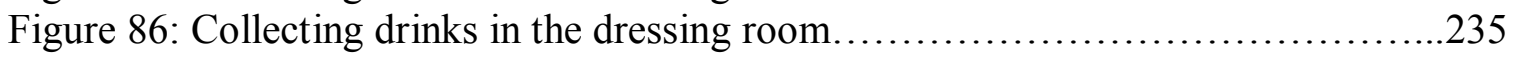

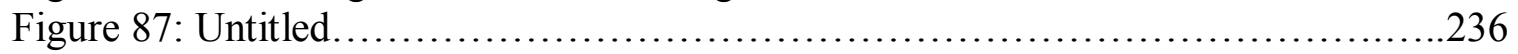

Figure 88: Who all are innocent I................................................. 236

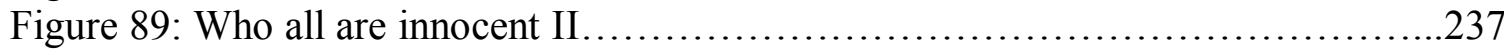

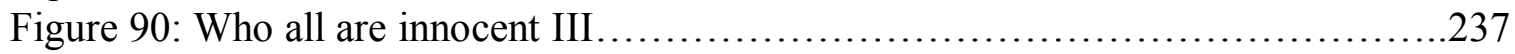

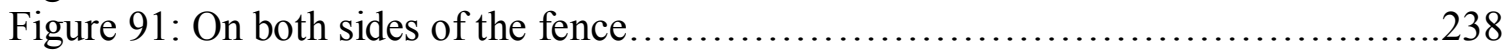

Figure 92: Untitled.......................................................239

Figure 93: It's a rich white-man's world- How many childhoods are lost? I started in sex work at the tender age of 12 in the USA.................................240

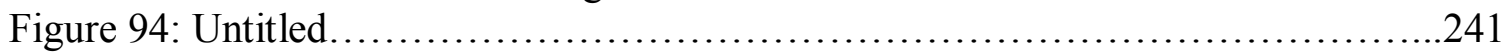

Figure 95: Untitled.........................................................241

Figure 96: Untitled......................................................242

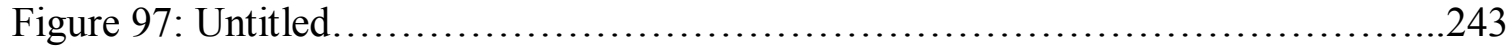

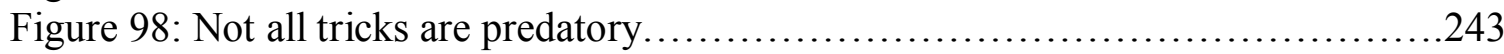

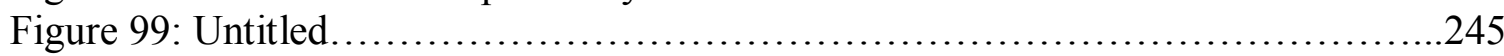

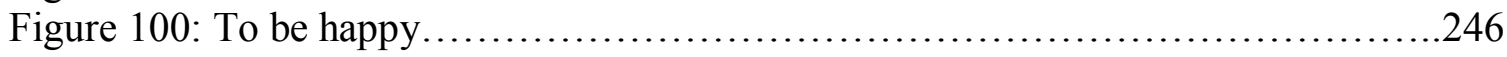

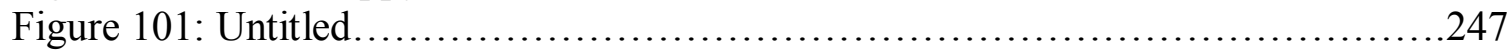

Figure 102: Life with hope is freedom to believe in your future.....................247

Figure 103: Untitled......................................................248

Figure 104: Awakening Vision..............................................248

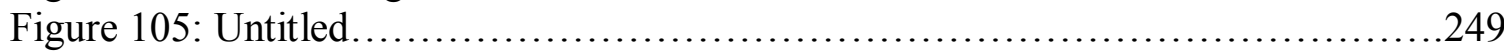

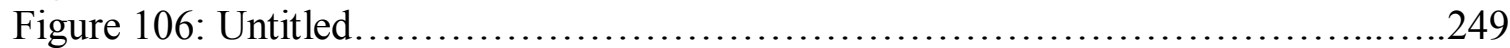

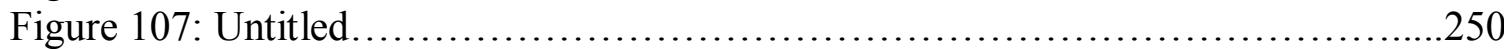

Figure 108: Untitled..................................................... 251

Figure 109: Untitled...................................................... 252

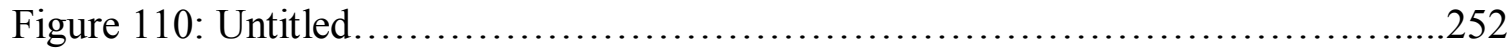

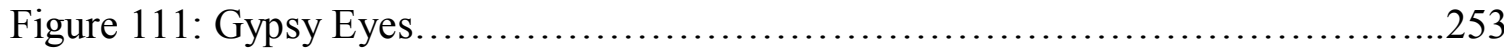

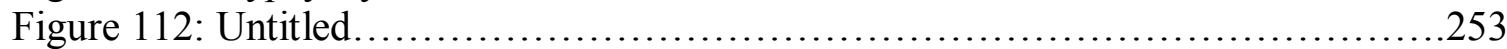

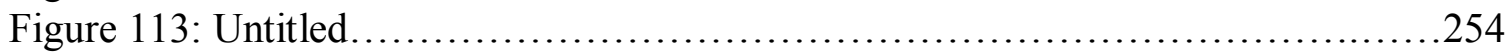

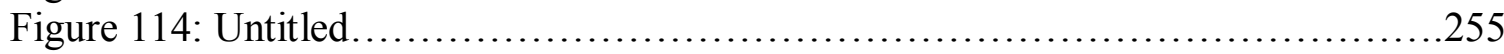

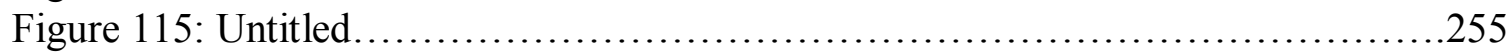

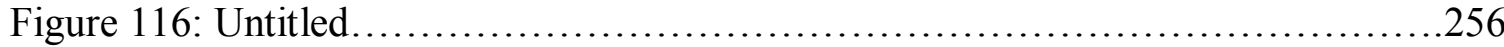

Figure 117: Wishful sign of dreams \& goals....................................256

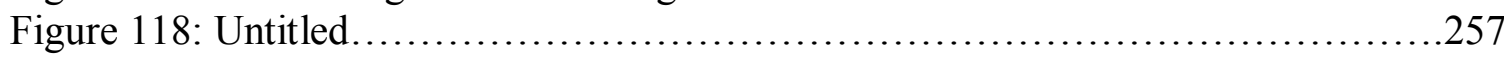

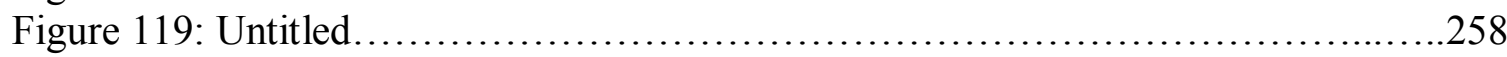

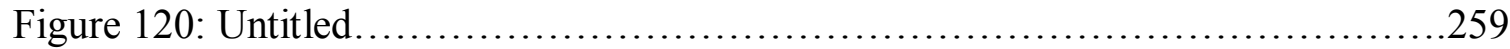

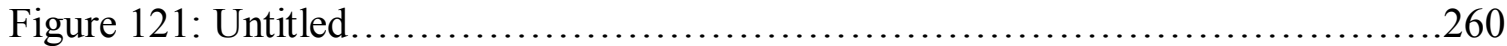

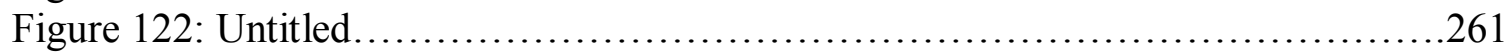

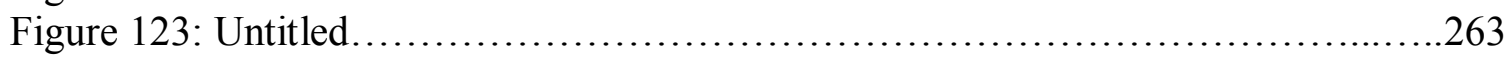

Figure 124: Untitled.................................................... 264

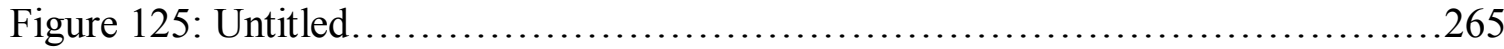




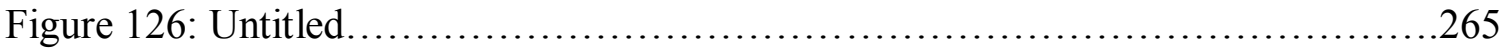

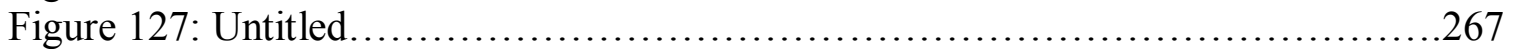

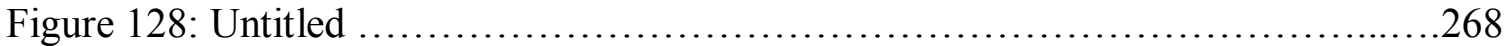

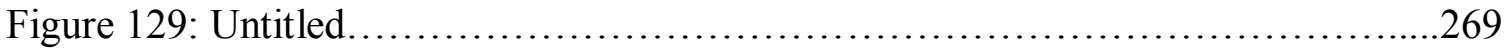

Figure 130: Untitled..................................................... 270

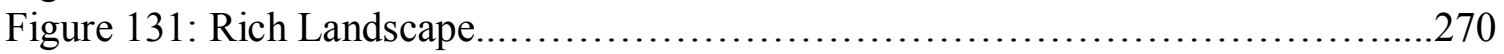

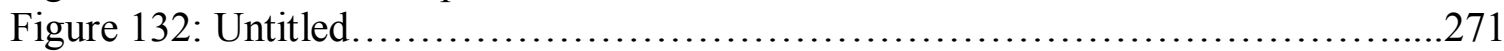

Figure 133: Seductive Tales: self-expressive, watch closely, but not too deeply.........272

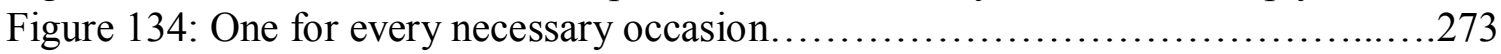

Figure 135: Untitled.................................................... 274

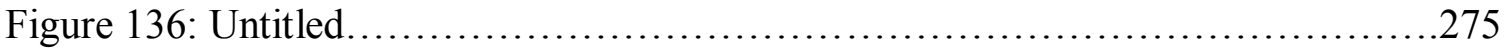

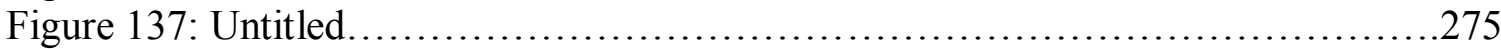

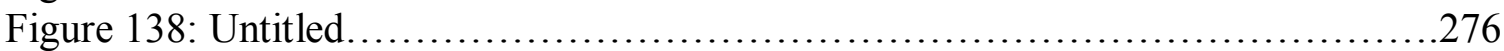

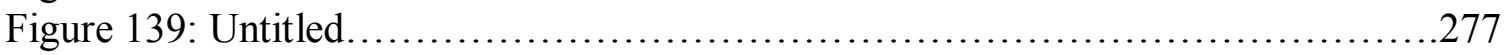

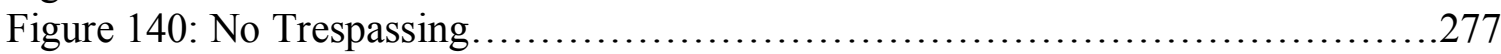

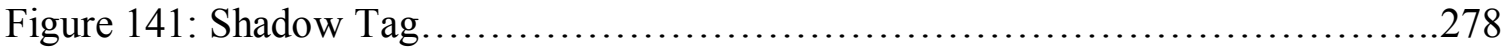

Figure 142: Can't see me...but I can see you....................................279

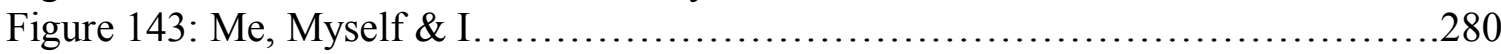

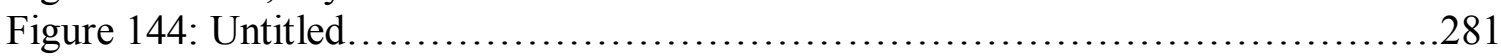

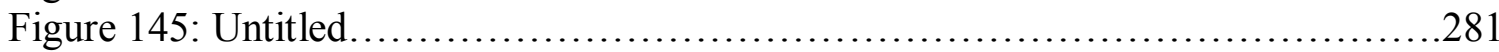

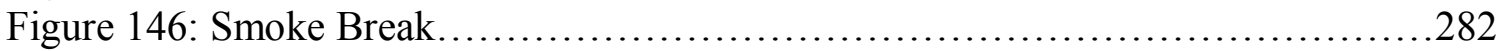

Figure 147: Untitled........................................................ 283

Figure 148: Rich Landscape.............................................. 320 


\section{CHAPTER 1}

\section{INTRODUCTION}

The ways in which sex workers have been studied and represented historically, socio-politically and academically do not take into account their voices, subjective experiences and participation in the process. Women working in the sex industry are seldom heard and their needs are consistently defined and represented by others. This contributes to the stereotyping and stigmatization of sex workers, while academic research is consistently being done on sex workers instead of with them. This study uses the arts-based research method of photovoice with individuals working in the sex industry in Portland, Oregon to understand their needs and aspirations through their own artistic self-representation. This allows for their visions and voices to reach a broad audience beyond academia, to re-present their diverse needs, and to challenge stigma and stereotypes. Understanding sex workers' needs from their own point of view provides the opportunity for collaborative knowledge creation. Valuing sex workers' aspirations supports the acknowledgement of individual strengths, skills, and visions. This arts-based study presents the richness and complexity of alternative forms of data, invites new levels of engagement that are both cognitive and emotional, and provides creative ways through which to explore the experiences of sex workers in Portland.

\section{Background}

There is currently no agency in Portland, Oregon that provides social services to sex workers, specifically to address their needs. After eight years of promoting safe sex in Portland (through education about disease prevention, free or inexpensive health care, 
and safety tips on needle exchange programs), the non-profit Danzine lost its funding in 2003. The Council for Prostitution Alternatives (CPA)/LOTUS (Liberating Ourselves through Understanding Sexploitation), another Portland organization working to educate sex workers, also lost its funding in 2005. In addition, two programs that specifically served people working in the sex industry-Lola Greene Baldwin Foundation and New Options for Women-both discontinued their services in mid-2007. At the beginning of 2008, CPA re-opened its doors under new management, with a stated mission to "save" women working in the sex industry. Six months later, this agency closed its drop-in center services that provided clothing and a safe space for women to convene for a couple of hours, twice a week. At this time, the only programs in Portland that are specifically for individuals working in the sex industry are through Volunteers of America (VOA) and Lifeworks North West. However, these are mandated services only for those female sex workers who were previously incarcerated due to a drug offense.

In an attempt to address the gap in services available to sex workers, the Sex Worker Outreach Coalition (SWOC) was created. SWOC is a network of social service providers in Portland, Oregon that meet monthly to address issues related to the sex industry. SWOC uses a harm-reduction lens to find better ways to coordinate services for sex workers and to do street outreach. Local organizations involved in SWOC include the Portland Women's Crisis Line, Legal Aid of Portland, Cascade AIDS Project, New Avenues for Youth, YWCA of Clark County, Outside In, and the Bad Dateline, among other affiliations. The coordination and collaboration of social service providers (physical and mental health, housing, child welfare, job training, etc.), drug and alcohol treatment programs, law enforcement, and legal assistance within Multnomah County may help 
respond to the service needs of sex workers given the lack of a specific agency that addresses the various needs of sex workers. SWOC predominately incorporates the voices of social services providers and what they have identified as the needs of sex workers. The voices of individuals currently working in the sex industry and their selfidentified needs are often missing within the coalition.

\section{Terminology and Definitions}

\section{Sex Work, Prostitution, and the Sex Industry}

The term "sex work" was first coined by performer and activist Carol Leigh, a.k.a. Scarlot Harlot, who felt motivated to construct an atmosphere of tolerance for women working in the sex industry (Alexander, 1987). It was created in the context of the feminist movement of the 1970s, in opposition to the use of the term "prostitute," and during a time when sex worker's rights organizations began to form to unite women in the sex industry (Leigh, 2000).

In this dissertation, sex work ${ }^{*}$ will be used to refer to a wide range of activities where sex or sexual services are exchanged for money or other material benefits (Outshoorn, 2005). Sex work also includes male and transgender individuals within various arenas of the sex industry. Weitzer (2000) provides a broad definition of sex work as "commercial sexual services, performances, or products given in exchange for material compensation” (p. 3). A more detailed definition by Sloan and Wahab (2004)

\footnotetext{
* I prefer to use the term sex work and sex worker (instead of prostitute and prostitution) since it focuses attention to the occupational health and safety issues of the sex industry and because the term is less stigmatizing. However, there are instances in this dissertation when I refer to sex work as prostitution, in recognition of the historical, political and social impact of the term and the use of the term by other academics.
} 
states:

Sex work is a term that includes many types of situations in which compensation is exchanged for some kind of sexual activity, including legal activities that do not involve person-to-person client contact (telephone sex), legal activities that involve person-to-person contact but not intercourse (such as lap dancing, stripping, topless dancing), and illegal forms of sex work where there is intimate person-to-person client contact (such as, sexual massage, sexual nude modeling, and other forms of prostitution). (p. 18-19)

Sex work also includes fantasy services (submission-domination, bondage, and crossdressing), escorting, call girls and call boys, hosts and hostesses.

Some research studies and theoretical publications on sex work by radical feminists, such as Sheila Jeffreys (1997), use the term prostituted women and survivors as a "deliberate political decision and is meant to symbolize the lack of choice women have over being used in prostitution" (p.330). Weitzer (2005) pointed out that the terms survivors and prostituted women are problematic since the former suggests people who have escaped something and the latter completely erases women's agency. The term prostituted woman also highlights the powerlessness and submission of those in the sex industry (Silbert \& Pines, 1982). While there is great debate about how prostitution and sex work should be understood and who should represent it or speak for it, many generally agree that the term "sex work" actually represents what women feel they are engaging in and the reasons for doing so. In a study of 294 sex workers in Miami, almost all of them "prefer(ed) the terms sex worker and working woman and refer(ed) to themselves as such" (Kurtz, Surratt, Inciardi, \& Kiley, 2004, p.359). However, it is important to note that there are some individuals working in the sex industry that do not identify with or use these terms.

A few scholars have pointed to the political and social significance of referring to 
sex work, as opposed to prostitution. "There is a shift from moral to economic references for describing the engagement of monetized sexual exchange, known as sex work" (Wardlow, 2004, p. 1017). Some assert that by using the terminology of sex work, there is a shift away from historical associations of prostitution as sinful, criminal and illicit (Jenness, 1990). In addition, using the phrase sex work is less stigmatizing because it suggests an income-generating activity rather than a totalitizing identity.

The sex industry includes those who sell services directly, as well as their customers. It also comprises of "the business owners and investors, managers, independent contractors, non-sexual employees (cashiers, waiters, drivers) and middlemen who facilitate business processes (some travel agents, guides) (Agustin, 2005). The sites of work include, but are not limited to bars, restaurants, cabarets, brothels, clubs, saunas, massage parlors, cars, motels/hotels, truck stops, crack houses, sex shops with private booths, dungeons for bondage and domination, Internet sites, and cinemas (Agustin, 2005; Williamson \& Folaron, 2003). Products and services involved in the sex industry consist of "erotic phone lines, escort and matrimonial services, films and videos, souvenirs, toys, clothes, equipment, and live and 'virtual' spectacles via webcameras...sometimes, art exhibitions and theatrical plays appear to temporarily form part of the industry" (Agustin, 2005, p. 622).

\section{Feminist Perspectives on Sex Work}

While various theories have analyzed sex work within feminism, two prevailing perspectives continue to dominate the understanding and discourse of sex work, thus informing theory, policy and research. One perspective conceptualizes sex work as 
violence and exploitation, and the other, sex work as legitimate work (Chapkis, 1997;

Sloan \& Wahab, 2000). Women of color have also contributed to the competing perspectives, examining how racism, classism, colonialism, militarism, and globalism shape the understanding of sex work.

Sex Work as Violence and Exploitation

The conceptualization of sex work as violence and exploitation is represented in radical feminist theory and domination theory, and evidenced particularly in the works of Millett (1970; 1975), Barry (1979; 1995), Dworkin (1987; 1989); MacKinnon (1987; 1989), Jeffreys (1997), Farley (2004), Raymond (2004), and Hughes (2004). For these radical feminists, sex work as violence is understood, "not only in the practice of prostitution but more fundamentally in the very idea of 'buying sex,' which is considered inextricably linked to a system of hetero-sexuality and male power" (Scoular, J., 2004, p. 344). Sex work is placed within the rhetoric of violence and oppression (Stout \& McPhail, 1998) so that for radical feminists, prostitution represents the epitome of patriarchal male privilege (Kesler, 2002). Radical feminist theory has illustrated the inequalities in sex work within the context of a gendered analysis of the state and sexuality (Scoular, 2004, p. 344).

Domination theory is similar to radical feminist theory, but differs in that it replaces gender with sex (Dworkin, 1987; MacKinnon, 1987). From this lens, prostitution is a system of male sexual dominance that undermines women's equal status and sexually objectifies women. Domination theory emphasizes the ways men attempt to control women's bodies and construct female sexuality to serve men's needs (Dworkin, 1987; MacKinnon, 1987). Prostitution is viewed as sexual slavery and the epitome of women's 
oppression (Outshoorn, 2005). The notion of prostitution as sexual slavery, first coined by Barry, informs many of the contemporary campaigns against trafficking (Scoular, 2004). Radical feminists and domination theorists view all types of sex work as inherently oppressive and exploitative for all women and assert that in order to eliminate women's oppression, society must be completely altered (Saulnier, 1996) and prostitution will need to be abolished.

Radical feminist insights into sex work have contributed the most to highlight the harms and violence experienced by sex workers. This perspective of sex work as violence and exploitation against women is often criticized for supporting a single view of sex work and for not acknowledging the various experiences of women (Weitzer, 2000). It fails to acknowledge the testimonies of sex workers and their experiences of pleasure in work, sex and choice. In addition, sex worker's rights advocates critique this view as being biased and based on street or outdoor sex work. The belief that sex work is violence maintains that sex workers are under the oppressed conditions of patriarchy (Bullough \& Bullough, 1987), they have no real freedom of choice, but rather they are victims of "false consciousness" (Abrams, 1990 in Barlett, 1993, p. 908). False consciousness suggests that those who are oppressed unconsciously internalize the dominant ideology. In other words, given women's unequal status in society, free choice is considered to be an illusion. Those who take on this position reject the notion of voluntary sex work, holding that no woman would choose prostitution by choice or free will (Outshoorn, 2005).

Limitations of this perspective include the lack of attention to the complexities and contradictions inherent in sex work, along with the role of culture, class, race, and 
gender. This perspective does not account for men and transgender sex workers.

Furthermore, critics of radical feminist positions on sex work have pointed out that the image of a sex worker from this lens portrays the female as a sexual subordinate and it also "sustains the myths and norms of the sex industry, of potential men and submissive women, rather than transforming them" (Shrage, 1994, p. 134). The simple reduction of sex work to gender and/or sexual oppression does not take into account the complexities of the workers, nor the power relations between workers, customers and managers. While there are gender and power inequalities in the heterosexual sex worker-client relationship, it is not certain that a sex worker abandons all control over her actions by engaging in sex work. Murphy (2003) asserts that women who use their bodies to make money are more "subjects with power than objects of power" (p. 308). Wood (2000) also agrees that while gendered power can be crucial to the experiences of sex workers, power is not always accepted but also contested and negotiated by women in their transactions with clients and in their personal relationships.

Sex Work as Legitimate Work

The sex as violence perspective has defined and shaped important policy arenas in the national and international discourse on prostitution for almost a century. However, this discourse has been challenged by those who conceptualize sex work as a legitimate employment option that can also represent sexual freedom and diversity. The perspective of sex work as legitimate work in the U.S. emerged with the formation of the sex workers' rights movement, founded on three basic premises: (a) many women freely choose sex work; (b) sex work should be viewed and respected as legitimate work; and (c) denying a woman the opportunity to work as a sex worker is a violation of her civil 
rights (Pheterson, 1989). The sex workers' rights movement founded in the 1970s provided a forum for sex workers to speak for themselves and to advocate for their right to work in the sex industry.

The sex-work-as-work/ pro-rights perspective supports the idea that restricting a woman's choice, for any reason, reduces her status as a full and equal human being since making choices for others implies having control over them (Jolin, 1994). This supports the view that women are selling a service, and that sex work should be acknowledged as a social contract, like any other free wage labor. The belief is that women sell their services, not their bodies, and it is a woman's free choice to engage in sex work "in as much as free choice can be achieved in a patriarchal, racist, and a sexist society" (Bell, 1994, p. 78). This view holds that given a woman's unequal gender status in society, sex work may often be the most viable option. The pro-rights perspective recognizes that sex workers, like most individuals, are making choices within limiting power structures of race, class and sexuality. However, this view supports the idea that structures aren't inevitable or unchangeable, but rather that they can be challenged and resisted through political organizing and action (Jeffrey \& MacDonald, 2006).

The sex-work-as-work perspective is theoretically represented by sex radicals, who share a similar ideology with the pro-rights feminists, but with a further emphasis on the identity politics of sex work and the role of discursive power (Jeffrey \& MacDonald, 2006). For example, radical sex liberals, also referred to as radical sexual pluralist theorists, celebrate sexual variety and free choice (Rubin, 1984; Bell, 1994) while acknowledging sex work as liberating and legitimate work. Sex radical theory/radical sexual pluralist theory is illustrated in the works of Califia (1998), Rubin (1984), Paglia 
(1992), Pheterson (1989), Chapkis (1997), Nagle (1997), and Doezema (1998). Sex radical theory, similar to the pro-sex worker's rights perspective, represents a free-choice point of view toward sex work, based on the right to self determination. Sex work is perceived as "a possible option or strategy of survival taken by women, which should be respected" (Outshoorn, 2005, p. 145; Bell, 1994; Chapkis, 1997). Sex radicals encompass a coalition of feminist academics, queer theorists, sex trade workers, and others (Califia, 1994). According to radical sexual pluralist theory, sex work is understood as undermining patriarchy's definition of traditional femininity and sex radical feminists strongly support sex workers' rights to perform erotic labor (Barton, 2002, p. 586). The emphasis of sex radical theory lies in the potential for sex work(ers) to expand the boundaries of sexuality and gender.

Ferguson (1984) illustrates the theoretical assumptions of sex radical theory concerning sexuality, social power and sexual freedom by stating that:

Social institutions, interactions, and discourses distinguish the normal/legitimate/healthy from the abnormal/ illegitimate/unhealthy and privilege certain sexual expressions over others, thereby institutionalizing sexual repression and creating a hierarchy of social power and sexual identities. (p. 109)

Sex radicals believe that sex work can be read in more complex ways than just confirming male power and domination. Sex work can also be seen as a site of resistance and can be understood as a place of agency where the sex worker utilizes the existing sexual order (Chapkis, 1997). For sex radicals, sexual freedom requires going beyond socially respectable categories of sexuality and refusing to place boundaries on what counts as politically correct sexuality (Ferguson, 1984). Instead of privileging one type of sexuality over another, there is the notion that changing ideas about sex can change sex 
itself, along with the balance of power in society.

Those who critique the sex workers' rights perspective assert that this view uncritically embraces only a civil rights emphasis on freedom of sexual expression (Weitzer, 2000). Also, others have pointed that this perspective is representative of those sex workers who are well-educated and upper-level sex workers (e.g. Bernstein, 1999). Therefore, it may not be applicable to street-based workers or migrant sex workers who may not identify as sex workers or who might not have any desire to participate in advocacy (Agustin, 2005). It has also been suggested that radical sexual pluralist theory may be overly celebratory in its focus on empowerment (Jeffrey \& MacDonald, 2006) and may not take into account race, class and ethnicity as informing sex workers' experiences. However, Chapkis (1997) argues that not all sex radicals are of the libertarian perspective where sex work is free from the repression of power, but rather, many sex radical feminists view sex work as a place of struggle.

The sex work as legitimate work position has been strengthened in recent years by a new postcolonial critique that views abolitionism and the sex work as violence perspective as a Western, White, middle-class women's movement seeking to protect and save women, similar to those efforts during the Progressive Era (e.g. Doezema; Augustin; Kempadoo). More recent proponents of the pro-sex workers' rights perspective are including a more global analysis of sex work as work that includes issues of race, culture, and nationality, along with politics, economics and women's migration.

\section{Perspectives Outside of the Sex Work Polemic}

The feminist perspectives that polarize sex work as exploitation or work- slavery or freedom- present a problematic dichotomy. These debates do not reflect the 
complexity of sex workers' experiences. There is a wide range of individuals involved in the sex industry, a myriad of ways in which sexual services and sexual fantasies are bought and sold, and much variety in the relationships that are developed in the workplace (Benoit \& Shaver, 2006, p. 249). In his anthology of writings, Sex for Sale, Weitzer (2000) expressed frustrations with the feminist sex wars, stating "essentialist claims about the intrinsic nature of sex work (whether oppressive or liberating) clash with the reality of variation in sex work" (p. 3). Chancer (1998) argues that the polarized frameworks have "potentially reconcilable goals: for women to enjoy sexual freedom (the emphasis of sex radicals) and to experience freedom from sexism (the emphasis of radical feminists)" (Barton, 2002, p. 600). In contrast, Sutherland (2004) asserts that "sex radicalism is not radical feminists opposite pole...it does not shore up the opposite side of the binaries" (p. 28). Sex radical theory, in its embrace of sexual and theoretical pluralism, holds considerable promise for exploring the multiple subjectivities and intricate lives of sex workers (Sutherland, 2004) on a feminist theoretical continuum. The theoretical pluralism discussed by Rubin (1984) and Bell (1994) illustrates how no singular site is privileged, but rather there are multiple spaces for differences.

Women of color present different perspectives on sex work that take into account the intersections of race, class and gender. Black feminist Patricia Hill Collins (1990) holds the position that sex work is sexual exploitation, but her focus is on race and racism that make certain forms of objectification possible. Collins (1996) illustrates the history of sexual exploitation of Black women through slavery and violence. This history of violence against Black women is linked to sex work as the representation of abuse of Black women's sexuality for economic purposes. Others have built upon Black feminist 
thought to point out that the sex industry is oppressive because it prospers on race stereotypes of exotic, sexually insatiable, yet subservient women of color who exist to serve the needs of the white man (Overall, 1992).

Collins also calls attention to the disproportionate number of Black women working in the sex industry as she writes,

Theoretical work explaining patterns of Black women's exclusion in the burgeoning international pornography industry has been...neglected. Perhaps the most curious omission has been the virtual silence of the Black feminist community concerning the participation of far too many Black women in prostitution. Ironically, while the image of African-American women as prostitutes has been aggressively challenged, the reality of African American women who work as prostitutes remains unexplored. (Shrage, 1994, p. 141-142)

The work of Collins is helpful for understanding how women of color may experience working in the sex industry. What may be liberating on an individual level may be simultaneously reproducing racism, classism, ageism, and sexism at the institutional level (Collins, 1990; 1997; Smith, 1998). Analyzing sex work on an individual and structural level may best capture the multitude of experiences of sex workers locally, nationally, and globally.

Other women of color, some of who identified as current or past sex workers such as Kempadoo and Doezema (1998), examined the structural issues of sex work from a global perspective. Kempadoo (2001) argues that "the global sex trade cannot be simply reduced to one monolithic explanation of violence to women" (p. 28). Viewing prostitution as a reflection of patriarchy and violence to women is "inadequate to capture the various histories, oppression, and experiences of women of color" (Kempadoo, 2001, p. 37). Overlooking the agency of women of color by treating them as passive victims of oppression does not address the complexities of the lives of women of color (Kempadoo, 
2001). Rather than conceptualize prostitution in terms of the sexual objectification and degradation of women, Kempadoo and Doezema (1998) advocate for understanding sex work as a kind of labor that is often performed by marginalized people. This avoids moralistic discourses about female sexuality and stays away from unrealistic abolitionist approaches (Sharge, 1996). Instead, there can be a focus on working conditions and empowerment, legal status of work, and occupational alternatives to people oppressed by race, class, gender, and nationality.

My own personal and political perspective of sex work is consistent with the idea that sex work is a legitimate form of labor. I recognize that commercial sex work involves both dangers and pleasures within a continuum of individual experiences. I also acknowledge the intersections of race, class, gender and ethnicity and the imbalance of power on an institutional, communal level. I believe that the complexity of sex workers' sexual agency can best be illustrated by sex workers themselves. Barton (2002) suggests this has the potential to enhance understanding of both gendered power relations in the sex industry, as well as women's sexuality within patriarchy. The voices of sex workers will also contribute to understanding the experiences of women of color within the social, political and economic structure of society. This requires moving away from a singular identity of the sex worker as either, victim or agent, and shifting the focus away from the free-versus-forced dichotomy. Instead, a move towards viewing women as active agents in a broader context will more successfully capture the multiple subjectivities and the range of experiences, contradictions and complexities of sex work. 


\section{Significance of this Study}

It is assumed that the needs of individuals working in Portland's sex industry are not being met due to a lack of available services for sex workers. While SWOC aims to coordinate agencies that assist marginalized populations, no organizations exist that only address the needs of sex workers. Many studies report that even if there were specific social service agencies to serve sex workers- the stigma and discrimination against sex workers- in addition to the illegal nature of work, prevents many sex workers from accessing mental health, legal and medical services. The absence of social services and the invisibility of sex-worker activists in Portland raises the question of whether or not they have needs, if they are receiving services, or if they are obtaining any support.

The subjective experiences and voices of sex workers have rarely been heard and their needs have been consistently defined and represented by professional non-sex workers throughout history and within academia. As a professional non-sex worker myself, who will be representing the needs and aspirations of sex workers for the purposes of this dissertation, I address this tension within my study by employing photovoice, an arts-based research method that allows for participatory, collaborative knowledge creation with sex workers. This method addresses the lack of sex workers' voices in research and the limited knowledge around sex workers' aspirations.

The purpose of this arts-based qualitative study is to utilize art created by sex workers to understand and represent their experiences, needs, and aspirations. An artsinformed paradigm states that by handing over creativity (the contents of research) and its interpretation (the explanation of its contents) to the research participants, they are empowered, and the content is more culturally exact and explicit, utilizing emotional and 
cognitive ways of knowing (Sarasema, 2003; Sclater, 2003). Through the use of photovoice, sex workers can utilize visual representation (photography) to generate art, collaboratively create knowledge, and raise awareness of their needs (Wang, 1999). Photovoice is designed to specifically tap into daily realities and the core meanings and significances of these realities as defined by the participants (Wang \& Burris, 1997). In general, sex workers have not had the opportunity to influence the design and implementation of social services and programs, and both their needs and capacities are undervalued (Vanwesenbeeck, 2001). I believe sex workers are the experts on what will work best for themselves and their communities.

\section{Relevance to Social Work}

The history of the social work profession in the United States and its involvement with commercial sex workers dates back to the early 1800 s with the social reformers, charity organizations and benevolent societies. While this relationship will be detailed later, it is crucial to note that historically, social work bodies have viewed sex work from a moral lens. Sex workers were perceived as victims that needed to be rescued and saved (Hobson, 1987). This perspective contributed to the perpetuation of stereotypes of sex workers as deviant and immoral women. Historically, the needs of sex workers were determined by social work bodies based on representations of sex workers as "fallen" women and carriers of disease. Social workers currently lack sex worker-informed information about the needs of sex workers due to these negative associations, stereotypes and judgmental attitudes. By continuing to regard sex workers as victims, social workers do not recognize their agency, strengths and power for self-determination. 
This can be disempowering for sex workers, preventing them from accessing services and voicing their needs.

Social workers encounter individuals working in the sex industry in the following social service settings: needle exchange programs, substance abuse treatment programs, HIV/AIDS outreach programs, domestic violence and homeless shelters, crisis hotlines, criminal justice settings, and safer sex and public health programs for individuals living with HIV/AIDS. Some commercial sex workers do not disclose their work to social workers due to the stigma associated with illegal behavior and fear of arrest (Weiner, 1996; Mathieu, 2003). This results in many sex workers not receiving necessary assistance for fear of being turned away because of their involvement in illegal work.

Due to the illegality of their work, sex workers tend to avoid interacting with social service agencies or institutions that might punish them. Consequently, social workers are limited in their abilities to build trusting relationships with sex workers. In order to maintain the profession's commitment to clients' right to self-determination (NASW, 1999), the voices of sex workers need to be heard and their agency valued. Attention to race, class and gender is crucial, as their intersections play a major role in the experiences of sex workers who seek assistance from social service agencies (Wahab, 1997). I believe sex workers are experts in their own lives, and I acknowledge the harm that judgment and bias from social workers can create in the lives of those working in the sex industry.

While the social work profession is centered on principles of economic justice and social inequality, it wasn't until 2005 that the National Association of Social Workers (NASW) created a public and professional policy statement to address issues faced by 
sex workers and to advocate for their rights. This powerful initiative to address the rights of sex workers began from a group of social workers who identified the need to move away from a moral, victim lens. NASW created this policy to help bring expertise to this area and to continue to provide accessible services for commercial sex workers. The policy statement identifies many issues faced by sex workers, including their increased vulnerability to violence, exploitation, disease and arrest, especially for sex workers of color and those who are undocumented. The current NASW policy statement has practice and policy implications, based on its Code of Ethics. These include: dignity and respect for the self-determination of commercial sex workers; prosecution of violence against sex workers; the detrimental effects of arrest of sex workers; condemnation of forced prostitution and sexual exploitation; the goal for economic justice, employment and education opportunity and health care for sex workers; and the acknowledgement of the role of racism, sexism and classism and their intersections into the lives of sex workers (NASW, 2005, p. 54).

The formation of this policy statement highlights social workers' role to work towards enhancing the quality of life of marginalized populations and pursuing social justice. Huff (1998) emphasizes how one of the strategies commonly used to do this in social work's history was through the use of the visual image. Social work campaigns used images, but today, social workers "have largely abandoned media-rich presentations, relying instead on statistics, tables, and- all too often- turgid essays. Consequently, much of our emotion is lacking in our appeals, and this diminishes the important mission of educating the public" (Huff, 1998, p. 582). The creation of visual images by marginalized individuals can be attained in academia through arts-based 
research. This has the potential for engendering empathy of stigmatized groups through the creation of art to express experiences, feelings and perceptions. In the process of forming art, a person is expressing a vision and a relationship with his or her own world (May, 1994). An arts-based approach to understanding one's needs and aspirations has the potential for capturing experiences in ways that do justice to the complexities of sex work and the diversity of those working in the sex industry.

An arts-based approach supports social work values of self-determination since the power to create art and impart knowledge are placed in the hands of the participants. Empowerment of sex workers through artful representation, dialogue, and community participation also adheres to the social work profession's goal of social justice. An artsbased approach brings the voices and visions of sex workers to broader audiences in order to create knowledge, build awareness and advocate for social change. Through the use of visual images, art has the power to reach the public in a memorable way. 


\section{CHAPTER 2}

\section{LITERATURE REVIEW OF SEX WORKERS' NEEDS \& ASPIRATIONS}

Historical \& Socio-Political Representations of Sex Workers' Needs \& Aspirations

Throughout United States history, the needs of sex workers were determined and represented by professional non-sex workers in order to address particular social and political agendas. Sex workers' needs were represented with underlying intentions: to protect the sexuality of women, to protect society from risks of disease, to control illegal immigration, and to control criminal activity. I aim to present how various faith-based organizations, social work bodies, medical professionals, and policy makers determined and/or defined the needs of sex workers from their own moral, class or racial lenses. These groups assumed sex workers aspire to leave the sex industry, without taking into account their diverse experiences and their own voices. These particular portrayals of sex workers and their needs led to the negative stereotypes and stigma. Sex workers' aspirations were addressed through social movements and organizations. These grassroots, activist efforts by sex workers provided a space for their voices to be heard in an attempt to create change and raise awareness of the multitude of experiences in the sex industry.

\section{Faith-Based Organizations}

In the early 1800 s, prostitution was seen as a moral, social, sanitary, and political threat symbolizing disorder, excess and pleasure. Early social work practice took the form of Evangelical work through organizations such as The Boston Society for the Moral and Religious Instruction of the Poor and New England Female Reform Society. 
These organizations viewed the prostitute as a "fallen woman," who needed to be redeemed through religion (Gilfoyle, 1999). Made up of groups of charitable ladies who held Sunday schools for sex workers, their work was devoted to saving prostitutes through religious conversion (Hunt, 1999). These Evangelical social reformers were women of privileged backgrounds who believed that sex workers needed protection from male sexual aggression (Boyer, 1978; Hobson, 1987). Their efforts included advocating for legal solutions to punish men who violated chastity codes. In addition, they tried to coerce men to marry the women they seduced and urged women to form alliances to oblige men to adapt behaviors that demonstrated accountability (Wahab, 2002). These reformers wanted to bring women back onto the "path of virtue," believing that women who engaged in non-marital sexual relationships did so as a result of being exploited by men, not because they might have enjoyed a sense of sexual freedom (Wahab, 2002). Evangelical reformers failed to take into account the voices of prostitutes and perceived sex work as women's lack of protection. Their religious and moral agenda served to depict young sex workers as passive, innocent victims forced into prostitution by evil men (Miller, Romenesko \& Wondolkowski, 1993). These early representations of sex workers served to influence subsequent social and political responses towards sex workers and their needs.

\section{Social Work Bodies}

During the progressive era, social reformers mostly operated collectively within organized women's clubs, mother's groups and charity societies (Abrams \& Curran, 2000). These social work reformers utilized individualized treatment approaches that placed the blame on the "fallen women" who needed to repair themselves (Kunzel, 
1993). These women were labeled "wayward girls" and associated with social problems like venereal disease, illegitimacy and prostitution. The symbol of the wayward girl emerged as a cultural representation of female sexual deviance (Abrams \& Curran, 2000). It was this depiction of women working in the sex industry that paved the way for the Charity Organization Society (COS) and for the Settlement Houses in the late 1800s to intervene with these women who had fallen from "virtuous womanhood" (Rothman, 1978). These social reformers played a major role in depicting female deviance from their own moral and class lenses. The needs of sex workers, as determined by these social work bodies, included the assumption that sexually deviant women needed assistance to return to a path of virtue.

Charity organizations and friendly visits began forming in 1870s by middle and upper class female volunteers who attempted to provide relief to the poor through their own value system. These volunteer organizations were grounded in the Protestant tradition of charity and community responsibility (Abrams \& Curran, 2000). The COS's aimed to change the behaviors of the poor by sending friendly visitors to impoverished neighborhoods in an attempt to create relationships, and, ultimately, to modify people's personalities and moral characters (Wahab, 2002). Unlike the earlier Evangelical workers who saw women as victims of male aggression, the efforts of the COS was driven by the belief that lower-class women were incapable of making good decisions (Stadum, 1992; Wahab, 2002). Like other white, middle-class reformers, these charity organizations determined that sex workers needed assistance with decision-making and behaviorchange to prevent women from falling into a "deviant" and immoral way of living. Charity workers wanted to restore order and social control over those who did not adhere 
to their middle class morals and values.

Settlement houses, which first appeared in New York City in 1886, were created to meet the needs of immigrants adapting to life in the U.S. and to assist low income females. At the time, there was great stigma against the large number of unmarried, working class immigrant women. It was assumed that these immigrant women could not care for themselves, so they resorted to prostitution for economic relief (Abrams, 2000). Settlement workers determined that sex workers needed positive aspirations in life to move out of prostitution and up from the lower class. Settlement workers differed from the COS in that they decided sex workers needed protection from the state through policies to abolish prostitution. Settlement workers participated in the anti-prostitution crusade by holding the belief that prostitution was "the social evil" and that women were incapable of helping themselves (Bullough \& Bullough, 1987; Wahab, 2002). Women working in the sex industry were portrayed by social work bodies as vulnerable and powerless victims of white slavery (Hobson, 1987). Settlement workers held the belief that a society without prostitution was necessary for the emancipation of women (Wahab, 2002; Abrams, 2000), and yet identified the need for advocating on behalf of sex workers. During this era, various women's groups, activists, reformers, and feminists joined together to speak out against prostitution. Even though their views varied, they all agreed that prostitution was a threat to women's bodies, health, family, morality and opportunity in life (Wahab, 2002).

As the U.S. entered World War I, the sex worker image changed from being a victim of white slavery to being the carrier of disease and infection. The heightened war propaganda presented the image of a prostitute that "could do more harm than a German 
fleet of airplanes" (Hobson, 1987, p.165). Society was absorbed and concerned with the high incidence in sexually transmitted infections. The fear of prostitutes as spreaders of disease created more work for social workers engaged in rescue and reform work. During this time, federal legislation mandated the detention of all civilian disease carriers (Wahab, 2002). As social work bodies adopted a medical model in order to become more professional, they created scientific classifications of women they considered to be sexual delinquents and the spreaders of diseases. In the beginning of the 1910s, "feeblemindedness" emerged as a diagnostic category to explain deviant behavior (Abrams \& Curran, 2000). Many women were finding themselves placed in long-term custodial homes for the "feebleminded" run by rescue workers. The prevailing idea of the time was that "an overdeveloped body signaled an underdeveloped mind," which related to the belief that women being sexually promiscuous at an early age were 'feebleminded' (Hobson, 1987, p.191). Women were institutionalized because their sexuality was viewed as threatening and needing to be protected. The social workers of the time developed rigorous diagnostic and medical treatment models to use in their practices in order to claim their authority in the science of social problems (Kunzel, 1993; Abrams \& Curran, 2000).

As social workers struggled to construct their professional identities, they separated themselves from individuals and organizations doing Christian, or churchbased work, such as the Evangelical and charity workers (Wahab, 2002). Instead, they began to attach themselves to the fields of psychiatry, psychology and medicine (Walkowitz, 1999); using more scientific-based models of treatment in order to gain their own social and professional status (Wahab, 2002). Social workers' view of sex workers 
then was shifting from regarding these women as immoral, sexual deviants to neurotic individuals (Hobson, 1987). Social workers were shifting toward trying to rehabilitate the "fallen" women by changing their personalities through case work and therapy, while Evangelical reformers were using religion to change women. While there was social distinction between the professionals and nonprofessionals, both groups continued to utilize interventions that focused on their own perceived needs of sex workers. These social work bodies perceived the needs of sex workers to be psychological interventions to change the mind of women. They determined sex workers needed therapy and psychiatric assistance to "cure" their neurosis that led them to pursue work in the sex industry.

The 1940s and 1950s brought about psychoanalytic perspectives used to describe the causes of prostitution. Women continued to be blamed and psychiatrists labeled the prostitute as "neurotic," "frigid" and "masochistic" (Hobson, 1987). Similarly, in 1953, psychiatrist Frank Caprio conducted research on sex workers in brothels across the country, concluding that deviant behavior of prostitution primarily appealed to women who had homosexual tendencies (Wahab, 2002). The social attitudes of this era continuously placed blame on the individual for social problems, for example the pathologizing of prostitutes shifted the blame from society onto sex workers who were then portrayed as needing psychoanalytic intervention.

\section{Medical Professionals}

The medical profession played a major role in identifying the health needs of sex workers and implementing policy to address those perceived needs. With advances in medical technology at the end of the $19^{\text {th }}$ century, medical professionals were able to 
discover the impact of venereal diseases, particularly syphilis and gonorrhea (Bullough \& Bullough, 1987). However, the underlying agenda of the medical professionals was to ensure that society was protected and safe from disease, without taking into account the negative consequences for those women working in the sex industry. Medical professionals founded the social hygiene movement and lobbied to pass the Social Evil Ordinance Law in 1870. The purpose of this law was to educate the public and to conduct compulsory medical inspections of sex workers. Women who were found to have sexually transmitted infections were committed to a special hospital until they were “cured” (Bullough \& Bullough, 1987). The obligatory medical checks imposed on sex workers depicts how their needs were identified by others to serve a social agenda and to further stigmatize women working in the sex industry.

In the early $20^{\text {th }}$ century, the spread of venereal diseases resurfaced as a social concern when high numbers of women and children became infected. Again, the blame was placed on prostitution, as sex workers were considered to be in dire need of "cleansing" in order to protect the men from the "disease carrying prostitute" (Wahab, 2002). This led the New York legislature to pass the Page Bill in 1910, which required all prostitutes convicted of an offense to be examined for sexually transmitted diseases (Wahab, 2002). This social hygiene movement continued through 1913, contributing to the formation of organizations, such as the American Vigilance Association/Committee, the American Federation for Sex Hygiene and the American Social Hygiene Association (Burnham, 1973). These organizations represented the continual attempts of the medical and social work bodies to impose middle class values and sexual standards on society. Sex workers were again portrayed as "potential reservoirs of disease" (Phoenix, 2007, p. 
81), and as women who needed purification. This construction of sex workers created the opportunity for privileged women to impose their moral agenda to reform society. Policy Makers

In the late $1800 \mathrm{~s}$, there was an increase in migrant Chinese and Japanese women to California. These Asian immigrants who settled in San Francisco were depicted as having been shipped into the U.S. on large boats, imported by merchants and tradesmen, either to be sold as prostitutes or wives (Bullough \& Bullough, 1987). Accounts from the San Francisco Chronicle from 1869 portrayed how some of these Chinese women that men chose not to marry were used as prostitutes and they were then discarded in an alleyway in Chinatown, left to starve (Bullough \& Bullough, 1987). These media accounts created the idea that foreign, powerless women needed to be protected from men. Throughout this era, similar newspaper accounts served to create the fear of a sexual slave trade of women. However, it wasn't until later, when the white, European women were thought to be traded and sold into slavery that sexual trafficking, also known as white slavery, became a major social and political concern.

The myth of white slavery was instrumental in maintaining the anti-prostitution sentiment of the Progressive Era (Grittner, 1990). Laws regulating prostitution were developed during the years of $1874,1881,1907$, and 1910, in response to the perceived threat of white slavery (Hobson, 1987; Wahab, 2002). With the arrival of new immigrants society perceived prostitution as a "big business" that extended internationally. There was the exaggerated image of women being tricked and "trafficked" against their will, typically by foreign men, pimps, madams, and proprietors who organized the business (Wahab, 2002; Riegel, 1968). This image, along with others, constructed the impression 
that all prostitution involved sexual enslavement of young, vulnerable and innocent women. Women were represented as naive victims who needed protection from the 'foreign villains' responsible for the sexual slave trade. Policy makers determined women working in the sex industry and "innocent" others in danger of entering the sex industry, needed to be protected from the state through measures that prohibited the transportation of women for sexual purposes.

In response to social fear of white slavery, Congress passed the White Slave Traffic Act in 1910, also known as the Mann Act. While the Mann Act was enacted to address the perceived need to protect women, it also served to prohibit unmarried women from crossing state lines for immoral purposes and it criminalized interracial couples (Saunders \& Soderlund, 2003; Riegel, 1968). In 1914, under the Mann Act, more than $70 \%$ of the convictions of women were related to voluntarily transportation of women for prostitution or other immoral purposes (Saunders, 2005). For those women who were fulfilling desires to travel and be independent, society labeled them as low class and socially deviant.

It has been suggested that the moral panic and fear of white American women being sexually victimized by non-white men was fueled by anxieties around race, class, gender and migration. Other scholars have reported that the recent emancipation of the male African American slaves into society contributed to social fears of threats to sexual purity (Chapkis, 1997). The $19^{\text {th }}$ century sex slave was represented as "a white woman, victim of the animal lusts of the dark races" (Doezema, 1998, p. 44) in contrast to oversexualized women of color. During this era, Chinese women, Mexican women and other women of color were depicted as overly sexual, deviant and promiscuous at the turn of 
the century (Doezema, 1998). These portrayals created an opportunity for social work bodies working in the settlement houses in the latter part of the century, to identify the needs of immigrant women from their own racial, social and class positions.

Trafficking in persons was equated with prostitution at the end of the $20^{\text {th }}$ century with the fear of a white slave trade. Trafficking is currently resurfacing as a political, national, and global concern. In the $21^{\text {st }}$ century, sex workers are being portrayed by policy makers, media and some feminists as sexual slaves without agency; as passive victims who need to be saved. Current anti-trafficking efforts are heavily supported by government and influenced by a radical feminist perspective of sex work. An overwhelmingly prevalent image in the media is one of thousands of women and children from the global South being trafficked into the U.S., primarily for sexual purposes. Many scholars and feminists have critiqued the modern human trafficking discourse and assert that the discursive history of trafficking is related to fears of immigration, the morality and racialized sexuality of women, and the abolitionist agenda to end prostitution (Shah, 2004; Sanders \& Soderlund, 2003; Doezema, 2000). The anti-sexual slavery rhetoric is being adopted by anti-trafficking organizations such as the Coalition Against Trafficking in Women (CATW) whose aim is to combat sexual exploitation. These organizations believe that all work in the sex industry is sexual exploitation and violence, working closely with government officials towards influencing public policy on human trafficking.

The implementation of anti-trafficking policy, the Trafficking in Victims Protection Act (TVPA) of 2000, has negative consequences on national and international non-governmental organizations (NGOs) working with sex workers to address their 
needs ${ }^{1}$. Included in the 2003 and 2005 reauthorization of the TVPRA are sections $113(\mathrm{~g})$ (1) and (2) which prohibit the use of State Department anti-trafficking funds to promote, support or advocate for the legalization or practice of prostitution and prohibit funding to any organization that has not stated, in a grant application or agreement, that it does not promote, support or advocate for prostitution as an employment choice (Weitzer, 2006). Otherwise, organizations are not funded, while grantees are now being asked to state their position on prostitution in writing (Block, 2004; Melzer, 2005; Ditmore, 2003). Programs that utilize the term "sex work" are now considered "inappropriate partners for USAID (US Agency for International Development) anti-trafficking grants or contracts” since they accept prostitution as employment choice (Saunders \& Soderlund, 2003, p. 21). NGOs that forcibly remove women from prostitution in order to "save" them have been among those given funding preferences (Melzer, 2005). As funds for programs to support the needs of sex workers disappear, the U.S. government is allocating funds under trafficking grants to social service agencies that state an opposition to prostitution in their applications. Policy makers are determining that women need to stay out of prostitution, which is being equated with trafficking and sexual slavery.

The current anti-trafficking policy also has negative consequences for sex workers. In order to receive any services, a woman must prove that she was trafficked into the sex industry and provide authorities with information about her "trafficker." Government funds to support anti-trafficking efforts may result in women being forced to adopt the stereotypical representation of a trafficking victim in order to receive social services (Chapkis, 2003). Not only are sex workers being portrayed as victims of sex

\footnotetext{
${ }^{1}$ For a social and/or legal analysis on the underlying, moral agenda of the trafficking policy see: Bindman \& Doezema (1991); Block (2004); Chapkis (2003); Ditmore (2003).
} 
trafficking in order to receive any type of assistance, but the needs of sex workers are once again being determined by others with underlying agendas.

Agustin (2002) points out that the aspirations of some women from the global South are hardly ever considered a possibility. Some women want to work in the sex industry abroad in order to have the opportunity to travel to other parts of the world, to explore, to be independent and to experience life. Some address the possible underlying agendas of some policy makers, academics and social work bodies whose interests lie in depicting sex workers as vulnerable, enslaved women. If sex workers' aspirations were actually considered, then privileged individuals wouldn't be able to "save" sex workers to serve their own career interests (Agustin, 2004). By blaming foreign "evil traffickers" of sexually enslaving innocent young women who would never choose to work in the sex industry, government funding can then be allocated to anti-trafficking programs and the salaries of professionals who want to "rescue and save" women from the immoral profession of sex work.

\section{Social Movements \& Organizations}

In the 1970s, prostitutes' rights movements and organizations emerged in the U.S and other parts of the world. For the first time, women working in the sex industry started to articulate their views and form their own interest groups (Outshoorn, 2005). The various grassroots organizations led by sex workers provided a forum for individuals to speak for themselves and claim their rights (Delacoste \& Alexander, 1987; Jenness, 1993). For the first time in history, sex workers were articulating their own needs and aspirations. Their movement was founded on the right to self-determination. The members of the movement believe that women freely choose sex work as an occupation, 
that sex should be perceived and respected as legitimate work, and that women's civil rights are violated when they are not allowed to choose to work in the sex industry (Sloan \& Wahab, 2000; Jenness, 1993).

COYOTE (Call Off Your Old Tired Ethics), founded in 1973 by former sexworker Margo St. James, was the first American sex workers' rights organization that fought for sex workers' rights and for sex work to be recognized as an occupational choice (Jenness, 1993; Pheterson, 1989; Delacoste \& Alexander, 1987). COYOTE works to enhance the welfare of sex workers and aimed for legalizing prostitution (Jenness, 1993). The group's belief is that "most women who work as prostitutes have made a conscious decision to do so, having looked at a number of alternatives" (Sloan \& Wahab, 2000, pg. 466). Since then, other sex-worker-led organizations have emerged, such as the Sex Workers' Outreach Project (SWOP) and Desiree Alliance.

Today, various sex-worker-led, rights-based organizations continue to develop around the nation to improve working conditions, increase safety and services for workers, and to eliminate discrimination. Sex workers' rights groups are concerned about sexual and physical violence, and exploitation that many sex workers suffer from customers, pimps or the police. While sex workers' rights advocates acknowledge the harms some may experience, they argue that the illegality of the work is exploitative since its status denies sex workers equal protection under the law (Alexander, 1987; Jenness, 1990; Weitzer, 1991; Zatz, 1997). For instance, due to the illegality of prostitution, if women involved in sex work experience sexual or physical violence, the law fails to protect them (Bell, 1987; Pheterson, 1989). Sex workers and sex worker advocates want these abuses (e.g. kidnapping, assault, rape and fraud) stopped by the 
enforcement of existing laws that prohibit these abuses (Pheterson, 1989). Pro-sex worker rights groups hold that the illegality of most sex work leaves workers vulnerable to abuse, rape and exploitation. Therefore, violence and exploitation can be significantly reduced through the creation of rights-based movements or unions that lobby for maintaining safe working conditions.

From this perspective, advocates proposed the decriminalization of all sex work and asked for the assurance of equal protection under existing laws of civil and legal rights as other workers are entitled to (Alexander, 1987; Jenness, 1990; Weitzer, 1991). By identifying sex work as an occupation, sex workers can be included and protected under existing instruments (Bindman, 1998). In addition, while advocates support decriminalization, they oppose the legalization of sex work, since it infringes upon other rights of sex workers and can result in mandatory health exams, registration, and licensure (Alexander, 1987; Jenness, 1990; Weitzer, 1991). Additional reasons as to why sex workers support decriminalization but not regulation or prohibition includes the fear of deportation for a migrant sex worker. There is also the risk of a mother losing custody of her children if she is found to be engaging in sex work. Sloan and Wahab (2000) wrote,

Initiatives to prohibit sex work or prostitution have resulted in the isolation, increased vulnerability, abuse, and exploitation of sex workers; programs to regulate sex work have resulted in the control and further stigmatization of sex workers; and efforts to abolish sex work have denied sex workers their rights to autonomy and self-determination. (p.468)

The existence of sex workers' rights groups provide a safe space for sex workers to voice their needs, desires and experiences. This image of sex workers challenges traditional existing notions of prostitutes as "social inferiors, sexual slaves, victims of 
pimps and drug addictions and tools for organized crime" (Jenness, 1993, p. 1). The aspiration of sex workers to decriminalize their profession and fight for rights contributes to a shift in how sex workers are being represented and perceived.

In 1985, the organization WHISPER (Women Hurt in Systems of Prostitution Engaged in Revolt) was founded. WHISPER, a widely known prostitution support organization within the prostitution-as violence-framework, was at the forefront of the movement to publicize the harm caused by prostitution through relaying personal stories and experiences of WHISPER participants (Weitzer, 2000). This organization ceased its operations in 1996 but provided a forum for those sex workers who wanted to share their experiences working in the sex industry. The founder and editor of WHISPER's national newsletter, Wynter (1987) stated that prostitution is

...founded on enforced sexual abuse under a system of male supremacy that is itself built along a continuum of coercion- fear, force, racism and poverty. For every real difference between women, prostitution exists to erase our diversity, distinction, and accomplishment while reducing all of us to meat to be bought, sold, traded, used, discarded, degraded, ridiculed, humiliated, maimed, tortured, and all too often, murdered for sex. (p. 268)

This political message directly contrasts those purported by St. James and COYOTE. Despite their shared immediate goal of decriminalizing prostitution for the women involved, prostitution-as-violence-and-exploitation advocates differ from their prostitution-as-work counterparts in contending that prostitution should remain criminalized for the procurers and customers of women working in the sex industry (Dworkin, 1987). These organizations, although different in their perspectives on prostitution, provided the initial forum for sex workers to voice their needs, share their aspirations, and take political action toward change. 
Currently, organizations that maintain a sex-work-as-violence perspective are emerging as anti-trafficking groups that conflate trafficking with prostitution. CATW participates in global campaigns to end trafficking, advocates for ending prostitution, seeks to develop better programs for victims of trafficking and advocates for the penalization of customers. CATW challenges the perspective of prostitution as work and views prostitution as sexual slavery. It is interesting to note that CATW and other trafficking groups differ from earlier organizations, such as WHISPER, in that they were not created by survivors of trafficking, but rather by radical feminist activists focused on an anti-prostitution agenda. Through these organizations, women working in the sex industry are being represented by others who are identifying their needs from a privileged location in society.

Academic Representations of Sex Workers' Needs \& Aspirations

Social science researchers' perception of sex work has been influenced by feminist perspectives and socio-political representations of sex workers' needs throughout history. Rajan (1999) points out that "apart from the function of illustration, representations carry significance also by serving as a cognitive frame for conceptual and practical understanding of issues" (p. 7). The representations of sex workers as criminals, deviants, carriers of disease, and/or innocent victims who need to be saved have influenced research topics so that there is a disproportionate focus on the harms of sex work instead of research on empowering or strength-based aspects of working in the sex industry. The harms of sex work can be grouped into topics that imply sex workers' need, while most studies omit positive attributes and aspirations of sex workers. Four areas of 
academic research related to the needs of sex workers include violence, mental health, drug and alcohol use, and HIV/AIDS; with a limited number of needs assessment studies. While very valuable, these topics perpetuate the construction and representation of sex workers' needs by professionals who are not sex workers. Missing is the involvement of sex workers in the research process and their voices. These studies also contribute to the homogenization of sex workers as a single group, which is not representative of individuals working in different parts of the sex industry, the multiple identities of sex workers, and their varied experiences.

There are only a few studies that specifically assess sex workers' needs without creating pre-determined topics of study around violence, drugs, mental health and HIV/AIDS. However, these studies focus on street sex workers and do not address the needs of individuals working in other areas of the sex industry. There is a great imbalance in the social science literature with regards to topics of study on sex work. While there is a focus on issues related to sex workers' needs, there are no identified research studies in the social science literature that have looked at sex workers' aspirations.

\section{Violence}

Many research studies consistently report on the high rates of violence experienced by sex workers, particularly those individuals working on the streets ${ }^{2}$. Some studies focusing on issues of violence are informed by radical feminist theories on sex work, which insist that "sexual violence and psychological harm both precede and are intrinsic to prostitution" (Farley \& Kelly, 2000, p. 30). Rubin (1984) critiques research

\footnotetext{
${ }^{2}$ For additional research studies on sex work and violence see: Weinberg, Shaver, \& Williams (1999); Pauw \& Brener (2003); El Bassel, Witte, Wada, Gilbert, \& Wallace (2001); Nemoto, Iwamoto, Wong, Le, \& Operario (2004); Chesler (1993); Hardesty \& Greif (1994); Miller (1993); Miller \& Schwartz (1995); Pyett \& Warr (1999); Nixon, Tutty, Downe, Gorkoff \& Ursel (2002).
} 
studies that only emphasize high rates of violence as intrinsic to sex work since these studies select "the worst available examples" and the most disturbing instances of abuse and present them as representative of the population (Rubin, 1984, p. 301). Weitzer (2005) adds that studies on violence are vulnerable to selection bias, whereas the most desperate segment of the population is most likely to contact service providers. A few studies have reported a difference in the amount of violence experienced by street workers compared to call girls, brothel workers and escorts (Church, Henderson, Barnhard \& Hart, 2001; Giobbe, Harrigan, Ryan \& Gamache, 1990; Lopez-Jones, 1999). In Church's et al. (2001) comparison study between indoor and outdoor sex workers, individuals working outdoors experienced higher levels of violence and drug use. Other findings indicate independent call girls and those who work for escort agencies, massage parlors, and brothels are at lower risk for violence since they have a greater proportion of regular customers (Lever \& Dolnick, 2000).

These studies tell us that street sex workers may need safer places to work, which might result in developing a steady clientele they can trust. Street sex workers might also need safety tips on identifying dangerous situations and staying safe when working on the streets. However, in order to better understand connections between sex work and violence, more attention to race, class and gender within various parts of the sex industry is needed. Wahab (2005) points out that the race and class bias in research studies on violence is problematic because it creates the impression that female street workers represent the problem, thus creating a situation where sex workers are "further targeted for arrest and prosecution because they are seen as the problem" (p. 264). The need to 
address violence against sex workers may be best addressed through laws protecting them.

\section{Mental Health}

The effects of violence experienced in sex work has led some researchers to also look at mental health issues, particularly Post Traumatic Stress Disorder (PTSD). While experiences of violence can lead to PTSD and other mental health issues, some research studies that are informed by a sex-work-as-violence lens identify mental health effects as being caused by work in the sex industry. This can be problematic because while Farley, Baral, Kiremire, and Sezgin (1998) present evidence of elevated psychological distress and PTSD of sex workers, one has to question whether the stress is related to sex work per se or the violent conditions of the work, especially in the context of street work (Shaver, 2005) $)^{3}$. Street workers are also most vulnerable to homelessness, violence and arrest, which may contribute to mental health needs. A research study by Romans, Potter, Martin, and Herbison (2001) gathered data from less vulnerable sex workers (off-street workers) using a comparison group of women matched by age. These researchers reported no differences between the two groups in mental health on the General Health Questionnaire or in self-esteem. It is important for researchers to not homogenize the needs of all sex workers, since workers in different aspects of the sex industry have different needs and experiences.

\section{Drugs \& Alcohol}

Multiple research studies focused on alcohol and drug related harm associated

\footnotetext{
${ }^{3}$ Additional research studies that examine PTSD and mental health issues in sex workers have been completed by Farley \& Barkan (1998); Farley \& Kelly (2000); Cwikel, Ilan, \& Chudakov (2003); Hutton, Treisman, Hunt, Fishman, Kendig, Swetz, \& Lykestos (2001); Surratt, Kurtz, Weaver \& Inciardi (2005).
} 
with sex work ${ }^{4}$. These studies are prevalent in the literature; especially with regards to the experiences of women of color working on the street. Both qualitative (Inciardi, Lockwood, \& Pottieger, 1993; Sterk, 1999) and quantitative (Logan \& Leukeld, 2000; Edwards, Halpern, \& Weschsberg, 2006) studies have specifically looked at African American street workers and crack cocaine, concluding that crack use is correlated to homelessness and abuse. In a study by Romero-Daza, Weeks and Singer (2003), in-depth interviews were conducted with 35 street workers (ages 23-41 years), 29 of whom identified as Latina or African American. Study results found that there was a complex relationship between drug abuse, sex work, violence, and AIDS, with most of the women suffering from major emotional trauma. It is important to note that these women were all recruited from a convenience sample of a recently completed drug and alcohol treatment program. Structural factors that contribute to poverty, racism and hierarchical differences among sex workers play a role in which sex workers enter treatment programs, and thus participate in research studies. A focus on drugs and alcohol in sex work research assumes they are an inherent aspect of the work and places a heavy burden on women of color and those most marginalized in sex work who might work in the sex industry to support a drug habit.

\section{HIV/AIDS}

A large body of literature on sex work is related to risk of HIV/AIDS, even though in the late 1980s researchers showed that sex workers were not responsible for the spread of HIV (King, 1990). Although the importance of HIV transmission through sex

\footnotetext{
${ }^{4}$ For additional research studies on sex work and drug use see the following: Romero-Daza, Weeks, \& Singer, 1999;Baseman, Ross, \& Williams, 1999; Latkin, Hua \& Forman, 2003); Logan, Cole, \& Leukefeld, 2003; Logan \& Leukefeld, 2000; Weeks, Grier, Romero-Daza, Puglisi-Vasquez, \& Singer, 1998.
} 
work has been evidenced in Africa, sex work is not a major cause for the spread of HIV infection in the U.S. (Porter \& Bonilla, 2000). One study concluded that street workers in the U.S. were more likely to perform oral sex with their clients and frequently used a condom (McKeganey \& Barnard, 1990). The assumption of sex workers as a "risk group" is used to justify and shape AIDS research and interventions (Murray \& Robinson, 1996, p.3). The HIV/AIDS discourse has contributed to representing sex workers as a threat to public health, regardless of where or how they work (Phoenix, 2007). Some scholars criticize the negative focus on prostitution in the context of HIV and the misrepresentation of sex workers in the media as carriers of the disease (Vanwesenbeeck, 2001). Yet, a large part of the literature on sex work(ers) is still HIV focused, which may be related to funding opportunities for HIV/AIDS research. Many studies on HIV and commercial sex work were conducted in countries of the global South $^{5}$. The majority of research completed with sex workers in the U.S. has involved large, quantitative surveys of sexual behavior, sexual risk predictors, assessment of HIV programs, drug-use ${ }^{6}$, and needle-exchange (Wyatt, Bloom \& Solmai, 2000). The focus of these studies is on sex workers' need to change their sexual behavioral and relations, as opposed to addressing the role that structural and societal relations as play in the transmission of HIV. It is important to note that this body of literature creates a discourse that is often moralizing, categorizing, and stigmatizing (Vanwesenbeeck, 2001). An

\footnotetext{
${ }^{5}$ For studies on HIV/AIDS and commercial sex workers in countries of the global South, refer to the following articles: Weeks, Abbott, Liao, Yu, et al., 2007; Jusza \& Baker, 2004; Riono \& Jazant, 2004; O’Neil, Orchard, Swarankar, et al., 2004; Truong, Do, Durant, et al., 2004; Morison, Weiss, et al., 2001. ${ }^{6}$ For studies on HIV/AIDS and drug use see: Wallace J, Weiner A, Steinberg A, Hoffmann B., \& Fielding C. (1992); Sherman, German, Cheng, Marks \& Bailey-Kloche (2006); Doherty, Garfein, Monterroso, Brown \& Vlahov (2000); Kral, Lorvick \& Edlin (2000); Ross, Hwang, Zack, Bull, \& Williams (2002); and Baseman, Ross \& Williams (1999).
} 
underlying political agenda of HIV/AIDS research within sex work is to minimize the potential risks to the health of sex workers in order to limit the perceived threat sex workers pose to the general population (Phoenix, 2007).

\section{Needs Assessment Studies}

Very few research studies have specifically assessed the general needs of sex workers. The existing knowledge of sex workers' needs comes from quantitative studies, with large sample sizes and standardized questions. One of the first needs assessment studies on sex workers was published by Weiner (1996), who utilized an ex post facto research design to quantitatively analyze the responses from 1,963 street sex workers accessing services from a mobile outreach van. More than half of the sex workers who participated in this study identified as Black women, more than a quarter identified as Latina women, and about one fifth were white women. Weiner's (1996) findings concluded that sex work makes a woman vulnerable to:

The loss of social services, removal of her children and termination of parental rights, expulsion from social support systems such as family or church, rape or other violence, and arrest. The stigma associated with being a prostitute may make it impossible for these women to return to more "legitimate" lifestyles. (p. 100)

This study also pointed to the experience of some women who were not able to access alcohol and drug treatment because of the unavailability of beds. Also, facilities that had co-ed populations also turned women down, believing that sex workers would continue to trade sex for drugs and therefore undermine the program (Weiner, 1996).

Another large, quantitative study by Valera, Sawyer, and Schiraldi (2001) surveyed 100 street sex workers in an interview format (due to concerns about literacy levels) using two existing survey instruments. The participants were female (42\%), male 
(32\%) and transgender (26\%), providing insight into the different needs of sex workers in Washington D.C., based on gender identity. The perceived needs of all of the participants included: support from others who had experienced life as a street worker (especially among males), counseling and support (highest percentage among males), a home or safe place to stay, drug or alcohol treatment, self- defense training (high percentage among females), and job training. It is important to note that the subgroups had different needs prioritized, confirming the significance of acknowledging heterogeneity among sex workers. A needs assessment study on indoor sex workers by Murphy and Venkatesh (2006) identified that immigration assistance was needed by $70 \%$ of sex workers, $35 \%$ needed other employment options, and approximately $37 \%$ needed medical assistance. Other needs identified were drug and alcohol counseling, legal help, domestic violence assistance, child welfare needs and psychological support.

While the large sample size of these needs assessment studies provides the opportunity to generalize among street-workers, the quantitative nature of these studies prevents a deeper understanding of the needs of sex workers working in various parts of the sex industry. In addition, it is unclear whether the categories of possible needs were pre-determined by the researchers or if the participants had an opportunity to report needs without having to choose from a list. It is also difficult to ascertain whether the perceived needs were a result of working in the sex industry.

\section{Limitations of Social Science Research}

Large, quantitative research studies have many limitations for conducting research on sex workers. They do not allow for a deeper understanding of sex worker needs and aspirations, nor do they allow for potential collaboration with sex workers so that their 
voices are taken into account. In addition, studies that use participants' self-reports to examine risky sexual behaviors among commercial sex workers may not be accurate due to a social desirability bias (Morisky, Ang, \& Sneed, 2002), thus threatening the internal validity of the studies. There is also the stigma associated with certain risky behaviors related to the transmission of HIV (e.g. multiple sex partners without a condom, intravenous drug use), further complicating self-reports. These limitations can be minimized if studies use in-depth interview methods (Sherman, et al., 2006). However, it is important to note that most studies are done on sex workers instead of with them. Also, the size and boundaries of the various communities of sex workers are unknown, making it difficult to obtain a representative sample (Shaver, 2005). Reliance on convenience and snowball samples does not allow the generalizability of the study results (Weitzer, 2005). Most studies on sex work consist of individuals who contacted social service agencies, were approached in the street, or were interviewed in jail. Therefore, data is often obtained from the most vulnerable sex workers; street-based workers who are most frequently victimized (Weitzer, 2005). More information is needed on the needs and aspirations of sex workers working in different branches of the sex industry, as Chancer (1993) points out that sex workers experiences, situations and circumstances greatly differ in a "highly stratified occupation" (p. 163).

Within the sex work literature, little attention is given to empowering aspects of working in the sex industry. This proposed study, which focuses on the aspirations of sex workers, aims to address this gap. Vanwesenbeeck (2001) believes this gap is due to the difficultly that some researchers have in understanding rational, not to mention positive reasons for choosing sex work. This results in the perception of sex workers as victims 
that could not possibly choose this type of work. Vanswesenbeeck (2001) points out that this may lead to a desirability bias, in which sex workers might stress their victim status and negative motivation for working or they might hide their experiences around further stigmatizing behavior such as drug use or risky sexual behavior. The large focus on studies related to violence, drugs and alcohol, and HIV/AIDS research may be related to opportunities funded by the government. This bias in funding areas presents an underlying political agenda to protect society from crime related to drugs and alcohol, from health risks associated with HIV/AIDS, and from the domination of violent men. In addition, the recent funds available for research studies on trafficking into the sex industry demonstrate an underlying agenda to protect national borders from corruption. The funding opportunities available for research on sex work (which are usually limited to begin with) shape the focus of social science research literature and serve to protect the interest of the general public from a stigmatized and marginalized population.

Creative and Artistic Representations of Sex Workers' Needs and Aspirations There is an expanding body of work from the perspective of sex workers in academia, literature, poetry, film, art, and performance. Former and current sex workers have performed art, created art and written about their experiences as sex workers and their involvement in the sex industry from diverse and passionate perspectives. These creative works contribute to transforming representations of sex workers as passive victims and social deviants to empowered activists, artists and scholars. In particular, writings by sex workers illustrate many different voices; voices of pain, voices of power, and voices of hard work (Alexander, 1987). This artistic expression and communication 
addresses the unique experiences of various sex workers; their needs, desires, pleasures, identity, spirituality, creativity and civil rights.

Anthologies also provide information and insight into the lived experiences and histories of sex workers. Sex work: Writings by Women in the Sex Industry (Delacoste \& Alexander, 1987) presents testimonials from sex workers and provides a space for various points of view to be written in creative ways through stories, poems, essays, articles and short reports. The motive behind creating this anthology was to give sex workers the opportunity to voice their experiences and to unite sex workers towards a common goal of ending violence and pain (Alexander, 1987). Good girls/Bad girls: Feminists and Sex Trade Workers, Face to Face (Bell, 1987) also brings the voices of sex workers together with feminists to discuss issues around pornography, sex work, racism, sexuality and the construction of women through the good girl/ bad girl image. Another anthology, A Vindication of the Rights of Whores (Pheterson, 1989), focuses on activism and civil rights. It presents an account of the international movement for sex worker's rights; the committees and organizations formed, the conferences attended and the experience of migrant sex workers and their development of international movements for sex workers rights.

Volumes of essays from sex workers have also provided powerful accounts of experiences in the sex industry, serving to illuminate the nature of these feminist sex workers as thinkers, writers, and activists. Many of the contributors to the volume of essays in Whores and Other Feminists (Nagle, 1997) acknowledged their racial and economic privilege within the sex industry and expressed their experiences through poetry, essays and testimonials. Using creative techniques to express thoughts, reflections 
and life stories, while challenging stereotypes and assumptions, can be empowering for sex workers and has the potential for reaching broader audiences. The internet is also a space for creating and sharing written and photographic art by sex workers. This offers the potential for reaching a broader audience. In addition, the annual Sex Worker Art Show provides a space for sex workers to perform and engage in artistic expression. Maggie O'Neill (2002) conducted a creative, arts-based research study that examined the lived experiences of sex workers and their needs. She used the research process of ethno-mimesis, which combines participatory research with ethnographic work to produce performance art. During the study process, the theme of safety emerged as a pressing need for sex workers. The collaborative process of this research included artistic forms for representing experiences and facilitating ideas for change. The transcribed interviews of the life stories of sex workers were combined with dance, text, sound and video. The immediacy and directness of live art performance has the ability to "get in touch with our 'realities', our social worlds and the lived experiences of others, in ways that demand critical reflection" (O’Neill, 2002, p. 218). This study demonstrated the potential of creative and artistic research for including the voices of sex workers, challenging representations and stereotypes, identifying needs, and highlighting experiences through art to create awareness for change.

Expressing and representing research data creatively has the potential for providing a deeper understanding of the needs and aspirations of sex workers. Arts-based research has the capacity for "re-visioning problems that are simply not possible through descriptive or linear language" (McNiff, 2008). Traditional forms of qualitative research using researcher-driven interviews and observations can be limited in their usefulness for 
understanding sex workers' subjective experiences. Interviews provide the space for sex workers to share their experiences; however, participants have limited freedom to shape their own stories, in ways that makes sense to them. No matter how flexible the interview protocol, the questions asked and the order in which they occur will at some level focus on what matters most to the researcher, and not necessarily to the participant. In addition, observations are usually described through the researcher's eyes. Through an arts-based research process, sex workers have the option to express themselves and their experiences using a medium other than language and have the freedom to construct their stories in ways that make sense to them. "Art, in any of its various forms, provides a medium for self-reflection, self-expression, and communication between and among creators and audiences" (Finely, 2005, p. 692). Arts-informed inquiry has the potential for evoking new and multiple levels of participation and understanding of the needs and aspirations of sex workers. 


\section{CHAPTER 3}

\section{RESEARCH DESIGN}

\section{Location of Self}

I am a first generation Greek-American, holding dual citizenship and claiming a transnational identity. I lived in Greece and currently reside in the U.S., continuously traveling between my two parallel worlds. My engagement with the visual arts developed in childhood. As a bi-cultural woman of color, art seemed to transcend boundaries, connecting my two worlds in a way that language could not. Art served as a source of knowledge and a form of expression for the feelings and experiences that I could not articulate. From a very young age, engaging with art and producing my own art was a source of inspiration. My self expression has taken shape in multiple forms and through various media; such as painting, drawing, ceramics, collage, jewelry making, sewing, and photography. As I grow, I feel most at home, most safe, most alive, and most expressive behind the lens of my camera. I use each of my cameras as a tool to make sense of my reality and to document my lived experiences, perspectives, and relationships. Years of art and photography classes, the creation of my own darkroom at home, and the opportunities to display my photography in various communities have all contributed to how I see myself as a visual artist. My personal creativity and commitment to the artistic process are also inspired by the artistic images and creativity of others. It is my love for the arts and my identity as a visual artist that fuels my passion for incorporating artistic inquiry into social science research with sex workers. I believe that fusing the arts with social science research provided the opportunity to develop unique knowledge and a 
deeper insight into the experiences of sex workers that had never been done before with this population.

My interest in conducting research with sex workers followed my initial interest in the feminist debates on sex work. The complexity and politicized nature of sex work challenged me to examine my own ideas acquired through media representations and images. As a social worker, my clinical experience with individuals working in the sex industry is limited to working in a drug and alcohol treatment program that serves dualdiagnosed, previously incarcerated individuals (some of whom had worked in the sex industry) and working with children of sex workers. I have never engaged in sex work, nor have I ever participated in other aspects of the sex industry. I acknowledge that my reality is very different from the study participants. I also believe that the experiences of working in the sex industry can vary according to age, social location, gender, race, and even personality or mood. I consider it important to avoid moralistic positions when discussing commercial sex work between two consenting adults. I believe in a sex workers' rights-based approach which demands citizenship rights for sex workers and their right to work with dignity, safety, and without discrimination.

During the past two years, I had the opportunity to become more involved with communities of sex workers and with the social service agencies that encounter them. I volunteered with the Portland Women's Crisis Line, at a mobile outreach van that provides health services to sex workers. I am an active member of the Sex Worker Outreach Coalition (SWOC). I helped to develop a training curriculum for SWOC volunteers, and I co-facilitated sex worker outreach volunteer trainings. I am on SWOC sub-committees that are involved in media advertisement and response. During the course 
of this project, I also facilitated a collage art-workshop for sex workers and a film screening and dialogue session to raise awareness about the violence against sex workers. Through these experiences I built relationships within various communities of sex workers and with multiple social service providers. My strong personal and professional relationships and my activism for the rights of sex workers contributed to strengthening my connection with those sex workers who were interested in co-creating knowledge in a creative manner. My status as a doctoral student and researcher granted me certain privileges and power that I tried to equalize and share with the participants in my study. Using the arts-based research method of photovoice with sex workers allowed for a more participatory way of knowledge making and sharing.

\section{Research Questions}

My interest in this study was to understand the lived experiences and perspectives of sex workers in Portland through their art and our dialogue about their art. The first and second research questions are answered from the sex workers' perspectives. The third and fourth research questions were answered with a focus on the conditions of photovoice as a process for illustrating the women's experiences.

- What do sex workers identify as the needs of their communities?

- What are the aspirations of sex workers?

- How do sex workers make meaning of their needs and construct their experiences in photographs as the creators and interpreters of their own images?

- How do sex workers make meaning of their aspirations and construct their experiences in photographs as the creators and interpreters of their own images?

I relied on a thorough review of the literature to identify research questions that others 
had not yet addressed. I also drew from my experience and knowledge of the lack of services available for sex workers in Portland and their missing voices in the community. At the start of this project, I presented the participants with needs and aspirations as initial themes for taking photographs. Throughout this research project, the participatory nature of the study supported the participants' desire to refine, substitute, eliminate, add, or redevelop any or all of the research themes or focus of the project. No one chose to do so, but rather, all participants' expressed their desire to use these themes as the ideas behind their photographs.

\section{Arts-Based Research Framework}

This proposed research study is informed by (visual) arts-based research, which is a form of qualitative inquiry that emphasizes constructivism, critical interpretation, and contextualism (Sullivan, 2005). Arts-based research makes use of the diverse ways of knowing and experiencing the world (Finley, 2008). Three main goals of arts-based research are: (1) social activism by giving voice to those with less power in society (Barone 2000; Finley \& Finley 1999); (2) making connections between research and lived experience (Garoian, 1999); and (3) making meaning through multiple senses and medium (Norris, 2000). What distinguishes arts-based research are the multiple creative ways of representing experiences and the different representational forms (medium) of expression that can effectively enhance the understanding of the human condition and experience. "Art seizes the fullness of lived experiences by describing, interpreting, creating, reconstructing, and revealing meaning" (Watrin, 1999, p.93). In arts-based research, the role of lived experience, subjectivity, and memory are seen as driving forces 
in knowledge construction. Arts-based research uses art to understand and represent the worlds in which research is constructed (Finley, 2008, p. 79). The arts provide a unique way of coming to understand something and how it represents what we know about the world.

Art as a Way of Knowing

Arts in research promote a form of understanding that is derived or evoked through empathic experience, thus, the artist provides a means through which feelings can come to be known (Eisner, 2008, p. 7). The relationship between arts and knowledge has been addressed by Susanne Langer, (1957) who writes:

What does art seek to express? ... I think every work of art expresses, more or less purely, more or less subtly, not feelings and emotions the artist has, but feelings which the artist knows; his insight into the nature of sentience, his picture of vital experience, physical, and emotive and fantastic. (p. 91)

From this perspective, works of art represent an artist's ability to create something in a particular form that is similar to human experiences and feelings. Eisner (2008) discusses four contributions of the arts to knowledge. First, the arts address the qualitative subtle differences of situations. For example, art has the potential to address what is subtle but significant about the world that one might not notice if they didn't know how to look. A second contribution relates to do with emphatic feeling. Images created in artistically expressive form generate a type of empathy that makes action possible. A third contribution the arts make to knowledge has to do with the fresh perspective they have to offer, so that our old habits of mind don't dominate our reactions with typical, collected responses. The arts offer new ways in which to perceive and interpret the world that would otherwise go unknown. Finally, the arts tell us something about the capabilities of 
individuals to experience the affective responses to life that the arts evoke. Eisner (2008) articulates,

If the arts are about anything, they are about emotion, and emotion has to do with the ways in which we feel. Becoming aware of our capacity to feel is a way of discovering our humanity. Art helps us connect with personal, subjective emotions, and through such a process, it enables us to discover our own interior landscape. (p. 11)

Art is a way of knowing what we actually believe and feel and can also be a way of expressing what we experience. Art within research can be a representation, a process, and a form of inquiry.

Key Features of Arts-Informed Research

Arts-based research is also referred to as arts-informed research, arts-based inquiry, or image-based research (Franz, 2005). Research based in and informed by art is broadly grounded in assumptions that describe a qualitative paradigm. These defining aspects, articulated by Cole and Knowles (2008), include a commitment to a particular art form that is reflected in elements of the creative research process and in the representation of the research text. Another distinctive trait is methodological integrity, which refers to having a rationale for the use of a particular art medium for guiding the inquiry or representation. In addition, the arts-based, creative inquiry process is defined by openness to the extensive possibilities of the human imagination. Butler-Kisber (2008) states that there is growing interest in using arts-based inquiry to "counteract the hegemony and linearity in written texts, to increase voice and reflexivity in the research process, and to expand the possibilities of multiple, diverse realities and understandings" (p. 268). It has the potential for offering ways of re-visioning issues that are simply not possible through descriptive linear language. 
Another characteristic of arts-based research is the subjective and reflexive presence of the researcher through the researcher's creativity/artistic ability. Artsinformed research also incorporates strong reflexive elements that indicate the presence and signature of the researcher (without the researcher necessarily having to be the focus of the study). Weber and Mitchell (2004) add that reflexivity in arts-based research forces a researcher to take a step back and look introspectively from a new perspective provided by the medium itself, increasing the potential for a deeper self-analysis.

Arts-based research has distinctive features that set it apart from other forms of postmodern qualitative inquiry. According to Finley (2008), arts-based research: (1) makes use of emotive, affective experiences, senses, and bodies, and imagination, as well as intellect, as ways of knowing and responding to the world; (2) gives interpretive license to the researcher to create meaning from experience; (3) attends the role of form (e.g. photography) in shaping meaning; and (4) exists in the tensions of blurred boundaries, between art and social science research. McNiff (2008) claims that original knowledge occurs while crossing those boundaries of previously separated domains (arts and science); when ideas are placed in new relationships to one another. A central purpose of arts-informed research is to enhance the understanding of the human condition through alternative processes and representational forms of inquiry (Cole \& Knowles, 2008).

Another main goal of arts-based research is to reach multiple audiences by making scholarship more accessible. Arts-based inquiry is committed to connecting the work of academia with the lives of people in the community through research that is accessible, evocative, empathetic and stimulating (Cole \& Knowles, 2008). It aims to 
democratize research and place control in the hands of the people. The objective is to "bring both arts and social inquiry out of the elitist institutions of academia and art museums, and relocate inquiry within the realm of local, personal, everyday places and events" (Finley, 2008, p. 72). The arts-based researcher aims to provide tools and opportunities for participants to perform inquiry through creative mediums. Arts-based

processes invite participants to reflect on their performances, and to preserve, create, and rewrite their experiences and culture in dynamic, local spaces (Finley, 2008). Artful representations by participants can provoke reflective dialogue and meaningful participatory action to change society.

\section{Creative Forms of Data Representation}

In social science research, data are usually represented and reduced to numbers and/or text. However, the concept of creative, artistic and alternative forms of data representation acknowledges the variety of ways through which our experience is coded (Eisner, 1997). The use of creative forms to represent research data contributes to deepening meaning, expanding awareness and enlarging understanding of a research phenomenon. There are many different ways in which the world can be experienced and represented (Barone \& Eisner, 1997). Creative forms of data representation allow meanings to take shape in different ways and invite us to engage with experiences in new ways. They provide opportunities to go beyond the limitations of our usual frame of reference and beliefs so that new associations are created. Creative forms invite us to develop insights that would otherwise be inaccessible and encourage us to see differently. Some human experiences are so complex and intensely emotional, that creative forms of representation can reflect their texture more powerfully than traditional academic text. 
Creative forms of expression can even make something intense out of experiences that are perceived to be mundane.

Eisner (1997) identified potential benefits for using alternative, creative forms of data representation in order to shape experience and expand understanding. $\mathrm{He}$ emphasizes the need for scholars to engender a sense of empathy for the lives of people they wish to know. Eisner (1997) maintains that facts described literally are less likely to have the power to provide a particular kind of access (acquired through creative forms) into the participants' lives that is necessary for empathy. Engagement with the arts fosters understanding and potential for shared meaning. Secondly, alternative forms provide a sense of particularity that abstractions cannot provide (Eisner (1997). For instance, through creative forms, we come to see the place, the situation and to know each individual person. These perceptions take on their own distinctive qualities and acquire dimension. Third, creative data representations can provide 'productive ambiguity'; defined by Eisner (1997) to mean that "the material presented is more evocative than detonative, and in its evocation, it generates insights and invites attention to complexity" (p. 8). Some forms of creative representation result in less closure and more possibilities for interpretations of the situation. With open texture of the form, there is a greater probability of the emergence of multiple perspectives (Eisner, 1997).

There are some limitations to using creative forms of data representation. While creative forms can provide multiple perspectives, the data presented incorporate the risk of meaning whatever anyone wants them to mean, since alternative forms do not provide precision (Eisner, 1997). The question then becomes one of how much precision do we need in order to test the validity of the data or their meaning? In addition, oftentimes, 
alternative forms of data (if the terrain is new) might need text since some genres of work cannot stand alone without an interpretive context. And finally, there is concern around what form these creative representations will take in order to meet practical academic requirements for establishing a publication record (Eisner, 1997). As creative, artistic forms of data representation are used more and more within the social sciences, these limitations may be addressed or redefined to resolve the tensions they raise.

\section{Use of Visual Images in Research}

Images are very valuable to research because they have the ability to convey multiple messages, pose questions, and point to both abstract and concrete thoughts (Weber, 2008). Visual images are constantly subject to reconstruction and reinterpretation, holding multiple meanings. Barthes (1981) takes the photographic image and explains that images have two main levels of meaning: denotative and connotative. The denotative meaning of an image refers to its literal, descriptive meaning; the visible truth, evidence, or objective reality that the image documents. The connotative meaning of that same image refers to the cultural and historical context of a specific image, in addition to the social conventions, codes, and meanings that have been attached to or associated with that image in a particular context (Weber, 2008). Images can act as useful metaphors. Working with metaphors can provide themes and patterns to form ideas and explanations (Simons \& McCormack, 2007). In addition, metaphors provide an opportunity to connect images and ideas in different ways. This can reshape the text from being one-dimensional to having multiple layers and meanings. The ability of images to express multiple messages contributes to the potential for obtaining rich data about human experiences and perspectives. Arts-based research approaches that incorporate 
visual images operate at a symbolic, metaphoric level, which invites multiple ways of understanding (Franz, 2005).

Weber (2008) makes a case for using visual images in research and identifies the potential for images to capture the indescribable, hard-to-put-into-words aspects of knowledge that might otherwise remain hidden or ignored. Images hold the power to engage us and make us pay attention to things from a different perspective. Images can illicit emotional and intellectual responses (Weber, 2008). These various responses make images more memorable, easier to disseminate, and accessible to a wider audience. Images can be used to incorporate multiple layers of meaning and evoke stories. Visual images can help us adopt someone else's point of view, enhancing empathic understanding (Weber, 2008; Eisner, 1997). They encourage embodied knowledge; "people are not ideas, but flesh and blood beings learning through senses and responding to images through their embodied experiences" (Weber, 2008, p. 46). Visual images can also facilitate reflexivity in research since artistic expression has the potential for revealing aspects of the self, personal experiences, and ways of seeing. There is also the power of images to provoke action for social justice (Weber, 2008; Wang, 1999). They can spark critical dialogue and encourage individual and collective action.

\section{Theoretical \& Practical Framework}

This study is informed by the following theories and approaches: feminist standpoint theories, Freire's (1970) approach to empowerment education (education for critical consciousness), and a participatory approach to documentary photography. These 
theoretical and practical underpinnings inform the use of the qualitative, arts-based method of photovoice.

\section{Feminist Standpoint Theories}

Standpoint theories are rooted in philosophy and literature. The philosopher Georg Hegel revealed that what people know depends upon which group they belong to and the knowledge created by those in control (McGlish \& Bacon, 2003). Standpoint theories are also influenced by symbolic interactionsim, which suggests that people act toward things based on the meaning that those things have for them. These meanings are derived from social interaction and modified through interpretation. Standpoint theories emerged in the 1970s and 1980s as feminist critical theories that examined the relations between the production of knowledge and the practices of power (Harding, 2004). Standpoint theories have roots in Marxian thought and are influenced by the ideas of Marx and Engels which held that the poor can be society's "ideal knowers" (McGlish \& Bacon, 2003). The assumption is that the socially oppressed class can access knowledge unavailable to the socially privileged, particularly knowledge of social relations. Hartsock (1983) coined the term feminist standpoint in 1983, while expanding on her work from a feminist Marxist stance. Hartsock developed a parallel argument that the position of women as an oppressed group placed them in a position of epistemic privilege (Hundleby, 1997). Feminist standpoint theories became crucial for understanding systematic oppressions in a society where women's knowledge is undervalued.

A standpoint is a place from which to view society that determines what we focus on as well as what is obscured from us. "A feminist standpoint is a way of understanding the world, a point of view of social reality, that begins with, and is directly from, 
women's experiences" (Brooks, 2007, p. 60). Haraway (1997) defines standpoints as "cognitive-emotional-political achievements, crafted out of located social-historicalbodily experience- itself always constituted through fraught, non-innocent, discursive, material, collective practices" (p. 304). The pluralizing of feminist standpoints acknowledges that there are differences among material experiences of women across history, race, class and culture (Hirschmann, 1997). Feminist standpoint theorists, such as Dorthy Smith, Patricia Hill Collins, Alison Jagger, Nancy Hardstock, Donna Haraway, and Sandra Harding offer slightly differing versions of this theory, however, they all share related theoretical concepts.

\section{Knowledge as partial and situated.}

In standpoint theories, all knowledge is situated and multiple "truths" are accepted. Rather than claiming one universal truth about the nature of the world's reality, feminist standpoint theorists seek partial and less distorted views. For feminist standpoint theorists, truth and knowledge are value laden, and all standpoints offer partial views of reality. Each person can achieve only a partial view of reality from the perspective of his or her own location in a hierarchically structured system of power relations (Harding, 2004). According to Harding (2004), situated knowledge is based on our social location and the social groups to which we belong that systematically shape what we know and how we communicate. Thus, standpoint theorists acknowledge that "who we are" and "what we know" will shift and change, in response to the different material conditions, as well as to the fact that each individual occupies more than one experiential and identity location (Hirschmann, 1997). 
Standpoint theories are grounded in a version of empiricism which supports the notion that knowledge depends on experience (Hundleby, 1997). Feminist standpoint theories foreground women's knowledge as emergent from women's situated experiences. Haraway (1991) and Longino (1999) argue that knowledge grows out of women's unique lived experiences and the specific interpretations of social reality (or standpoints) that go along with those experiences. Standpoint theories reject postmodernism's absolute relativism, offering a middle ground between "feminist empiricism" and "feminist postmodernism" (Hundleby, 1997). Standpoint theories do not deny scientific authority but rather aim to improve it through valuing the most discredited perspectives of knowledge (Alcoff \& Potter, 1993).

Dominant and marginalized groups, as well as sub-groups, each contribute “distinctive knowledge emerging from its particular social situations" (Swigonski, 1994, p. 392). However, feminist standpoint theorists suggest that social inequalities generate unique accounts of nature and social relationships. Standpoint theories emphasize the notion that dominant groups, by virtue of their role or position in society, have greater influence on what knowledge is produced. However, the perspectives of the lives of those less privileged can provide a more objective view than the perspective of those who are more privileged (Harding, 2004; Olesen, 2005).

Feminist standpoint theories grant epistemic privilege to those who are marginalized since these individuals may better know different things than those who are privileged by virtue of what they experience and how they understand it (Harding, 2004). Therefore, the perspectives of marginalized groups are more complete, more valuable, and far less limited than those of privileged groups in society (Haraway, 1988; Harding, 
2004), as some assert that the dominant groups' view is more superficial. This is due to the dominant group's interest in maintaining the status quo, regardless of how incomplete their understanding of the world may be (Swigonski, 1994). Since marginalized populations have less to lose, their perspective can generate a fresh, critical analysis of current systems of power (Swigonski, 1994). Standpoint feminist theories allow us to understand degrees of power and privilege that fit together with particular differences by holding on to the material reality of oppression (Hirschmann, 1997). Feminist standpoint scholars emphasize the importance of using women's experience as a lens through which to examine society as a whole (Brooks, 2007; Harding, 1991). Prioritizing women's perspectives and knowledge from their experience can be used to illuminate social inequalities and injustices.

Woman as epistemologically privileged.

Feminist standpoint theorists view differences between men and women as a result of cultural expectations and the divergent treatment that each group receives from one another (McGlish \& Bacon, 2003). However, theorists acknowledge that culture is not experienced the same by everyone due to inequalities on multiple levels, such as race, class, and sexuality. Women are seen as disadvantaged, but they are not viewed as a single group, therefore, they do not share the same standpoint (Harding, 1991; Wood, 1982). Women are seen as “occupying different standpoints and inhabiting many different realities" (Hekman, 2004, p.227). It is in these differences, diversity, and even conflict between women's experiences that more can be revealed about society at large (Harding, 1993). 
Scholars also argue that women, as members of an oppressed group, have developed a "double-consciousness;" a heightened awareness of their own lives and the lives of the dominant gender, men (Brooks, 2007; Smith, 1990). Women cultivate this double-consciousness to perform their socially imposed role in society, while others develop this double-consciousness to protect themselves and ensure survival (Brooks, 2007). bell hooks (2004) concludes that double consciousness serves as both a powerful "space of resistance" and a "site of radical possibility" (p. 156). Feminist standpoint theorists argue that women's subordinate status and ability for double-consciousness gives them unique epistemological privilege from which to begin research (Jagar, 1997; Narayan, 2004); an approach labeled as "strong objectivity" (Harding, 1991). In contrast, knowledge generated from the standpoint of dominant groups yields "weak objectivity" (Harding, 1991). The feminist standpoint concept of strong objectivity asserts that the representation of reality from the standpoint of women is "more objective and unbiased than the prevailing representations that reflect the standpoint of men" (Jagar, 2004, p. $62)$.

According to feminist standpoint theories, there are two reasons why the standpoints of women and other marginalized groups are less partial, distorted and false than those of men in dominant positions: (1) marginalized individuals have more motivation to understand the perspective of the more powerful, and (2) marginalized people have little reason to defend the status quo (Wood, 1982). Narayan (1989) argues that in this point in history, women of various positionalities will have more to say to men about sexism. Likewise, African-Americans have more to say to whites about 
racism; and lesbians and gays, more to say to heterosexuals about heterosexism, since standpoint feminism considers the experiences of the oppressed as less partial.

The purpose of feminist standpoint theories is to help us understand the conditions in society and to envision the possibilities for liberating social change (Anderson, 1997). These theories view women as authorities on their own lives; they enable them to construct their own knowledge about women according to their criteria as women, and to empower themselves through knowledge making (Kramarae \& Spender, 1992). Feminist inquiry into women's realities is carried out by and with women, instead of on women, in ways that empower people to honor women's intelligence and value knowledge grounded in experience (Reinharz, 1992).

\section{Limitations of theory.}

While feminist standpoint theories claim the epistemic privilege of women and other marginalized groups, more recently, some scholars are challenging the claim that women can produce more "objective" results and a more complete understanding of social reality (Brooks, 2007). Nielsen (1990) and Longino (1993) both reject feminist standpoint theories' claims that the experiences and perspectives of one group (women) are more accurate and objective than another group. Others point out that reducing all women to a group that shares one experience and one single point of view based on that experience is problematic. Women are diverse and socially positioned on various dimensions that affect their lives, therefore many critics question whether there is sufficient commonality on which to base common experiences, perspectives, and interests (New, 1998). Some scholars disagree with the hierarchy of the oppressed which assumes that the heavier the oppression, the better knowledge it yields (Stanley \& Wise, 1993). 
Other critics of standpoint feminists theories are concerned about the theories' risks of relativism (Harding, 1987), their potential for being overly simplistic (Hawkesworth, 1989), issues around validity (Ramazanoglu, 1989), and their danger for essentialism (Lemert, 1992). Critics call attention to problems of evaluating accounts from different perspectives (Longino, 1993).

A limitation in Harding's version of standpoint theory is the lack of attention to the role of language, which is influenced by society and culture and cannot be separated from standpoint. In addition, feminist standpoint theories, which divide the world into oppressed and dominant groups, have difficulty accounting for the fact that some individuals of the oppressed group are simultaneously members of dominant groups. Feminist standpoint theories do not account for the possible status of some members who are part of a dominant group, or whose position continues to shift between the two. Nevertheless, feminist standpoint theories are committed to the emancipation of marginalized and/or oppressed groups through valuing the socially constructed category of women to mobilize collective action for change.

\section{Freire's Approach to Empowerment Education}

A major theoretical and practical underpinning of this dissertation stems from Paulo Freire's empowerment education for critical consciousness, also commonly referred to as problem-posing education or liberation pedagogy. As a Brazilian educator in the 1950s, Freire initiated a successful literacy and political consciousness program for the poor living in shanty towns in Brazil (Wallerstein \& Bernstein, 1988). He was concerned about social transformation; awakening a critical consciousness whereby people perceived the social, political, and economic contradictions in their life and take 
action against the oppressive elements. His ideas around democratic and empowering education came from his own educational background in Catholic liberation theology and Marxist ideology.

Freire's methods created a concept of popular literacy education for personal and social liberation (Gibson, 1999). His process of empowerment education was created with an emphasis on organizing at the individual, organizational and community level. In this context, empowerment is characterized not as achieving power to dominate others, but rather, power to act with others to influence change (Wallerstein \& Bernstein, 1988). Freire's approach initiated a process where oppressed individuals examined their potential roles as self liberators and collaborated in community efforts toward social change. Empowerment education theory surfaced in the 1960s as a result of group reflections of the Brazilian Institute of Higher Studies (Gibson, 1999). Empowerment education theory, as developed from Freire's teachings and writings, involves individuals working together in group efforts to identify their problems, critically access social and historical roots of the problem, visualize a healthier society, and develop strategies to overcome barriers in achieving desired goals (Wallerstein \& Bernstein, 1988). Freire's approach to empowerment education involves reaching a level of critical consciousness and awareness of oppression and realizing the need for change.

\section{Education for critical consciousness.}

One of Freire's central tenents is that education is not neutral and takes place within the context of people's lives. In class or community settings, adults and young people bring with them their life experiences, current pressures, and future expectations. Within this context Freire (1973) asks: who does education serve and for what purpose? 
Does education socialize individuals to be passive objects of learning who accept the status quo or does it encourage people to question the critical issues of the day and challenge the systems and power? According to Freire, all pedagogy is a call to action for change and social justice.

Freire believes that knowledge is always actively manufactured in dialogue (Roberts, 1999). “The dynamic relationship between knower and known isn't just an unreflective being-in-the-world, but an active consciousness involving the deliberate use of the imagination, the emotions, and the ability to conjecture and compare" (Joldersma, 2001, p. 134). According to Freire, the purpose of education should be individual liberation so that learners can be both subjects and actors in their own lives and within society (Wallerstein \& Bernstein, 1988). To emphasize this dual role, Freire proposes a dialogue approach where everyone participates as equal learners who co-create knowledge. The goal of group dialogue is to think critically by framing problems in a way that participants reveal the causes of their status and location in society. Critical reflection then focuses on the influence of the socioeconomic, political, cultural and historical context of their personal lives (Wallerstein \& Bernstein, 1988). Critical thinking and reflection moves toward praxis; actions that people can take to become empowered in their lives and within their communities. Freire (1970) conceptualizes praxis as the dynamic of reflective action or active reflection, where words and action are closely intertwined. Freire's educational praxis, or problem-posing education, stresses the importance of individual's sharing and speaking from their own experiences, identifying a common theme among their own situations, creating an analytical perspective from which to understand root causes, and developing solutions and strategies for change 
(Freire, 1970; Wallerstein \& Bernstein, 1988). Freire sees critical reflection as central to transformation in the context of problem-posing and dialogue with others.

The philosophical underpinnings of Freire's approach to empowerment education are very similar to feminist standpoint theories in that both start from problems identified by individuals and their community. Both use active listening and learning methods through the dialogue process and engage individuals to take action toward emancipation. Freire (1976) also refers to this process of liberation as transformation, or the process of changing objects (who have a naïve consciousness of reality) into subjects (who see theory behind the reality). Similar to standpoint theories, Freire insists on situating educational activity in the lived experiences of the participants (Taylor, 1993). Both feminist standpoint theories and Freire's approach recognize the power of the oppressed and value the voices of those less privileged. "In the culture of silence, the masses are mute, that is, they are prohibited from creatively taking part in the transformation of their society and therefore prohibited from being" (Freire, 1985, p. 50). Freire acknowledges that established knowledge comes from those in power; therefore less powerful individuals are left voiceless. He emphasizes creating collective knowledge that comes from a shared group experience and understanding of the social influences that affect their lives (Wallerstein \& Bernstein, 1988). Empowering education teaches more than individual development. Efforts are directed at individual change, community quality of life, and structural changes for social justice.

Freire (1970) believes that with the proper tools, anyone is capable of looking critically at the world, his or her personal and social reality, and the contradictions that exist everywhere. Where Freire's approach to empowerment education differs from 
feminist standpoint theoretical perspectives is in Freire's notion that those underprivileged are preoccupied with survival and often lack information with regards to understanding how power structures work. In contrast, feminist standpoint theory points to the concept of a "double-consciousness." Freire's idea is that the oppressed often share the oppressor's viewpoint, blaming themselves for their own powerlessness. Freire (1982) states:

The oppressed, having internalized the image of the oppressor and adopted his guidelines, are fearful of freedom. Freedom would require them to eject this image and replace it with autonomy and responsibility. Freedom is acquired by conquest, not by gift. It must be pursued constantly and responsibly. Freedom is not an ideal located outside of [us]; nor is it an idea which becomes a myth. It is rather the indispensable condition for the quest for human completion. (p. 31)

Freire emphasizes that freedom must to be worked for in order to improve quality of life and justice in communities. Individuals develop consciousness, or "conscientization," which is the process of learning to perceive social, political and economic contradictions through dialogue. It is this consciousness that has the power to transform reality (Taylor, 1993). In comparison, feminist standpoint theories give automatic privilege to the knowledge of those who are marginalized, based on their life experience and their position of holding dual-consciousness in order to survive around those more powerful.

Use of the visual image.

The visual image is one tool that enables people to think critically about their communities and reveals the everyday social and political realities that influence their lives (Freire, 1970). Within Freire's process of community dialogue, the use of visual images is encouraged for building awareness of one's community and for encouraging the construction of knowledge. Freire proposes the creation of discussion objects called 
"codifications" or "codes" to serve as problem-posing issues to be addressed in the dialogue process (Wallerstein \& Bernstein, 1988). In this context, a "code" is a concrete physical representation of an identified community issue that can be in any form, such as, role-plays, stories, slides, photographs, and songs. The "code" re-presents the community reality back to participants for discussion. Freire (1973) used line drawings and photographs that represented significant realities or "coded situation-problems." $\mathrm{He}$ argues that visual images can inspire a group to critically analyze many social relations and conditions within their communities. Photographs may fuel critical consciousness and collective action by making political statements about the reality of people's lives. As a communication tool, photographs can educate, inspire and influence decisions. Influenced by a participatory approach to documentary photography, photovoice method takes this a step further since the community produces the image (Wang, Burris \& Ping, 1996). The process of creating visual images is often a source of empowerment, as are the group dialogues that confirm the collective struggles and insights of individuals (Wallerstein \& Bernstein, 1988).

\section{Limitations of approach.}

Some have critiqued Freire's approach to empowerment education, or critical consciousness, as being too binary in focus-we are either with the oppressed or against them-creating a simplistic political analysis. Similar to the limitations of feminist standpoint theories, critics draw attention to Freire's failure to address the complexity of overlapping and contradictory positions where the location of oppressor and oppressed are shifting and ambiguous (Weiler, 2003). Others point to the "revolutionary pedagogy" and its presumption of universal notions of what it means to be oppressed, liberated, and 
how this is done (Cho \& Lewis, 2005, p. 314). Influenced by his Marxist roots, Freire emphasizes material relations and not the issues of patriarchy, race, or colonization (Haymes, 2002; Weiler, 1991). Freire's earlier work fails to take into account the radical differences between forms of oppression, as well as their complexities and contradictions within an individual. Critics also point out vocabulary in that Freire's writing suffers from sexism and a patriarchal notion of revolution, and lacks emphasis on domination based on race and ethnicity (Wang \& Redwood-Jones, 2001). Another weakness of Freire's constructivist epistemology is the tension between the concept of freedom (constituted as having the action of agency and spontaneity), and his ethical project of a pedagogy for justice (one based in responsibility and non-difference) (Joldersma, 2001). A concept of knowledge promoting justice is in conflict with an epistemology rooted primarily in agency and freedom.

\section{Participatory Approach to Documentary Photography}

The final theoretical and practical underpinning of this dissertation is rooted in a participatory approach to documentary photography. Documentary photography is described as the social conscious presented in visual imagery (Rosler, 1989). Many argue that photographic images can arouse a viewer's conscience (Berger, 1980). Documentary photography has also been discussed as the portrayal of the social and mental wellness of both its subjects and the society of which they are part (Wang \& Burris, 1997). By giving ordinary people cameras, documentary photography can be used within a community for social change. To describe the term "community photography," Spence (1995) writes:

The most recent break in traditional fields has been the use of photography as a tool by community activists... Community photographers are encouraging people to photograph each other, friends and family, then their social environment. This 
provides immediate feedback for discussion, provides aids for storytelling and reading, and makes it possible to look at the world differently. People can discover how to relate to themselves and to others more positively when aimed with images, of themselves-images which counteract the stereotypes usually seen in the mass media. (p. 33, 35)

Spence (1995) explains that the main objective of community photography is to enable people to document aspects of their lives, express themselves and gain solidarity with one another. Spence provided individuals with cameras to photograph the same things she herself had photographed, capturing illness, social justice, explorations of sexuality, and joyful events. By giving cameras to people who have typically been the subjects of photographs, community members have an advantage over professionals in their ability to use grassroots voices and images to advocate policy (Wang, Redwod-Jones, 2001).

Throughout history, various photographers and educators used participatory photo documentaries within communities. This entails the act of training nontraditional photographers to record their own lives with a camera. For example, in the 1970s, Wendy Ewald taught 150 children, between the ages of six and fourteen, living in Kentucky to photograph themselves, their families, their community, their pets, their dreams, and their fantasies. In her book, Portraits and Dreams: Photographs and Stories by Children of the Appalachians (Ewald, 1985), children presented the images, words and stories of their everyday lives. Ewald (1985) describes how the students learned that they could create characters for themselves through self-portraits. This had a profound effect on the students' sense of power and control in producing any image they wanted. In 1989, Ewald settled in the village of Vichya in Gujarat, India for seven months. There she lived among children whom she gave cameras to photograph their lives and dreams. In her book, I Dreamed I Had a Girl in My Pocket: The Story of an Indian Village, Ewald 
(1996) describes the children's experience of shared human meaning and communication through photography. She was awarded a MacArthur Foundation Fellowship and continued to teach children in India, Columbia, and North Carolina to photograph and write about their lives (Wang \& Burris, 1994).

In the early 1970s, Worth and Adair used documentary photography with indigenous people in Philadelphia and New York. Their famous book, Through Navajo Eyes (1972) captured the experiences of teaching Navajo citizens to photograph their world. Worth and Adair (1972) further explored this method by giving Navajo males $16 \mathrm{~mm}$ video cameras in an attempt to discover how they understood and structured their world on an Arizona reservation. Their primary interest was in noting how the Navajo edited the footage. Worth and Adair described their own surprise at discovering that the Navajo had filmed themselves walking for miles (Stokrocki, 1994).

In the early 1980s, Jim Hubbard also initiated documentary photography by members of a community. After working as a professional photojournalist for 25 years, Hubbard gave cameras to homeless youth living in shelters in Washington, D.C. so that they could document their everyday lives. His efforts initially began with teaching one homeless child how to use a camera, and after the excitement spread through the community he then the recruited more photographers to teach other children, resulting in his book, Shooting Back: A Photographic View of Life by Homeless Children (Hubbard, 1991). Other research by Hubbard (1994) includes a similar project conducted with Native American youth.

By using a creative and powerful tool, such as documentary photography, participants can draw attention to the realities of their lives (Zhao, 1993), and ignite 
public interest and curiosity (Wang, Burris, \& Ping, 1996) and promote the well-being of themselves and their communities. In drawing community involvement with documentary photography, photovoice method involves giving cameras to people who might otherwise not have access to such a tool. This allows individuals to record and initiate change within their communities, instead of being passive subjects of other people's intentions and images (Wang \& Burris, 1997). Oftentimes, what researchers may think is important in a community may neglect what the community actually views as being important. Again, photovoice method views participants as the experts on their own lives and communities because they hold a visual voice.

\section{Photovoice Method}

Photovoice is an arts-based, qualitative method with participatory features (Mitchell \& Allnutt, 2008), that combines health promotion principles and communitybased approaches to documentary photography. Photovoice is built on the theoretical foundations and approaches of Freire's (1970) education for critical consciousness and feminist theory (Wang, Cash, \& Powers, 2000).

While these theories and approaches embody a distinct set of underlying values, they share many commonalities that inform the photovoice method. They acknowledge that the absence of participatory research with underrepresented groups perpetuates a lack of power. Each questions the political power structures that undermine the expertise individuals have for their own lives and situations. They all strive to shift the control over representation and knowledge creation from those in positions of power to those whose standpoints are seldom heard. All contribute to breaking down the traditional power 
imbalance between those with power and those without. Finally, the photovoice method aims to equalize power differences between participants and researcher (Frohmann, 2005). These theories and approaches all seek to apply the knowledge gained from the perspectives of marginalized individuals to inform and implement social change. They all identify the visual image as a means to initiate critical dialogue around social and political forces that influence their daily lives and create change (Israel, Eng, Schulz, \& Parker, 2005).

The process of photovoice entails giving cameras to individuals who use photography to identify, represent, and enhance their communities (Wang \& Burris, 1997). Participant-generated images provide an opportunity for traditionally silenced populations to document their lives and environments (Hubbard, 1994). As a form of self-expression, visual techniques provide a window into the participant's (photographer's) immediate environment, significant relationships, feelings, and perceptions of self (Hubbard, 1994). Through photovoice, the power of the visual image is used to communicate life experiences and perceptions, which then has the power to influence social policy. Specifically, this method is used in communities with limited power or status to communicate to influential community advocates where change must occur. The three main goals of photovoice are: (1) to enable people to record and reflect their community's strengths and concerns, (2) to promote critical dialogue and knowledge about important community issues through large and small group discussions of photographs, and (3) to reach policy makers and others who can be mobilized for change (Wang, Cash, \& Powers, 2000, p. 82; Wang \& Burris, 1997, p.370). 
Photovoice emerged from of an arts-based research method that was originally coined "photo novella" by Wang, Burris, and Ping (1996). In photo novellas, participants use a variety of visual methods, including paintings, sculpture, body casting, and written narratives to artistically express their experiences (Herbison \& Lokanc-Diluzio, 2006), whereas photovoice denotes the specific use of photography to illustrate stories. Photovoice was first developed by Caroline Wang and colleagues in the Ford Foundation-supported Women's Reproductive Health and Development Program in Yunnan, China (Wang \& Burris, 1997). This program provided cameras to Chinese village women who photographed their everyday health and work realities and communicated their issues and concerns to policy makers. Since then, many studies have utilized photovoice to illustrate community needs and to involve less privileged populations in a research process to create social and political change.

\section{Concepts of Photovoice}

There are five key concepts of photovoice, which are: (1) images teach, (2) pictures can influence policy, (3) community people should participate in creating and defining images that shape healthful public policy, (4) the process requires that planners bring policymakers and other influential people to serve as an audience, and (5) there must be an emphasis on individual and community action (Wang, 1999).

(1) Images teach: The visual image is a site of learning that has the capability of strongly influencing people's well-being (Wang, 1999). Images have the potential of conveying more meaning and feeling than text. The image itself is not as powerful as the meaning people attribute to the photograph (Wang, 1999). Wang believes that images 
contribute to how we define ourselves, how we define and relate to the world, and what we perceive as being important or different.

(2) Pictures can influence policy: To understand the influence of images, Wang (1999) suggests an analysis of the production of images, the reception of the images and meanings attributed to them by audiences, and the content of the images themselves. Policy is not shaped by images in a linear manner, but rather, the images viewed by people influence each individual's world view. By contributing to how we perceive the world and our place within society, images can influence community advocates and society.

(3) Community people should participate in creating and defining the images that shape public policy: Wang (1999) points out that policies created to benefit underprivileged groups are not necessarily based on what these groups need or want. Photovoice is more than individuals taking pictures; it's about them defining the images they have produced to add meaning and value to their story and perspective. This provides a better context for understanding the condition of people's lives.

(4) From the beginning, the process requires that influential community advocates serve as an audience for community people's perspectives. Photovoice can be used as a tool to influence policy when there is an exchange of knowledge through the images among community members, health and social workers, and policy makers (Wang, 1999). These interactions must be planned in order to mobilize change with those in power. It is crucial that community leaders, workers in the social services, board members, researchers, funders and other influential community advocates serve as significant participants in a dialogue with community members. 
(5) Photovoice emphasizes individual and community action: Sharing similar values with participatory action research, photovoice incorporates a community approach to documentary photography, the production of social knowledge and social action (Wang, 1999). Photovoice is grounded in "the understanding that policies derived from the integration of local knowledge, skills, and resources within affected populations will more effectively contribute to healthful public policy" (p. 187). Community collaboration contributes to power of the individual and group voice and the local knowledge of issues to be addressed.

\section{Photovoice Research Studies}

Research studies have used photography with a number of populations in a variety of fields, including anthropology, sociology and nursing (Dyches, Cichella, Olsen \& Mandelco, 2004). However, photovoice studies are most prevalent in the fields of community health and nursing. The process of using photo documentary as voice for social change has been implemented with youth (Strack, Magill \& McDonagh, 2004); older adults (Killion \& Wang, 2000); homeless adults (Morrell, 2007; Wang, Cash \& Powers, 2000); individuals with learning disabilities (Booth \& Booth, 2003); immigrant populations (Streng, Rhodes, Ayala, Eng, Arceo \& Phipps, 2004); persons living with HIV/AIDS (Rhodes, Hergenrather, Wilkin \& Jolly, 2007); and within communities of color (Wang \& Pies, 2004). Photographs are used to document experiences, perspectives, needs and hopes. Participants in photovoice research studies are given cameras and asked to photograph their daily activities, concerns and struggles, needs, views on family and health, what makes them happy, and other topics that reflect personal experiences and 
their communities. Photography allows participants' voices to be heard through oral interpretations of their photographs. Narrating photographs has shown to promote selfreflection and self-understanding of important issues in people's lives (Killian, 2001). Photovoice provides a platform from which to engage in critical dialogue with others and to initiate community action for change.

Relevant to this dissertation are studies that utilize the photovoice method to identify and address individual and community needs within marginalized populations. In the Ford Foundation supported Women's Reproductive Health and Development Program in Yunnan, China, the images produced by 62 women using the photovoice method influenced Chinese policy in three main areas: day care, midwifery, and girls' education (Wang, Burris, \& Ping, 1996). The decision to set up child care centers for the women resulted from photographs taken by women that showed their infants exposed to the rain and sun while their mothers worked in the fields performing heavy farm labor. Other photographs and testimonies illustrated children playing near water unsupervised, indicating that the women had no alternative methods for caring for their children. Another policy decision developed from a photograph of a mother lying in bed with her three-day old baby, which documented the poor medical hygiene and lack of access to health services for these women. The accompanying testimonial to the photograph documented how the woman had delivered the baby at home because she could not afford to go to the hospital. As a result of this work, a program to train midwives, indigenous older women, to provide birthing assistance to rural women was implemented. A discussion subsequently emerged between women and policy makers about the widespread use of unsafe procedures such as un-sterilized scissors and risky methods of 
cutting the umbilical cords. Finally, a photograph depicting a girl caring for her baby brother during hours when she should have been in school prompted policy makers to provide scholarships, not only for poor girls, but also for outstanding female students regardless of income. This study illustrates the potential for photovoice to create relationships between influential community advocates and community members who are seldom heard, and who might not normally have access to one another.

Wang, Cash, and Powers (2000) used photovoice with seven homeless men and women living in a shelter in Ann Arbor, Michigan. The Language of Light Photovoice Project enabled these individuals to photograph their everyday health, work and life conditions to capture and reflect their community's strengths and concerns. A 55-year old man titled one of his photographs of a clock and digital display on Main Street as, "Good times, But We're Not Feeling It.” To describe his photograph he said,

Not only does it tell the time, but it also shows the Dow Jones as high as it has ever been. Why is the Dow Jones so high? Everyone is making a bundle of money on the stock market; but even though many of us at the shelter have jobs, we can barely find a hamburger to eat sometimes. (Wang, Cash, \& Powers, 2000, p. 85)

This participant taught policy makers that many homeless men and women living at the shelter often have two or three jobs. The realization that most homeless people worked served to change stereotypes and enabled board members, planners, community people, and community leaders to reconsider issues from the standpoint of the homeless. This particular study illustrates the power of images and the narratives accompanying photographs to alter stereotypes of marginalized individuals.

Photovoice was also used in a pilot study by Killion and Wang (2000) with young, homeless African American women and elderly, low-income African American 
women to establish intergenerational contact between the two groups. Five African American women participated in this seven-month pilot study; two homeless women, ages 28 and 36, and three women between the ages of 67 and 86, who lived independently in their homes. While these two groups of African American women were unlikely to encounter one another because they were separated by age and life station, this study provided the opportunity for the two groups of women to discover that they shared parallel housing, health and personal needs. The women photographed favorite people, places, and things, creating the theme of my own space, my own place, emphasizing the significance of having their own space and possessions.

The project also created a space for the older group of women to informally share mothering tips with the younger mothers. Also, through dialogue around their photographs, two major challenges of being African American, female, poor and a mother emerged; finding affordable housing and raising children with limited resources. This pilot study involved outreach to policy makers and provided a model for intergenerational women to use photovoice to build community. This study shows how photovoice can unite women of color of different ages groups and socio-economic status. Having the opportunity to discuss concerns are around issues of race and class through photographs provides a foundation to create a sustainable relationship of support between individuals living in low-income communities.

A large photovoice study was conducted in Contra Costa, an economically and ethnically diverse county in the San Francisco Bay area. The Picture This Project by Wang and Pies (2004) recruited 60 county residents, between the ages of 13-50, who were encouraged to take photographs reflecting their views on family, maternal, and child 
health concerns in their community. The themes identified by participants were different from those identified by the health department personnel. The first theme- the need for safe recreation for children- emerged as some individuals photographed: 1) roadside crosses where children were killed; 2) insufficient posting of neighborhood stop signs, especially near schools; 3) a Spanish- English park sign that read, "This area is not maintained by the city of Antioch. Enter at your own risk" (Wang \& Pies, 2004, p.98). The second theme- the need to improve the general community environment within a county neighborhood- surfaced as participants photographed the neglect of property by landlords; graffiti; trash; and the closure of a hospital that provided insufficient services to low-income individuals.

Several participants from Picture This Project were asked to be part of an advisory committee to provide input, ideas and suggestions on future programs. The project also mobilized members of the community to start cleaning community parks and campaign to keep a local recreation space open. Photovoice provided a platform that acknowledged the voices and local expertise on community issues. Action was taken based on participant-identified needs and the generation of new ideas for improving the community. The creation of an advisory committee depicts the potential of photovoice to initiate sustainable community participation and improvement of participants' living conditions.

In Portland, the social service agency Sisters of the Road used photovoice with homeless individuals who were encouraged to photograph their everyday lives and share their unique stories and perspectives (Morrell, 2007). Forty people began this project, ten participants completed the project, and over 500 images were produced of their lives on 
the street. This project raised community awareness of homelessness and poverty issues, reaching close to 15,000 community members such as youth, businesses, associations, universities, and faith-based groups. A school curriculum (K-12) was also created to accompany the photovoice exhibit, in order to educate students and alter stereotypes about homelessness. This study demonstrates the potential of photovoice to empower, educate and inspire action toward social change. The artistic process of documentary photography supports self-determination and may increase feelings of independence and self-esteem (Hubbard, 1994). Engaging in an arts-based method like photovoice also has the potential to heal individuals who have experienced multiple barriers, hardship and social isolation.

\section{Advantages of Photovoice}

Photovoice has many potential advantages for the various participants involved:

(a) for those with the least amount of power; (b) for those holding more power; and (c) for the community at large. For marginalized communities, photovoice offers the opportunity to represent and enhance one's own communities through a vivid and specific way of taking pictures and telling stories. It can enhance self-esteem and peer status, express appreciation, and build new ties. Through the medium of photography, photovoice gives something tangible and personal to others. The process of creating visual images is often a source of empowerment, as are the group dialogues that affirm a collective struggle and insight (Wang, Burris, \& Ping, 1996).

Using this method with marginalized populations whose voice is often missing from society, or whose image is often misrepresented in the media, can be a powerful 
catalyst for change. Rollins (2007) asserts that there is an opportunity for participants to control the means of political representation of themselves and of their realities.

When the subordinated represent, they also re-present and reposition themselves apart from a location of disenfranchisement, alienation, and social invisibility. We capture responsibility for our appearances. The re-presentation of representation, especially self-representation, performs a coup over the dominance of forced inscriptions. (p.8)

For Rollins (2007), every re-presentation establishes new boundaries, a new sense of place, space and meaning. The use of photographic images to create new meaning, to change stereotypes, and to convey a message to society makes presentations more accessible to diverse audiences (Gold, 2004). Through exhibitions in public spaces, participants' photographs and voices reach broader audiences, including policy makers and others who have power to create change (Wang, Burris, \& Ping, 1996).

Through photovoice, those participants holding more power, such as university researchers and influential community advocates, have the opportunity to learn from local people's expertise and engage in work that is valued by others. There is also opportunity to innovate in a community context through publications and community approval, since actions are community-driven. Participants with more power can recognize others as individuals and thereby enhance their own humanity (Wang, Yi, Tao, \& Carovano, 1998). Photovoice also helps build rapport with participants through continual collaboration and sharing. "Visual documentation often demands that researchers come into contact with participants and details of social life to a degree that exceeds what is generally applied in other methods" (Gold, 2004, p. 1554). Photovoice links the needs of the community with active participation. On a community level affecting all participants, photovoice can contribute to effective, healthy change. There is also the increased 
credibility of all members by affiliation or collaboration and the exchange of new ideas, methods and resources for improving the quality of life (Wang, Yi, Tao, \& Carovano, 1998).

According to Wang and Burris (1997) photovoice offers distinctive contributions to needs assessment. It enables researchers, as outsiders, to gain access to insiders' information. People with cameras can record settings, moments and objects that may not be readily available to researchers (Wang \& Burris, 1997). This approach to participatory needs assessment confronts a fundamental problem: "What researchers think is important may neglect what the community thinks is important" (Wang \& Burris, 1997, p. 372). Photovoice also contributes to needs assessment through the visual image by placing a human face on the data. In addition, photovoice is accessible to anyone who can use a camera and does not presume the ability to read or write.

As illustrated in previously discussed studies, an advantage of photovoice is that the images produced and the issues discussed and framed by individuals may have the potential for stimulating action toward social change. Wang and Burris (1997) argue:

Photovoice can be a tool to reach, inform, and organize community members, enabling them to prioritize their concerns and discuss problems and solutions. Photovoice goes beyond the conventional role of needs assessment by inviting people to become advocates for their own and their community's well-being. ( $p$. 373)

Furthermore, Wang, Burris, and Ping (1996) point out that the media are often attracted to the "human interest" strength of photovoice, which draws people to exhibits and spaces where photographs are presented. The media is very influential in affecting social interest and concern about certain issues, as well as what policymakers focus and take 
action on. Photovoice can be a powerful method for drawing attention to voices and visions.

\section{Limitations of Photovoice}

While the advantages of photovoice outweigh the limitations, there are a few disadvantages that need mentioning. First, a potential ethical implication concerns the unfair distribution of the burden of social change (Wang, Burris, \& Ping, 1996). Caution should be used against placing the burden of organizing for change on less powerful groups, rather than on privileged groups, who have the responsibility to restore social equality (Minkler, 1978). Also, it is important that all participants are aware that photovoice enables individuals to communicate their perspective to influential community advocates, but it does not shift the power to them to decide on policy (Wang, Burris, \& Ping 1996). There is also the chance that participants who are motivated to make community change could feel a sense of cynicism, despair or powerlessness when the results of their efforts do not match the results they had hoped for (Wang, Yi, Tao, \& Carovano, 1998).

Due to the uncertainty and unpredictability of what may occur when giving someone a camera to photograph friends, family and community, participants may be at risk. The photovoice method may produce unintentional consequences. There may also be the fear of not wanting photographs taken used against them (Wang, Yi, Tao, \& Carovano, 1998). Participants mindful of these issues may become fearful and censor what they photograph in order to protect themselves and others. Personal judgment may intervene at different levels of representation, for example, "who used a camera, what the user photographed, what the user chose not to photograph, who selected which 
photographs to discuss, and who recorded whose and what thoughts about whose and which photographs" (Wang \& Burris, 1997, p. 374).

Wang and Burris (1997) caution others that photographs are easy to gather but difficult to analyze and summarize. There is also debate around issues of validity and reliability of research with participatory features. Some argue that the integrity of the research is compromised when researchers give up control over the content and process of the research. Some might view research that is conducted in a participatory manner as unscientific. However, others argue that it is inherently political and value-driven, and that participatory approaches give priority to the community's needs as opposed to the researcher's agenda (Wang, Yi, Tao, \& Carovano, 1998).

The photovoice process is also costly and time-consuming. Issues related to transportation, communication and finances could surface. Limited funds to cover the cost of cameras, film developing, transportation allowances, and interpreters (if needed) could impact the outcome of a successful project. Photovoice requires a great deal of time commitment and follow-through from all participants involved. Despite these limitations, photovoice has many strengths and the opportunity to create new knowledge around the implementation of arts-based methods with sex workers

\section{Photovoice Research Design}

\section{Rationale}

The purpose of this study is to gain a deeper, more complex understanding of the needs and aspirations of female sex workers through the artistic medium of photography. Art, as a form of experience, has the potential for helping us understand social issues 
imaginatively and emotionally (Eisner, 2006). It was important to select a methodology that would provide an opportunity for female sex workers in Portland to express and represent their needs and aspirations in a creative, effective and meaningful way in order to reach a broad audience with the potential for empowerment and societal change. To support this objective, I utilized the photovoice method since it provided the possibility to reflect the original richness and complexity of the data, to invite new levels of engagement that are both cognitive and emotional, and to provide multiple ways through which to explore experience. In addition, the terms participant(s), woman/women, and artist(s) are used interchangeably to capture the depth and range of embodied experiences of each individual who took part in this study.

\section{Manifestations of the Photovoice Process}

In this research study, I tried to adhere as closely as possible to the intent, activities and sequencing of activities recommended by Wang and Burris's (1997) photovoice method. The five stages of photovoice involve: (1) Conceptualizing the problem (selecting the site, methodology, sampling and recruiting); (2) Implementing the method (conducting the photovoice training, creating initial themes for taking the pictures, taking the pictures); (3) Participatory analysis, critical refection, and dialogue (selecting photographs for discussion, contextualizing issues, themes, and theories, and documenting stories); (4) Disseminating the findings (selecting photos and stories for presentation and writing journal articles); and (5) Advocating policy (sharing information and implementing policy).

While using these stages as a guide, my own process of implementing the photovoice method with diverse women working in the sex industry was flexible and 
fluid in order to meet the requests and lifestyles of the participating artists. My process differed from Wang and Burris's (1997) in two major ways: (1) I conducted multiple photovoice training sessions, instead of one group training session, and (2) I held individual dialogue sessions with each participant and an optional group dialogue session, instead of holding only one group dialogue session to share photographs. The stages of this photovoice research study involved:

VII. Contextualizing the project Identifying the site Selecting the methodology Community partnership Community support

VIII. Finding the artists Sampling and recruiting Participant diversity

IX. Orientating the artists to the tools of artistic expression

Conducting the photovoice trainings

Group photovoice training session Individual photovoice training sessions

Devising the initial theme for taking the photographs

$\mathrm{X}$. Taking the photographs and creating art

Artists in the community Unanticipated occurrences

XI. Individually reflecting, dialoguing and storytelling

Selecting photographs for discussion

Contextualizing and storytelling

XII. Communally dialoguing and sharing the artistic creations

Group dialogue session

Selecting photographs for the art exhibit

Organizing the representation of the art

VII. Disseminating artistic creations to the public

Community art exhibits

Media coverage and attention

Audience interactions with art

Stage I: Contextualizing the project.

Identifying the site.

This study took place in Portland over a period of ten months. This site was 
chosen to understand the needs and aspirations of diverse women working in various aspects of the sex industry for several reasons. As previously mentioned, there is no agency in Portland, Oregon that specifically provides services to sex workers unless they are involved in the criminal justice system. In addition, the voices of sex workers in Portland have not been heard in regards to the creation of social services or programs. Beginning in 1995, the City of Portland enacted the Prostitution Free Zone (PFZ) ordinance, which allowed law enforcement to issue citations of exclusion from designated areas to individuals suspected of engaging in prostitution. After the PFZ ordinance expired in September 2007, there was an influx of complaints from the neighborhood associations regarding visible street workers in their neighborhoods and a perceived increase in crime. During the summer months of 2008, I attended numerous town hall meetings focused on addressing the needs of sex workers and the community on $82^{\text {nd }}$ Avenue. I observed that the voices of law enforcement, business owners, neighborhood associations and radical feminists were present. However, the diverse voices and perspectives of sex workers were silenced and missing from the community dialogue meetings.

In response to the complaints about the termination of PFZs, the City of Portland of took a rehabilitative and criminal justice response to the issue of prostitution on $82^{\text {nd }}$ Ave and awarded a grant to the organization, Lifeworks North West. However, this agency received funding to serve only those sex workers that are referred by a parole officer in relation to a drug or soliciting charge. Individuals working in the sex industry were not consulted on what services would best meet their needs.

Selecting the methodology. 
Influenced by the photovoice method created by Wang and Burris (1997) and colleagues, this study consisted of multiple photovoice training workshops for participants, an individual dialogue session with each participant, and two optional group dialogue meetings. A crucial component of the photovoice method was dialoguing, which was consistent with participatory action research approaches. Park (1989) describes dialoguing as the process of talking with participants as equal partners in an exchange of information, sentiment and values.

Dialogue is a means of discovering the sharedness of a problem, the connectedness of the lives, and the common ground for action. This cannot be achieved through the exercise of merely answering questions in a conventional questionnaire or a formalized interview which do not allow the respondents to speak in a full voice. (Park, 1989, p.12)

In photovoice, dialogue sessions center on participant-generated photographs. In this study, the individual dialogue sessions focused on the photographs taken by participants and allowed individuals to reflect upon and analyze parts of their lives that they might not have ordinarily paid attention to or questioned.

Ada and Beutel (1993) contend that in a dialogue we share and engage in spoken and creative thought. In this study, dialogue contributed to shared power between me and the participants. It allowed for producing and sharing personal insight and critical knowledge. This enhanced reciprocity, openness, and sharing between me and the participants, as we collaborated in knowledge creation (Finley, 2003). The training workshop, the individual dialogue session, and the group dialogue sessions with participants will be explained in further detail in later sections.

Community Partnership.

Throughout this study, a community advocate from the Portland Women's Crisis 
Line and the Sex Worker Outreach Coalition served as community partner and cofacilitator on this study. This individual provided support and acted as a resource throughout the study since she held unique expertise and practice experience working with sex workers in Portland. Her involvement enhanced the credibility of this project among sex workers in Portland, some of whom had already built a good rapport with her prior to the start of this project. She educated herself on the photovoice research method and its implementation process and provided valuable feedback throughout the study. My community partner assisted with the recruitment of the participants and co-facilitated the various training workshops and group dialogue sessions. She also served as co-art exhibit coordinator for the art exhibit opening and a peer reviewer for the analysis of data.

Community support.

In order to raise awareness and money for this photovoice study, my community partner and I hosted a fund raiser in the community prior to the start of recruitment. This benefit served multiple purposes: (1) friends and family donated $35 \mathrm{~mm}$ cameras that they did not need or no longer used, (2) social service providers, influential community advocates, and members of the community attended the fund raiser, (3) money was raised to pay for the rolls of black and white film and to pay the participants/artists for their time, and (4) everyone became aware of this project and the art show that would ensue.

Stage II: Finding the artists.

Sampling and recruiting.

Multiple methods and strategies of recruitment were implemented over a period of four months. The first recruitment strategy involved creating a flyer that described the research study, its purpose, and eligibility requirements (Appendix A). My phone number 
and my community partner's phone number were included on the flyer so that potential participants could contact us. ${ }^{7}$ During this time, I also changed my telephone answering machine message to reference the photovoice research study in hopes of increasing the rate of call-back from those individuals who would not feel comfortable leaving a telephone message.

Study flyers were distributed in various neighborhoods and venues in Portland where it was assumed that individuals working in the sex industry might be located. These locations included inside the dressing rooms and bathrooms of different exotic dance clubs, a methadone clinic, an outreach clinic for the homeless, and various drop-in centers for the homeless. Flyers were also passed out to women working in the sex industry through street outreach with my community partner. ${ }^{8}$

Another approach involved mailing a letter describing the study (Appendix B) to social service agencies who may serve sex workers (e.g. those that have needle exchange programs). Members of SWOC were contacted, as well other social service agencies, such as Cascadia Bridgeport, Sisters of the Road, Rosehaven, Transition Projects, Inc., SAVE Shelter, Lifeworks Northwest, Royal Palm, Young Women's Christian Association (YWCA), and Immigrant and Refugee Community Organization (IRCO). In addition to receiving a letter, these organizations were also given study flyers to pass out to those female sex workers who expressed an interest in participating in the study.

\footnotetext{
${ }^{7}$ Both of our telephone numbers were included on the flyer to maximize opportunities for recruitment. When talking with potential participants, my community partner made arrangements for them to speak with me prior to participating in the photovoice training workshop to ensure that they met the eligibility criteria.

${ }^{8}$ It's interesting to note that five potential participants read about the study by randomly encountering the flyer at one of these venues. These women contacted me individually with an interest in the project, but did not show up for a photovoice training session. After a number of attempts to follow-up with these five women, I discontinued contact.
} 
On-line methods were also used to recruit potential participants by posting a graphic version of the study flyer (Appendix M) on the SWOC website, through the SWOC list-serve and on the SWOC myspace webpage. The research study was also announced on a local feminist radio show called Bread and Roses.

Purposive sampling was implemented with potential participants that were referred to me through my community partner and/or through a social service agency. These women were identified prior to the start of the project and had the opportunity to participate in the first and only group photovoice training session. Of these five women, only three completed the entire project; the other two did not contact me again about developing their film after having attended a photovoice training session.

Snowball sampling was also used to recruit additional sex workers who were interested in participating in the study. All of the study participants were invited to identify others working in the sex industry that would be willing to consider participating and were given additional flyers to pass out to friends and acquaintances. After two months of extensive outreach and efforts to recruit by repeating the same strategies mentioned, there was still a lack of responses from potential participants. With only three women having completed the individual dialogue session, I was concerned about whether this study appeared to be too demanding, time-consuming or uninteresting to individuals working in the sex industry. I also worried that my status as an outsider played a role in the lack of interest. The three participants who had followed through with the individual dialogue session reported talking about the study to their friends but no other potential participants contacted me. At the same time, it was important to me to be very mindful of not placing the burden of recruitment on those women already participating in the study. 
After experiencing difficulties with recruitment, my community partner and I engaged in dialogue around how to access those individuals who might not have heard about the study through a participant, their workplace, a social service provider, or a friend. We decided to request additional Institutional Review Board approval to advertise the study on the university e-mail start up page and to post an advertisement for the project in the local Mercury newspaper, in a special section featuring an annual arts festival called Sex PDX.

Twenty-four hours after a graphic version of the research study flyer (Appendix M) was published in the Mercury newspaper, I received an influx of phone calls from sex workers interested in participating in the photovoice project. One woman contacted me and wanted to meet that same day to participate in an individual photovoice training session. I found that conducting individual photovoice training sessions (instead of waiting for enough potential participants available to coordinate a group training session) was more effective for engaging potential participants and supporting follow-through. Through word of mouth, four more women working in the sex industry also contacted me individually within the next few weeks to learn more about the study. Also in response to the advertisement in the Mercury newspaper, a woman called me with an interest in participating and referred her two friends who also wanted to be involved in the study. It was during this recruitment period that I decided to invest in a cell phone (even though I was previously resistant to getting one) in order to maintain contact with the participants whose primary methods of communication was text messaging. Phone calls and e-mail contact were the other preferred method used by the study participants. 
Once I was contacted by potential participants over the telephone, I described the purpose of the study and talked to the women about the procedures, risks and safeguards of the study (Appendix C). We also discussed the time-commitment it would require. Women were encouraged to ask any questions they had regarding the project. If the potential participants expressed interest in participating, they were screened over the telephone to ensure that they met the eligibility criteria stated on the flyer. Those participants who were eligible to participate in this study had to meet the following criteria: (a) over 18 years of age; (b) female; (c) currently working in the sex industry in Portland, Oregon for the past six months; (c) engaged in sex work, defined as the exchange of sex or sexual stimulation for material goods like money, drugs, food, transportation, or rent.

During the recruitment stage, a total of 19 women contacted me and expressed an interest in the project. Out of those, 5 did not set up a meeting for a photovoice training session. Fourteen women signed the consent form, completed the photovoice training workshop and were given a $35 \mathrm{~mm}$ camera with a roll of 36 -exposure black and white film. Of those 14, three did not contact me again about developing their film. After numerous attempts to follow-up over a period of three months, I discontinued contact. Two women individually contacted me to participate in the project one month after all the data was collected. I maintained contact with these women and invited them to the community art exhibit at the end of the study. One of the women, a self-identified artist, was invited to display her own artwork in the second art exhibit. A total of 11 women working in the sex industry participated in all stages of this photovoice study.

\section{Participant Diversity.}


The eleven participants ranged in age from 18 to 52 years old, with an average age of 31. Five of the women self-identified as women of color and/or of mixed ethnic background including Scottish-American/Indian, Hispanic/White, $1 / 8^{\text {th }}$ Native American/ European, Creole/Black/Native mix, and Indian. One participate stated that she did not believe in race. The other five women identified as Caucasian, European-American or Eastern European. Their educational experiences ranged from not having finished high school to working on the completion of a bachelor's degree. Four women did not complete high school and one woman received her G.E.D. Four women completed high school, and of those four, three took some college courses. Two women were enrolled in a private college and working to earn an undergraduate degree.

With regards to their work in the sex industry, the participants varied in the type of sex work they participated in, their years of experience, and the hours of current work. Years of experience working in the sex industry ranged from 7 months to 39 years, with an average of 10 years of experience. The different sectors of employment included exotic dancing, escorting, erotic massage, pro-domination work, street work, and erotic modeling photography. Six of these women worked in multiple sectors of the sex industry. Their hours of sex work per week ranged from 5 hours to 50 hours, depending on the week, and averaging 26 hours per week. Five women mentioned earning an additional income unrelated to working in the sex industry.

Their living situations varied and even changed during the course of the project. Four women were living in rented apartments with roommates, one woman lived in lowincome public housing, three women stated they were living with friends or family (one of whom also lived in a hotel at some point during the project), and three women were 
homeless (two of whom often stayed in a motel and one who lived in a van at certain times during the study). Six of the participants did not have any children, one woman had a teenage son, two women had two children each and two women had four children each. Of the eleven diverse participants, eight women stated that they were single (two emphasizing "by choice"), one woman had an open and "complicated" relationship status, one woman was recently engaged and another woman stated that she was happily married.

\section{Stage III. Orienting the artists to the tools of artistic expression.}

Conducting the photovoice trainings.

Each woman began her participation in the project by attending a $1-1 \frac{1}{2}$ hour training workshop (Appendix F) either in a group setting or individually. Training workshops were offered to ensure that all participants were knowledgeable of the study goals, photovoice method, procedures, risks and ethics prior to taking their photographs. The first training workshop was held in a community location that was convenient for the women. The four participants who were initially recruited through social service agencies attended the first and only group photovoice training. Following the group training session, a total of ten other individual photovoice training sessions took place in locations that were most convenient for the women. The different locations chosen by the participants for holding the individual photovoice training sessions included: my office at the university, a coffee shop, my home, the participant's home, on the sidewalk of a street downtown, at a bar/exotic dance club, and at a restaurant. Some training sessions were more formal in nature while others were more casual and consisted of informal conversations and relationship building. 
The purpose of the initial meeting and training session was to review the project goals, the photovoice process, and the participatory, artistic aspect of photovoice which required the participants to take on a role as active partners in the project and as cocreators of knowledge. Shared power was emphasized by letting the participants know we all held joint ownership of the research project. It was also highlighted through a collaborative, participant-based analysis of the photographs, our group efforts for organizing an art exhibit, and our collective orientation toward community action. Kemmis and McTaggart (2005) suggest similar methods for photovoice. An additional goal for this initial training workshop was to familiarize the women with underlying issues about the use of cameras, power, and ethics; potential risks to participants and how to minimize them; and the practice of giving photographs back to community members to express appreciation, respect or camaraderie (Wang, 1999).

\section{Group photovoice training session.}

Those participants who attended the first group training session were asked to arrive at the training workshop 15 minutes early to review and sign their informed consent (Appendix D). The basic elements of the informed consent were highlighted (procedures, risks, safeguards, confidentiality) and assistance was provided to those who wanted their consent form read to them. Time was allocated to address any individual questions that participants had related to the consent forms. I emphasized that participation was voluntary and that each woman had the opportunity to withdraw from the study at any time without consequence.

The group training workshop began with an icebreaker activity. This allowed participants to become familiar with each other, myself and my community partner. It 
also contributed to my building trust and connection with participants. The women were given the option to not disclose their full names, but rather choose pseudonyms to be used throughout the study. Then, the concept and method of photovoice was described. A project summary handout (Appendix E) with an overview of the goals and the photovoice process was distributed to each participant. The study objectives were presented along with the project's aim to influence community advocates and leaders. There was also a discussion around the power, authority and responsibility that one has using a camera. Critical dialogue was facilitated around participants' responsibilities when carrying a camera and the importance of respecting the rights and privacy of others. Safety was emphasized, along with ways to minimize potential risks.

As a group, we talked about ways to approach and photograph someone in the community. To facilitate a discussion on participants' safety and ways to approach people, the following questions, suggested by Wang and Burris (1997), were explored with participants during the training workshop: (a) What is an acceptable way to approach someone to take his or her picture? (b) Should someone take pictures of other people without their knowledge? (c) To whom might one wish to give photographs, and what might be the implications? (d) When would someone not want to have their picture taken? The purpose of this discussion was to focus participants' attention on ways to minimize risks (whether physical danger or loss of privacy to themselves and their community) when taking photographs. Participants were advised to always obtain verbal permission before taking someone else's photograph. We discussed how asking for other people's consent would help to prevent misunderstandings and build trust by giving participants an opportunity to describe the project and establish longer-term relationships 
and knowledge exchange with other community members. Obtaining verbal consent to photograph someone would help to promote community wellness. We also discussed giving photographs back to people as a way of expressing gratitude (Wang, 1999).

During the second half of the workshop, each participant received one used $35 \mathrm{~mm}$ film-based camera with a flash feature along with one roll of 36-exposure black and white (C-41 processing) film. Participants were also given a small, hand-held journal to record their thoughts or reasons for taking their photos. After the participants received their cameras, I explained the mechanical aspects of camera use and photographic tips (Appendix G). This included how to protect the camera (what happens if it is dropped, how heat and water can affect the camera); parts of the camera (the viewfinder, the flash); operating the camera; when to use flash (the range at which it works); indoor, outdoor and night use; camera handling when taking photos (holding the camera steady when pressing the shutter release); distance from subject; and framing. We discussed close-ups and angles; different ways to photograph a group of people; posed and un-posed pictures; and how symbols of the community or culture might be photographed as suggested by Wang and Burris (1997). The technical advice was minimal to avoid stifling participants' creativity. More emphasis was placed on reminding participants to keep their fingers out of the camera's lens, to place the sun at their back as often as possible, and to avoid putting the center of interest in the middle of the photograph every time.

Individual photovoice training sessions.

Participants who met with me individually to receive the photovoice training were given the same handouts and orientation to the project as those who participated in the group training session. However, the manner in which each woman was presented with 
the photovoice training material was less structured in order to meet the individual needs of each potential participant. Meeting with the women individually often provided the opportunity to connect on a deeper, more personal level (if they were interested in doing so). The informal nature of the individual photovoice training sessions allowed me to be attuned to each individual participant. Their fluid, individualized nature emphasized a sense of power in comparison to conducting a group training session where there was a sense of talking to a group of women instead of with each individual. Conducting the individual photovoice training sessions within hours or days after a receiving a phone call from a potential participant was helpful for retaining participants and engaging them immediately in the research study.

Devising the initial theme for taking the photographs.

Participants were instructed to photograph places, objects, events, and people related to their everyday experiences that were important to them. Within this broad scope, participants received the initial themes to center their photographs on, needs and aspirations. These themes were kept broad so that participants had the freedom to photograph experiences meaningful to them. I told the participants how I came up with these two themes; through the academic literature, my knowledge of the lack of services available in Portland, and my experience with attending community forums on the PFZs. Then, we collectively discussed these themes as the framework for taking photographs of their experiences and communities.

We discussed the appropriateness of these themes and their relevance to the participants' lives. The women were given the option to refine, substitute, eliminate, add, or reframe any or all of the themes posed in order to best suit what each one wanted to 
express about her experiences and communities; however, no one chose to do so. During the group and individual photovoice training session, the participants brainstormed and discussed ways in which to portray the themes. It is interesting to note that along with photographing their needs and aspirations, the artists took photographs unrelated to the themes, which were later described as being important to their lives.

\section{$I V$. Taking the photographs and creating art.}

Artists in the community.

In the group and individual photovoice training sessions, we discussed the reasonable amount of time needed by participants to take their 36 photographs (approximately 18 photographs of needs and 18 photographs of aspirations). Once an estimated deadline was set by each participant for taking her photographs, the women went out into their communities with their cameras. Ideally, the time between the photovoice training workshop, the individual dialogue session, and the group dialogue session should have been minimal (around a month), in order to stay connected with each participant and to support follow-through. However, in this study, while some women took a week to take their photographs, others took well over three weeks, prolonging the individual and group dialogue sessions over a period of three months. It is interesting to note that those participants who were homeless and financially stressed completed their roll of film the fastest. All participants were compensated $\$ 50$ in cash as a thank you for their time and effort. One participant did not wish to take the money and chose to donate it back to the photovoice project toward the costs of hosting the art exhibit. Another participant repeatedly stated that she didn't want to accept the money because she was participating in the study out of her passion for the project and its purpose. 
After taking a roll of 36 photographs, I met with each woman to collect her film for developing. During this time, we scheduled a date and time to hold her individual dialogue session. Over half of the dialogue sessions occurred on the same day that the film was developed since this seemed to be most convenient. For each roll of film, two sets of 36 prints were developed and a CD was made. Each participant received one set of her photographs and the camera to keep. I kept the other set of photographs (for analysis), along with the $\mathrm{CD}$ (for presentation purposes) and the negatives (for enlargement of photographs). At the end of the study, the negatives were returned to the artists.

\section{Unanticipated occurrences.}

During the individual and group photovoice training sessions I emphasized that if anything happened to the participants' cameras, film or anything else related to the photovoice project, I was available to assist. I stated my willingness to replace any broken cameras, provide more film, or distribute more photo release forms, if needed. Six of the women did not encounter any problems with their cameras, film or developing; with almost every photograph being in focus. One participant contacted me after taking a few photographs because her camera stopped working. I immediately replaced her battery so that she could successfully complete her roll of film. Another artist reported her camera breaking after she had taken 10 photographs. This participant made the decision to shoot the rest of her photos for the project with her personal digital camera instead of using another $35 \mathrm{~mm}$ camera.

One participant did not return my phone calls one month after her individual training session. Eventually, she asked her friend (also in the study) to relay to me her embarrassment around leaving her camera at someone's home and being unable to 
retrieve it. After learning this news, I communicated with her and assured her that this wasn't a problem and nothing to be embarrassed about. I then gave her another camera to use along with another roll of film. After meeting with her to develop her film, she revealed that she had lost her second roll of film that she had spent time shooting. However, she had pro-actively bought a roll of black and white film on her own in order to complete the project. After her individual dialogue session, she expressed feeling so inspired by photography that she decided to take another roll of film to photograph those things she wasn't able to capture.

Two participants, who were recruited towards the end of the recruitment phase of the study, turned in their cameras with only $1 / 3$ of the photographs taken. Both expressed feeling pressured to meet a deadline. I met with each woman individually and explained that they could take as long as they needed to capture the photographs they wanted. I asked each artist if she would be willing and able to complete her roll of film before the scheduled group dialogue session. Both women needed more time and within a few days, successfully completed their roll of film. However, one of the two artists accidentally opened her camera (to remove her film) before the film had time to completely rewind, thus exposing a few photographs that were meaningful to her. After we developed her film and discovered which photographs had been lost to light-exposure, she chose to use a digital camera in order to capture the four images that she had lost.

Stage V. Individually reflecting, dialoguing and storytelling.

$\underline{\text { Selecting photographs for discussion. }}$

Each artist chose a private, quiet place where she met with me individually to view and discuss her photographs. These individual dialogue sessions were held in 
various locations: in my home, in the participant's home, in my office at the university, and one was held in the car. For those (nine) individual dialogue sessions that were held either in my home or in my office at the university, participants were exposed to multiple photographs that I had taken (displayed on the walls of the rooms). I was able to share my own artwork with the women and connect on a creative level. This contributed to building trust and reciprocity. For those women who chose to hold their individual dialogue session in my home, I treated them as I would any other guest.

Wang's (1997) photovoice method advocates for a participatory group dialogue session for sharing photographs. However, I found that holding individual dialogue sessions with each artist was deemed more helpful in this study, due to the possible sensitive nature of some photographs and private nature of some reflections. I wanted to eliminate any potential for participant discomfort in sharing their photographs and stories within a larger group. All participants were invited to attend the two optional group dialogue sessions to share their photographs with each other.

Prior to beginning each individual dialogue session, each woman's subjectivity (living and working experiences) was explored (Appendix H). Afterwards, each participant was given the option to write her own artist biography or verbally provide what information she wanted me to include. Half of the women chose to write their own biography after the individual dialogue session and later sent it to me via e-mail. The other half dictated the contents of their biography during the individual dialogue session and later met with me to review what I wrote to ensure accurate representation. It is interesting to note that the artists had multiple opportunities to make revisions to their biographies and many chose to make various changes, additions and omissions more than 
once prior to the art exhibit. This spoke to the fluidity of their identity and it is possible that their sense of self (and self as artist) may have changed over time. Perhaps, as the women took more ownership of the project, their perceptions of themselves as artists transformed.

\section{Contextualizing and storytelling.}

After taking the time to view her photographs on her own, each artist chose the order in which to talk about her photographs. Some participants chose to discuss their photographs in the order in which they were taken. Others spread out their photographs around them and allowed the flow of conversation to inspire the order in which they talked about each photograph. While the women were told that they didn't have to talk about every photograph taken, it is interesting to note that in this study, every participant discussed and analyzed why she took each and every photograph.

While each artist discussed her photographs, we engaged in a dialogue together centered on her photographs. The process of discussing the content of photographic imagery allowed participants to both share and guide me through an external view of their internal realities (Collier, 1979). The women were given a guide from which to address questions about their photographs associated with each letter in the PHOTO acronym (Appendix I). The acronym PHOTO (Hussey, 2006) asked the following:

1. Describe your Picture?

2. What is Happening in your picture?

3. Why did you take a picture $O$ f this?

4. What does this picture Tell us about your life?

5. How can this picture provide Opportunities for us to improve life (with regard to sex workers' lives in Portland, Oregon)? (The phrase in the parenthesis was added to adapt to the study). 
For some artists, this questioning guide provided a way to focus on the specific stories and experiences portrayed in the photographs, and then move toward thinking about ways to improve life conditions. It served as a way to contextualize the meaning of their photographs. While this guide was encouraged, it was not enforced in order to maintain the natural progression of dialogue and to maintain creativity and freedom of expression. It is interesting to note that those participants who chose not to refer to the guide while explaining their photographs still provided rich, contextual descriptions for each of their photographs, while addressing these questions in their own way.

After discussing each photograph, the artist was asked if she would like to say anything else about the photograph (that might not have been captured by the five questions). In addition, some artists were asked what was missing, if anything, from each photograph. At the end of the individual dialogue session, each artist was asked if there were any photos that she wanted to take but was unable to. Also, each woman was asked to describe her thoughts and feelings around participating in this project.

With the permission of the artists, the individual dialogue sessions were audiotape recorded. The individual dialogue sessions ranged in duration, from 45 minutes to 4 hours (as one participant requested smoke breaks). On average, most individual dialogue sessions were $1 \frac{1}{2}$ to 2 hours long.

Stage VI. Communal dialoguing and sharing the artistic creations.

Group dialogue sessions.

Prior to the start of this study, my intent was to hold an optional group dialogue session for those participants who were interested in sharing their photographs and stories with one another. I created a group dialogue session facilitation guide (Appendix K), 
which included specific questions for discussion and sharing. My hope was that those participants who chose to attend the group dialogue session would have the opportunity to share their photographs with other sex workers, collectively identify common themes, and plan for the community art exhibit of their photographs. While this did occur, it happened very differently than I had imagined.

The first group dialogue session was held at a convenient community location with eight out of the eleven participants in attendance. Of the three women who did not attend, one reported getting lost and not being able to find the location, another had previously mentioned that she had to work, and one later admitted that she was too intimidated to participate in a group setting. The first group dialogue session lasted three hours. In preparation for the group dialogue session, I made copies of everyone's photographs (a total of approximately 400 black and white photos, 4x6 inches in size) and placed each participant's 36 photos on two white poster boards (18 photos to a board). Each photograph was numbered and the poster boards were hung on the walls of the room so that each artist had a "station" with a bowl underneath for the voting process. The tables in the room were filled with homemade food and various sweet and salty snacks, and there was another table with prizes (e.g. coffee shop and grocery store $\$ 5$ gift certificates, scarves, mittens, jewelry, books, and magazines) to give away in a raffle at the end of the group dialogue session, as a way of thanking the women for their time.

The group dialogue session was scheduled to begin at 3:00 pm, but the participants all came at different times, so the session started 30 minutes late. While we waited for everyone to arrive, the women were invited to eat and get acquainted with each other informally. I asked the women to make self-introductions with whichever 
name they felt most comfortable (since I didn't know if they wanted to be referred to by their "real" names or pseudonyms). Prior to the start of the dialogue session, some women ate food, others talked on their cell phones, some were engaged in conversation with me (when I wasn't on the phone giving directions to other participants who were on their way), some were chatting with my community advisor, and some were smoking outside (we had bought a pack of cigarettes for those women who smoked, since smoking can be a social activity and often times an icebreaker).

The dialogue session began with an ice breaker activity that included introductions to one another through humor. After getting to know one another, ground rules were created by the women and we talked about creating a safe space for sharing. The participant-created ground rules included the need to listen to one another, be respectful and not to be in competition with one another. Then, I talked about the purpose of the session, the importance of confidentiality, and the voluntary nature of the group session. A photo release form for participants to sign was also provided (Appendix J). Each woman was given a folder with her typed biography (to edit/change or approve), a list of themes from her own photos that emerged (to provide feedback on), and a list of the group dialogue questions (from which to begin sharing stories and photographs). Following my group dialogue session guide (Appendix F), I proceeded to talk about the discussion questions that I created to guide the dialogue session. However, the women started to nod off and appear disinterested. Observing and sensing this from the participants, I realized that I had an "agenda" that was not participant-led, so I stopped talking to the women. It was at this moment that I realized, in an effort to "stay true" to the photovoice methodology, I was taking on the role of the researcher who had 
not yet completely given up her power. So I decided to talk with the participants and asked them what they wanted to do and how they wanted to spend these three hours together. My desire to equalize the power imbalance resulted in turning the group dialogue session over to the artists and allowing the course of events to naturally evolve. The participants voiced that they wanted to talk about the art exhibit and how they would share their photographs with the community. While, initially, I had intended to keep the art exhibit separate from my dissertation, it clearly became the focal point of this project for the participants; therefore it is important to illuminate it in this scholarly work.

\section{Selecting photographs for art exhibit.}

The participants expressed their interest in talking about the art exhibit and how to display their photographs. Excitement arose over planning the date of the art show, the possible locations, the guest list, and advertisement for the exhibit. Together, we discussed how the participants wanted to be represented on the art show flyer (Appendix N). Specifically, the women suggested that a flyer be created that referred to the artists as "diverse women working in the sex industry" as opposed to just "sex workers." The women discussed the type of image to be placed on the flyer and the color scheme. Then, each participant reviewed her own artist biography, making necessary changes to the text when relevant. The women discussed how they wanted their biographies and photographs presented and whether their photos would be presented as a group or individually. The participants chose to have their biographies grouped together and their framed photographs intermixed on the wall. As a group, the number of photographs displayed in the exhibit and framing was also decided upon. 
We also discussed the way in which we could all anonymously vote on the artists' photographs that would be representative of the diverse voices of the group. A decision was made that each artist would have three photographs displayed in the exhibit that would be voted on by the group; totaling 33 photographs for the art show. We also agreed that one of the three photographs voted on by the group could be "switched out" by each artist if she chose to replace a "voted on" photo with one that she felt best represented her voice. Once the voting terms were discussed and set, each artist went to her station, where her two poster boards of numbered photos were displayed. Each participant was given the option of covering those photographs that she did not want to share with others or that she did not want the group to vote on for the art exhibit. Some artists chose to cover many of their photographs on the poster board; others did not cover any. Then each participant cast her three votes for her own favorite photographs.

After each participant completed the voting process for her own artwork, she walked to the other stations and voted on other participants' photographs. It is interesting to note that it was during this time of voting that the women laughed, joked, hugged and complimented one another; appearing to connect on a personal level. I found women huddled together around photographs at each station, asking questions and sharing stories with one another. This moment of support and sharing brought the group together in a way that my scripted "agenda" could not. After every participant had the opportunity to vote at each station, everyone took a break while votes were tallied.

\section{Organizing the representation of the art.}

The top three photographs from each artist that received the greatest number of votes from the group were announced after the break. Only one artist chose to substitute a 
photo that was voted on for one that she really wanted in the art show. All of the other participants were content with the photos that were voted on by the group. We discussed the inclusion of captions, stories, and/or poems beside each artist's photographs. The women spent time writing titles for their three photographs, and those participants that wanted to include a story or caption talked about meeting again before the art exhibit to put those together. During this time, we also discussed the artists' desire to sell their framed photographs, as well as smaller prints of their images. As a group, the women decided that each artist would choose seven of her photographs to sell as postcards at the art show. The participants also talked about the pricing of their artwork. They decided that the proceeds from the art exhibit would be divided equally among them.

The participants talked about making a calendar of everyone's photographs where every artist could be featured each month out of the year. However, in our dialogue session this idea was replaced with the proposal to create a self-published, coffee table book of everyone's photographs. The participants all agreed that a coffee table book would be more artistic, so the women chose which photographs they wanted to include in the book. We also discussed and decided on the size and photographic layout. There were some images that they wanted cropped in certain places, so these changes were noted.

In preparation for the art show, I attended to the mechanical aspects of enlarging, cropping and framing the participants' photographs. My knowledge and experience with contrast, composition, and other technical and aesthetic aspects of photography enhanced the presentation of the photographs (without changing their content) for the art exhibit. The opportunity for me to personally enlarge and crop participants' photographs also offered a sense of shared artistic creation in addition to the co-creation of knowledge. 
Three weeks after the group dialogue session, another gathering was held at my home and all participants were invited to attend. A total of four participants came. They were eager to debrief the first group dialogue session and share their thoughts about the study process, their poems, and stories to go along with their photographs. This second group dialogue session was very informal and participant-led. One of the women, not at the first group dialogue session (stating she felt too intimidated to come), showed up and brought with her a bag of clothes for the other women. This kind gesture appeared to create a sense of sisterhood and support among the women, setting the tone for a comfortable atmosphere. After we spent some time connecting with one another, the artists chose to work on their stories and poems to accompany their photographs. This time, I did not present my "agenda," but rather allowed for the participants to guide the conversations and events of the gathering. The artists decided to tape record their reflections about the photovoice method and how meaningful this process was to them.

There were only two participants who chose to not attend either one of the group dialogue sessions. However, one of the two contacted me to set up a time to meet with me individually to title her photographs and to choose which postcards to sell. Also, she was able to attend both art exhibits. The other participant chose not to attend either group dialogue session nor title her photographs. She did not attend the art exhibits nor did she return any phone calls inviting her to participate in activities related to the project.

However, I did meet with her again, one month after the art exhibit, to give her the equal share of the proceeds from the art exhibit.

Stage VII. Disseminating artistic creations to the public.

Community art exhibits. 
The participants, my community advisor, and I identified and invited influential community advocates, sex workers, journalists, students, professors, social workers, social service professionals, community leaders, friends, and family to the art exhibit. Policy makers and influential community advocates received a personalized, hand-made invitation to the art exhibit. Advertising to the public for the art exhibit was done inperson, through telephone, by word-of-mouth, and electronically via the internet. An email list serve generated by the university's School of Social Work was used to contact faculty, staff and graduate students about the photographic exhibit. An e-mail list serve generated by SWOC informed social service providers about the exhibit. The art exhibit was also promoted through the SWOC website and a my-space internet page dedicated to the photovoice study. The week of the art exhibit, two local newspapers featured the opening in their current events section and on-line in the art gallery portion of their paper.

Many people attended the art opening that was held in a donated public space and various guests reported having to wait in line to get into the cafe's gallery section to see the exhibit. In addition, many of the individuals who attended the fund raiser also attended and supported the art exhibit. Seven of the artists were able to attend and stay until the end of the evening. One participant was unable to attend because she had to work and another artist could not attend because she was ill. One of the women had already moved to the east coast, but called me after the art exhibit to hear about its success since she was unable to attend. Only one out of the eleven participants did not contact me afterwards regarding the exhibit.

One month later, the director of the women's resource center at a local community college invited us to hang the 34 photographs featured in the art exhibit on 
the walls of the campus library. The photovoice project was featured in this space for one month, gaining much attention from students, professors and the community. In addition, the photographic art exhibit was later displayed on the walls of a café at Portland State University for six weeks. The university provided funds to host this second art exhibit opening to honor the artists and their work. The same methods of advertising were used for this art exhibit, and the event was featured in one local newspaper. Four of the study participants attended this event, along with students, professors, social service providers, sex workers, friends, family and members of the community. Additional places where the exhibit was displayed include a social service agency in the community, the lobby of a performance space at a community college, and the art gallery of a private university. The art exhibit is also scheduled to be on display at an independent, feminist bookstore.

\section{Media coverage and attention.}

It is important to note that while this research study might not have had any immediate or direct effects on policy decisions, it received a lot of media attention and community support. The art exhibit was featured in a local activist newspaper. My community partner and I were interviewed and three artists, also interested in being interviewed, contacted the reporter on their own and talked about their participation in the project. Their thoughts, perspectives and photographs were presented in a feature story. In addition, the local news station contacted me and my community partner with an interest in doing a story about the art exhibit for the 6 o'clock evening news. The film crew documented the art exhibit at the community college and interviewed my community partner. One artist, very interested in appearing on the news (while remaining anonymous), contacted the news reporters and participated in a televised interview. 
Audience interactions with art.

With arts-based research projects, it is important to consider the audience that is viewing the art and the power of art to evoke strong emotions within people. It was anticipated that there could be ways in which the photographs might harm those people witnessing them, especially those individuals most affected by the subject matter (Sinding, Gray \& Nisker, 2008). When publicly promoting and passing out flyers for the art exhibit, the context and purpose of the show was made explicitly clear.

There was an overwhelming amount of positive feedback from individuals who attended the art exhibit. Many people wrote their comments and impressions in a book that the artists had dedicated for feedback from the guests of the two art exhibits. Some comments were written by individuals who worked in the sex industry and highlighted the positive impact that the art exhibit had on them. One person wrote, "I really loved all of the art. It was very touching and inspirational. As a sex worker myself for $2 \frac{1}{2} \mathrm{yrs}$, I wasn't going to come, but now that I'm here I love it. Thank you to all the artists and people who put this exhibit together with much love and respect." Some one else wrote, "After 13 years working on the street for crack cocaine I'm finally clean and sober at the V.O.A. rehabilitative center and I found great inspiration here tonight. Thank you." An additional comment stated, "Thanks so much to the artists. Such real and inspiring work makes me proud!" These reflections demonstrated the power of the women's art to touch the audience and the ways in some art exhibit guests personally related with the art.

Other audience members reflected on how thought provoking the images and voices were for them. One individual wrote, "Beautiful display. Very touching photographs. A special thank you to all of the participants for sharing their thoughts and 
feelings through their photos." Someone else wrote, "Amazing, thought-provoking, sad, human- I learned a lot. Thank you.” Some responses expressed solidarity, gratitude and support. One guest wrote, "Great idea! Very creative and direct way at looking at the struggle that some people face to survive. A way to bring attention to an issue that needs publicity in a positive light!" While another person wrote, "In solidarity with all workers...Thank you for sharing your stories and courage!" Others highlighted the power of the photographic image for bringing about awareness and enlightenment. Another comment stated, "It is interesting to note how much a photo can capture. A photo by this show's definition can move one to tears and enlightenment."

These comments from the guests of the art exhibit express the political nature of arts-based research for reaching a broad audience beyond academia while making both art and scholarship more accessible. In addition, these audience reflections emphasized how audience engagement is central, whereby the reader/audience is involved in an active process of meaning making that is likely to have transformative potential. 


\section{CHAPTER 4}

\section{DATA ANALYSIS PROCEDURE}

Given that I was interested in the lived experiences of sex workers and the meanings that they assigned to objects, people, places and events in their everyday lives, as expressed through their photographs, I borrowed techniques from phenomenological approaches to analyze the data from the individual dialogue sessions. Specifically, I used tools from interpretive phenomenological analysis, as described by Smith and Osborn (2008) to explore how participants make sense of their personal and social world and the particular situations they are facing by focusing on the meanings that various experiences, events, and states hold for them. My analysis was concerned with trying to understand what their world is like, from their point of view. Also borrowing from the processes of Creswell (1998) and Rieman (1998), my analysis involved sustained engagement with the text and a process of interpretation aimed at understanding the content and complexity of the meanings.

The analysis of the data involved two major parts: (1) a within-case analysis of each participant's transcript, and (2) a cross-case analysis comparing all of the participants' transcripts together. The analysis took several forms, which included looking at each photograph and its description produced by each artist (to answer the first and second research question), identifying common themes for each artist based on her dialogue session (to perform a within-case analysis of each transcript), and then comparing and synthesizing all of the artist's themes together (to perform a cross-case analysis of all dialogue sessions in order to answer the second research question). The 
data collected included approximately 36 photographs taken by each participant (along with their titles and captions), field notes, and journal entries for a total of 396 photographs. How the data was triangulated is discussed below. I created various visual tables to organize, account for and ground all of the data to help with the analysis. The steps of the analysis for each transcript are represented in multiple tables that build upon one another in order to proceed into deeper meaning. While the first table served to organize and provide a foundation for the data, the sequential tables represented the progression of the analytic themes (associated with the dialogue, captions, titles, field notes, and journal entries), their connections, and the meaning created from the transcripts and photographs. The entire analytic process was then visually represented through the symbolism of a tree (see figure 1).

\section{Artistic Representation of Analysis Process}

To depict my within-case analysis process for each artist in a visual manner, I drew a tree and inserted mini replicas of the various tables I created on different parts of the tree (i.e. underground roots at its base, trunk, branches, and leaves) (see figure 1). I wanted to show how my data was organized in each table. This was my way of illustrating my organic process of working with each artist's data over time. In this drawing, the soil illustrates the multiple forms of data I started with prior to beginning of my analysis (the photographs and their captions, the transcripts, the artist biographies, my journal, and my field notes). My initial contact with the data is represented by the roots that developed. These roots symbolize my feelings and impressions while reading the transcripts, looking at the photographs along with their captions and titles, and comparing 
my field notes and journal entries. The tree trunk is used to symbolize the foundation of my understanding of the data through the analysis process. It also represents the growth of working with the data, the strong relationships between the information collected, and steps of my analysis process. The tree braches represent the connections between the themes that allowed for the superordinate themes to surface. The emerging themes presented a solid foundation for understanding how each artist was making meaning of her experiences while the analysis continued to build upon itself. The miniature photographs at the top of the tree, attached to the branches, represent the leaves of a tree. These "leaves" symbolized the power of the visual image in the form of a photograph, to express additional layers of understanding, representation and liveliness of experiences.

The photographs were also representative of leaves on a tree, since they would be detached from the data in the visual cross-case analysis, spread out before me, and explored for visual patterns and further insight. While the textual data provided an understanding of the meaning that particular experiences held for the participants, each artist's photographs offered an additional layer of expression and depth of perception. 
Figure 1: Visual Representation of Analysis Process

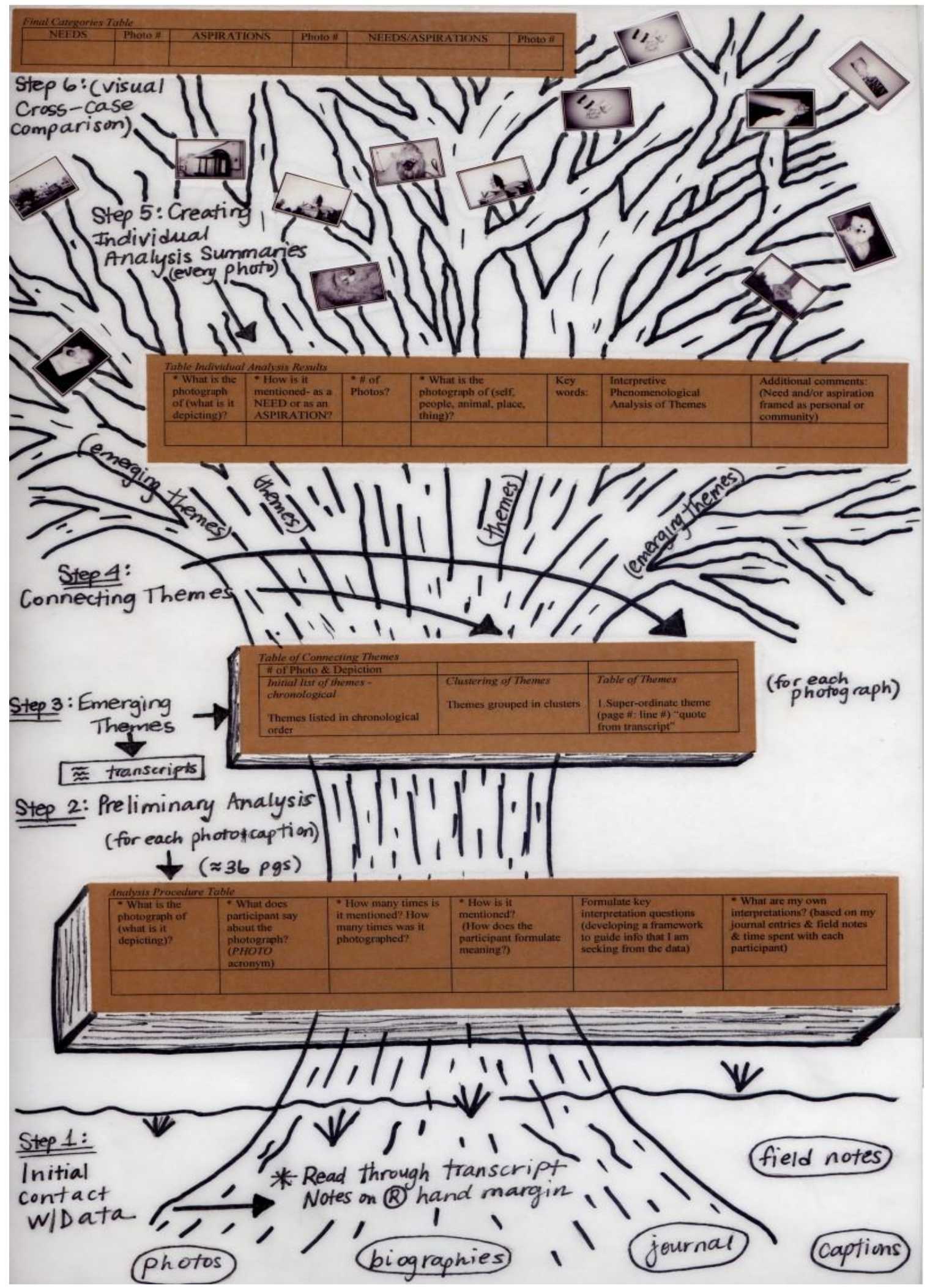




\section{Within-Case Analysis of Individual Transcripts}

\section{Step 1: Immersion in the Data}

I personally transcribed the audio-tapes of each dialogue session verbatim. I began the analysis process of some individual dialogue sessions while finishing the transcription of others. The first step involved my initial contact with the data, where I immersed myself in the photos, captions, biographies, field notes and my journal. Focusing on one artist at a time, I began by performing multiple readings through an individual dialogue transcript to become familiar with the text, while simultaneously listening to the recorded dialogue session to get a feel for voice, intonations and pauses. As I listened and read along with the transcription, I noted what was interesting or significant on the right hand side of the margin in pencil (Smith \& Osborn, 2008; Creswell, 1998). For example, my initial comments were related to the participants' use

of language, my sense of her and my interpretation of how she presented herself. I noted similarities, differences, amplifications, repetitions, pauses and contradictions in what each artist was saying. Some of my comments were attempts at summarizing what the participant said while others were related to connections that came to mind. This process continued for the entire first transcript.

To make the reading of each transcript easier, each participant's transcript was divided into sections corresponding to the different photographs discussed. For example, I used a pencil to draw a horizontal line above each sentence that started a discussion of a new photograph. This was done in order to visually organize and link the dialogue text in the transcript with each photograph taken and discussed.

\section{Step 2: Preliminary Analysis}


The second step consisted of reading and listening to the transcript once more, and creating a table to organize my interpretation of the data. The purpose of conducting a preliminary analysis, or preliminary interpretation, and taking hand-written notes on the table was to (1) synthesize each photograph with the accompanying stories embedded in the transcript, (2) highlight significant ideas, photographs and their frequency, (3) document how experiences were mentioned in the transcript and related to the photographs, (4) formulate key interpretation questions, and (5) document my own interpretations of the photographs and what was said about each one (based on my journal entries and field notes). I created this table to provide me with an overview of how each photograph discussed by the participant using the PHOTO acronym and the theme of the photograph as identified by the artist.

Documenting how the experience happened, how it was talked about and experienced by the participant is referred to as "structural description" (Creswell, 1998). Structural description is the process of seeking all possible meanings, varying the frames of reference about the phenomenon, and constructing a description of how the phenomenon was experienced. This is where I reflected on the setting and context in which the phenomenon was experienced.

Key interpretation questions were developed for each photograph to guide what information I was seeking from the data (Rieman, 1998). The key interpretation questions reflected the different ways that participants talked about their lives and experiences and the meanings they ascribed to them. Examples of some key interpretation questions include: "How might her idea around having an equal playing field as a stripper be reflected in her description of the photograph of her clothes over the seesaw at the park?" 
and "What tension exists between her religious and spiritual beliefs in Islam and her identity as an artist and a community activist?" and "What does the comparison of her basket to a gun and a cross say about how she views the basket she has photographed twice, with one photograph being a self-portrait?" Key interpretation questions were posed to also distinguish what the participant said from my interpretation or account of each photograph.

During the preliminary analysis process, I referred to the artist's transcript to complete the following table for each photograph taken (approximately 36 tables for each participant).

Table 1: Preliminary Analysis Procedure Table

\begin{tabular}{|c|c|c|c|c|c|}
\hline \multicolumn{6}{|c|}{ Artists-Identified Theme: (need, aspiration or both) } \\
\hline $\begin{array}{l}* \text { What is } \\
\text { the photo- } \\
\text { graph of } \\
\text { (what is it } \\
\text { depicting)? }\end{array}$ & $\begin{array}{l}\text { * What does } \\
\text { participant } \\
\text { say about } \\
\text { the } \\
\text { photograph? } \\
\text { (using } \\
\text { PHOTO } \\
\text { acronym) }\end{array}$ & $\begin{array}{l}\text { * How many } \\
\text { times is it } \\
\text { mentioned? } \\
\text { How many } \\
\text { times was it } \\
\text { photographed? }\end{array}$ & $\begin{array}{l}\text { * How is it } \\
\text { mentioned? } \\
\text { (How does } \\
\text { the participant } \\
\text { formulate } \\
\text { meaning?) }\end{array}$ & $\begin{array}{l}\text { Formulate key } \\
\text { interpretation } \\
\text { questions } \\
\text { (developing } \\
\text { questions to guide } \\
\text { info that I am } \\
\text { seeking from the } \\
\text { data) }\end{array}$ & $\begin{array}{l}\text { * What are my } \\
\text { own inter- } \\
\text { pretations? } \\
\text { (based on my } \\
\text { journal entries } \\
\text { \& field notes } \\
\& \text { time spent } \\
\text { with each } \\
\text { participant) }\end{array}$ \\
\hline & & & & & \\
\hline & & & & & \\
\hline
\end{tabular}

The Preliminary Analysis Procedure Table above was completed for every photograph or group of photographs (with the same subject matter, idea or story) that corresponded with each participant's transcript. On the back of each table's page, I pasted the artist's caption and/or title for each photograph and wrote my own comments and perspectives. For example, I described each photograph in technical and aesthetic terms (i.e. assessing the use of self, contrast, angles, cropping, centering, distance and lighting). I noted any use of self in the photograph and how the self was portrayed. In addition, I 
used colored highlighters on the transcripts to illustrate the words that were used and repeated in each story or experience. My intent was to use color to visually illuminate the unique words and phrases that were used by each artist to share her experiences.

\section{Step 3: Emerging Themes}

After completing approximately 36 Preliminary Analysis Procedure Tables for each photograph taken by the participant for the whole of the first transcript, I returned to the beginning of the transcript and used the left hand margin to document the emerging themes. Here, my initial notes on the right hand margin were transformed on the left hand margin into concise phrases (themes) for each photograph in order to capture important qualities found in the text of the transcript (Smith \& Osborn, 2008). Through this procedure, the themes moved to a slightly higher level of abstraction. The themes documented in the left hand margin were grounded within the stories and descriptions of the photos that the participants gave and could be directly traced back to the text.

\section{Step 4: Connecting Themes}

A table (see Table 2) was created to document the themes found in the left hand margin of the transcript and the process of clustering and organizing the themes. For each photograph or group of photographs, the themes that emerged in the left hand margin of the transcripts were typed in the first column, in chronological order "based on the sequence with which they came up within the transcript" (Smith \& Osborn, 2008, p.70).

In the second column of Table 2, the themes were moved around and clustered into groups. This stage involved a more analytical or theoretical ordering, which means that I tried to make sense of the connections between the themes that emerged. The initial list of themes was moved around and clustered according to what captured most strongly 
or what was most aligned with the participant's concerns for a particular topic (Smith \& Osborn, 2008). Some themes were merged if a similar idea was repeatedly expressed. As the clustering of themes materialized, I returned to the transcript to check the themes to ensure that the connections worked for the actual words of the participants (Smith \& Osborn, 2008).

In the third column of Table 2, each different cluster of themes was given a name that represented a superordinate theme. These superordinate themes signified what stood out as most reflective of the clustered list of themes. An overall description of the meaning and the essence of the experience was represented in each superordinate theme that emerged (Creswell, 1998; Rieman, 1998). During this process, certain themes were dropped; those which neither fit the clusters of themes or those that were not very rich in evidence within the transcript.

The description of the initial themes, their clustering and the superordinate themes for each photograph were documented in the respective columns in the following Table of Connecting Themes. I also present an example from one of the artist's transcripts for further clarification of the manifestation of superordinate themes

Table 2: Table of Connecting Themes

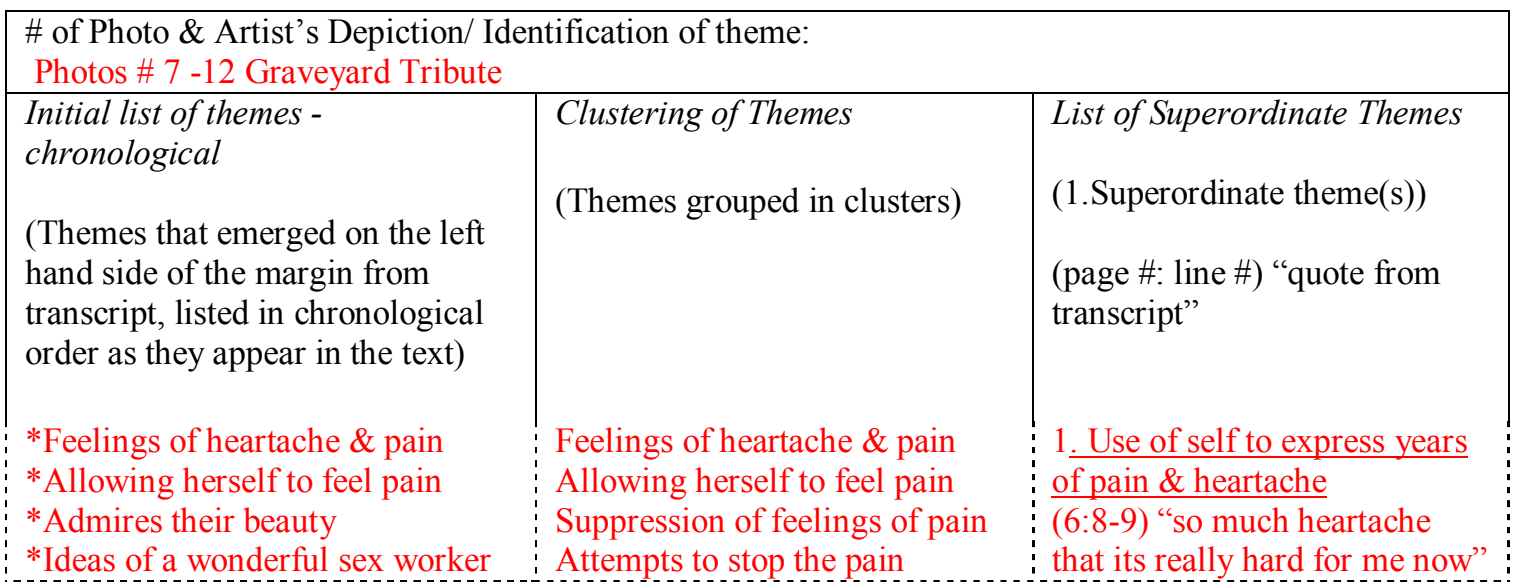




\begin{tabular}{|c|c|c|}
\hline $\begin{array}{l}\text { * Sense of people not caring } \\
* \text { Feeling unimportant, unworthy } \\
\text { * Suppression of feelings of pain } \\
\text { *Attempts to stop the pain } \\
\text { *Undesirable, destructive self } \\
\text { *Experiences of physical pain } \\
\text { *Humiliation } \\
\text { * Feelings of survivor guilt } \\
\text { * Needing to stay safe } \\
\text { * Worthiness-certain people care } \\
\text { * Sense of sisterhood }\end{array}$ & $\begin{array}{l}\text { Experiences of physical pain } \\
\text { Advocating for safety } \\
\text { Sense of people not caring } \\
\text { Worthiness-certain people care } \\
\text { Feeling unimportant, unworthy } \\
\text { Humiliation } \\
\text { Feelings of survivor guilt } \\
\text { Undesirable, destructive self } \\
\text { Sense of sisterhood } \\
\text { Ideas of a wonderful sex worker } \\
\text { Admires their beauty }\end{array}$ & 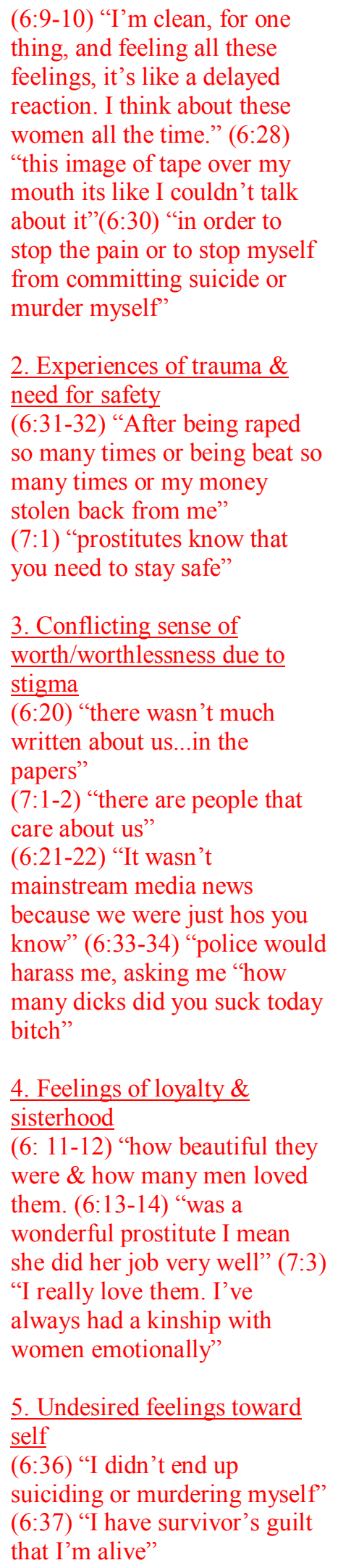 \\
\hline
\end{tabular}


The list of clustered themes under each superordinate theme (in the third column of the table) corresponded with multiple identifier quotes in the transcript (according to line number and page number) to aid the organization of the analysis and to facilitate finding the original source. Each photograph or group of photographs were connected to one or more (even up to eight) superordinate themes.

\section{Step 5: Creating Individual Analysis Summary}

A table titled Individual Analysis Summary (Table 3) was created for the artist in preparation for a cross-case analysis of all participants. This table built upon previous ways of organizing and categorizing the data and incorporated: (1) how the participant identified her photo(s) as a need, aspiration or both, (2) the number of photos taken to depict her need, aspiration or both, (3) what the photograph depicted- categorized into one of five categories- things/objects; people; places/location; animals; or self, (4) the superordinate themes from the analysis process, and (5) whether the artist described the need or aspiration as personal (micro), communal (mezzo), or societal (macro).

Table 3: Individual Analysis Summary

\begin{tabular}{|l|l|l|l|l|l|l|}
\hline $\begin{array}{l}\text { * What is the } \\
\text { photograph of } \\
\text { (what is it } \\
\text { depicting)? }\end{array}$ & $\begin{array}{l}\text { * How is it } \\
\text { mentioned } \\
\text { (as a need, } \\
\text { aspiration or } \\
\text { both)? }\end{array}$ & $\begin{array}{l}* \text { Photos? } \\
\text { Phot }\end{array}$ & $\begin{array}{l}\text { * What is the } \\
\text { photograph of } \\
\text { (self, people, } \\
\text { animal, place, } \\
\text { thing)? }\end{array}$ & $\begin{array}{l}\text { Key } \\
\text { words: }\end{array}$ & $\begin{array}{l}\text { Analysis of } \\
\text { (super- } \\
\text { ordinate) } \\
\text { themes }\end{array}$ & $\begin{array}{l}\text { Additional } \\
\text { comments: } \\
\text { (need and/or } \\
\text { aspiration } \\
\text { framed as } \\
\text { personal or } \\
\text { community) }\end{array}$ \\
\hline & & & & & & \\
\hline Subjectivity & & $\begin{array}{l}\text { Any } \\
\text { additional } \\
\text { photos she } \\
\text { wanted to take } \\
\text { but didn't? }\end{array}$ \\
\hline $\begin{array}{l}\text { Feelings } \\
\text { around }\end{array}$
\end{tabular}




\begin{tabular}{|l|l|}
\hline process \& & \\
project & \\
\hline Journal Notes & \\
(interactions & \\
wher \& my & \\
perceptions) & \\
\hline Field Notes & \\
(individual \& & \\
group & \\
meetings \& & \\
interactions) & \\
\hline
\end{tabular}

After representing my analytical findings in the Individual Analysis Summary table, I included any information about the participant's subjectivity (if she referenced herself at the beginning of dialogue session or at the end), her description of any photographs that she may have wanted to take but did not, her feelings around the photovoice process, my journal notes and my field notes related to my interactions with her. My intent was to have a holistic, written illustration of each artist in the form of a detailed table to accompany her 36 photographs for use in the visual cross-case comparison between all participants. This was also a way to continue to create tables that build upon one another; all connected and rooted in the data.

\section{Step 6: Final Categories}

To prepare for my cross-case analysis of (1) the artist-identified themes of their needs, aspirations, or both based on their photographs, and (2) my own analysis of themes based on their transcripts and photographs, I condensed the data table even more for each artist. This allowed me to organize and condense the artist-identified themes of needs, aspirations, or both and to link those themes to their corresponding photographs. A Final Categories table was created and each participant's photographs were numbered and listed under a category (needs, aspirations or both), as determined by each artist. Then, depending on how each participant spoke about her needs and/or aspirations in her 
photographs (as a personal-micro, communal-mezzo, and/or societal-macro) each category was colored-coded.

Table 4: Final Categories Table

\begin{tabular}{|c|c|c|c|c|c|}
\hline NEEDS & Photo \# & ASPIRATIONS & Photo \# & NEEDS/ASPIRATIONS & Photo \# \\
\hline & & & & & \\
& & & & & \\
\hline
\end{tabular}

All of the artists' superordinate themes were listed on a sheet of paper in order to be cut into strips of pieces to be moved around for a cross-case analysis.

Visual cross-case comparison \& synthesis

Step 7: Parallel Process of Analysis

The visual cross-case analysis among all participants involved the comparison and synthesis of (1) significant statements made by the artists (regarding self-identified needs, aspirations, or both), (2) formulated meanings of experiences that I identified for each artist as expressed in the superordinate themes that emerged, and (3) all of the photographs taken by the artists. This was a visual process because I used my hands to move around strips of paper and photographs to spatially and visually juxtapose the statements and the visual images created by all of the participants. The fluidity of the visual cross-case analysis involved data that were color-coded, tactile and portable.

The significant statements of the artist-identified needs/aspirations listed in the Final Categories Table were placed on three different colored pieces of paper according to each category. Each statement was cut up into strips of paper and moved around on the floor into various piles of association. The significant statements of the artist-identified themes were spatially grouped according to the patterns of ideas and associations that 
emerged in each pile. All of the artist-identified themes were placed in distinct clusters that illustrated their needs and aspirations in various aspects of their lives.

Similarly, the superordinate themes for all of the artists were cut into little strips of paper that were moved around and spatially positioned and re-positioned for the crosscase analysis. Various clusters between all of the participants emerged that expressed how participants were making meaning of their needs and aspirations as creators and interpreters of their own images. All of the photographs taken by each participant were labeled and numbered on the back according to how each artist defined the subject matter in her transcripts. In a parallel manner, I laid out all of the photographs taken by the participants to allow for patterns, categories and ideas to surface. These photographs were also moved around and placed into various categories (i.e. photos of self, animals, places, community members, drugs and alcohol, work) and positions to see what might emerge visually and spatially. All of the women's photographs formed into unique clusters that were not mutually exclusive, thus overlapping into various categories of associations.

\section{Trustworthiness \& Quality}

Several steps were taken to ensure the trustworthiness and quality in this study. These included prolonged immersion into the data and in the field, extensive memberchecking, triangulation of the data through multiple sources of data collection and data analysis, analytic and reflective journal keeping, peer review of analytic procedure, and expert review throughout the study process.

I personally collected all of the data, transcribed the dialogue sessions, and analyzed the data. My multifaceted approach and continual immersion in the data 
contributed to the increased rigor of this study. I constantly worked with the data to see if my categories, themes, constructs, interpretations, and conclusions made sense and reflected the nature of what I was trying to understand. I also worked with all 396 of the artists' photographs over and over again, arranging and rearranging them visually and spatially.

The triangulation of the data contributed to the thoroughness of the analysis process and the credibility of the study. Multiple and different sources of data were collected, including the individual and group dialogue sessions, the photographs, the artists' biographies, my journals, and my field notes. I also incorporated my own artwork, in the form of collage, throughout the research process which is discussed in the following chapter. Since this study involved participatory aspects and multiple stages, there was prolonged engagement with the artists. I met with each participant at least four times over the course of the study and I met with some over ten times.

In addition, my community partner also analyzed the data independently, using her own process, so that we could compare our coding schemes and findings to ensure similarity in the themes that emerged. I also worked very closely with my dissertation chair. She reviewed the data analysis process and we engaged in reflexive dialogue around my analysis steps, the tables that I created, and my thought process throughout.

A peer reviewer, guided by my analysis process, read through four complete transcripts with (hand-written) codes along with the accompanying photographs and the multiple tables depicting the initial and superordinate themes. She was chosen to review and audit the analysis based on her experience and knowledge of qualitative research and her status as someone who was not directly involved in the data collection or other parts 
of the study. I took notes on the conversations I had with my peer reviewer who served as a sounding board throughout the research process.

Participant checks also occurred at different stages of the study and with all of the different pieces of data collected and presented. All eleven participants had the opportunity to either write their own biography or review the biography we had written together. All of the artists had a say in which photographs were included in the art show. Before the art show, three participants changed the quotes that accompanied their photographs and also asked that these changes be made in their transcripts. The women were invited to review their transcripts and make clarifications to their statements and ideas. Only four participants chose to re-word what they said in some areas, omit parts of their transcripts, or further elaborate their thoughts. The participants made changes to their transcripts prior to the start of my analysis. After my analysis of the data, I invited the participants to review the themes that emerged. I met with three of the participants who were interested in reviewing the themes and findings. Two participants asked for a copy of this dissertation. 


\section{CHAPTER 5}

\section{SELF AS RESEARCHER AND ARTIST}

\section{Reflexivity Through Collage}

Reflexivity is defined as the awareness of the researcher's own presence and contribution to the construction of meanings throughout the research process. It requires an acknowledgment of the impossibility of remaining "outside of" one's subject matter while conducting research. Reflexivity then urges us "to explore the ways in which a researcher's involvement with a particular study influences, acts upon and informs such research" (Nightingale \& Cromby, 1999, p. 228). Critical subjectivity, or critical reflexivity, is when one enters into "high-quality awareness" of one's own psychological, philosophical, and emotional states before, during, and after the research experience for the purpose of understanding the personal and psychological state of others (Lincoln, 1995, p. 283). To capture my inner, reflective processes that occurred throughout this study, I kept detailed field notes and a journal of my thoughts, feelings, observations, experiences and interactions with participants. These data sources were creatively expressed and represented in the art form of collage. I created three collages throughout the study to reflect, illustrate, and contextualize my physical, mental and emotional experiences of the research and analysis process.

Making collages allowed for the integration of both my researcher and artist self. As a visually oriented person, I respond artistically to my own lived experiences, and I am committed to creative ways of knowing and self exploration. I chose the art form of collage over other artistic mediums because the process of creating collages closely 
mirrored my own interactive and tactile analysis process of moving images around to understand and formulate meanings. By creating collages, I used art to reveal the intersections of my life as a researcher with the lives of the participants. I used collage to document my research journey and to reflect on my research process in a way that would honor my personal approach of making sense of my world, my self, and my experiences. I created collages to make more transparent my own ideas, perspectives, experiences and analysis process. Through collage, I located my reflections and participation in the research process and presented artistic representations that provided a visual context where one could see the multiple layers of personal exploration. I didn't want to rely on language as the single form of expression. Creating collages allowed me to use visual images to represent the various levels of my experiences; to move from my intuitions and feelings to thoughts and ideas.

\section{Creation of Collages}

The artistic process of collage entails collecting, piecing together, and juxtaposing images and quotes from multiple sources in order to create connections, and to express thoughts and emotions (Vaughan, 2005). Creating a collage is more than just cutting, moving, and pasting images on a surface. La Jevic and Spinggay (2008) describe the collage process as "the placement of spaces, meanings and subjectivities together in a rhizomatic sequence, and from this fluid, hesitant and non-linear arrangement, multiple meanings ensue" (p. 85). My own process of creating collages began by selecting various magazine photographs and cut-out book illustrations from my personal collection. Also, I flipped through magazines and cut out additional images that drew me. I own a large collection of vintage National Geographic and fashion magazines (from the 50s, $60 \mathrm{~s}$ and 
70s) that characterize my own fascination with how women were portrayed and represented in the media in previous decades. I am interested in how these representations change and continue to take different shapes and forms over time. Since I already had a plethora of words documented in my journal entries and field notes to express my own experiences and emotions, I chose to use visual images in my collages for (re)imagining, (re)presenting and critically reflecting on my experiences.

I made my selection of images based on styles, colors and sizes of pictures that would contrast well enough that they would not blend together, but, rather, complement one another. When going through a multitude of cut-outs, I paid attention to color, space, directionality, position and style of images, as well as what thoughts and emotions they invoked in me with relation to my research experience. I also chose to incorporate various images of animals whose meanings I knew had symbolic or cultural significance. While some images were intentionally chosen based on intuition or aesthetics, others were based on my interest related to relationships and encounters I shared with the participants.

I experimented with overlapping the images and shifting open spaces within the frame. This juxtaposition of seemingly random images based on my own feelings and experiences provided the potential for eliciting new awareness of hidden relationships, patterns and associations. Sinner, Leggo, Irwin, Gouzouasis, and Grauer (2006) refer to this process as “crossing boundaries by joining things together that don't normally go together" (p. 1254). My process of composition was fluid and entailed assembling images, adding new pieces and rearranging them intuitively until a schema was achieved. The "intuitively known content," situated with other images, allowed for the "appearance 
of unexpected new associations" (Davis \& Butler-Kisber, 1999, p. 4) and connections that may otherwise have remained unconscious.

Understanding the power of artwork to evoke a certain mood, I emphasized a color scheme of earthy, natural colors to represent my organic relationships with the participants and the data. In her work with collage in qualitative research, Davis and Butler-Kisber (1999) reflects on the idea of framing as a metaphor for a completed piece of art work. It is interesting to note that I began my first two collages on frames as opposed to framing them after completion. This speaks to my feelings of "duty" to the methodological steps of the photovoice research process and the "completion" of a particular stage. Since the photovoice method incorporated multiple stages, long-term involvement, and multiple interactions with the participants, I chose to look at the research process in segments so that the photovoice method wouldn't feel so overwhelming.

Throughout the study, I harbored anxiety around whether or not I would be able to gather enough data and participant follow-through for this project as an "outsider." Creating a collage on a framed surface provided the sense of completion of the particular methodological step. In contrast, the third collage piece, completed while analyzing the data, was created on four pieces of found wood that served as the base surface of my collage. The pieces of wood were not framed, symbolizing the infinite ways in which the data analysis process was continuously evolving, unconfined to borders and enclosures. Also, these pieces of wood were painted orange, reflecting my sense of confidence and my rich experience working with the various forms of data. As a color, orange often represents warmth, energy, and enthusiasm. My excitement in working with the artists' 
photographs as data was reflected in the color that I chose to paint the pieces of wood, prior to juxtaposing and pasting the images. In the following sections below I present three collage pieces illustrating the stages of my research process: (1) the recruitment and photovoice training process, (2) the group dialogue sessions, and (3) the analysis process.

\section{Collage I: Possibilities for an Outsider}

The first collage (figure 2) reflects the initial stages of the research process; specifically related to the recruitment process and the photovoice training workshops. It incorporated my thoughts, feelings and experiences with the methodology, my role as a researcher, and my initial relationships with the participants.

The gray background of the collage stands for the unknown possibilities of implementing this research and immersing myself in the communities of activists, social service providers, sex industry workers, neighborhood associations and others who had direct and indirect interests related to the sex industry. As a color, gray represents neutrality. I wanted to use my location as an outsider to be open to every experience and encounter without being quick to make judgments or assumptions. I wanted to stay "neutral" while still acknowledging and documenting my personal biases and perspectives with every interaction. The repetition of the diamond pattern in the background reflected my initial sense of security in the photovoice method due to its repeated implementation by researchers with various populations all over the world. I thought that if I just followed the steps like a diligent researcher, what could possibly go wrong? 
Figure 2: Possibilities for an Outsider

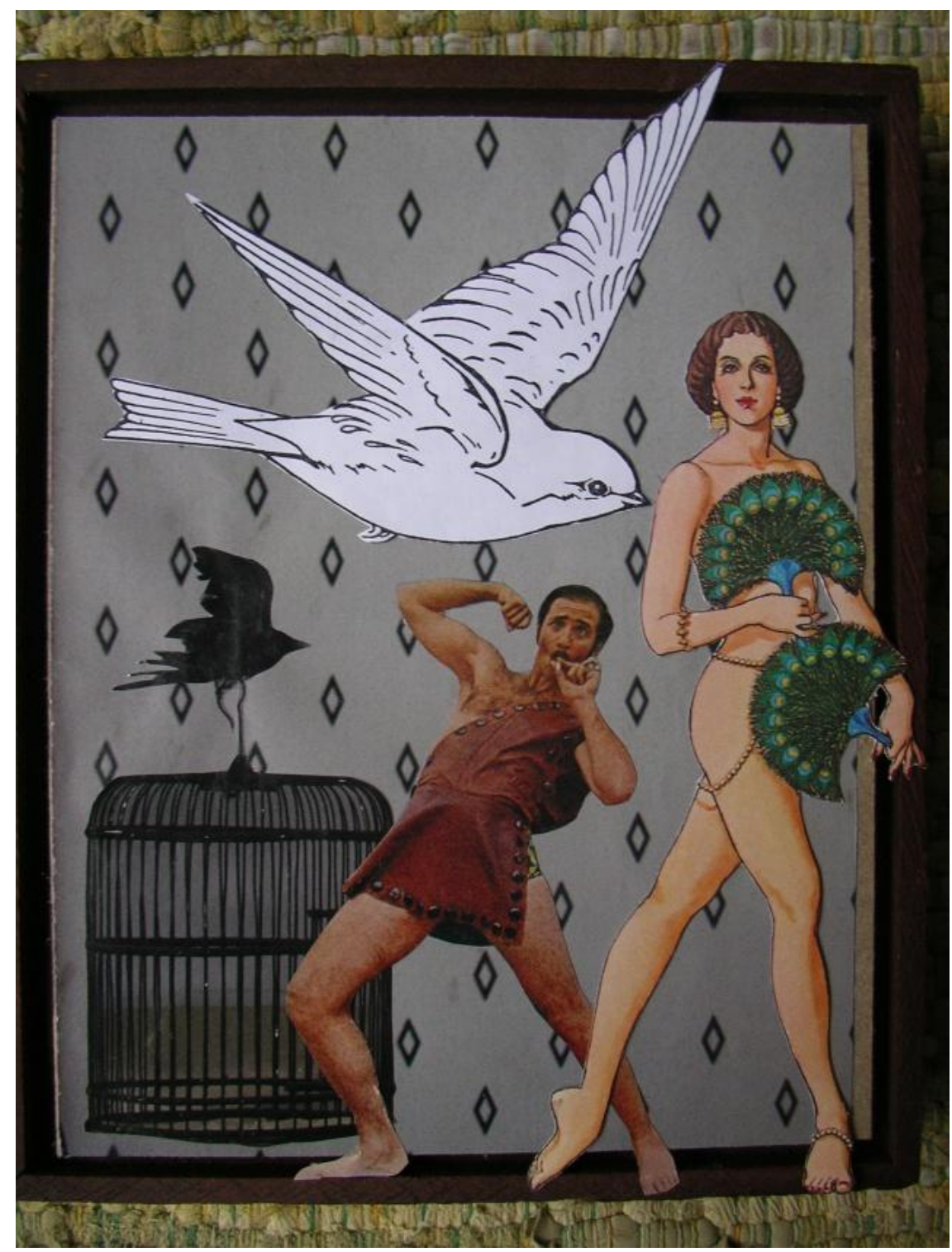

Prior to beginning this study, I spent a lot of time researching the differing feminist views and perspectives on sex work, locating my own political and theoretical perspectives within the debates, as mentioned in earlier chapters. These opposing perspectives were represented in the collage through the white bird, which symbolized the idea of sexual freedom and independence, and the black birdcage which represented the idea of sexual slavery and victimhood. While these dichotomous and opposing 
philosophical viewpoints were prevalent in the academic literature, I was surprised to see them manifesting within the community. As an advocate for the rights and well-being of sex workers, and as a community member for the neighborhood coalition $82^{\text {nd }}$ Cares $^{9}$, I attended numerous town hall meetings during the months of recruitment and trainings. I was overwhelmed with my experience in these community meetings and the ways in which the feminist debates were reenacted among the attendees.

Overwhelmingly present were the voices of anti-prostitution activists who talked about evil pimps who were forcing women into sex work and sinful "johns" who needed to be arrested for "abusing" women. I was uncomfortable with the way in which these ideas were perpetuating stereotypes of sex work and the sex industry. I included a caricature of a man in a position that displayed a sense of power and control over others. My intent was to express my own concern and fear of reinforcing stereotypes and representations of sex workers as weak, controlled and powerless within my research, even though I did not believe that this was the case. I was aware of the well-intended motives from members of differing feminist perspectives, however, I had a heightened sense of consciousness of who was speaking for whom, how important it was for me to be conscious of my power as a researcher, the weight of my words and the choices I made with representing the data, and what it would mean to "give voice" to someone, if this was even possible.

This collage also speaks to my diverse experiences with participant recruitment in various exotic strip clubs, adult video stores and other venues of the sex industry in

\footnotetext{
${ }^{9}$ The $82^{\text {nd }}$ Cares Neighborhood Coalition was formed in the summer of 2008 in response to the situation on $82^{\text {nd }}$ Ave and the expiration of PFZ ordinances. The Coalition advocated for the health and safety of sex workers and for addressing economic and social justice issues instead of using law enforcement to further criminalize women working in the area.
} 
different parts of Portland. These contradicting images against the gray background correspond to the wide range of my feelings within a continuum of extremes; from comfort to discomfort, from fascination to disgust, from acceptance to rejection. Some venues that I entered to pass out study flyers felt safe, comfortable and extremely supportive of women. Other venues felt scary, unsafe, and suspicious. Some women with whom I spoke with about the study were very receptive and interested in participating, while other women seemed disinterested. I had one experience outside of a strip club where I was yelled at and cursed by a group of four exotic dancers who I approached with a study flyer. They angrily asked me and my community partner what we were doing there, while injecting their speech with curse words to question our motives. For hours after this encounter I felt guilty and anxious and wondered about how we had been perceived by the women, and how I might have (mis)represented myself in order to elicit such an angry response. Questions that came up for me included: How could I (blindly) enter this space, shaped by socio-economic status and race, and (naively) think that I would just be accepted? What did this reveal about my own privilege? How might the different color of our skin, our social and class privilege have played a role in how we were perceived, distrusted and rejected? Would I have received the same response if I had been alone?

The title of this first collage, Possibilities for an Outsider, refers to the multitude of experiences that this project was beginning to offer and had yet to offer, my location as an outsider (a non-sex worker), and my struggle with how to present myself to the participants in order to form a connection. I was drawn to the image of the naked woman holding peacock feathers to cover her body because this image embodied my own 
internal conflict of how much to reveal of myself in the photovoice training sessions and my concern of the exposure and the possibilities of what would be revealed through this arts-based project. It also reflected my insecurity of being an outsider and how I would be perceived by the women working in the sex industry. I wanted to be perceived as "cool," hip, non-judgmental, strong, and street smart. How would I present myself to the participants as a non-sex worker interested in their stories, lives, experiences and artistic expression?

Along with my internal struggles, I felt excitement about the possibilities that this method offered. This also led me to question my own fascination with a profession that was so far removed from the current reality that I was living. I thought back to the stories my father told me about his experience living as an illegal immigrant in New York City in the 60s and 70s, and his involvement with different types of illegal work. Was I trying to understand this idea of a perceived "underworld" where an illegal economy had a life of its own? Would I come closer to understanding my father and his experiences if I studied the lives of individuals engaged in illegal work? These questions led me to creatively explore the representations of the sex industry that I subconsciously carried from films, books, media, music and stories.

While coming into contact with the participants to individually conduct photovoice training sessions, I found myself connecting with each woman in different ways. My interaction with each person brought forth a unique part of myself, and oftentimes, sides of my character that had been dormant for years since entering an academic setting, such as my experience with playing music and my own identification with a sub-culture. It was interesting to uncover those parts of myself that could be free 
and not feel confined to a sense of conservative professionalism that I sometimes felt among academics. Having grown up with a mother who closed her own business after moving to the U.S. from Greece, choosing instead to raise a family, and a father who worked in a non-professional environment as a construction worker, I was not familiar with the professionalism of educated occupations. My understanding of work was as something casual and informal, so in academia I often feel cautious and reserved. For example, sometimes I feel like the interests I am able to share with colleagues are confined to research or teaching interests related to work, as opposed to hobbies or passions outside of the academy. After conducting multiple photovoice training sessions, I began to form a way of performing; a way of presenting my self and the research study that was authentic, sincere, fluid and adaptive to each unique participant.

There was one instance that caught me off guard and led me to explore my personal style and needs as a person, not just as a researcher. After completing a photovoice training with one of the participants at a local coffee shop, I assumed that after we discussed the process, timeline, etc. that we would spend a few moments "connecting" as I had experienced with other participants thus far. For me, "connecting" usually involved an exchange of ideas, the sharing of personal information and an expressed sense of where each one of us was coming from. However, after this particular photovoice training session, the participant immediately left without engaging in any conversation beyond the scope of the study. I felt a sense of rejection and questioned whether she would contact me again or discontinue her participation in the study. Why didn't she want to get to know me? Why didn't she ask any questions? Didn't she want us to connect? How could she trust me if she didn't really get to know me? While all of 
these questions entered my mind, I realized that these were my needs of wanting to establish rapport, connection and trust; they weren't needs and values I could impose on someone or expect some to share with me. My personality and own personal needs were interacting with the researcher side of me. This tension revealed my need to be informal and friendly with the participants as a way of bridging the power inequality and sense of authority that my title and role held.

\section{Collage II: Chaotic Liberation}

The second collage that I created (figure 3) corresponded to my experience with the individual dialogue sessions, the group dialogue session, and my relationships with the participants. The images for this collage were collected over a period of a few weeks, and continued to shift in directionality and position on the frame. Some images were chosen to represent specific ideas and perspectives; others were selected as a way for me to process some of the intense emotions that surfaced from the stories and experiences shared with me in the individual dialogue sessions.

During each of the individual dialogue sessions I was led on a journey of emotions, images, and stories that presented a kaleidoscopic moment of time in the past, present and future lives of the artists. While some experiences brought laughter and joy, others made me angry, sad and fearful. I was especially affected by stories of violence and racism. Two images in particular, the Black man in the center and the porcelain female head, were included in this collage as a way for me to process my discomfort associated with the stories shared with me. I also included a butterfly holding the weight of a zebra. The butterfly, symbolizing transformation and change, carries the weight of a zebra to show the resilience and strength that I saw in each of the women. The zebra 
embodies the beauty in individuality and its distinctive stripes serve as a protective camouflage against predators.

Figure 3: Chaotic Liberation

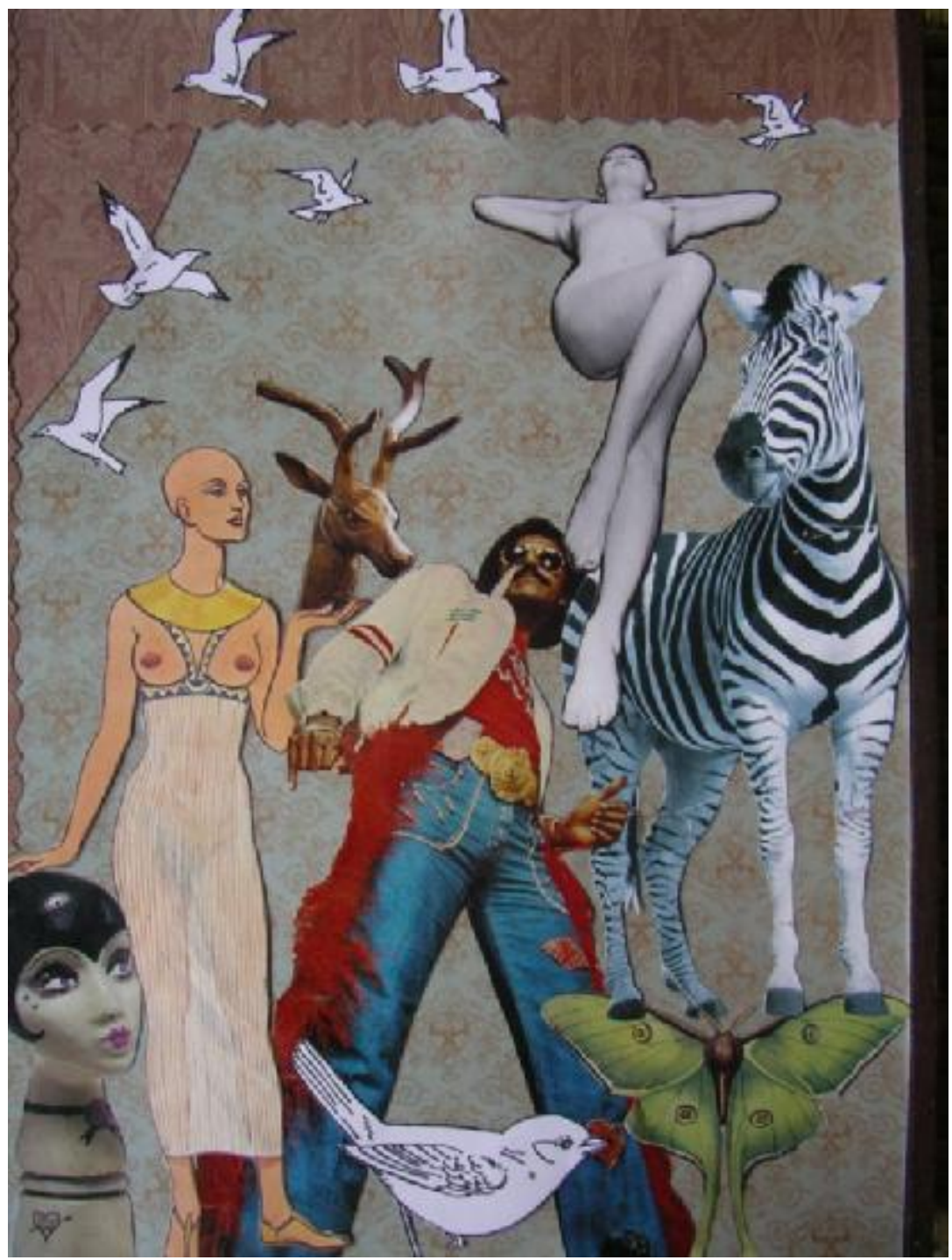

The individual dialogue sessions were especially sacred for me because I felt that I was given a gift of trust and creative expression through the artists' images and stories. I felt excitement with each new roll that was developed and eagerly shared that experience of curiosity with the participants. In these moments, I connected with many of the women as artists. In the individual dialogue sessions, when I learned about various "behind the 
scenes" occurrences at different strip clubs, among dancers, on Craigslist, and on the streets my location as an outsider no longer seemed to be a barrier to gaining trust and openness. This was a very different perspective from what I had experienced as an activist and member of SWOC. For example, an insider constitutes someone who shares a similar characteristic, role or experience with the participants. As a non-sex worker, my location as an outsider shifted as I entered the space between that of an outsider and insider, challenging this dualistic parameter. The dichotomous reference of insider/outsider locations became more complex and fluid in order to address the multiple layers and sites on this continuum.

In the collage, the curtain signified the performance we all engaged in throughout the study; for example, the roles of researcher and researched; of artist and observer; of partner and collaborator; and the performances of our gender, race, class, sexuality, abilities and status. The group dialogue session was like a center stage, where I was most challenged in my performing role as a researcher who wanted to equalize my power with the study participants. I felt that there was a power differential inherent in my relationship with the participants by virtue of my role as the researcher, we well as elements of difference by virtue or race, class, ethnicity, age, ability, circumstances and position. Prior to the group dialogue session, the equalizing of power had been theorized and romanticized, and believed to have already occurred by the nature of the methodology chosen.

This shifting of power that took place was not planned or anticipated since I had already assumed it had taken place and that as a researcher I had already taken a "back seat" in the study. I prepared myself for the group dialogue session with a research 
"agenda," but from the responses of the participants in attendance, I realized that in order to truly shift the power dynamics, I had to set my agenda aside, allow the participants to lead the group, and feel comfortable in my role. My journal notes from that day were filled with words like "chaos," "loss of control," "stress," "frustrating," and "disruptive." My efforts to create structure in the group based on what I thought I had to do as a "responsible" researcher following photovoice method protocol was met with resistance in various ways. This resistance was a space of empowerment for the artists and a location where control of the research study and agenda was (re)claimed by the participants. The various acts, occurrences and discussions during the group dialogue session that led to the natural shift in power felt disorienting in that moment in time and liberating in retrospect.

The day after the group dialogue session, five participants called me individually to discuss their experiences in the group. It was the participants who decided that a second group dialogue session should take place. While my initial journal entries identified a state of bewilderment with the turn of events in the group dialogue session, after debriefing with some of the women, the subsequent journal entries identified my feelings of liberation through the process of letting go of my power. I thought back to other moments when my power as a researcher continually fluctuated throughout the stages of research, and how it shifted into the hands of the artists when they shared their visions and voices in the individual dialogue sessions. If I hadn't had the experience of the group dialogue session, if the artists had followed my agenda, would I still be making claims of a shared sense of power among us? Did certain research methodologies always lead to the equalizing of power or was it something about those particular group 
dynamics that day that allowed for this to take place? Was there something more than just the theoretical tenents of a method or an approach that allowed this to transpire within research? I think that particular methods like photovoice that incorporate communal dialogue, provide the necessary spaces for balancing the power in a collective manner. Through the acknowledgement and understanding of the negotiation of power that occurs within research processes we can interrogate, recreate, and strengthen mutual researcherparticipant partnerships.

It is important to illustrate that during the group dialogue session there were moments when the power not only shifted from myself to the participants, but also shifted from woman to woman based on, but not limited to race, class, age, size, shape, ethnicity, experience, personality and presence. The image of the woman holding down a female head in one hand and holding up a deer's head in the other speaks to this dynamic that ensued, based on our multiple locations and shifting status. I chose the symbol of a deer, which represents gentleness and compassion for ourselves, others, and situations in life, to highlight the importance of considering how our locations and multiple identities may serve to oppress others in moments least expected.

The act of holding the deer in a particular manner, as observed in the collage, brings up the idea of ownership of the photovoice project. Throughout the research study, there were some women who were more vocal about their participation and sought out opportunities to represent themselves and the project at the various art exhibits and within the media. Other artists were equally invested yet less vocal. My community partner was also very eager to have her participation acknowledged, while I was uncomfortable with drawing attention to myself. There were times when I struggled with issues of ownership 
and wanting to emphasize that the project was "ours" while also wanting to be credited for the work I contributed. There were other times when I felt so much pride in the photographs created by the artists that I felt as if it was my own artwork on display.

The figure of the ancient Egyptian woman also raises the question and concern of how I was perceived by the study participants. One of the artists talked about her desire to travel to exotic places, and in particular Egypt, so that she could climb the pyramids. She thought that I was from Egypt and this made me wonder if I was perceived as being foreign or exotic. If so, did this make it easier to connect with me because there weren't any expectations attached to my perceived identity? These questions surfaced my need to be liked and accepted by the participants and the importance of feeling connected. This need stems from my belief in the importance of relationships for enhancing communication, honesty, openness, commitment and growth. Not only did I want to feel connected with each participant, I desired to be seen in a positive light. I wanted to be seen as trustworthy, understanding and compassionate.

While I wondered how I was viewed by some of the women, others voluntarily told me directly what they thought of me. I was fascinated, pleased and sometimes disappointed by the variety of comments. Aside from positive comments that reaffirmed acceptance, some women saw me as a "goody-two-shoes who wanted to help losers like us," a "chicken" who didn't seem like she would ever get a tattoo, and a "hippy, indierocker" that cared about social issues. Throughout the research process, I found myself wanting acceptance, desiring the label of being "cool," and admiring the sense of confidence, courage and freedom that I saw in many of the participants. I felt that being 
accepted by each artist would lead to the formation of a meaningful relationship and a deeper understanding of their life experiences.

\section{Collage III: The Wait, I Carry}

The third collage (figure 4), a series of four images, was completed during my analysis process. I created this series of collages to reflect, clarify and contextualize the different issues that I thought about through the analysis process. I painted the pieces of wood in an orange, earthy tone to symbolize the organic process of working with the data in a physical manner (i.e. moving around the photographs and the themes on strips of paper). The painted orange color reflected my excitement with having collected such a wealth of data and my immersion in the information gathered. I began to juxtapose various images on each wood panel, shifting and altering the positions of the cut-outs, then leaving them in different arrangements to see what connections would emerge over time. I wanted to present four pieces/parts as one cohesive piece of work, to represent the cross-case analysis process of working with the data. My intent was to use these fragmented pieces as one collage representation as process for understanding and exploring the multiple ways to merge and represent the findings of the data analysis.

While searching for images that captured my attention for various reasons, I found myself drawn to media portrayals of femininity, representations of sexuality, and images that reflected confidence, strength and power. These images also reflected particular stories that stood out in the analysis, while the butterflies infused in each of the four pieces characterized the transformative aspects of the multiple self-portraits presented by the artists, as well as my own transformation throughout the study. 
Figure 4: The Wait, I Carry

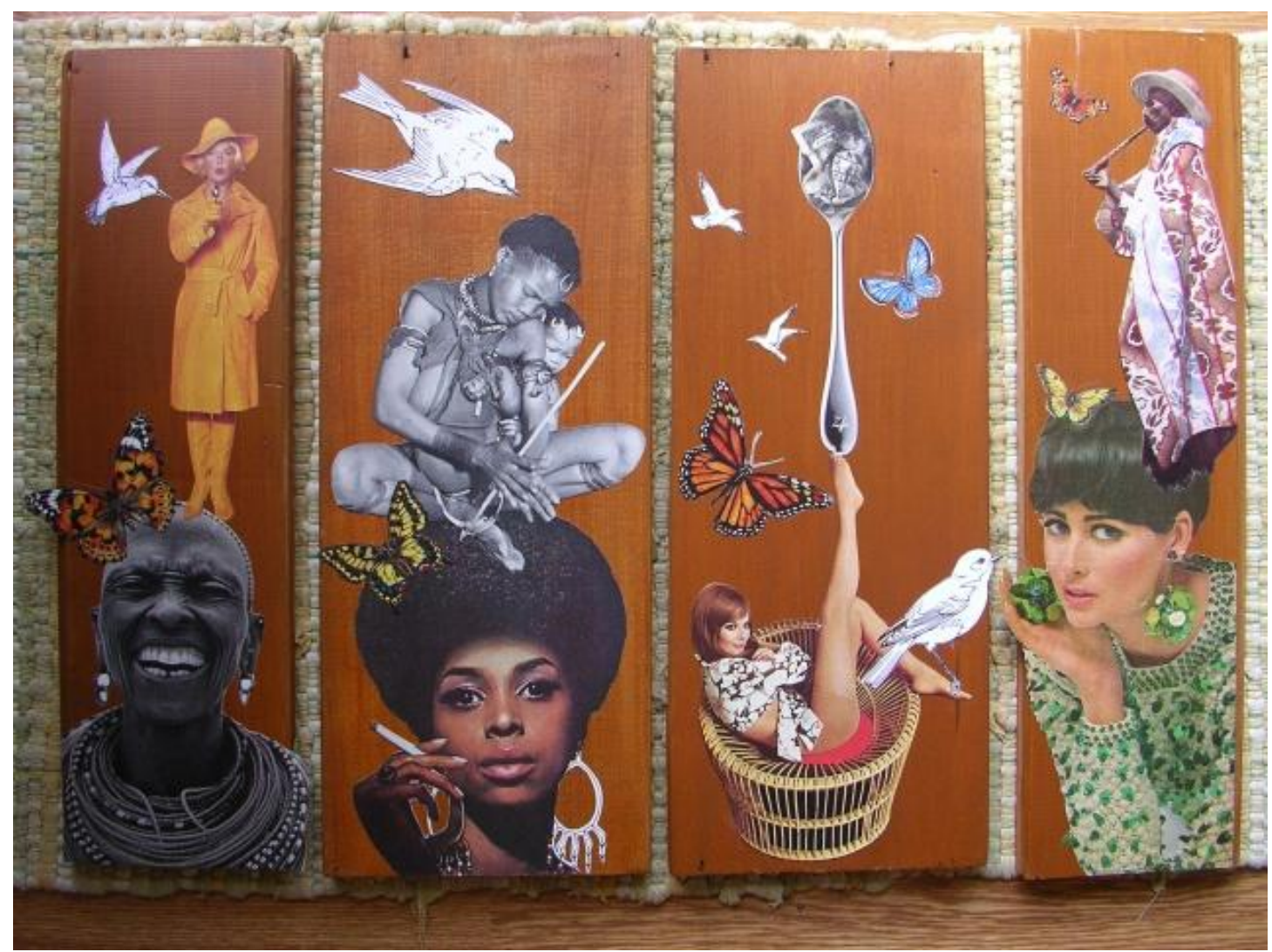

By linking the content of this collage piece to my journal notes and interpretations of the data, I realized the potential of collage as an analytic memo. Davis and ButlerKisber (1999) discuss the use of collage as a contextualizing analytic strategy that emulates "memoing" in ways that opens up the data for further insight. Upon closer look at the images in the collage and linking them to the content in my journal and reflexive notes, a few things stood out in relation to the data. The images of women represented in the collage depicted various aspects of the human condition, for example, laughter, fear, power, love, playfulness, safety and spirituality. These expressions were also reflected in the analytic themes that surfaced among the artists' photographs and stories. 
I was also drawn to the variety of clothing and accessories worn by the women in the collage. Reflecting on the collage brought to my attention to the unique clothing, or lack of clothing, that the artists wore in their own self-portraits to express certain experiences or ideas. Their individual choices in clothing were deliberate and used to tell a particular story. Some pieces of clothing were similar to costumes, depicting the performative nature of the self-portraits. Vaughan (2005) points out that clothing reflects a border between one's self and their world, between individual preferences of selfpresentation and accepted societal norms. I was intrigued and impressed by the personal choices in clothing made by the artists in their self-portraits and the ways in which the women used their clothing to challenge the social boundaries of self-representation.

This collage provided a portrait of my internalized world. Most of the characters in the collage are holding something; either in their hands, on their heads, or on their feet. These symbols of "holding" or being "weighed down" correspond to my feelings of honor and burden. I feel honored to hold the participants' photographs, stories and experiences, and sat with the data for a long time. While this allowed me to have the opportunity to revisit the data from different angles and at different moments in time, I felt burdened and weighed down with how to (re)present the participants' artwork. I didn't want to use the representational space of the dissertation to further stereotype or marginalize the artists. I felt this recurring anxiety and tension around how to represent the representations of others in a way that would honor their unique voices while highlighting their common themes in a holistic manner.

My discomfort and anxiety over issues of representation was projected onto, situated within and clarified through the collage, thus offering a sense of release and 
transparency. The collage provided an opportunity to present the tension in my research and redefine it as a chance to display the interactions between my thoughts and my artistic creations. I felt the need to explore my own inner landscapes before presenting the landscapes of others (Wattsjohnson, 2005). Through the process of creating the collage, I was able to move through my resistance of representing the stories of others and tell my own story of the research process through art. This allowed me to preserve the participants' stories connected to their images and accept the co-creation of our knowledge in the presentation of the findings. By being transparent, I was able to move forward in order to relay the collective vision of the represented needs and aspirations of the artists. In the following chapter, I (re)present the photos and voices of the women, keeping in mind the tension between the richness of the images and the depth of the text, sometimes in competition and other times in complement. 


\title{
CHAPTER 6
}

\section{PRESENTING THE ARTISTS AND THE FINDINGS}

\author{
Portraits of the Artists
}

As previously described in Chapter 3, each artist had the opportunity to write her own biography. Seven of the women (Alex, Bee, Grahm, Jasmine, Lady Purfection, Merry Mag, and Sarah) wrote their own "artist biography" and four of them asked me to write (while they dictated the contents), which I reviewed with them afterwards. The artists describe their unique traits and diversity in the following biographies below. Underneath each artist's biography I discuss my interactions with each artist, our relationship, my perceptions of her, and significant themes I found in her art.

Alex

Alex is a 33-year-old exotic dancer of Scottish-American and Indian decent. She danced her way across North America, from HI, CA, OR, WA, CT, OH, NY and all the way up to Canada. While living in California, Alex worked as a professional photographer for a rock magazine's charity benefit, Stop the violence, face the music. Alex's ultimate dream is to have the opportunity to host her own photography exhibit featuring abandoned places and things in Portland, Oregon. She is drawn to mystery, history and the original state of things. Her other hobbies include painting on photographs and writing. She is a published poet who is inspired by beautiful men. Alex has some experience with performance and acting, and hopes to pursue this when she quits dancing.

[I was introduced to Alex through one of the participants. We had the opportunity to meet numerous times throughout the duration of the study, and we soon discovered that we lived within a few blocks of each other. Our meetings took place in my home, at her workplace, and at restaurants in our neighborhood. Alex lived in a house with a roommate, but struggled to pay her rent every month. She had ten years of work experience in the sex industry. During our first meeting, Alex talked at length about her experiences at the different local strip clubs where she worked and the type of clientele that desired her "look." At the time of this study, she was working approximately 40 hours per week as an exotic dancer. She often talked about the stress of her work schedule and her lack of sleep. Alex described and photographed 
her desire to transition out of the sex industry and to pursue a college education. She held a high school diploma and her aspiration was to go to college to obtain her bachelor's degree in graphic design. She also spoke of pursuing photography and nurturing her creativity. At the time of the study, she was not in a relationship nor did she have any children, but she photographed and expressed her desire for romantic love, her need for a man, and the experience of motherhood. While she was more private and guarded than the other artists, her photographs mostly depicted the direction she wanted her life to go in. Alex did not take any self-portraits or any photographs of people. Instead, all of her images consisted of places and things. She photographed buildings, homes, trees, tires, a fence, a stairway and signs. These images represented the stability she sought in her life, as well as her feelings of loneliness and her need for love and connection with people she could trust. Alex infused a lot of humor in her photographs and experimented with different camera angles. She expressed a desire for social mobility and change, and seemed very hopeful about her future. Her needs and aspirations were framed as personal, and the only communal and societal need she articulated was not to be stigmatized, judged and stereotyped by others. Throughout the study, she emphasized her desire to find happiness and lead a peaceful existence. She emphasized her need and aspiration for faith and spirituality in her life. While Alex did not share too much of her past, she expressed not wanting to always run away from life, but rather, run towards a better life for herself. She attended the various community art exhibits and took great pride in her photographs.]

Bee

Bee is a 42-year-old exotic dancer who identifies as Caucasian. She has worked in the sex industry for the past 10 years and has an 18-year-old son. She started dancing at a young age and has professional training in ballet, tap and jazz. She was also a dancing instructor for young girls and views dancing as a form of art. Bee has many stories to tell about her various life experiences and her work in different sectors of employment. She has worked as a telemarketer, bartender, caterer, business manager, and in construction. Bee considers herself a "matriarch" in the business industry and hopes to utilize her managerial skills to open her own business. She is at the end of her career in the sex industry and aspires to return to school in order to follow her lifelong dream of working with animals.

[My first meeting with Bee was at a strip club where she worked and we spent two hours together talking. She was very inquisitive about who I was, why I was interested in the lives of sex workers, and what my views were on sex work. Bee was very talkative and we connected right away through our mutual love for story-telling. She had many stories to share of her past, including her life as a Hell's Angel "biker chick." We met numerous times over the course of the study and she often talked about how she was at a stage in her life where she was ready to focus on herself. Her son had recently turned 18 years old and was ready to pursue his own goals in life. She felt that this was the time in her life to transition out of the sex industry and 
pursue some of her childhood dreams, like becoming a veterinarian. Bee had ten years of experience working in the sex industry as an exotic dancer and prided herself in being skillful and talented, often referencing her training in ballet. She photographed her feet and described her stripping as a form of art. Bee's photographs consisted of places and things, and centered on what she needed or aspired to that would make her happy in life. While she often mentioned that she didn't know how to be happy, she photographed things that made her feel happy that she desired to bring back into her life: creativity, artwork, hobbies, sports, dreams, and working with animals. She also photographed her need to go back to college and finish her degree in order to be able to pursue another type of work. Bee photographed her aspiration to get married and her need for reciprocal romance, and exposed her ambivalence when she explained that she didn't need to be involved with anyone; that she was "done playing house." She talked at length about her experience with domestic violence, her shame surrounding her violent situation, and her distrust of the men in her life. As a cancer survivor, Bee discussed this difficult time in her life and her inability to have anymore children as a result of her surgery. She also shared that all of the money she had saved to buy a home went to her medical debt. At the time of this study, she lived in an apartment with a roommate but photographed her aspiration to own a home. Bee highlighted her accomplishments in life connected to her hard work, inner strength, survival, and resilience. She also expressed a desire to open her own business, emphasizing her organizational skills and her ability to connect with different types of people. At one of the group dialogue sessions, she brought clothes to give to the other participants and felt an affinity towards the other women. Her photographs expressed the possibilities that lay ahead for her and her need to continue to have dreams in life.]

\section{Crystal}

Crystal is a 29-year-old woman who identifies as Hispanic and White. She has been working in the sex industry for the past ten years as an exotic dancer, erotic masseur and escort for elderly gentlemen. She dropped out of high school in the $10^{\text {th }}$ grade, acquired her GED and spent one year at community college. She has aspirations of going back to school and entering the helping profession. After being in an abusive relationship for eight years, Crystal, now currently single, aspires to give back to the community by working with domestic violence survivors. She has four children (two boys and two girls) and hopes to be reunited with them once her life is more stable. Her greatest joy is the time she is able to spend with her children, family, and friends. Crystal also loves street art, such as graffiti and murals. She also has a passion for costumes and dressing up during performance.

[Crystal responded to the study flyer that she saw in the PDX Sex magazine and took great interest in the opportunity to engage in sex worker activism. We initially met at a coffee shop and then at my home. She was very polite and soft spoken, and eager to connect. From our conversations and her photographs, I felt her sense of loneliness and longing for reunification with her four children, whom she no longer had in her 
custody due to domestic violence. At the time of the study, Crystal had ended an abusive relationship and was trying to reconnect with friends and family again. Her newfound sense of freedom contributed to internal peace but continued isolation from loved-ones. She wanted to transition out of the sex industry and gain economic stability in order to have her children returned to her care. She worked approximately 20 hours a week and talked about how the economic recession had also influenced the decline in clientele. She aspired to attend beauty school since she felt that working in the sex industry could be exhausting at times due to the pressures of staying young and desirable. She also valued self-care and the need for women to be healthy. At the time of the study, she lived in a house with many women with whom she shared rent. She expressed feelings of sorrow and guilt around not living with her children, but optimistic that her situation would change. Her photographs were very personal in nature, and depicted her hopefulness and desire for continued self-improvement. She did not take any self-portraits or images of people, but rather, she photographed the places where she worked, the places where she went to relax and find peace, and those things that were important to her. Her needs revolved around her work; for instance the need to make more money by learning new pole tricks, the need to have a dependable driver for her out-calls, the need to set personal boundaries while working, and the need for support. Crystal's aspirations included owning a home, a family vehicle, staying healthy and having spirituality in her life. She expressed the importance of feeling at peace and having hope, and photographed things that represented future possibilities. Crystal attended the art exhibits and relayed appreciation for the opportunity to think about her future. Throughout the study, she shared her sketchbook with me and found comfort in creativity.]

\section{Grahm}

Grahm is a 21-year-old student, activist and stripper. She moved to Portland from a big city a few years ago. She blogs her feelings about sex workers' rights, activism, and books she likes and she is in the process of putting together a sex worker 'zine in collaboration with other like-minded folks. Grahm thinks it's fun to describe herself as a "queer feminist anarcha-stripper who voted for Obama."

[My interactions with Grahm began prior to the start of this study. We met through our community-based, sex worker activist efforts and connected through our shared experience of being students as well as politically, socially and environmentally likeminded. Grahm was immediately drawn to the study and did not accept money for her participation, but rather donated the funds to the project. At the time of the study she attended a prestigious, private university and lived in a house with a roommate. We often met for coffee or drinks to discuss her thesis research on sex work and share academic perspectives and ideas. For the past two years, she had worked approximately 15 hours a week. For Grahm, working in the sex industry was a source of empowerment and a means through which to explore her sexuality. Her biggest concern was maintaining anonymity due to the stigma associated with her work and the risks of "coming out" to family, friends and colleagues. Her concern for 
anonymity and privacy was also evidenced in her photographs; she did not take any self-portraits and the photographs she took of people did not show any faces. This was also related to her deliberate attempt to bring attention to the way in which sex workers are often objectified through body parts. All of her images centered on communal and societal needs related to one's sex worker identity. She did not photograph or share her personal needs or aspirations outside of her sex worker identity. Those needs and aspirations identified as personal were in relation to her need for an on-line community of support and the aspiration to continue to learn about her own body and sexuality. While she expressed and photographed her aspiration for a stronger activist community around stripping, she discussed this challenge and dilemma in relation to her need to stay anonymous. Grahm used symbolism to relay specific ideas regarding stereotypes and stigma of sex workers and to critique radical feminist discourse on sex work. She specifically created her own scenes and most of her photographs relayed an activist message. Some of her images were taken inside of the club where she worked to document the safety needs of strippers. Others were taken in her home. She also took a series of photographs at the park to challenge the notion of female sex workers as innocent, helpless, victims without agency. Grahm experimented with different angles (i.e. photograph taken from underneath a woman's dress) in order to highlight the voyeurism of sex workers and their depiction as vulnerable victims to be saved.]

\section{Jasmine}

Jasmine is a 31 -year-old gutter-punk ${ }^{10}$ who spent the last couple years of her life riding freight trains all across the country and meeting many interesting people along the way. She is not afraid to defend herself and also knows how to diffuse difficult situations. She has worked in the sex industry for the past ten years at an escort agency as well as on the streets. Jasmine has two children (one boy and one girl). She is "single by choice" and identifies as 1/8 Native American and of European ancestry. She currently works off of Craigslist as an escort and accepts outcalls in order to support her addiction. Jasmine hopes to pursue a career as a nature photographer. She loves animals and her dream is to work for National Geographic. You can always find her downtown with her dog, Wagner.

[I met Jasmine through another participant in the study who also identified as a gutter-punk. Since Jasmine was homeless, it was difficult to stay in contact with her at the start of the study, but once she acquired a cell phone, in order to carry out her work off of Craigslist, we met frequently. Jasmine was always accompanied by her dog, and eager to meet, connect, and discuss her life and photography. She was incredibly invested in the project and wanted to pursue a career in photography. As Midwestern teenager, Jasmine left her home and hopped trains, living the lifestyle of the gutter-punk subculture. She felt that she had a unique perspective to capture on

\footnotetext{
${ }^{10}$ A gutter-punk is a homeless or transient individual, often through means of freight-hopping or hitchhiking. Gutter punks are often associated with the anarcho-punk subculture. Gutter-punks are notorious for panhandling and often display cardboard signs that make statements about their lifestyles.
} 
film, things often overlooked by the general public. Her major concern throughout the duration of the study was her heroin addiction. This need and aspiration was often discussed in many of her photographs and dialogue about the direction of her future. She prided herself in her resilience, but often admitted to how hard her life had become, especially because she felt stigmatized and judged by society based on her gutter-punk lifestyle, her homelessness, her heroin addiction, and her work in the sex industry. All of her photographs depicted personal needs and aspirations linked to her various identities and social locations. Her images highlighted her experience of homelessness and survival, and featured her living environment on the streets and under bridges (i.e. architecture of buildings, flowers, trees, signs, camp, and railroad tracks), which she found beautiful. Jasmine also presented many self-portraits that served as a mirror for self-care and a reminder of what was important to her. These photographs affirmed her existence. She experimented with different camera angles, lighting, shadows, and reflections. Her aspirations centered on having freedom and privacy. Jasmine desired recognition, acceptance, and becoming a part of society. She aspired to contribute to society through art and activism to address poverty and injustice. Jasmine expressed her aspiration to stand on her own two feet and have stability in life that would come from addressing her addiction. She also talked about her body image issues and expressed feeling overweight and very insecure about her body. She aspired to feel confident and made efforts to accept herself through selfportraits. Her needs included housing, food, good friends, and overcoming obstacle in life. She also expressed the need for her spiritual practices, performing rituals, and ceremonial magic. Jasmine emphasized her need for good friends and feeling connected to animals. She was very open with her feelings and experiences and often initiated our meetings. She shared photographs of her children who were in the care of family members and told stories of her adventures hopping trains. Jasmine attended all of the art exhibits and continued to stay in touch after the study.]

\section{Lady Purfection}

Lady Purfection is a 23-year-old entertainer who chose to work in the sex industry because its fun and it offers an experience that you can't get anywhere else. She has worked in the sex industry for the past two years and currently works as a dancer and an escort anywhere between 40-60 hours a week. Lady Purfection identifies as Creole and Blackfoot Native Mix. She is a high school graduate with some college credits. She is involved in numerous activist projects and was recently engaged. For Lady Purfection, entertaining in the sex industry is a form of art and she aspires to be famous; not just for her sex work, but for her art. She is a spoken-word poet and a sex worker artist recently featured in Spread Magazine.

[Lady Purfection was referred to the study through a court-mandated, drug and alcohol treatment program. I met her for the first time at the group photovoice training session. She was incredibly friendly and easy-going, and involved in various forms of sex worker activism. Lady Purfection viewed her work in the sex industry as a form of art and was confident in her talents as a dancer, poet and artist. At the time 
of the study, she was living with her fiancé in different motels and working approximately 60 hours a week to make ends meet. Each time we met, she would express great frustration with her parole officer, who she felt judged her for working in the sex industry. She had to hide her stripping and escorting from her parole officer, which made it difficult for her to establish a permanent position at clubs. Lady Purfection loved performing and felt empowered and fulfilled by sex work. She emphasized that it was her choice and that all she wanted was the freedom to live her life without being judged and stigmatized. She desired admiration, compassion and respect from society. Lady Purfection's images included numerous self-portraits and photographs of the places and spaces where she spent most of her time (i.e. inside the dance clubs, on the streets of downtown, inside motel rooms, inside her car). She talked about personal, communal and societal needs. For example, she identified the need for clean, public restrooms downtown, resources/social services for people without drug and alcohol issues, and housing. Her aspirations included unconditional love (from pets), having support from her fiancé, and maintaining her faith and spirituality. Lady Purfection expressed her need and aspiration for being around calming bodies of water, like the river, as a healthy alternative to coping with life stressors and difficult situations. Her self-portraits depicted her confidence, resilience and desire to be respected and treated with humanity. She attended the art exhibits and stood with pride next to her photographs while she explained the ideas behind her images and poetry. She was also featured in an independent magazine by and for sex workers and those who support their rights. Lady Purfection proudly autographed copies of the magazine at the art exhibits and accepted an interview with a local grassroots newspaper where she talked about her experience with this photovoice study.]

\section{Merry Mag}

Merry Mag is a 52-year-old self-described "activist ho" who has been working as a prostitute doing all types of work in the sex industry (from high class escorting to working in a brothel to working off of the streets) on and off since age 13. She has struggled with addictions to heroin and cocaine, homelessness, and schizoaffective and bi-polar disorder. She has also been a successful business owner of two familyoriented social clubs. She is a highly respected leader in her community. She is a mother of two adult children as well as a proud grandmother. She is a risk-taker and is energized by involving herself in a variety of social justice movements that address issues of violence, sex workers' rights, homelessness and poverty. She is also passionate about social justice for prisoners and is vocal on human rights issues. She is a deeply spiritual woman with hopes for a special "ho heaven" where she will one day reunite with her oldest and closest sisters/friends.

[My community partner introduced me to Merry Mag who was involved in street outreach to sex workers and community activism with homeless individuals. Merry Mag had worked in the sex industry for 39 years and at the time of the study she worked a few hours a week with a steady set of clients. She lived alone in a low- 
income apartment complex and I was invited to her home on multiple occasions. Merry Mag was a dynamic story-teller and shared her wisdom from life experiences. She often wore elegant hijabs and talked about her struggles with being Muslim related to her engagement with sex work. She specifically spoke to the internal tension she felt and her desire to not shame her religion due to the nature of her work. For years Merry Mag struggled with mental health issues, drug addiction, and homelessness. At the time of this study, she was in a very stable place in her life mentally, physically and emotionally. As an independent thinker and activist she often expressed great passion about issues dealing with racism, poverty, the prison industrial complex, sex worker's rights, and child prostitution. Her photographs reflected her activist identity and the needs she identified were personal, communal and social. She often used herself in photographs to relay certain ideas. She also photographed symbols of importance in her home and artwork she had created. For example, she highlighted the need for awareness of racism, slavery, injustice, western white male privilege, poverty and ending war. She presented images of her homeless friends, symbols of oppression, body parts and important objects in her life. To depict the need for reducing stigma against sex workers, Merry Mag photographed various collages. To relay the need for ending violence against sex workers she took multiple self-portraits at a graveyard to symbolize her emotions and experiences. Her aspirations included her need to foster women specific communities, in particular, homeless women with whom she shared similar life and work experiences on the streets. Her faith was important to her, as were her dreams of love and companionship. She expressed her loneliness and desire to fall in love but felt she was undeserving of love because of her work. While she expressed the complexity of her feelings with regards to working in the sex industry, she often described sex work as a source of empowerment. Merry Mag used this study as a way of healing, to express her activist voice, and share her dreams of a better life. She attended the art exhibits and shared how meaningful the experience had been for her.]

\section{Mouse}

Mouse is a 21-year-old exotic dancer and erotic model. She is a college student studying psychology who loves to read. Mouse identifies as a gutter-punk and has spent the past few years hopping trains around the country. She likes to hitchhike and live freely. She adores dogs and their playfulness, and especially admires their carefree essence. Mouse also plays the accordion and trumpet, as music is one of her many passions. She hopes to devote her attention to playing music and being with animals once she is able to settle down and have a comfortable, stable place of her own.

[Mouse found out about the study from her friend, also a participant, and immediately contacted me. We connected the moment we met, sharing similar idealistic and romantic views of life. I found her to be very insightful and engaging, and we spent four hours together in dialogue about her photographs. At the time of the study, she was in a very experimental stage in her life and saw her work in the sex industry as a 
form of artistic self-expression and an exploration of her sexuality. This study served as a space for her to think deeply about her life and the direction she wanted it to take. Her images were very intimate and depicted her personal needs and aspirations. She took photographs of dogs to represent how she wanted to be: playful, carefree, not over-analytical, patient, and happy. Most of her photographs consisted of selfportraits with her performing her needs and aspirations based on her various, interlocking identities (sex worker, student, gutter-punk, etc.). Mouse had worked in the sex industry for 7 months for approximately 30 hours per week. Her personal needs were related to her work in the sex industry, highlighting the contradictions and complexity of sex work. For example, she expressed her need for more synthesis in her life: not having everything so compartmentalized as she depicted in a photograph of the different bags of her life (one for school, another for work, one for traveling, etc.). Yet, she also expressed the need to keep separate her "true self" from the "stripper character" she played at work. Through a series of images, Mouse identified her need to meld together love and romanticism in her life, simultaneously challenging her own perceptions and separation of the two with regards to her work. Another need photographed by Mouse was to not be stigmatized, judged, and looked at as a piece of meat. She expressed the need to be respected and admired at work and to be recognized as a human being with a life. Mouse identified her aspiration to challenge ideas of beauty by viewing stripping as a form of art. Her aspirations also included having more balance in her life, personal growth and privacy. Mouse's selfportraits presented herself in action, as she illustrated her aspiration to do more seemingly spontaneous things in life and to be fearless and able to dive into the unknown. She identified things that were both a need and an aspiration, like quitting heroin, continuing to play music, and completing college. She used a lot of symbolism in her photographs and created her own scenes. Mouse's thoughtfully crafted images represented her desire for new experiences, self-exploration, and a search for a deeper understanding and direction.]

Rizzo

Rizzo is an 18-year-old gutter-punk who has worked in the sex industry for the past two years. She has her GED and attended some business classes in web design. Rizzo identifies as white and is currently single. She currently works approximately 20-30 hours per week through Craigslist by posting for outcall escort services. She has no tolerance for violence and has an immense passion for cooking. Her dream is to attend culinary school and work as a chef once she receives treatment for her addiction to heroin. Rizzo also aspires to travel around the world with a backpack.

[Rizzo contacted me the same day that the study flyer was featured in the PDX Sex magazine. I met her downtown where she waited for me at a coffee shop with a friend. She did not seem to want to know much about me or engage in discussion about the project, but rather, was eager to get started taking photographs. While we did not have lengthy, intense interactions, we met on multiple occasions and checked in with each other throughout the duration of the study. I felt accepted and trusted by 
her as she introduced me to three of her friends who also chose to participate in the project. Rizzo had worked in the sex industry for two years after running away from home to escape a violent situation. She was very guarded with her emotions and offered limited self-disclosure, strictly addressing her needs and aspirations for the purpose of this study. Her images did not reveal her current living and working situation, but rather focused on presenting ideas in the form of photographs for addressing personal and communal needs and aspirations. She did not take any selfportraits. Aside from an image of her feet and one of her dog, most of her photographs consisted of things in her environment, specifically, different types of signs with words on them that expressed a particular need or aspiration. The photographs that depicted her needs focused on her lack of access to resources, homelessness and addiction. For example, she expressed her need for basic resources for survival such as water, food, restrooms, shelter, transportation, and clothing. She also photographed various objects to relay communal needs, including clean needles, mailboxes, beauty services specifically for sex workers, and job centers. Her photographs advocated for the implementation of specific social services to improve her current life circumstances and that of other women working in the sex industry. She also photographed a knife to highlight the need to address violence against sex workers and the stigma attached to sex work. Rizzo's aspirations focused on future career opportunities, learning new skills, and pursuing her dreams. She was passionate about discovering her strengths. She expressed her aspiration to attend culinary or cosmetology school. Rizzo also expressed a desire for stability in her life and addressing her heroin addiction. Other aspirations revolved around her identification with the gutter-punk sub-culture such as traveling, backpacking and hopping trains. The majority of Rizzo's photographs represented her hopes and dreams, and there were many times when she talked about her desire for change, growth and stability. Rizzo spoke of her situation as being temporary and contingent upon her addressing her addiction and getting her life back to "flowing smoothly."]

\section{Rogue}

Rogue is a 30-year-old woman who identifies as Indian. She is happily married to a man who is her greatest support in life. Rogue met her husband on the bus after going home from band practice where she was the lead female vocalist. After making eye contact and wonderful conversation, she instantly fell in love with him and has been happily married every since. Rogue currently engages in street work and works off of Craigslist in order to support her heroin addiction, but states that she does not want to keep doing this work any longer. Rogue completed the 11 th grade and proceeded to work as a dancer shortly after high school. She has four children ( 2 girls and 2 boys) who do not live with her but hopes to be reunited with in the near future. Her dream is to open a family restaurant where she can be the chef and where kids can do karaoke.

[I met Rogue through another participant who was also living on the streets at the time of this study. We met a total of four times and when we first met, Rogue did not look me in the eyes. She was very ashamed and explained that she did not like having 
to engage in prostitution. Rogue also shared that she hated having to keep her work a secret from her husband. She often talked about how much she loved him and how she would be lost without him. I had the privilege of meeting him and also seeing him depicted in her photographs. Rogue had worked in the sex industry for nine years and at the time of the study was working approximately 20 hours a week. She expressed unhappiness with her lifestyle and talked about her desire to have her children (from another marriage) and her husband's children returned to them once they were more stable. Rogue aspired to a middle-class lifestyle, as evidenced in her photographs that depicted nice houses, new automobiles, and expensive objects in storefront windows that she desired and longed for. While many of her needs were related to survival (shelter), she photographed expensive things (a Victorian home) to represent these needs, in addition to less expensive, more attainable objects (a tent). She presented self-portraits, images of her husband and friends, as well as buildings, and signs around the city. Through her photographs of different objects, Rogue expressed needs related to survival such as water, food, shelter, transportation, clothing, and eyeglasses. She also expressed the need for stability by photographing a tree and the need for protection by presenting an image of her dog. She strongly emphasized her need to not be judged, stigmatized and stereotyped. Rogue became very emotional when describing being stigmatized and treated poorly. Some of her images depicted both a need and an aspiration, and were emphasized as crucial in her life; such as having good friends, her husband, as well as having strength and confidence in herself. Rogue had dropped out of high school and identified her aspiration to attend college. Her dream was to manage a karaoke restaurant for children. Additional aspirations included pursuing art and music, traveling, and attending football games. In a selfportrait, she represented her desire to never again have to wait for a client. Rogue shared that she was raised Mormon, but while she did not necessarily belong to the church anymore, she wanted faith and spirituality back in her life. After we met to discuss her photographs, she explained that she did not want to attend any of the art exhibits and preferred to discontinue contact. We met once more after the first art opening, at her request, but have since ended contact.]

\section{Sarah}

Sarah is a 37-year-old Euro-American street worker who loves getting crafty and creating art. She completed a few years of college, majoring in art and psychology. She comes from an educated, middle class family. Sarah has traveled throughout the U.S. and her experiences include working as a bike messenger in San Francisco and as a fisher in Alaska. She has many hobbies and passions, including craft-making. Sarah has struggled with addiction for more than 20 years and has a lot to say regarding the war on drugs and the ways in which our society treats individuals with addictions. She has worked in the sex industry for 11 years and is an outspoken activist for ending police violence against sex workers. This photovoice project has inspired Sarah to pursue photography as a hobby. Sarah dreams about being an art therapist or studying international business and world affairs. 
[Another participant referred Sarah to the study, but it was a few weeks before we were able to connect due to her health issues and associated pain. Our initial meeting took place at her mother's home where she was living at the time of the study. We met there several times, as well as at my home, when she was able to coordinate transportation with her medical driver. Sarah had engaged in street work for the past 11 years and had many stories to tell of her experiences with homelessness, addiction and violence. She was very outspoken about the stigma and mistreatment she had experienced by the police. Sarah was a strong advocate for sex workers' rights and the legalization of sex work. She talked about her resilience and emphasized that regardless of her negative experiences on the streets she did not identify as a victim, but rather, felt empowered as a sex worker. Sarah identified personal, communal and societal needs that centered on her compassion for other sex workers on the streets, her sisters. She photographed her need for shelter/housing, food, drug rehabilitation, public bathrooms, and quality health care. Even though her living situation was stable at the time of the study, it was only temporary, so her needs addressed past experiences and the challenges she still faced. Sarah's photographs consisted of places, things, people, and pets. She did not use herself in her photographs, but did take a picture of herself with her mother to discuss their complicated and strained relationship. She presented a series of many photographs addressing the need for safety, protection, criminalizing predators (not sex workers), and paying tribute to her murdered sisters. Sarah identified the aspiration for society to have compassion for sex workers and her personal need and aspiration to address her drug-addiction. Her photographs reflected the various challenges she experienced when living on the streets and the struggles she continued to face. She was also passionate about addressing racism and spoke at length about feeling judged by others while being in an interracial relationship. Sarah talked about the importance of faith in her life and the value it had for helping her through difficult times. Her photographs consisted of people and things she appreciated in life, like her pets and her best friend who was her medical driver. Sarah was so excited about the opportunity to photograph her needs and aspirations that after she shot her initial roll of film she bought an additional roll of 24-exposure film on her own to document more images that were important to her. This study inspired Sarah to save money to buy a nice camera in order to pursue photography.]

\section{Overview of Photographs and Themes}

The artists took their black and white photographs inside and outside, with and without the use of a flash. They experimented with different ways of framing, depth of field and the use of various camera angles. The subject matter consisted of people, places, things, and animals. Photographs were taken at various locations, inside homes, at parks, 
in hotel rooms, on the city streets and in different exotic dance clubs. The artists photographed friends, family, partners, co-workers, and street people. Eight of the women included themselves in their photographs. Seven of the artists photographed their dogs. The different objects or things the women photographed most often were buildings, signs/words, money, bags, needles, clothing, shoes, trees, flowers, bridges, and bodies of water. The artists documented various aspects of their lives, photographed their desires, and created their own scenes to represent concepts they wanted to share.

I asked the participants to photograph their personal and community needs and aspirations. In their individual dialogues sessions, the artists identified a need as a lack of something they wanted or deemed necessary arising from circumstances or a specific situation. Some women also identified a need as pressing and urgent. A need related to survival was often prioritized over an aspiration. The ways in which the artists defined a particular need were related to their social location, access to resources, race, class, age, experience, level of education, and the conditions of their work, among other factors related to participant diversity. The artists identified an aspiration as a vision, hope, dream, desire (to achieve or have something), a want, a longing, or an ambition. For some artists, an aspiration was also conceptualized as an inspiration or a motivation.

In the individual dialogue sessions, the artists discussed their needs and aspirations on three different levels; personal, communal and societal. A personal need or aspiration was related to the individual artist. A communal need or aspiration pertained to other sex workers and other communities of sex workers in Portland. A societal need or aspiration was associated with the general public living in Portland and sometimes generalized to all people living in the United States. Communal needs and aspirations 
depicted in their photographs referenced some type of advocacy for other sex workers (or communities of sex workers) or other marginalized groups in society.

I initially thought that there would be a clear distinction between photographs related to needs and photographs related to aspirations; however, the expressions of participants' needs and aspirations surfaced in complex ways. The needs and aspirations identified by the artists were not mutually exclusive experiences or desires, but rather intersecting and mediated by the artists' social location, working conditions and other aspects of self. For example, a need for one artist was sometimes an aspiration for another. Some women took photographs that were simultaneously a need and an aspiration. Analysis of the data surfaced six recurring themes with relation to the artists' needs and aspirations.

1. Sustainability of the Body

2. Nourishment of the Heart

3. Fostering of the Mind and Soul

4. Social Justice and Activism

5. Dreams and Desires

6. Self-Empowerment and Identity

These themes represent and speak to the humanity of the artists as diverse, creative and politicized individuals with dreams and desires. Within these six themes, sub-themes emerged that represent a specific emphasis on each of these themes. Representation of needs and aspirations varied between individuals and within their photographs and varied in terms of priority (high or low) across artists. For example, those artists who had the least access to resources expressed a high priority for survival needs. The funnel below (figure 5) helps us conceptualize the continuum of needs and aspirations. 
Figure 5: Continuum of Needs and Aspirations

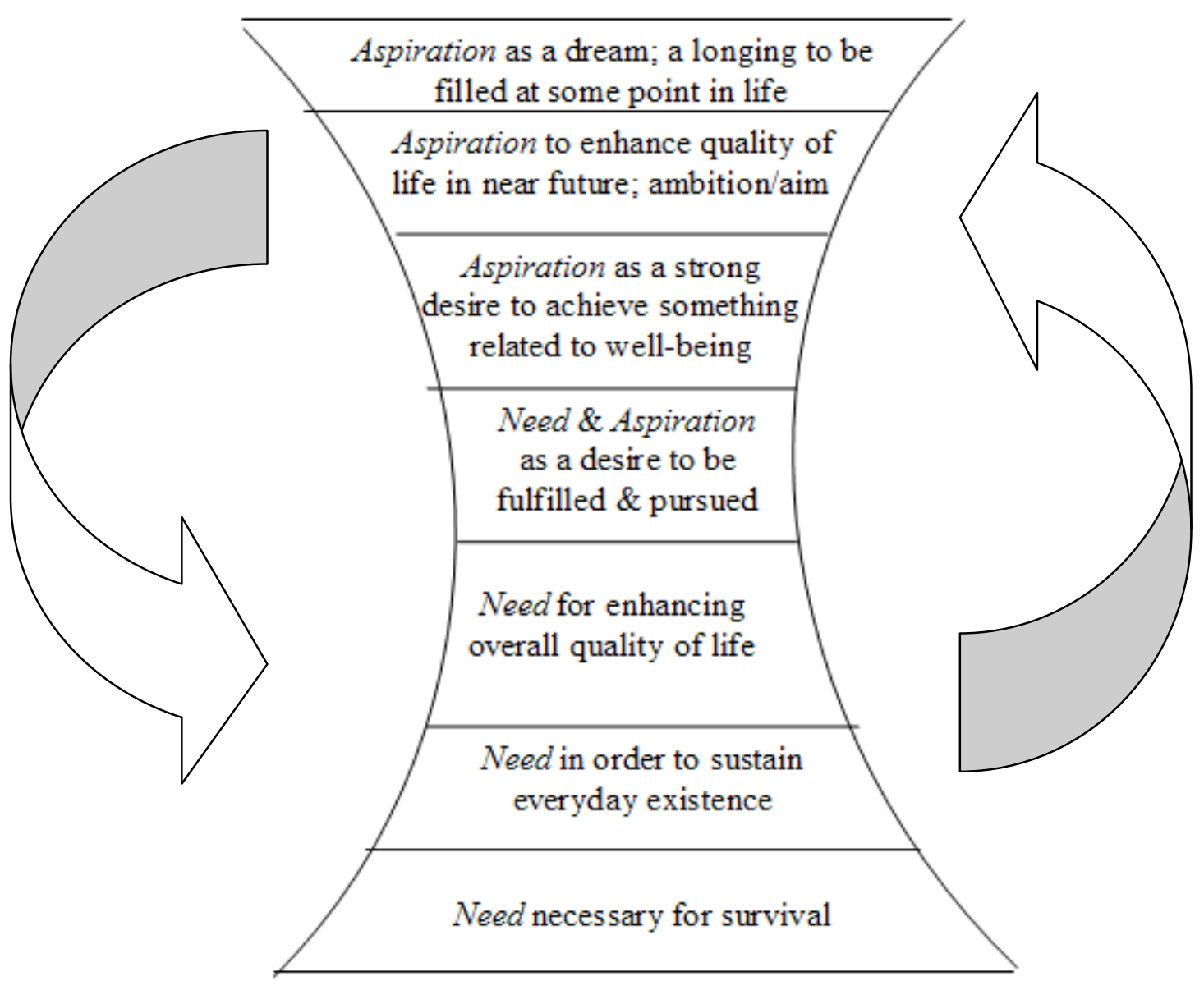

An artist's social location typically informed how she identified, articulated and prioritized a need and/or aspiration. The tree diagram (figure 6) symbolizes the holistic, organic and multi-dimensional nature of the six themes. The funnel diagram (figure 5) was created in the shape of the tree to be placed on top of the tree diagram below as a diaphanous layer, as an additional level of understanding the ways in which needs and aspirations emerged, blended together and were expressed differently for each artist. The arrows on both sides serve to emphasize the fluid continuum of needs and aspirations, as opposed to a hierarchy or top down model. 


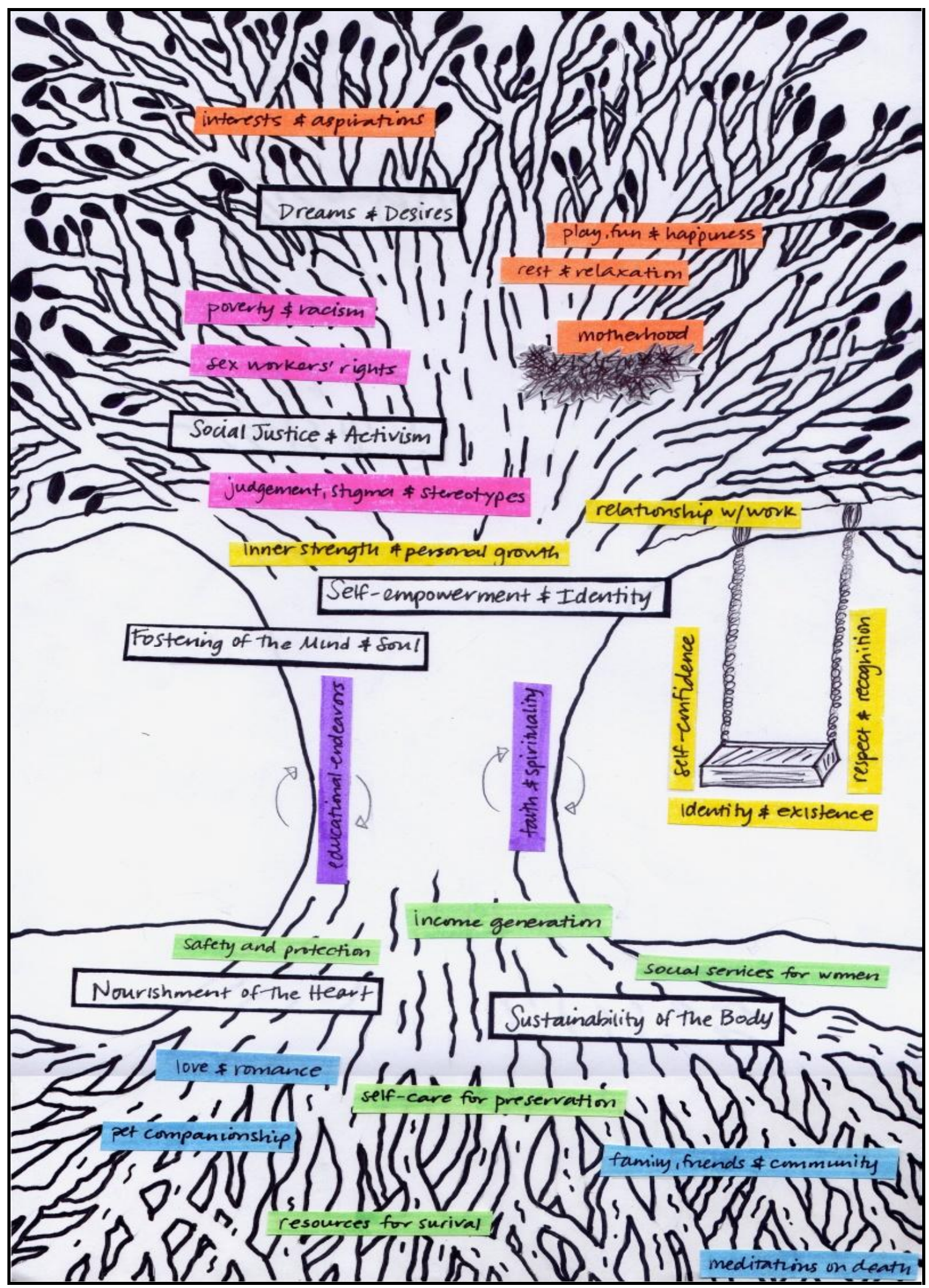

Figure 6: Visual Representation of the Themes of Needs and Aspirations 


\section{Artistic Representation of the Six Themes}

I chose to visually represent the themes through the symbolism of a tree, paralleling my artistic representation of the analysis process and illustrating the multidimensional nature of the findings. The six themes (and sub-themes) were mapped on a tree to represent the diversity of needs and aspirations and how the participants prioritized them. I chose this symbol because it stands for growth, resilience, strength, and potential, as observed in its trunk, grounded roots, and intricate branches.

The first theme, Sustainability of the Body, is represented by the tree roots, as the life-line and foundation. The sub-themes include: (1) resources for survival- expressed by those artists with the least amount of resources; (2) social services- placed as part of the solid ground that provides support to its community members; (3) protection and safetycloser to the outer roots and potentially affected by the environment; (4) self-care for preservation- as part of the trunk; and (5) income generation- important for sustaining everyday existence.

The second theme, Nourishment of the Heart, is represented by the soil. The subthemes include: (1) love and romance; (2) family, friends, and community; (3) pet companionship; and (4) meditations on death. Needs and aspirations under these subthemes enhanced the overall quality of life for the artists. The soil was used as a metaphor since it is rich in nutrients, representing loyalty and support.

The third theme, Fostering of the mind and soul, is symbolized in the trunk of the tree as education and faith. The sub-themes include: (1) educational endeavors; and (2) faith and spirituality. The trunk represents strength and resilience, the possibilities for a stronger future, and the enhancement of self. The arrows show how both education and 
faith can be found from within or from one's environment, for example, through an institution like school or church.

The fourth theme, Social justice and activism, is signified in the branches of the tree. The sub-themes include: (1) sex workers' rights; (2) poverty and racism; and (3) judgment, stigma, and stereotypes. Their socio-political agency and activism is represented in the branches; as a growing extension of their need for dignity, justice and social action.

The fifth theme, Empowerment and identity, is represented by the branches and a swing hanging from the tree. The branches incorporate: (1) inner strength and personal growth; and (2) the artists' relationship to work. The swing, constructed to hang from a stronger branch, corresponds with the idea of identity as constructed, fluid and complex. The swing incorporates the sub-themes of: (3) identity and existence; (4) self-confidence; and (5) respect and recognition. These are sub-themes that the artists related to different areas of their work. The growing and expanding branches symbolize the individuality of the artists and the different directions and paths of their lives.

The final theme, Dreams and desires, is embodied in the leaves of the tree, the blossoming of the artists' talents, skills and dreams. The leaves stand for the sub-themes of: (1) play, fun and happiness; (2) rest and relaxation; and (3) interests and hobbies. The bird's nest was created to symbolize the artists' unique connections related to their needs and aspirations of (4) motherhood.

The women captured their needs and aspirations in their photographs through the use of self, use of bodies, emotions, imagination, intellect, humor and storytelling. In the following sections the themes are discussed and supported with the participants' 
photographs, titles, captions and statements taken from their individual dialogue transcripts. Some artists chose to write their own poetry to accompany their images.

All of the participants chose to share every one of their photographs along with a description of each photograph. While the artists assured me that they wanted their photographs and descriptions of needs and aspirations shared, my ethical dilemma centered on how to accomplish this in a manner that accurately (re)presented their art and text. To achieve a level of faithful representation, the following images and text are presented in their natural state; for example, the photos as taken by the participants (untouched other than cropping as directed by the artists and blurred faces to maintain confidentiality for one artist who did not want her face shown) and verbatim excerpts from the transcripts (occasionally abbreviated for the sake of clarity). I attempted to equally represent the images and voices of all the artists as best as possible.

From my position as an arts-based researcher, I chose to present the artists' visions and voices in a way that centers on the participants' analysis of their art, a method consistent with the photovoice methodology (Wang \& Burris, 1997). The participatory aspects of the photovoice method highlight self-representation, the "subjectivity of the photographer," and the opportunity for participants to engage in dialogue about their art (Newbury \& Hoskins, 2008, p. 234). While the themes organizing the women's photographs in this chapter are a result of my analysis and of their analyses, words and art, I am mindful of my analytic voice and its potential to overshadow the artists' verbal and visual representations of themselves, their lives, their needs and aspirations. 


\section{Presenting the Findings}

\section{Sustainability of the Body}

Five sub-themes surfaced associated with Sustainability of the body that further illustrate the care of their own bodies, the bodies of other sex workers, and the bodies of other members of society. The first sub-theme, resources for survival, speaks to the women's experiences of homelessness and articulates their personal, as well as communal and societal, need for water, food, clothes, and public restrooms. Depending on each woman's living circumstances, the artists expressed their need for shelter and transportation differently. The second sub-theme, social services for women, represents personal and communal needs for a variety of services. The third sub-theme, safety and protection, includes photographs related to working conditions. Street workers, escorts and exotic dancers expressed different needs and aspirations for safety and protection. The sub-theme, self-care for preservation, incorporates the artists' personal needs to take care of their health by addressing drug addiction/abuse and exercise. Privacy and solitude reflects the personal need and aspiration for the women to have privacy and time alone. The final sub-theme, income generation, represents the personal need to keep making money and the personal aspiration to save money to survive. The photographs representing the artists' needs to work in order to sustain a certain lifestyle varied depending on the type of work each artist engaged.

The common thread within the five sub-themes is the importance of sustaining the human body. This theme speaks to the importance of attending to one's body and the interconnectedness of the body to other aspects of one's life, such as physical and mental health, safety, environment, and economics. 


\section{Resources for survival.}

The artists with the least amount of access to resources identified needs related to their biological sustainability (water, food, shelter, clothing, and restrooms). Those women that did not have to worry about their daily survival associated these needs with other areas of their life, including the need to eat with others, the need to experience community through food, the need for bathrooms as a form of human dignity, and the need for shelter to have independence. For these artists, the need for housing and transportation was related to improving their living situation, not necessarily for survival.

\section{$\underline{\text { Water }}$}

The need for water was expressed through photographs of water fountains downtown. Rizzo said, "I took one of the water fountains "cause they turn the water fountains off at night. It would be nice to have them kept on longer 'cause I fill my water bottle up at night before I go to camp." Rogue's photograph of a fountain downtown (figure 7) echoed Rizzo. She asserted her need "to never be thirsty and always have something to drink. That's why I took that picture. You need to drink water to survive. You don't need juice or soda, you need water. Without water you die of dehydration."

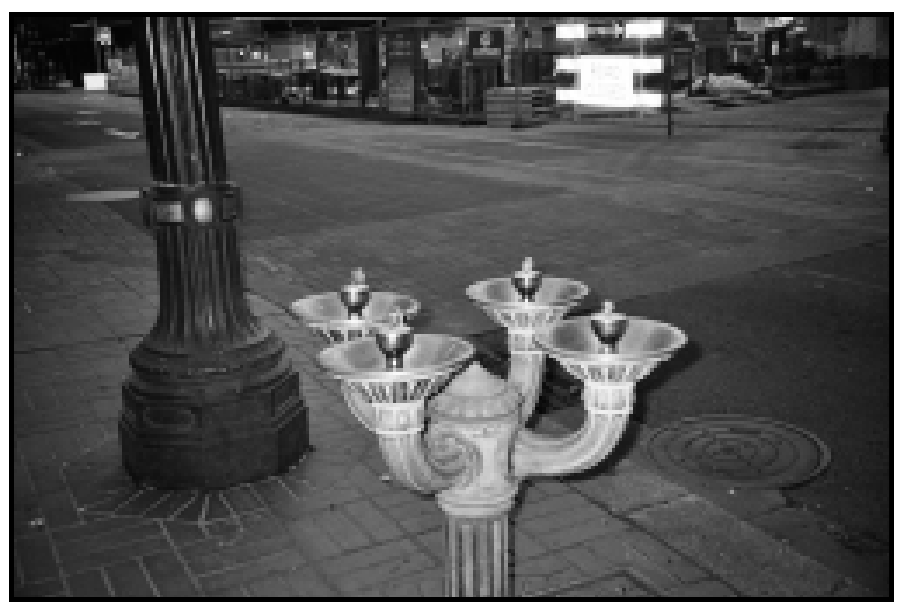

Figure 7: Untitled. 
Food

Some of the participants expressed the need for food and simultaneous

circumstances including poverty, having to work during "feed" hours, and prioritizing drugs over food. Rizzo, Rogue and Jasmine, all homeless at the time of this study, described their need to eat more often. Rogue photographed a stocked refrigerator at a convenience store (figure 8) and explained, “Everybody needs to eat, everybody. I don't care who you are... Sometimes its 2 to 4 days before I eat. Usually the only time I ever really good is the beginning of the month, because we get food stamps."

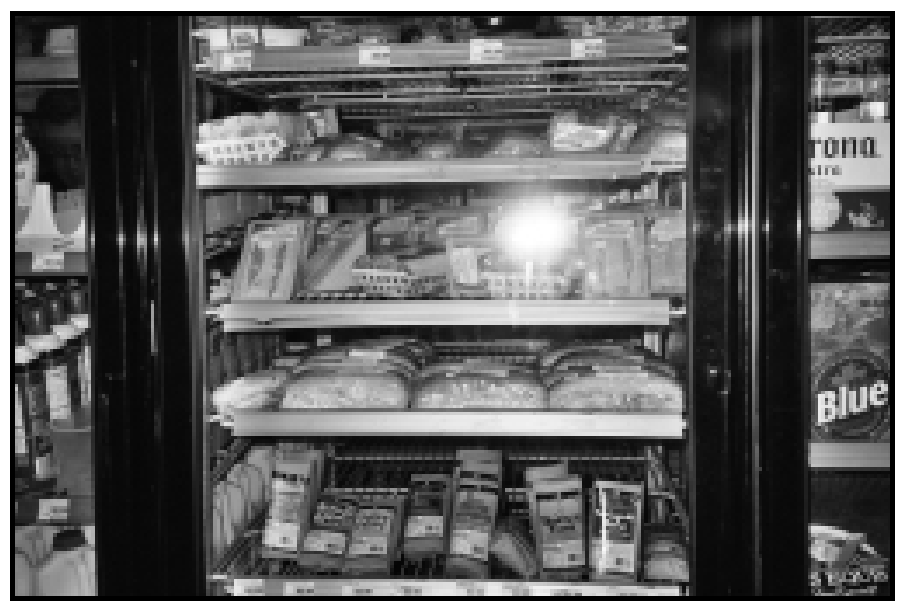

Figure 8: Untitled.

In describing her personal and communal need for food, Rizzo suggested that

organizations provide take-away lunches.

That's a need 'cause its hard to get food, especially on Saturdays when there aren't feeds. Mostly at night it's hard to get food 'cause I'm meeting clients, so sometimes I don't eat because I have to support my habit and I usually don't have enough to eat. I've lost so much weight since I've been out of jail. This is my second pair of pants that have gotten too big on me and fallen off...there should be more services, drop-in centers maybe, where's there's food available or even sack lunches where there's different times of the day you can go get a sack lunch.

Jasmine photographed a bag of candy to represent her need to eat healthy food instead of prioritizing of sweets. Sarah also spoke about her personal need to eat and stay healthy. 
She was living with a relative at the time of the study, but often found herself staying in hotels or on the streets. She photographed a cupboard with food and talked about how her drug use prevented her from prioritizing food in her life. Reflecting back on when she was homeless, she shared:

When I was out there, I never ate, or I ate just crap- you know, like candy bars, or soda pop from the store so I was really underweight. It kinda goes along with the need to stay healthy and to eat, to have food. Every human deserves to be able to eat. And, you know when you're a drug addict, most of your money goes toward your drugs, you don't want to spend your money on food, so you get the cheapest crappiest food you can.

For those participants whose living situation was stable (either living in low-

income housing or a shared apartment) the need for food was linked to community and communal eating. Merry Mag connected her personal and communal need for food through empathy and care for others. Like Sarah, she also photographed shelves of food in her cupboard at home (figure 9) and recalled:

I just remember being so hungry. I haven't eaten one thing off the top of this shelf. I just like lookin' at it and knowin' I have it...I give it to different people...

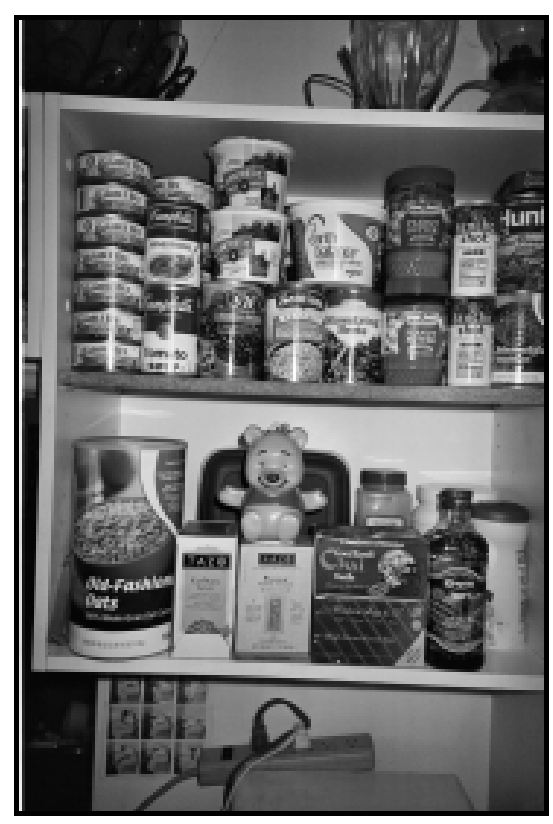

Figure 9: Untitled. 
Merry Mag relayed her appreciation of having food since she experienced homelessness and hunger in the past. She also talked about her desire to share food with others who were less fortunate and living on streets. Merry Mag spoke about her feelings of loneliness now that she is clean and sober and no longer living on the streets. For Merry Mag, the homeless community was like her family and a series of her photographs centered on the sisterhood and support she received when she was homeless.

Mouse also associated food with community. She presented a self-portrait and photographed her friend's kitchen (figures $10 \& 11$ ) to express her need and desire to experience cooking with others. She identified her need and desire to incorporate communal cooking and eating in her life by photographing the space where cooking and eating takes place, in contrast to other artists who photographed actual food.

Thankfully food is a need that I don't have to be too concerned about, but... I need to experience cooking food and for me, cooking food is a very social thing. I don't really cook in a kitchen unless I am cooking with other people or for other people...So, it's the need for food in a more wholesome, fulfilling way.

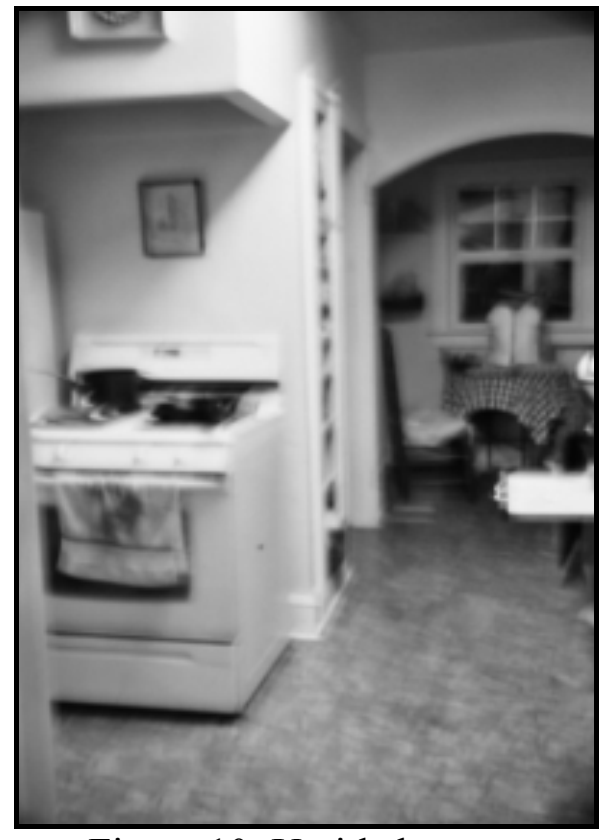

Figure 10: Untitled.

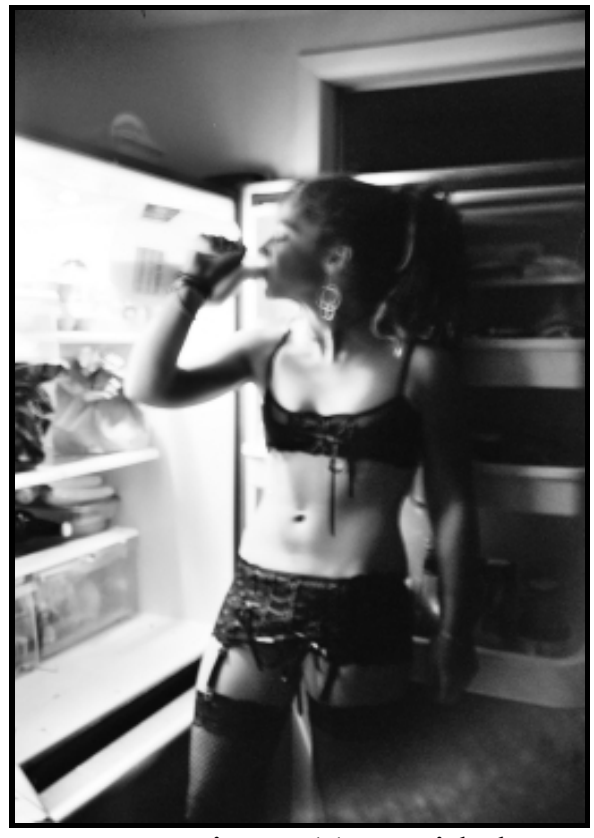

Figure 11: Untitled. 


\section{Clothing}

Those women experiencing homelessness expressed a need for clothes. Rizzo took a photograph of socks (figure 12) and a jacket through a shop window to represent her clothing needs.

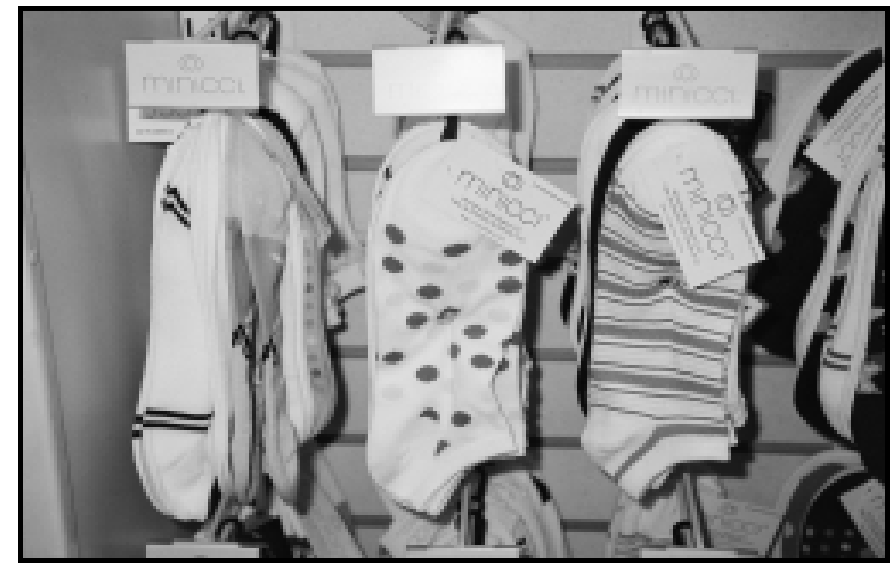

Figure 12: Untitled.

I took the picture of the socks and coat because its wintertime coming up and I need socks and a coat. I am sure other girls need winter wear, definitely. Especially ones who have a habit and are probably not going to spend their money on winter wear. I know that it sucks to be soaking wet and a lot of times. Clients don't want to see you if you're fucking soaking wet you know...they don't like that. I'd be nice to be able to maybe have a clothing closet or something like that if there ever was a day center.

Similarly, Rogue photographed mannequins in a store window (figure 13) to represent her need for clothes and shoes.

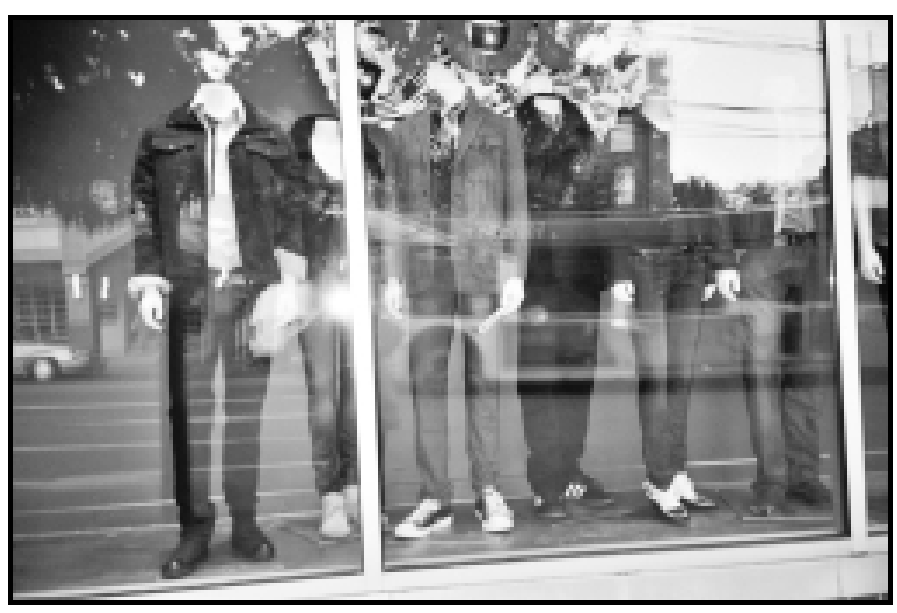

179 
Figure 13: Untitled.

She talked about how she tried not to "look homeless or dress homeless," always carrying a brush with her everywhere. Rogue explained how her appearance determined whether she would have access to restrooms in grocery stores or other places, since the public restrooms weren't open 24 hours.

\section{$\underline{\text { Restrooms }}$}

Many of the artists verbalized and photographed the personal, communal and societal need for restrooms. The exterior and interior of public restrooms, portable toilets, and restroom signs depicted this need. Sarah, engaged in street work, took a photograph of the inside of a public bathroom downtown (figure 14). She articulated the multiple uses of a public bathroom and shared a story from her past.

This is the bathroom. Everyday we would stay up all night and then work. My boyfriend would sell drugs, and then we'd sleep in the park in the day, and then when I woke up in the evening, I would come into this very bathroom, to get well, to fix, to do my drugs, and then to get ready to go out and work - disgusting, isn't it? And the bathrooms all over town-that's what people are doing. Also women do dates in these bathrooms. I've done a few dates in this very bathroom myself, it's disgusting.

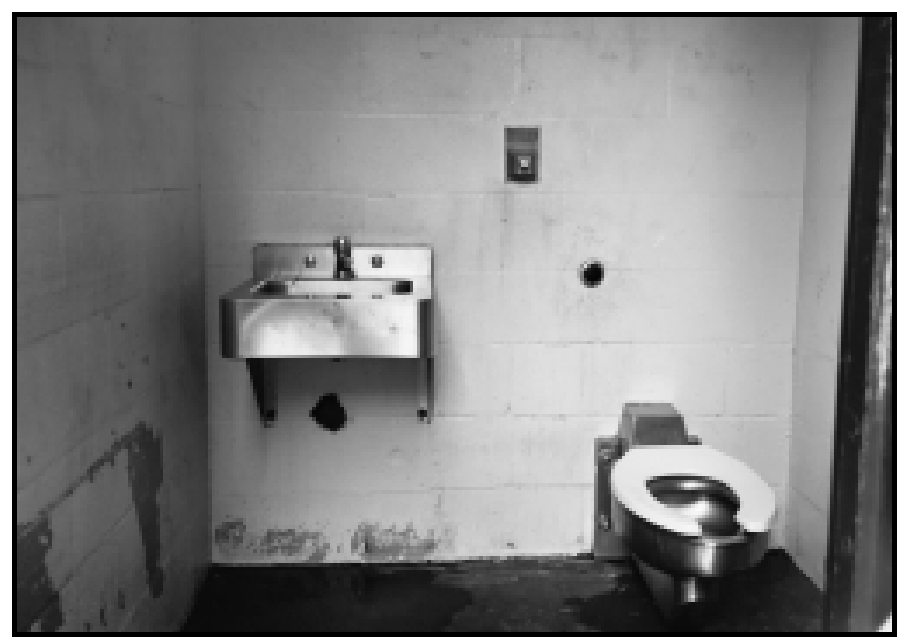

Figure 14: Shooting gallery, office, beauty salon, motel room, and also, surprisingly, just a bathroom. 
Rogue also photographed the inside of a bathroom (figure 15). She pointed out the need for more public restrooms and stated with frustration,

When you live on the streets, finding a bathroom is like finding a needle in the haystacks. Because the public bathrooms that they have out here, they close them at 10 or 11 o'clock, so those of us that are homeless have to squat in the bush. And I don't necessarily like doing that. I really don't.

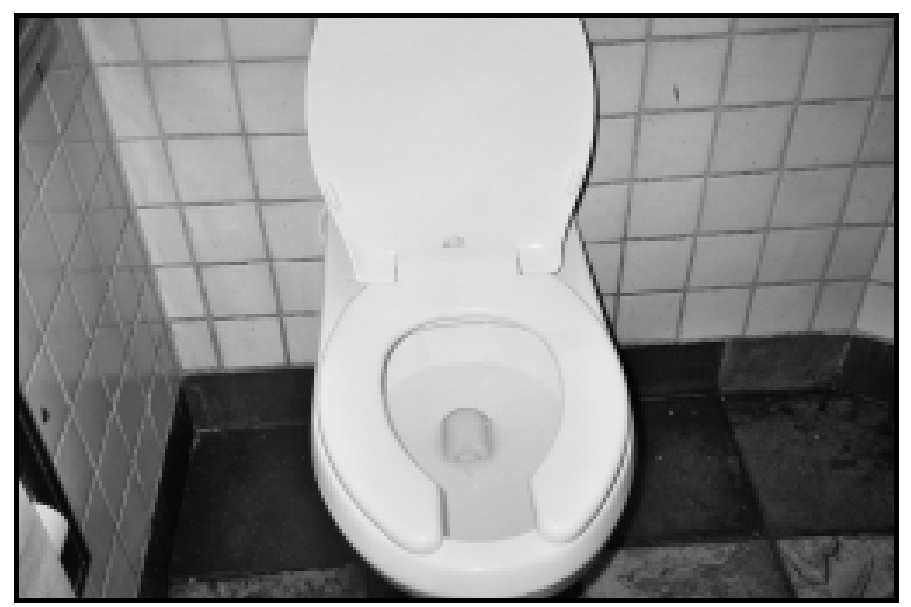

Figure 15: Untitled.

For Lady Purfection, the personal, communal, and societal need for public restrooms was depicted by a restroom sign and framed as basic human dignity (figure 16).

I mean, just because people are homeless or sex workers living on the street, or whatever the case may be, doesn't mean that they don't want to use the restroom in some place that's clean and sanitary...I mean its basic human dignity.

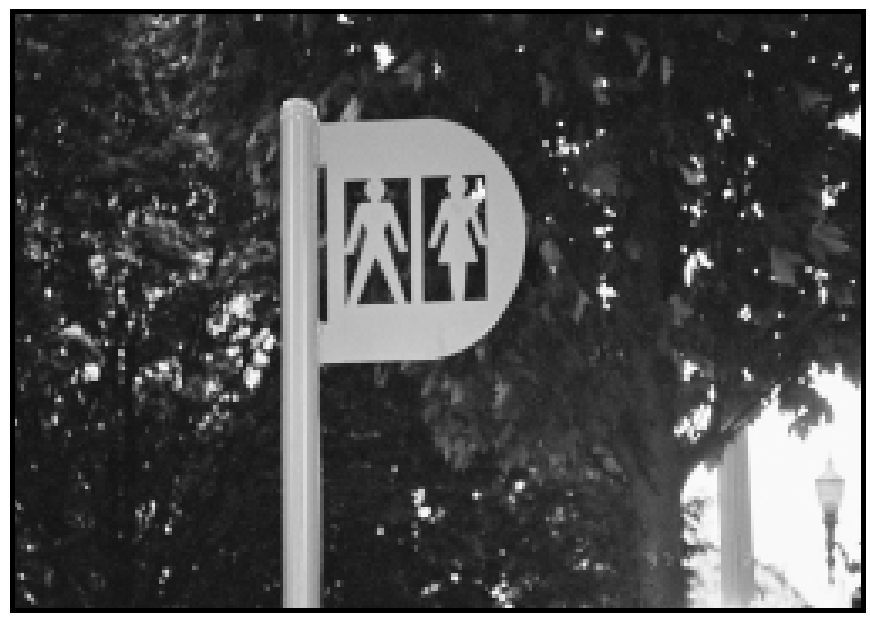

Figure 16: Our rights-basic human dignity 


\section{Shelter}

The need or desire to have a home was illustrated and articulated differently depending on each woman's living situation and past experiences. For some, home was a place to relax and have privacy. Others associated the notion of having a home with protection from discrimination. For one woman, home was connected to fulfilling a childhood void. The type of home that was desired by participants seemed to be influenced by sub-culture, western notions of home (white picket fence), and age.

Jasmine, who was living under a bridge at the time of the study, photographed her friends sleeping at her camp (figure 17). She discussed her need for solitude and a place to call home by presenting her current home. She explained, "That was the need for a home, a place to rest my head, you know, relax, just for that one time at night when I can have time to myself...and a place where I can just spread out everything in my pack..."

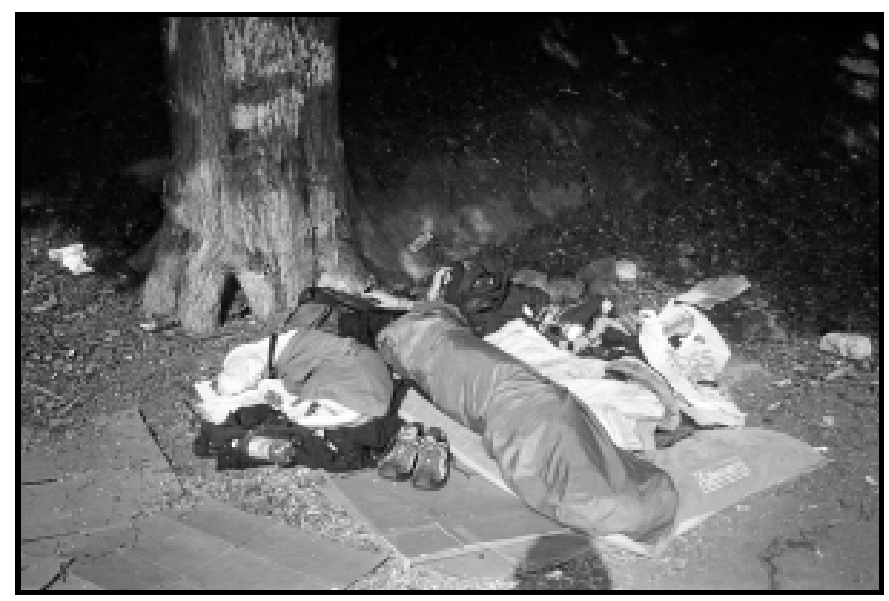

Figure 17: Camp, Sweet Camp.

Similarly, Lady Purfection photographed the place were she was living at the time of the study: a hotel room. She photographed a towel rack in the room and said:

This is the life that entertainers live when they have really no choice; when they don't really have nowhere to go, you know... I'm an entertainer and I'm living in 
a hotel. You're paying damn near $\$ 300$ a week if you're staying here. But I can't get a place; it's hard to get a place for me...

Lady Pufection felt she had limited housing options due to the instability of her income.

Sarah conveyed frustration with staying in a motel and depicted her personal and communal need for housing (figure 18). Sarah told a story about her experience of being judged and mistreated by the motel management.

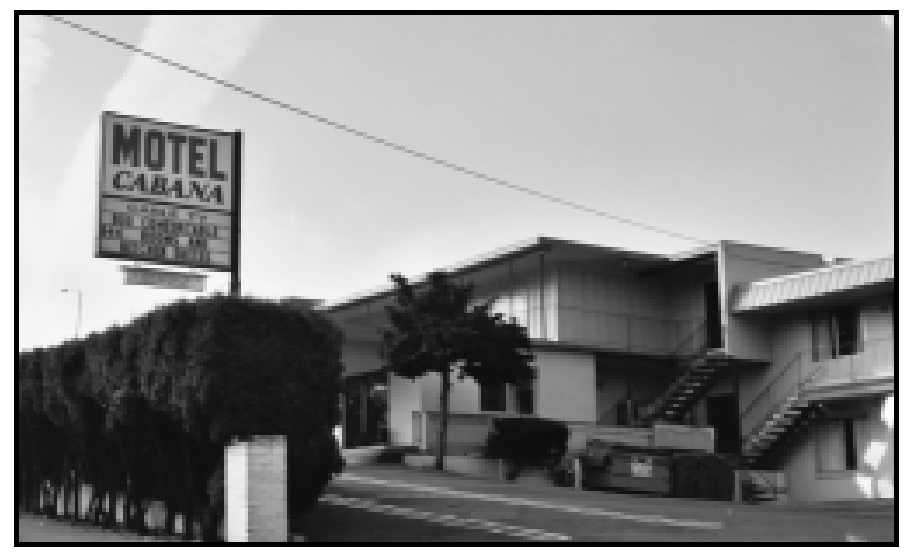

Figure 18: Untitled.

Motel Cabana. I used to live there when I worked 82nd (Ave) and those bastards! You know what they did to us? We paid our rent, which was like, 70 bucks or something; a couple of us [women] were living there. They came and cleaned and then they came back with a washcloth and like, mascara, and wiped the mascara off the counter with the washcloth and said, "This is drugs!" and he [manager] kicked us out, and we had just paid our rent, like, one minute before... So, the need for women to have shelter where they're not being abused, taken advantage of and treated like dogs. That happened to me three times where they took my rent and then kicked me out for no reason.

In contrast, Alex was living in an apartment with a roommate at the time of the

study. She photographed a house with a white picket fence to represent her need for a certain type of home (figure 19).

The house with the gate in the front, with lots of leaves- the great looking housethat is to represent home. The one thing I never seem to have. I never felt like I've had a home- even growing up because we moved all the time. And now, it seems like- I just want to be somewhere where no one asks me to leave. 


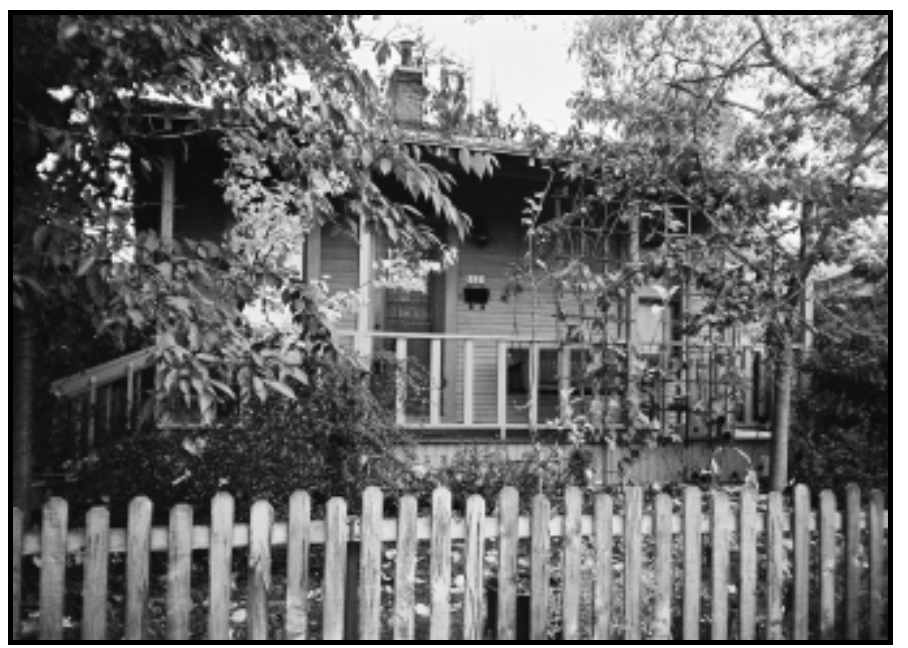

Figure 19: Untitled.

Crystal and Bee also photographed a house with a white picket fence to represent the aspiration to own a home. To accompany her photograph, Bee explained, "It is such an aspiration to own my own home again because I did that. I was this close to getting ahead of the game. I lost my home due to cancer." In contrast, Mouse photographed an abandoned house (figure 20) to represent her aspiration to own a home and reclaim the discarded. She explained:

I feel really at home in these houses because they are the kind of houses that I've lived in for awhile. You just buy an abandoned house, you crack it, and you go in and sleep in there. So, for one thing, I feel at home looking at a house like this but for another thing, it being abandoned is- it's kind of like a blank slate.

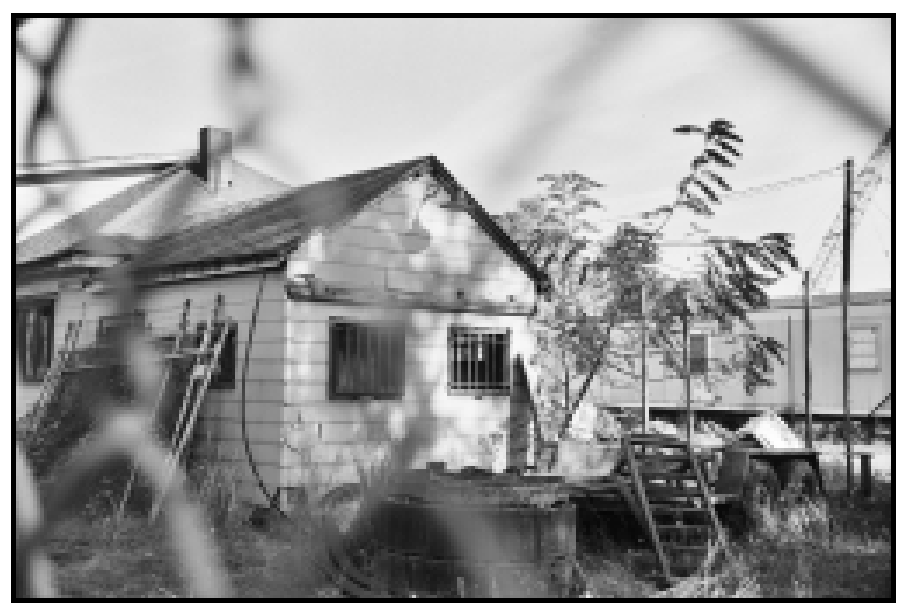

Figure 20: Untitled. 


\section{Transportation}

Transportation emerged as a need for some and as an aspiration for others depending on age, type of work and lifestyle. Rizzo, the youngest participant, photographed bikes (figure 21) to express personal and communal needs for transportation. She presented the idea of having bikes for rent at affordable prices.

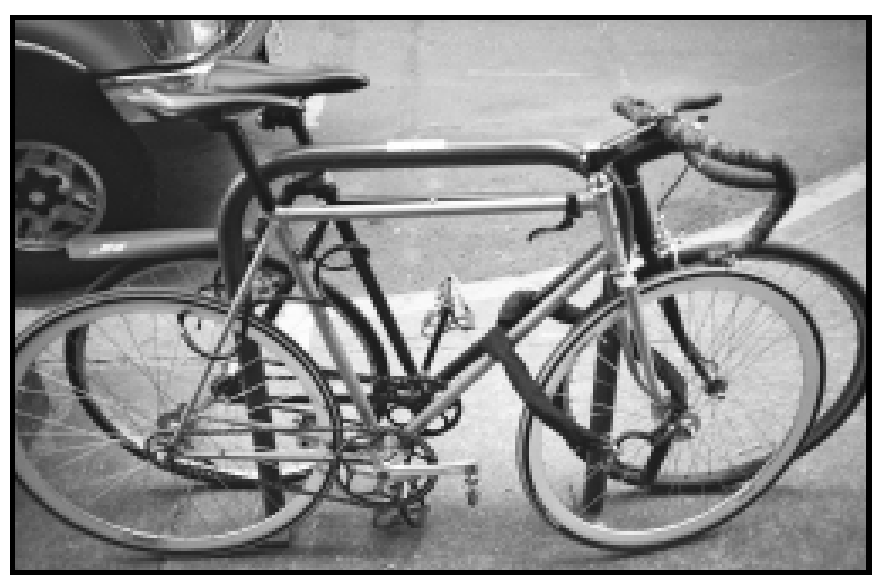

Figure 21: Untitled.

Rogue took a photograph of a VW van to depict personal and communal needs for transportation (figure 22). She described its multiple uses by stating, "Everyone that lives on the street needs something that they can sleep in and use to get to and from work...and also for shelter too."

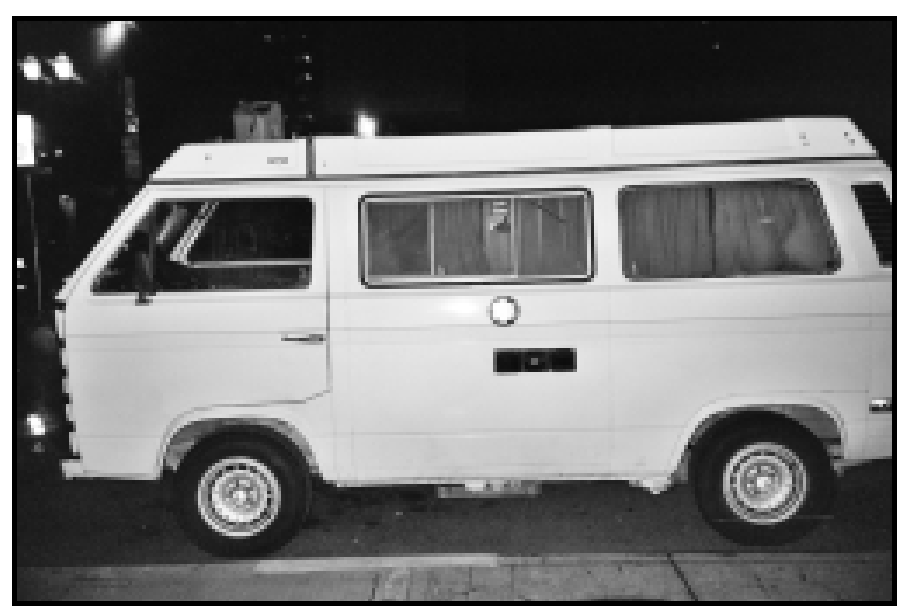

Figure 22: Untitled. 
Those participants who had some mode of transportation expressed the desire to have their own cars. Alex photographed a vintage car (figure 23).

That represents the need for better transportation and also to like, have it be, you know, nice transportation. I don't have a car right now-it broke down. But I'll just save money and get another one. But I'd rather save a decent amount of money and get something that I like because I don't want to just buy a car, any car, I want to buy something I can be excited about.

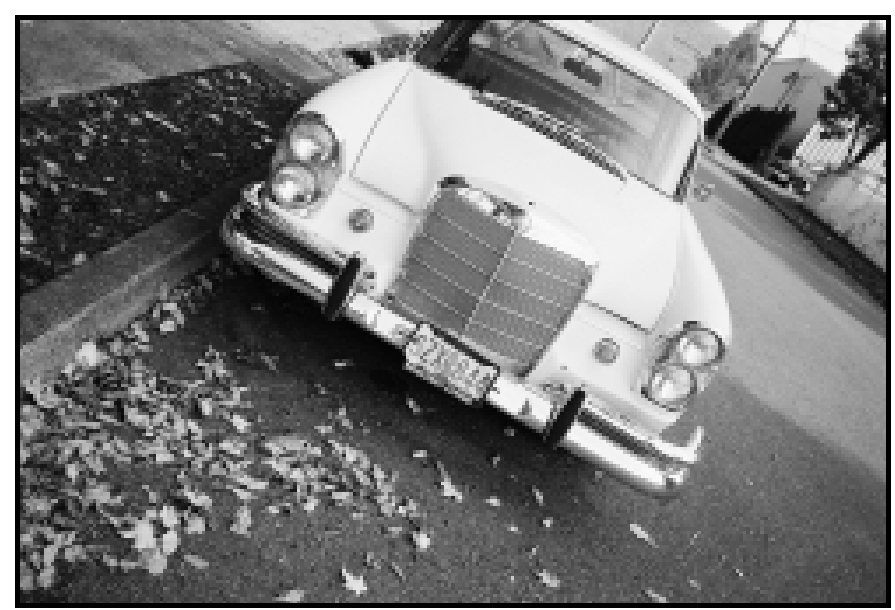

Figure 23: Better Means.

Crystal was in a similar situation; she also owned an unreliable car. She represented her need to have transportation by capturing her driver's car (figure 24).

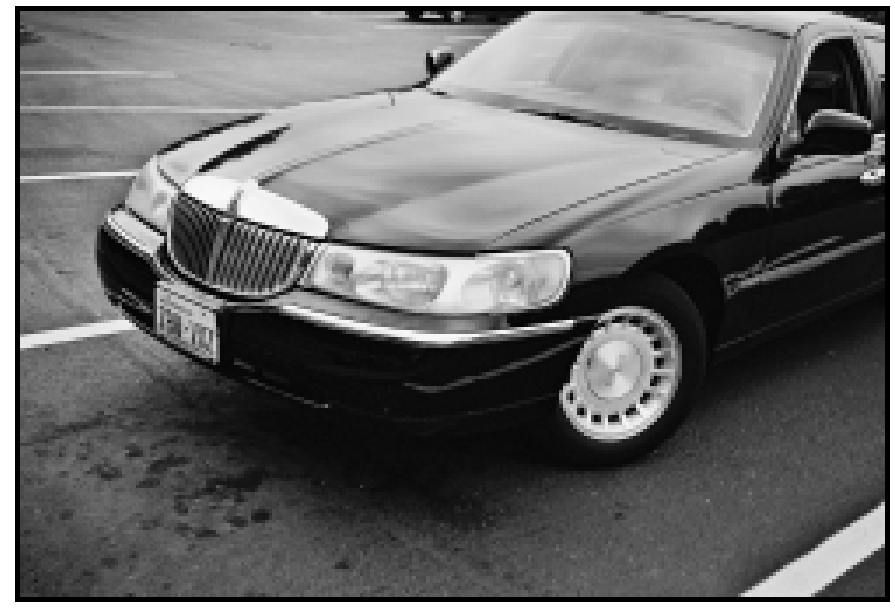

Figure 24: Everyone needs a great driver.

I have a car, but it kinda smokes sometimes; it runs, it drives, it's good, it just needs a little work. So, I have a town-car driver. This is my town-car driver's car 
for when I'm going to do a massage or an outcall- to spend time with elderly gentlemen that are lonely, all alone, and want to go out to dinner or something.

Crystal took another photograph of an SUV and discussed her aspiration to have a family car in the context of feeling lonely. "I would like to have a family vehicle... So I can bring friends and family in it, and you know...it's a hope of mine. It can be a lonely life sometimes, you know." She explained that her four children were in foster care, so an aspiration of hers was to be reunited with her children who she would drive around in a family vehicle.

\section{Social services for women.}

Several of the artists who were homeless or who had experienced homelessness discussed and represented the need for social services. Rizzo photographed various signs and objects around downtown to depict various communal needs. For example, she photographed a U.S. Mail Box to highlight the need for a mailing address (figure 25). "A lot of girls don't have mailing addresses and that is definitely a need. I have a mailing address but a lot of girls don't, and it's nice to get letters from family and stuff. It's nice to be able to get your mail from, like, the DHS office."

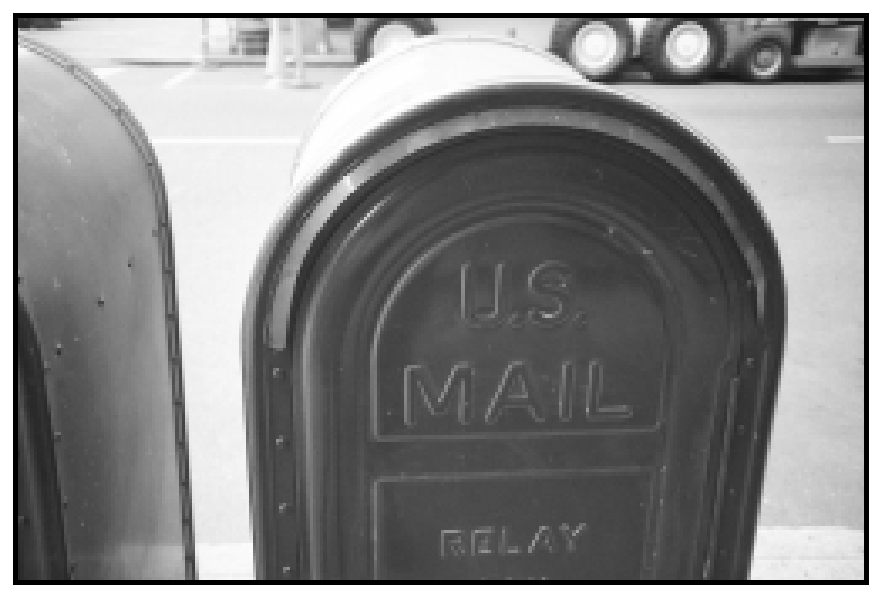

Figure 25: Untitled. 
Rizzo also photographed a sign that read "Hair and Skin Care" to illustrate the need for beauty services for sex workers. She expressed this communal need and explained:

I think there should be more things like the Portland Homeless Connect but for girls in the sex industry so that it could help them take care of their hair and skin. Like, maybe hair cut vouchers and stuff like that...just to take better care of themselves because I know a lot of girls who are supporting drug habits, so it helps to get your haircut or even shampooed or conditioned professionally.

Another social service need expressed by the women was drug rehabilitation as depicted by Sarah in a photograph of the methadone clinic she frequented. In contrast, Lady Purfection articulated the personal, communal and societal needs for more general resources for sex workers who don't have drug addictions by photographing a door sign of a strip club to advocate for a drop-in center for youth and sex workers to hang out (figure 26). Lady Purfection shared a personal story to illustrate the need for a safe drop in center and resources for sex workers that aren't just focused on drug rehabilitation.

I entered the sex industry when I was 21 and that was my choice. I remember when I was first in the sex industry...I put myself in a horrible situation and I was a street worker for a week and a half. The only place I could find to go was a 24hour deli downtown... There need to be places for sex workers, places for youth...for people that don't have drug problems. That's who the majority of the resources are for...

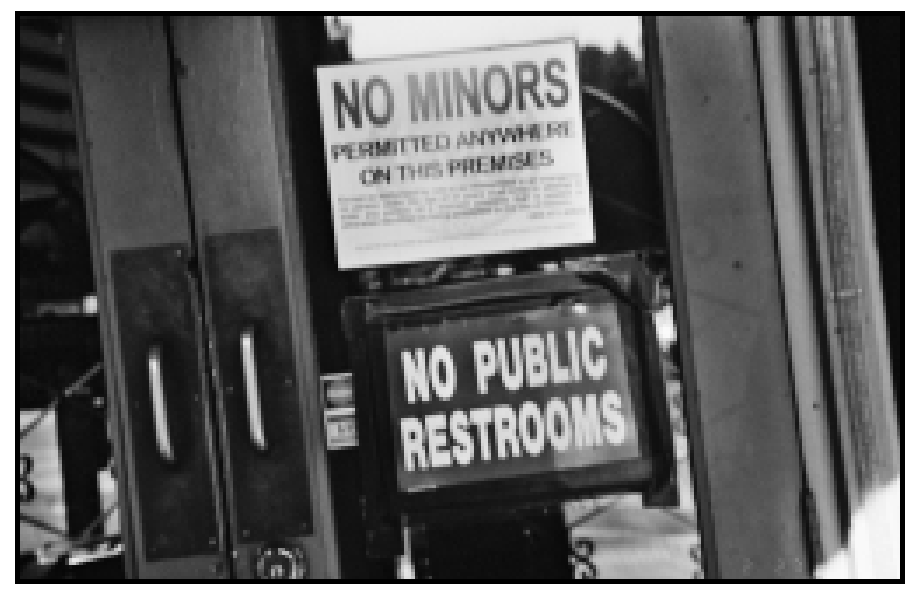

Figure 26: Untitled.

Safety and protection. 
Many of the women specifically photographed their personal, communal and societal needs for safety and protection while working in the sex industry. The images for representing this need varied among the artists and included photographs taken of strip clubs, animals, statues, weapons, and body parts. Artists engaged in street work expressed feeling unsafe with some clients, feeling unprotected by the police, and feeling disregard by society due to stigma. Participants who worked in strip clubs pointed to the lack of protection from management and feeling discounted as dancers.

Merry Mag juxtaposed a flyer used to report violence next to stitched body parts to create meaning of her experience of violence while working on the streets (figure 27). Reflecting on the need for safety and protection, she recalled her traumatic experience.

This one time, I almost got murdered by this man [client] and I thought that I was gonna die. I had 2 broken ribs by him...I ended up in the hospital and that's what this picture represents to me. The part on top where it has the Portland Bad Date Line, I just was happy that someone cared about us like the bad date line and cared that we even lived and existed because there is such a stigma against us especially street workers. He was going to kill me- that's what he was saying- that he was gonna kill me because I was a whore and his mother was a whore and he was angry. The photo also has the syringe exchange hotline number on here which is another group of people who care about people like us. You know, as kids we don't say "well, when I grow up I wanna be a ho and a junkie," and so that's what this picture means to me.

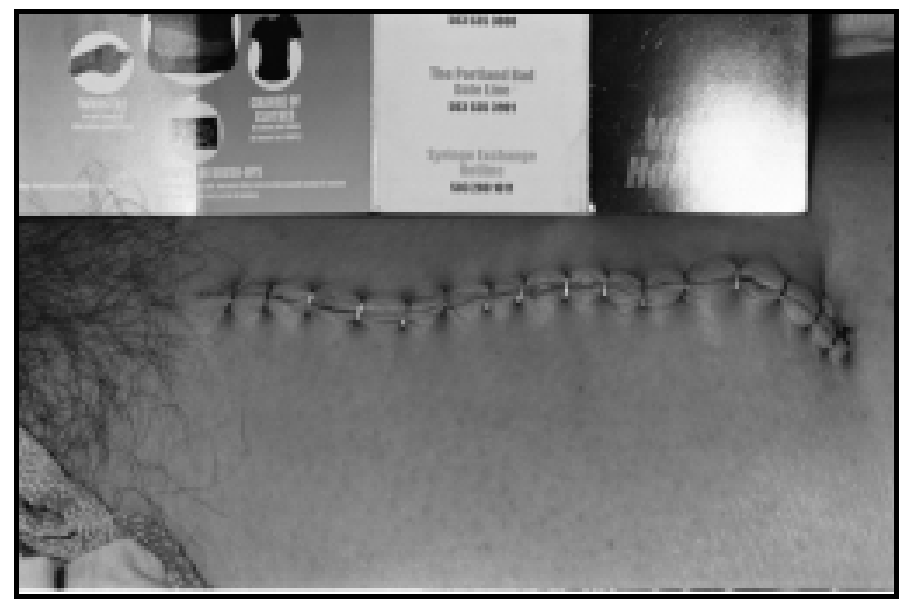

Figure 27: Sometimes Sex Work Hurts-Call the Bad Date Line. Not all People Hate Us. 
Merry Mag presented a physical metaphor for the external pain of violence, while her story held the internal scar of her trauma. She emphasized her deep appreciation for those who cared about the well-being and safety of sex workers.

Sarah described her fear of violence by the police. Sarah accompanied her story with the image of an angel statue to symbolize protection (figure 28).

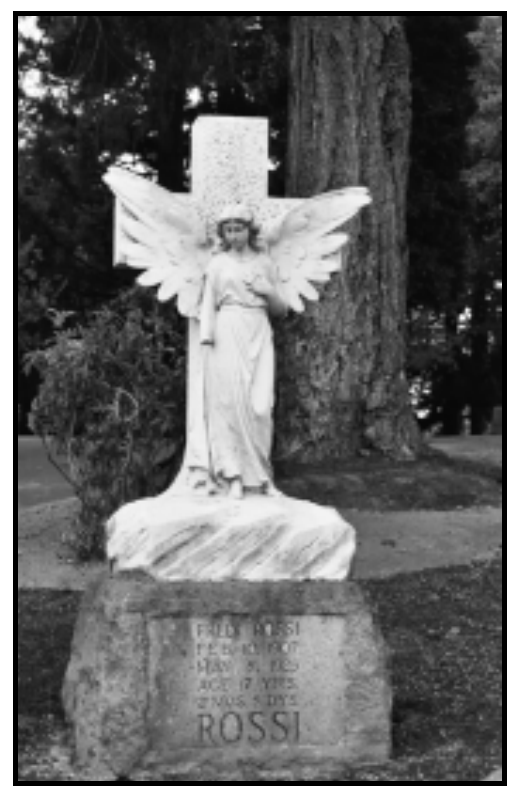

Figure 28: An angel always watching over the women working the street who are vulnerable to the utmost evil.

I don't get anxious about the dates, I get anxious about the police. I get terrified. I don't feel safe until I get into a guy's car. Isn't that funny? It should be the other way around, shouldn't it? But I feel safe once I open that door and I'm in the car. I got kidnapped one time by the police. They took me somewhere- it wasn't even a station- held me there for two hours, told me I was under arrest, for nothing! I was eating my breakfast at McDonalds, and he started, like, telling me that he saw me the day before with some guy, and I said, "Well you must have me confused with someone else." And he said "you calling me a liar? That's it- you're under arrest for prostitution!" I didn't even have any condoms on me, no money, no nothing! I was eatin' my breakfast, waiting for my girlfriend to get home where I was staying. And he took me to this place, and all these cops who weren't even on duty were there. I was crying and at this point I'd never been arrested- they had me handcuffed and they were like, "don't get your AIDS-diseased tears on our desk!" Then they were calling me, "fucking bitch" and "nasty whore" and this and 
that. They had me there for two hours. Then they go, "well we're not going to arrest you "cause you'll be out next day doing the same thing."

Both Merry Mag and Sarah shared personal experiences to illustrate the importance of feeling safe, protected, and not alone when working on the streets.

Grahm, who worked as an exotic dancer, illuminated the unsafe working conditions in some strip clubs. She took a photograph of cleaning supplies positioned on the edge of a dance stage (figure 29) to represent the personal and communal need for safety and safe working conditions.

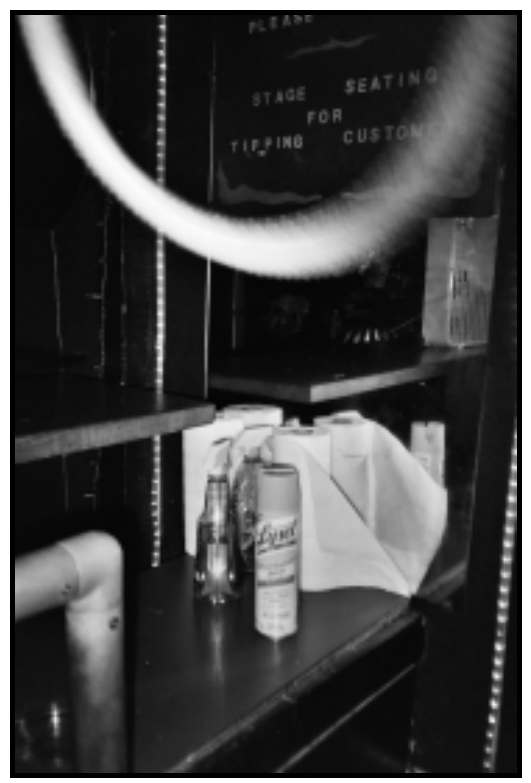

Figure 29: Untitled.

Grahm shared her experience of getting hurt at her workplace and the negligence of her employer.

When I was working there for only a few weeks before I quit, I had a lot of people tell me about how five girls had gotten staph infections over the course of a month before I started working there. I was totally grossed out. So a friend of mine who I was working with there, we got these Clorox bleach wipes and scrubbed the stages. Then we showed them all to the manager and we were like, "this is disgusting, this stage is disgusting!" Then he went back and yelled at the cook for not cleaning it and it was really gross. Then he didn't deal with it, of course. I 
ended up quitting when I cut myself on something onstage; I sliced my leg. Another dancer told me that one of the mirrors- one of these tile mirrors or whatever- one of them had broken, and they hadn't cleaned it up well enough. I was cutting myself on broken glass on the stage! So right after that, I went up them [management] and I'm like "I'm bleeding, I need a band-aid" and they didn't have a band-aid! They told me that I should keep working my shift with a bandana tied around my leg-so I quit.

\section{Self-care for preservation.}

Among some of the women, bodily care was crucial in their lives and took the form of seeking treatment for substance abuse. The need and/or aspiration to address one's drug addiction was photographed and articulated differently depending on the years of addiction, the type of drug(s), and the perspective one had with their use. Sarah took six different photographs depicting bottles of methadone, a methadone clinic, drugs and drug paraphernalia (figure 30) to present her years of experience with addiction. Sarah described her undesirable behavior, the stigma against her, and her desire for help.

That just represents addiction- crack, I got pills, heroin, syringes-and again the need to stay well. Heroin- the need to get treatment and the aspiration to get treatment. I was in the hospital 13 times all because of drug use! You know, I've ruined my health. I am disabled because of it and people think we choose that... I want people to understand that we're people- not animals. We didn't choose to live a life of addiction, we need help.

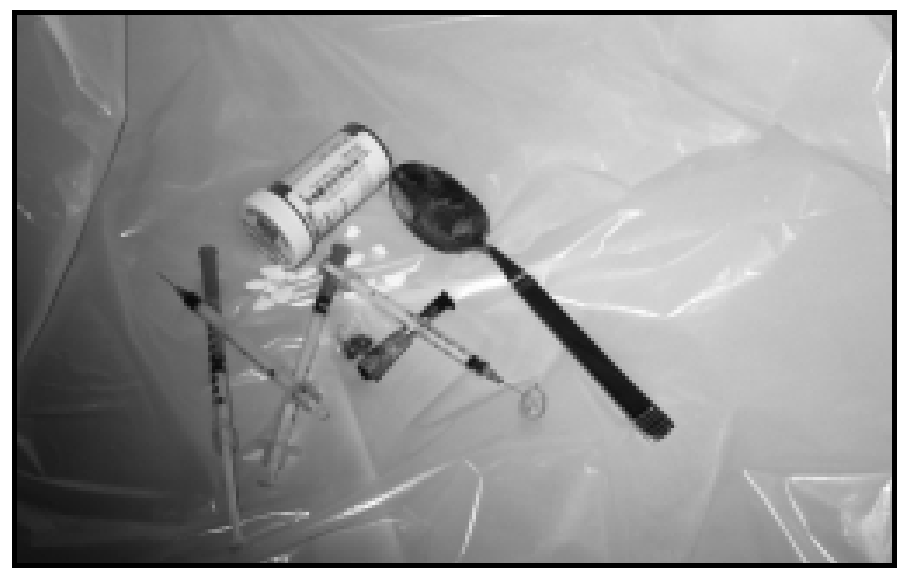

Figure 30: Untitled. 
Similarly, Jasmine illustrated her need to battle against her heroin addition through a selfportrait of a heroin needle between her teeth (figure 31 ). She identified her behavior as self-destructive and expressed anger towards herself as she described her addiction.

I need to get clean, that's part of my problem. I'm a heroin addict and heroin addiction takes up every aspect of your life. The only time that I have to myself is at night, when I get to go back to my camp to relax, go to bed, or play with my dog- the rest of the time is spent is trying to hustle to get that money to get that fix, cause I have to have that fix or I'll get sick. Ugh! I hate it! I can't believe I fucking- I was so stupid to do this shit to myself.

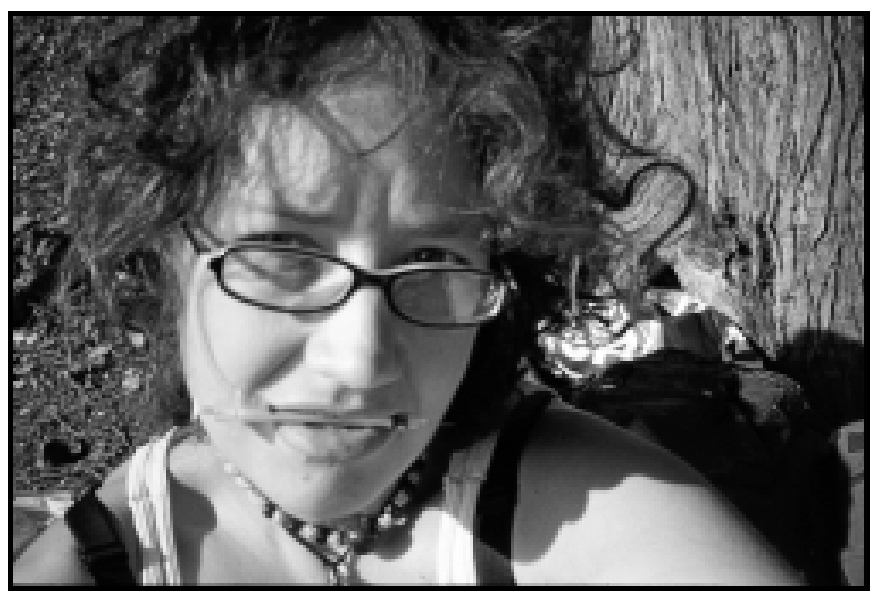

Figure 31: Wake Up.

In contrast, Mouse had a stable living situation, was enrolled in a private university and had economic privilege. She framed her drug use as an undesirable behavior, not as an addiction, and as a habit that consumed too much of her time. Mouse used syringes to spell out "QUIT" on the ground, and photographed this to represent her need and aspiration to stop using heroin (figure 32). She shared:

I started doing heroin back in March and this picture was almost kinda like a nobrainer, because it is something that I think about a lot- that I think about wanting to not do a lot because it's not something that really occupies a lot of my mental energy, a lot of my thought process, but definitely occupies a lot of my time. I don't really look at it as being in anyway a part of who I am, I don't really identify with it, but it's something that just takes up a lot of time in my life. 


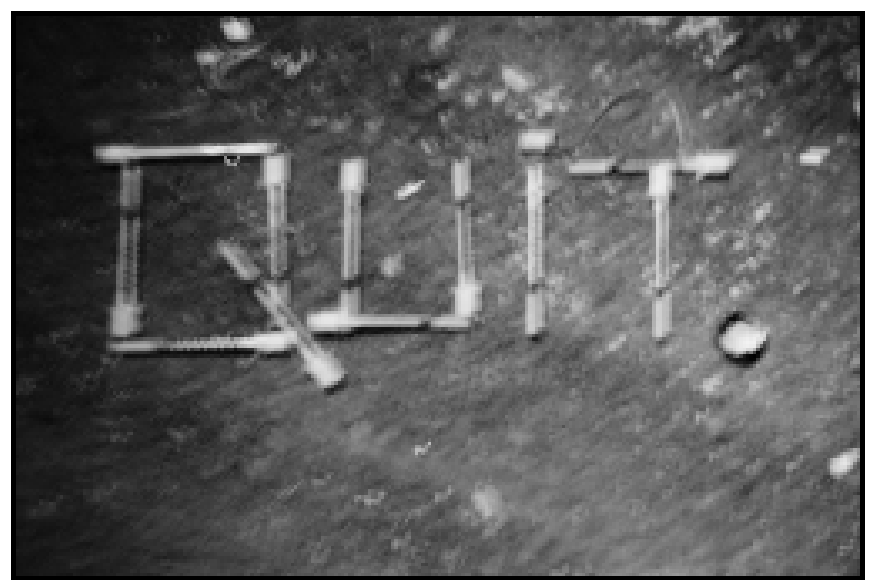

Figure 32: Untitled.

For both Mouse and Jasmine, their need for personal time was identified as something important that their heroin use infringed upon.

Privacy and solitude.

Some artists highlighted the need for privacy and solitude as part of their self care. Living circumstances, type of work, and privilege informed how this need was expressed. The need for bodily privacy and solitude ranged from not wanting to be physically surrounded by others on a daily basis to feeling physically over-exposed while working. Jasmine photographed herself in the mirror of her motel room (figure 33).

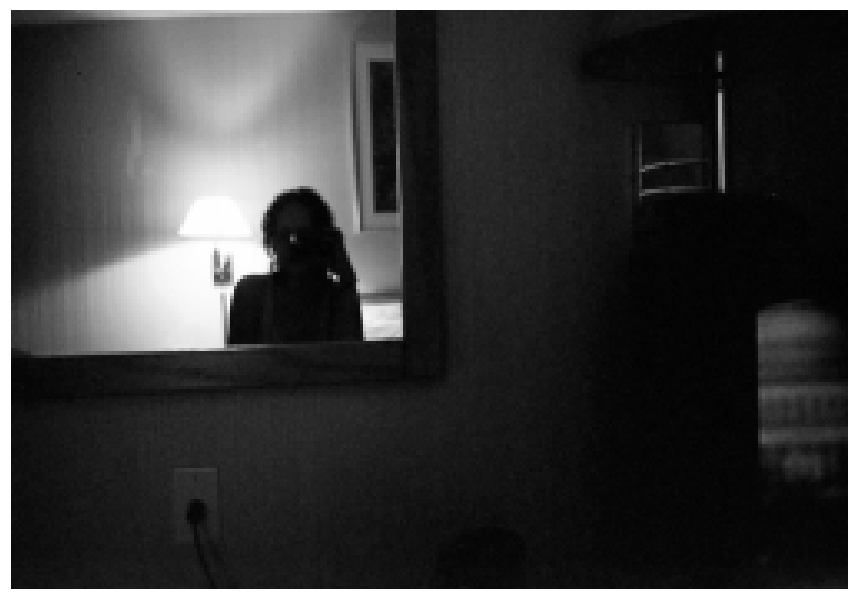

Figure 33: Untitled.

She described her pleasure in having time to herself. As a homeless woman, she always 
found herself surrounded by others.

For some reason I just wanted to capture that moment because it was just, "ahhh, I'm here. I've got a room to be in, all by myself where I don't have ten bums sleeping around me and all that stuff." It was really nice. It would be the aspiration and need for solitude.

Mouse described privacy in the context of her work. She went to a park and

photographed clothes strewn over a seesaw (figure 34). Mouse explained how and why

she created this image to represent her deprivation of privacy and feelings of over-

exposure when stripping.

I took a lot of clothes that I dance in to the park... I just threw all the stripper clothes all over. I was thinking about how the idea of having all my underwear just thrown all over these seesaws in a public park, how public my private life feels when I am dancing because, I mean, just literally being physically naked or scantily clad in front of other people. There is really no privacy and I would like to retain a little more privacy in my life. You know, it's funny though, because at the same time, privacy feels like it's an issue when you are around other people that have the luxury of privacy [clients]. But when you are in a dressing room with a bunch of other girls you don't worry about getting naked while you're changing or putting on your make up or brushing your teeth or rubbing your crotch down with a baby wipe in front of them. Because they don't have that privacy either and you are un-concerned about it when you are with them...It's like, privacy is a luxury but you only feel deprived of it because you are around other people that have it when you don't. And I don't care about having privacy or not if I feel like I am on an equal field with other people.

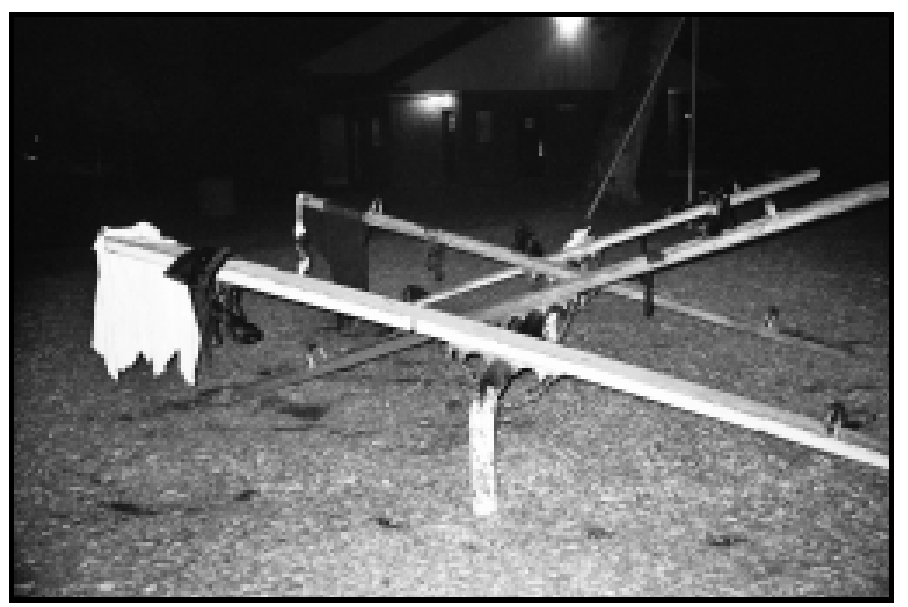

Figure 34: Untitled. 
While both women discussed the need for privacy, Jasmine referred to her desire for mental solitude while Mouse talked about her internal dilemma of not having the privilege of bodily privacy in the workspace and her need for this. However, at the same time Mouse was unconcerned about this need for privacy if others were in a similar position as her self.

\section{Income generation.}

The artists presented their need to make money in order to "keep things going." The use of their bodies was crucial to their livelihoods. Their bodies were seen as an asset and often a space to express their talent. For example, Jasmine presented a portrait of herself panhandling; something she did to supplement her income (figure 35).

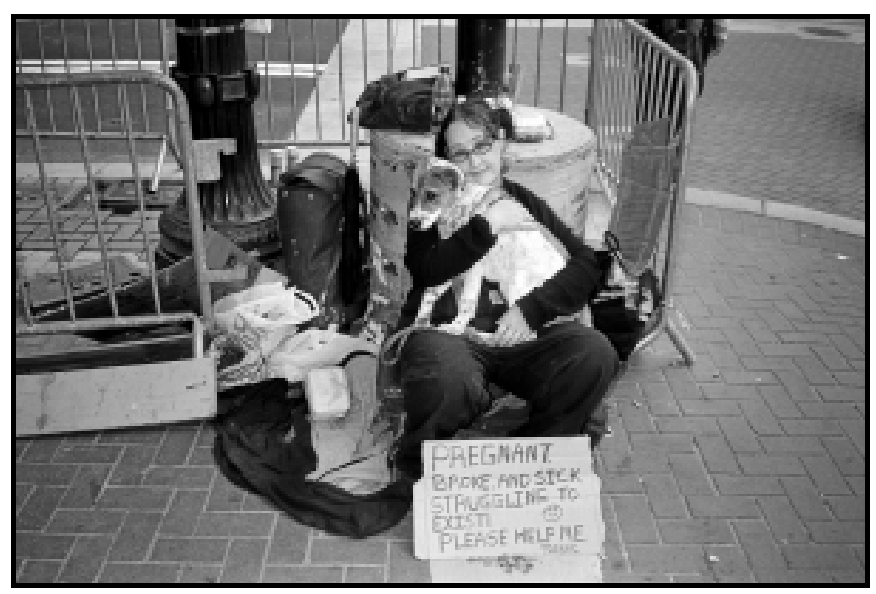

Figure 35: Untitled.

Bee photographed a specific part of her body to connect dancing to income and art. She took two photographs; one of her feet in ballet slippers (figure 36) and the other of her feet in her stripping shoes (figure 37). 


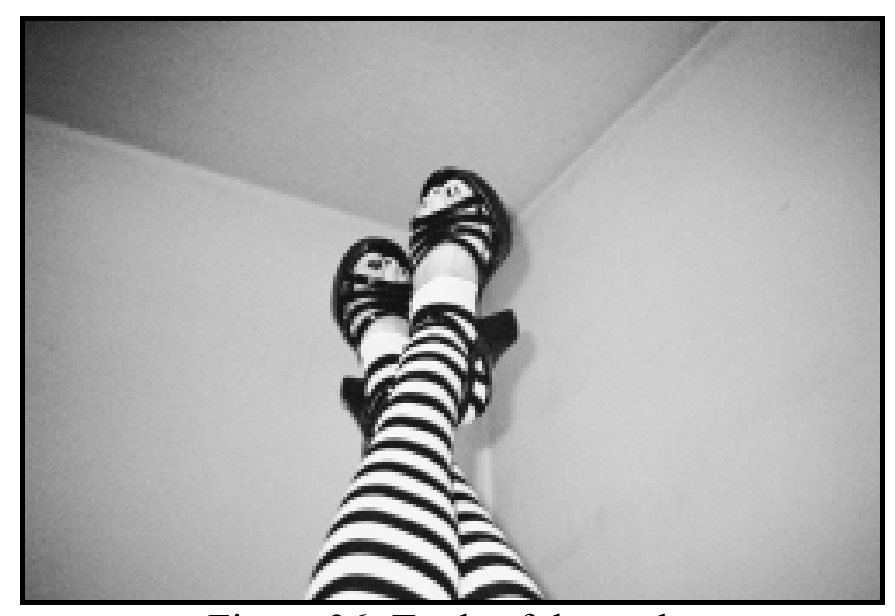

Figure 36: Tools of the trade.

She explained how both images represented the art of dancing and talked about her training as a professional ballet dancer. "I have my stripper-hooker shoes on...I am wearing the big heeled model. These are for work; this one is a need... So, the other one, the one with the ballet shoes, was an aspiration. But both are pictures of my feet." While Bee enjoyed ballet, she explained that it didn't pay as well as stripping. She continued, "I enjoy it [ballet]. It is great for stress...but you don't get paid so I can’t do it..."

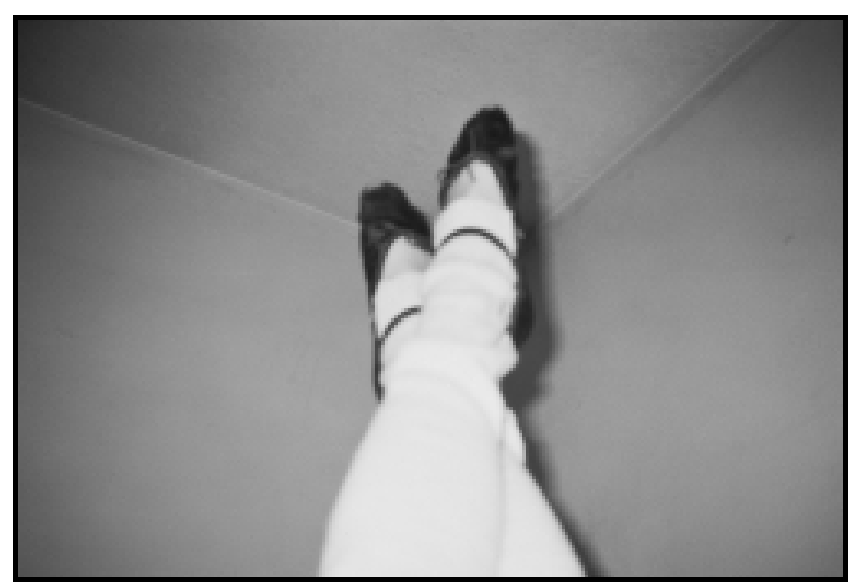

Figure 37: Untitled.

Other participants referred to their work and their need to sustain their livelihood through their jobs and the use of their talents. Crystal took a photograph of a poster displaying a stripper wrapped around a pole (figure 38). She stated, "You know, they 
actually have classes on how to pole dance and stuff. But when nobody's around, we all get up there and twirl around just to see if we can figure out a new move that's kinda cool...it's kind of a need, you know, to keep on making money."

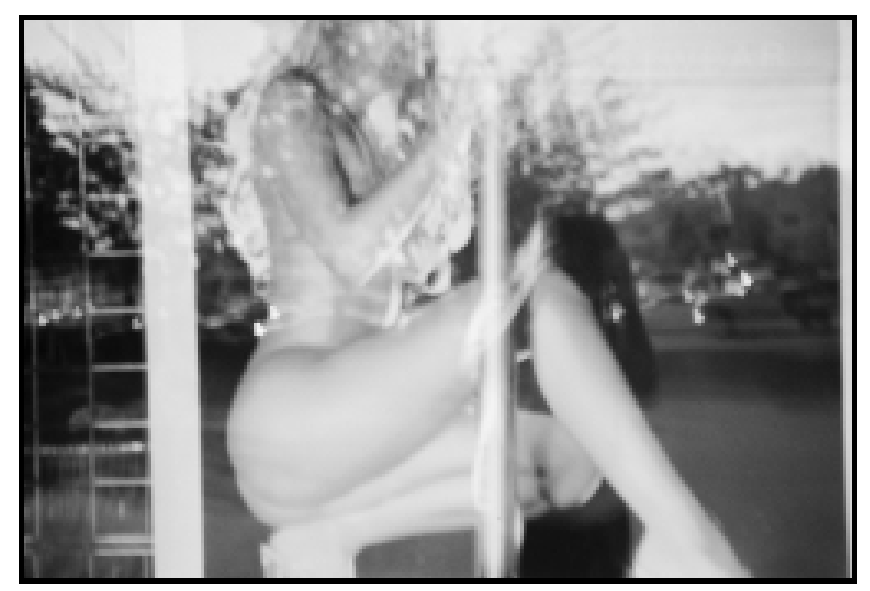

Figure 38: Portland's Finest Exotic Dancers.

Crystal used a poster to represent her need for exploring new dance moves in order to increase her tip money. She also mentioned taking pole-dancing classes to highlight the technique and expertise involved in job.

Alex explained the importance of her personality in her work as a dancer. She used humor to make meaning of her photograph depicting a pile of tires (figure 39).

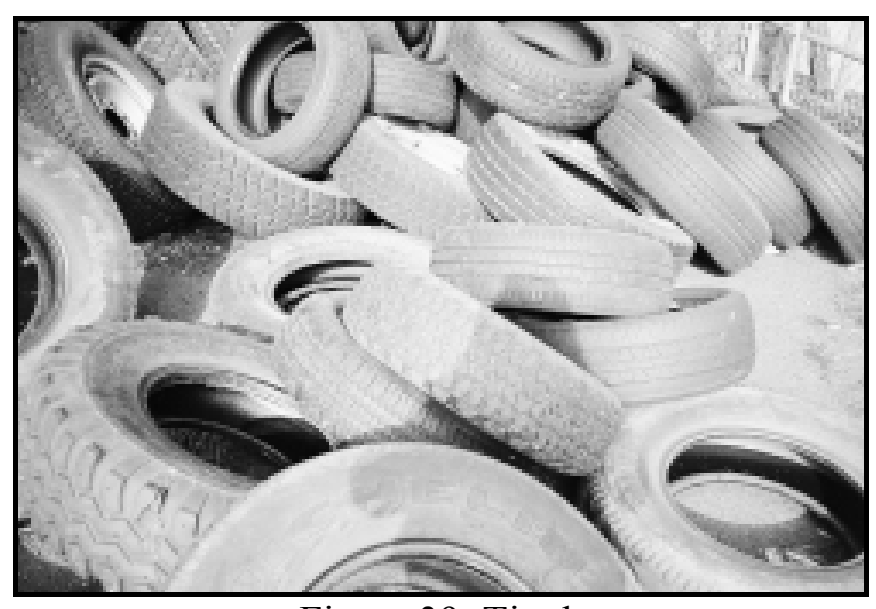

Figure 39: Tired.

"This is the need to not be tired (laughter). 'Cause you know, this job-it's your attitude 
and your personality that really makes you money. It really doesn't matter what you look like or what kind of body you have, it's your attitude." Alex identified her personality as a personal strength in her line of work and her need to not be tired in order to make money.

Similarly, Crystal explained, "You want to be friendly...there's a lot of customer service...that's brought me a lot more money, actually, is to be friendly (laughs) and out there." Those artists who expressed the need to make money presented their personal skills and assets through their photographic images and discussed ways in which these strengths assisted them with generating an income.

\section{Nourishment of the Heart}

Four sub-themes emerge associated with Nourishment of the heart emerged that illuminated the cultivation of deep emotions often symbolized as emanating from the human heart. The sub-themes include: (1) love and romance; (2) family, friends and community; (3) pet companionship; and (4) meditations on death. The personal need or aspiration for love or romance was prevalent among those artists who had the most access to basic resources for survival (e.g. those women living in stable housing and not dealing with addiction). However, the personal need for friends, family and community was articulated by almost all of the women in the context of trust, support and acceptance. These key features were considered important to their relationships. The personal need or aspiration for pet companionship was also articulated by many of the artists as central to their life, regardless of their social location, type of work, and circumstances. The sub-theme, meditations on death, involves the need for some of the 
artists to address emotions associated with the death of a loved one. The unifying factor within these four sub-themes was related to feelings and emotions associated with nurturing the heart. Another commonality was the importance of relationships and connection in life.

\section{Love and romance.}

The personal need or aspiration for love, romance, companionship, and a significant other was expressed in a variety of ways. The women took photographs of symbols of love (rose) and sexuality (lingerie), symbols of marriage (church, wedding ring), romantic statues, lingerie stores and family members. Many of the artists took two or three different photographs to differentiate their need for love and their aspiration for romance. The women had different notions of love based on their life experiences with previous relationships. Some women felt undeserving of love because of their work in the sex industry while. Others had clear ideas of the type of love they aspired to and deserved to have in their lives.

In one of her photographs, Alex used humor when describing her image of a mailbox (figure 40).

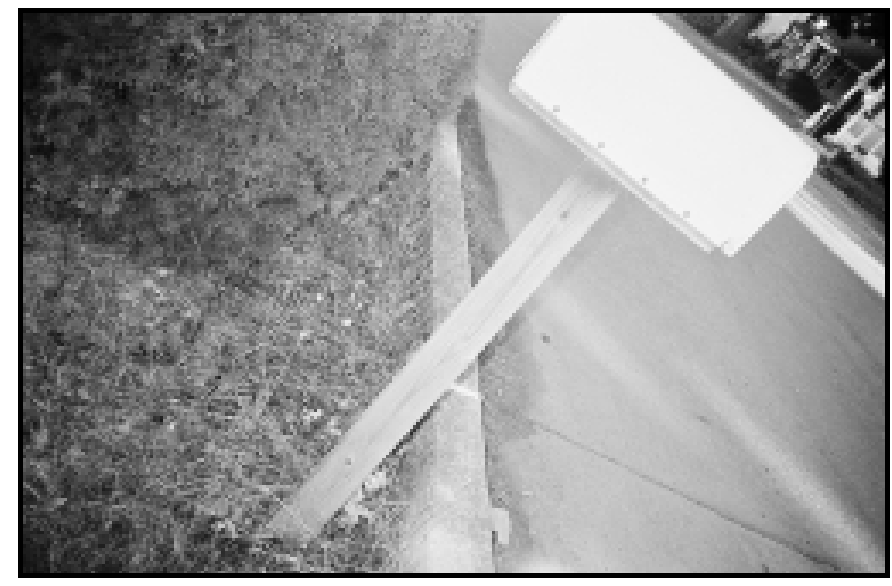

Figure 40: Untitled. 
I present an excerpt from the transcript to demonstrate how she explained her need:

Alex: the mailbox, is for um, a male (laughter)

Moshoula: a mail? (my face shows confusion)

Alex: yeah, a male, (laughter) a dude. A dude, you know? That would be more like a need, other than romance, which is something that I would aspire to.

She took another picture to differentiate her aspiration related to love (figure 41).

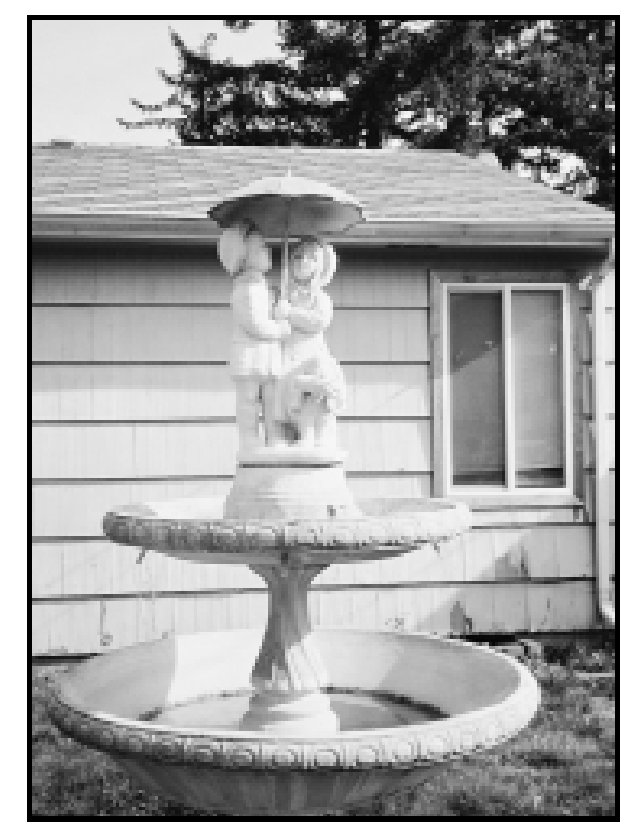

Figure 41: Untitled.

Alex explained, “That is to represent romance and compatibility. I don't- I don't need it in my life, but you know...it's an aspiration."

Bee photographed her aspiration to get married in a church (figure 42). She shared a story of her previous marriage, "The reason I took a picture of a church is because I got married when I was like 21, 22 or something like that. And my son's dad, I married him and it was a total disaster and he abused me." She shared her experience of domestic violence and her difficulty with trusting men. For Bee, "a marriage this time around would be more along the lines of bonding; to be with someone that treated me well." 


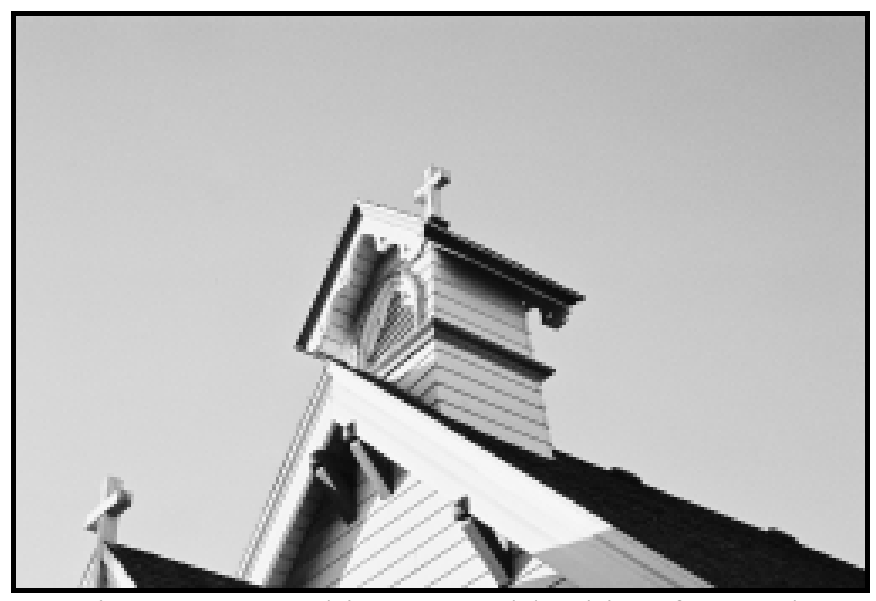

Figure 42: Looking up and looking forward.

She juxtaposed her image of a church with a photograph of a lingerie romance store (figure 43) to express her need for reciprocal romance from a partner.

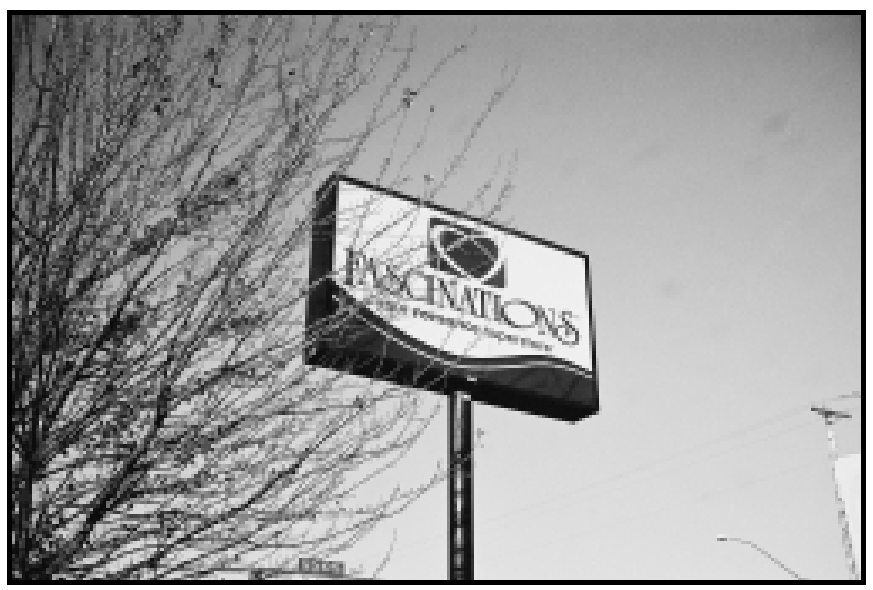

Figure 43: Untitled.

Mouse conceptualized romance through symbolism. In one image, Mouse placed

a pair of her underwear on a rose bush to represent her need to meld together romanticism with her sexuality (figure 44).

If I am getting naked in front of a bunch of strangers, you know, like a hundred times in a night, is that going to make, getting naked in front of somebody that I love seem completely meaningless? You know... and sometimes yeah, it kind of does detract from some of the specialness, I think. But I don't think that's something that I can't get past. So I want to meld those things back together again- romanticism and my sexuality...I always thought it [rose] was an appropriate analogy for love because its beautiful and it smells wonderful, but it 
hurts. It hurts a lot.

She shared her worries of losing intimacy in her personal sexual relationships as a result of her work in the sex industry. Mouse raised the dilemma of presenting her naked body in public (at work) in relation to preserving her notion of romanticism in private (personally). In a second image, Mouse represented her aspiration for romantic love in her life that would be preserved like a rose (figure 45). Mouse explained the symbolism behind her second image:

This one is an aspiration because the roses have been dried... coming back to roses again, it's a symbol of romantic love. These are very well preserved and I like that once you dry one flower, it's going to stay that way forever. And someday I do want to have love in my life and it's going to be like that. That's going to be beautiful like the rose, but that is going to mature and age to such a point that it will stay that way forever... and the ring too, symbolizes that for me.

She shared a story about the engagement ring in her photograph and the circumstances surrounding a painful break-up with her fiancé. She described her experience with violence and her feelings of betrayal.

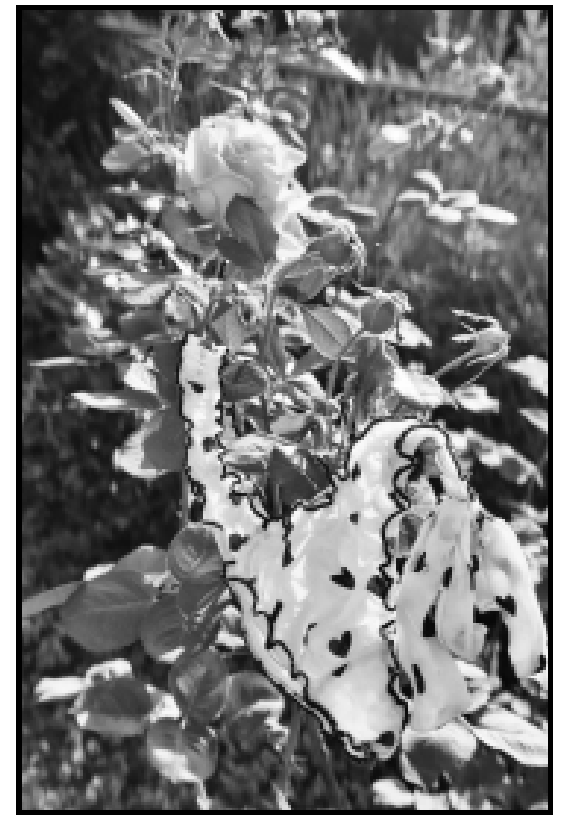

Figure 44: Untitled.

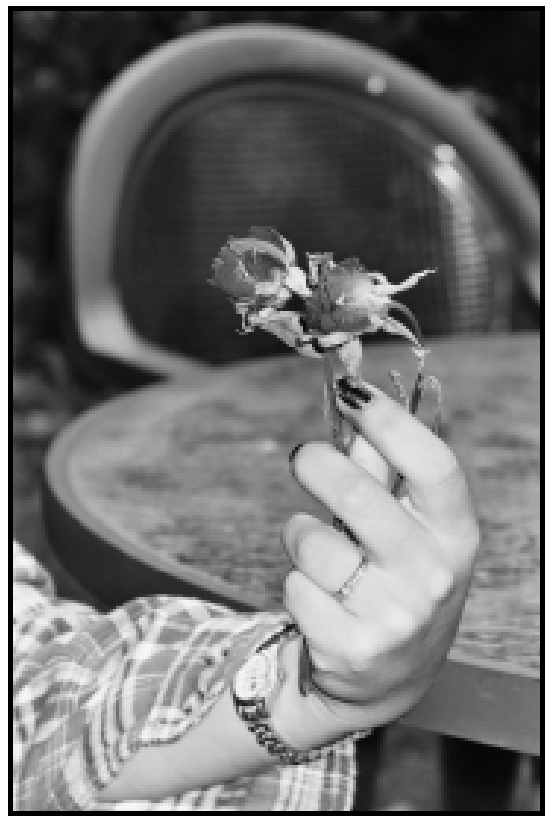

Figure 45: Untitled. 
Then, Mouse told a story to explain what the roses in her photograph represented to her:

The roses were kind of funny because (laughter) there is this one Mexican guy who would come into the strip club with a rose...he had tried giving it to every other girl in the bar before he got to me... he just looked so sad by the time that he offered it to me that I was like, "yeah, I would love a flower, thank you." And he got so happy, and he's like, "you are not like all the other girls." He is like, "you are special, you are nice to people," and ever since that night he came in every single night. He would come in at the beginning of my shift and he would stay until they closed. He would tip me... so, this guy gave me two hundred dollars a night, and I would just sit and hang out with him and he would buy me drinks all night and we didn't even talk that much because his English wasn't great, my Spanish wasn't great, but he just wanted like a pretty girl to sit with him and smile at him. And he would bring in a rose every single night, too. And he bought me diamond earrings once...It was just very sweet and very pure, because he never expected anything from me. He didn't even expect conversation- he just wanted me to be there. So, those two things embody a lot of the things that I would like to expect from romantic love at some point, in a very idealistic sense. So that picture's got a lot of story behind it.

Through the story of her connection with a client Mouse illustrated her desire to feel special, beautiful and appreciated. She presented an example of what idyllic romantic love would look like for her; something she was unable to sustain in her private life but experienced at her work.

In contrast, Merry Mag shared her aspiration for love and companionship, but shared her doubt of ever having the possibility to experience love because of her job as a street worker. She photographed an image that she created, which depicted an E.T. doll holding an old childhood photograph of herself (figure 46).

I love this picture of me as a child and I haven't always been a ho. I had dreams of a partner, someone to love me unconditionally but I guess that was just a fairy tale for a woman like me. I do service work to stop the pain and loneliness. Pray to Allah. I'm about 7 (yrs. old) there with ET and I loved ET. I had dreams as a kid and it wasn't this... 


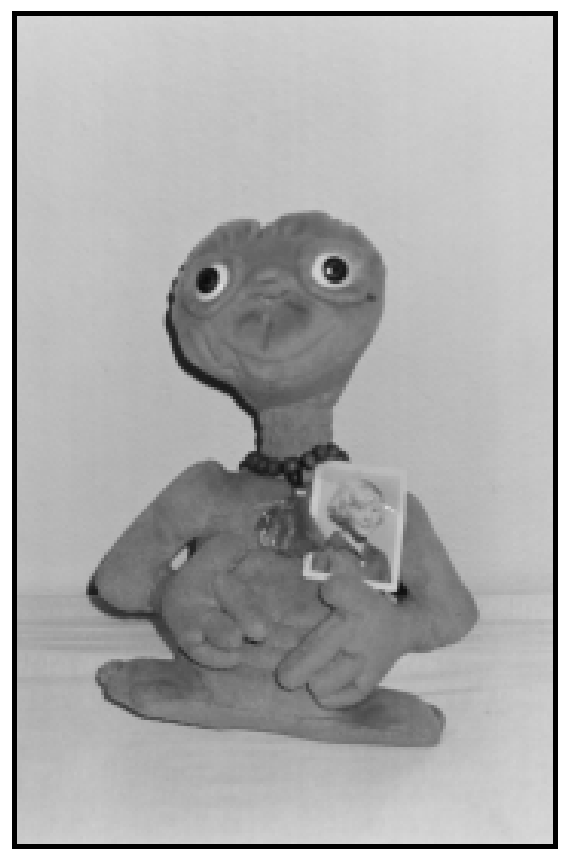

Figure 46: Untitled.

Merry Mag internalized the social stigma of street workers who are considered unworthy of being loved and simultaneously expressed her aspiration for a better life, a companion, and love. When Merry Mag placed her own photograph in the arms of E.T., she symbolized her childhood dreams of love that were still protected and alive. She connected her childhood dreams with her unfilled desires of adulthood. Both Merry Mag and Mouse placed personal objects in specific positions within their photographs to represent their experiences and perspectives around love and romance.

\section{Family, friends and community.}

The women identified the significance of their immediate systems of support: family, friends, lovers and their communities. Their photographs related to family revealed the complex relationships and the lack of familial connection. Participants presented images of family members, themselves with family members, and symbols commonly associated with the idea of family. Those artists who did not mention family 
photographed their friends and lovers to relay the importance of having human

connection. The women identified trust, loyalty, intimacy, and support as valuable traits.

Their photographs served to honor and appreciate important people in their lives.

\section{Family}

Sarah addressed the personal and communal need for maternal love; something

she struggled to have growing up. She took two photographs to represent this need; one of her mother and another one of herself hugging her mother (figure 47). Sarah shared:

I wanted to get a picture of my mother and I in a maternal embrace because I think a lot of females did not get that maternal care as children and as adults. I think that is a real need, you know. I think that if you get that love and that care you're not going to be out there looking for it in different ways.

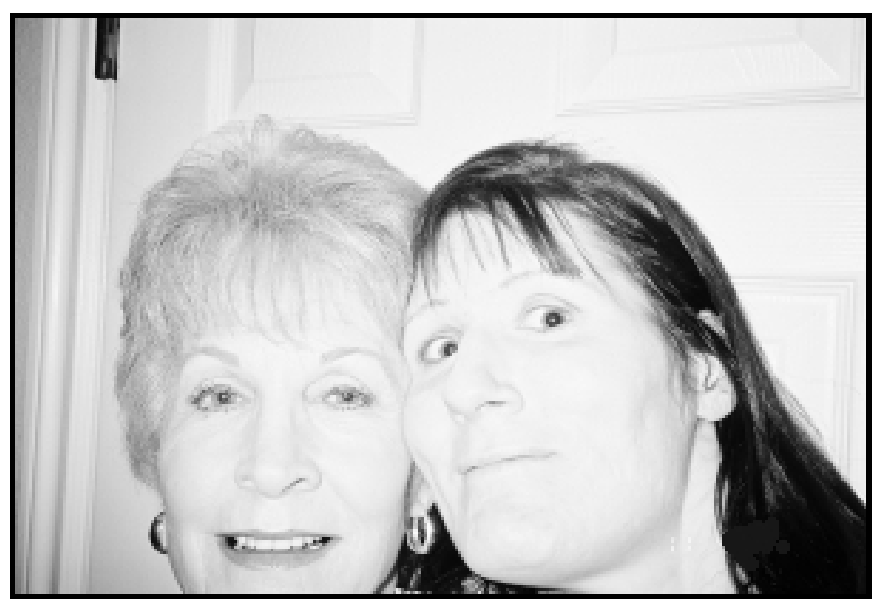

Figure 47: Untitled.

Merry Mag presented a photograph of herself smiling and holding her granddaughter with pride (figure 48).

And this is, of course, my grandbaby, which I didn't know if I would live to see. And I love this scarf in this picture. I look pretty in this picture. And my grandbaby looks beautiful and I am very, very pleased with this picture. My children, they're afraid because of my schizophrenia to let me baby-sit her and it really brings me a lot of pain even though the other grandparents who have a lot of money get to see her. My children are elitist and that makes me very sad because I didn't raise them that way. But society and their other grandparents 
taught them that; I didn't teach them that. It's like they think I'm contagious or something, even though they know how good I am with children.

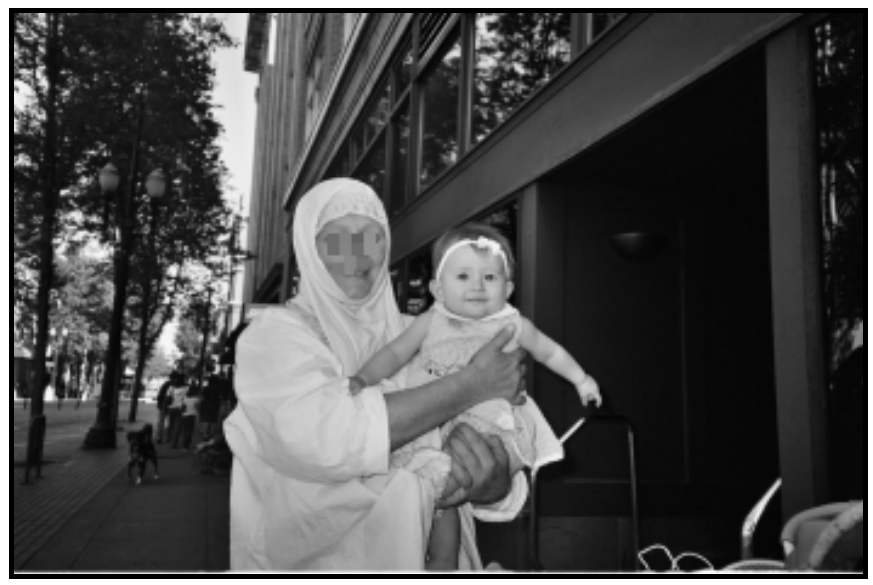

Figure 48: Untitled.

Merry Mag captured an image that brought her happiness in the moment, but also sadness and pain. While Merry Mag presented the complexities of her multi-generational family, in contrast, Alex used her creativity to represent her lack of family. She photodocumented the empty picture-frames that hung from the walls of her home (figure 49).

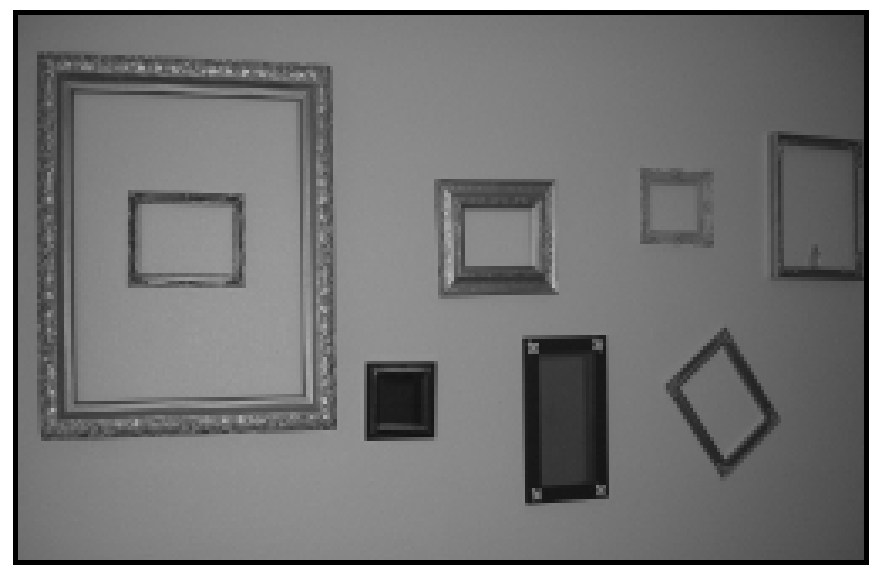

Figure 49: My family portrait.

Alex explained that the empty frames were symbolic of the empty void that she aspired to fill by having a family.

Friends

The artists also highlighted the need for friends in their lives and depicted this 
through photographs of friends. Rogue took photographs of her friends (figure 50).

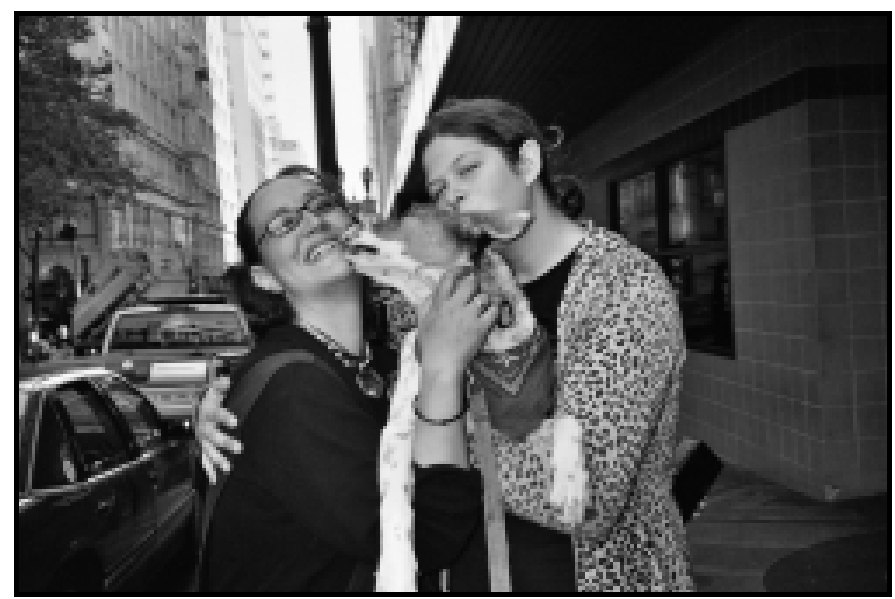

Figure 50: Untitled.

You need to have friends out here [on the streets]. That one has always been there. For the last nine months since I've known her, she's always been there. I've needed something and she's had it- she's given it to me, she doesn't put me down. I need to have friends, and always have them.

Rogue emphasized the importance of always having friends and keeping them in your

life. Jasmine echoed these words with her "need for good friends" and presented images of her friends on the street and hanging out at a homeless drop-in center (figure 51).

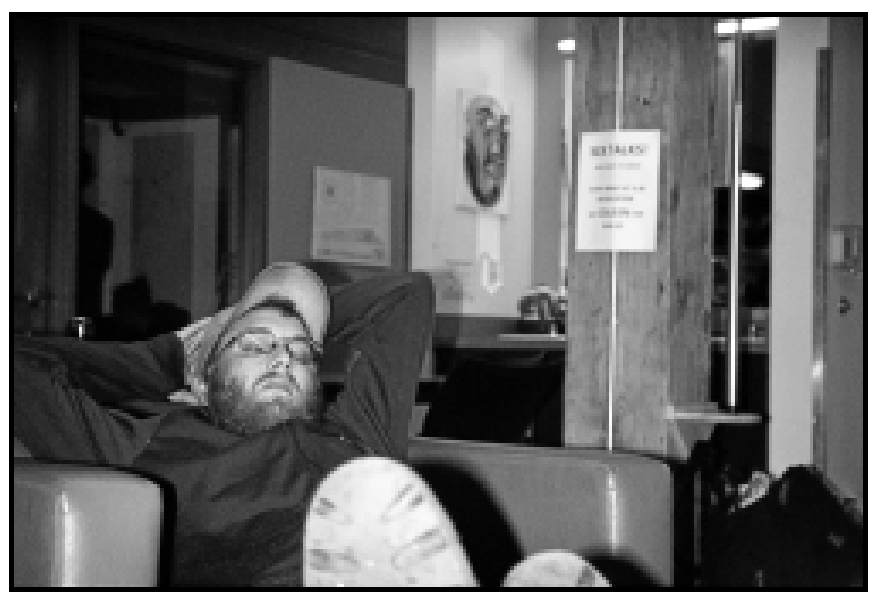

Figure 51: Untitled.

To represent her need for good, trustworthy friends, Sarah took a photograph of her medical driver behind the wheel of a car (figure 52). 


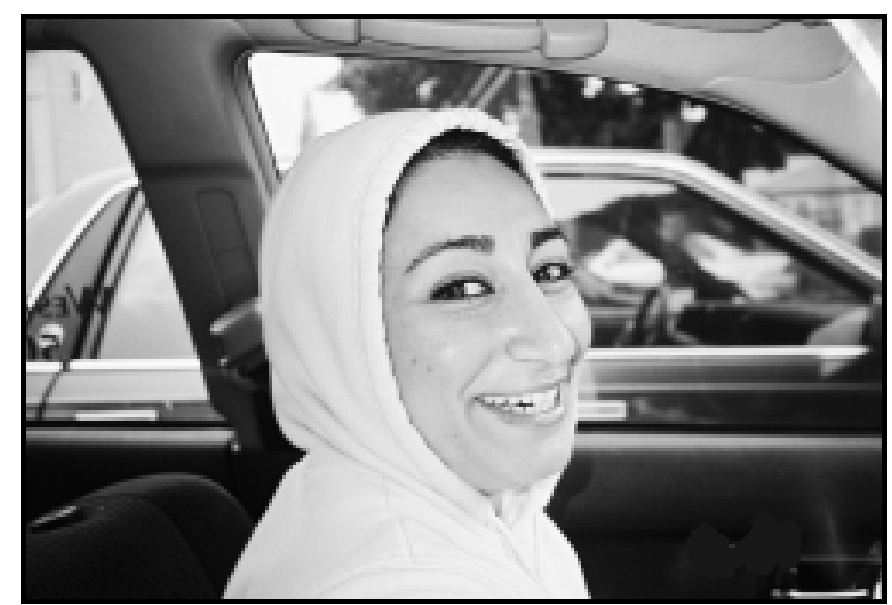

Figure 52: Untitled.

She described her photograph:

This is my friend. She drives me to my clinic every morning- she's actually my medical transportation driver and she's 27 . She's ten years younger than I, and she's been driving me for about two years...from Azerbaijan...she's the only person, friend, I have that's never been involved in drugs and prostitution and what not, but she knows all my stories, she knows everything about me... I call it my therapy. I get more out of sitting and talking to her than I do with my psychologist. I have somebody that I can trust that has no agenda...that happens a lot with addiction... people have a hidden agenda, or they're always up to something... I'm really glad I have her- without her I think I'd be crazy. She's talked me through some really hard times. So I just adore her.

Other participants who mentioned the need for support from loved ones during hard times also photographed their friends engaged in different activities. Mouse took a picture of her friend petting a dog (figure 53) and said:

The two of them just gravitated towards each other and they just both looked really sad...it made me think of how you need to find that bond with other people when you are having hard times. You just need to have another being there with you who will help you to pull through. 


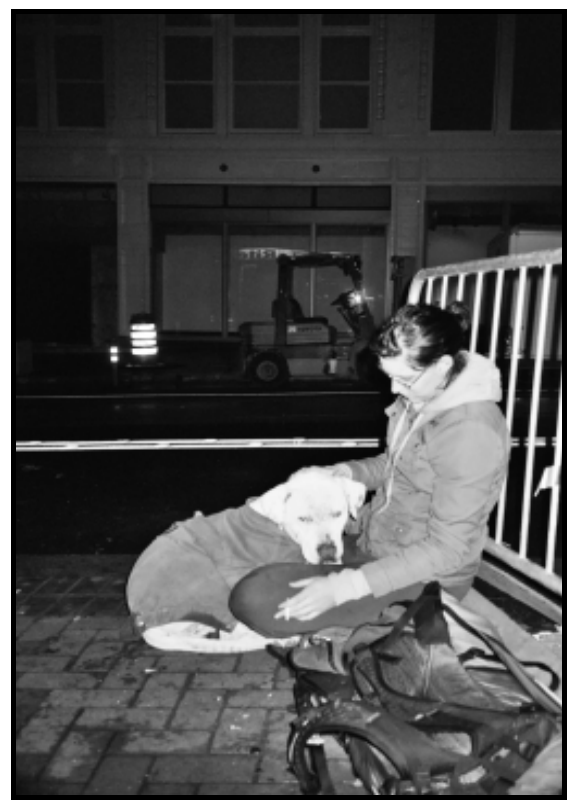

Figure 53: Untitled.

\section{$\underline{\text { Partners }}$}

Lady Purfection emphasized the need for support and presented photographs of herself sleeping next to her fiancé after a night of "grinding” (figure 54). She described her experience of trying to make ends meet and the strenuous lifestyle that she was living at the time when the photographs were taken. She presented herself in the arms of a loved one to illustrate her need for support during hard times and her optimism that her situation was only temporary.

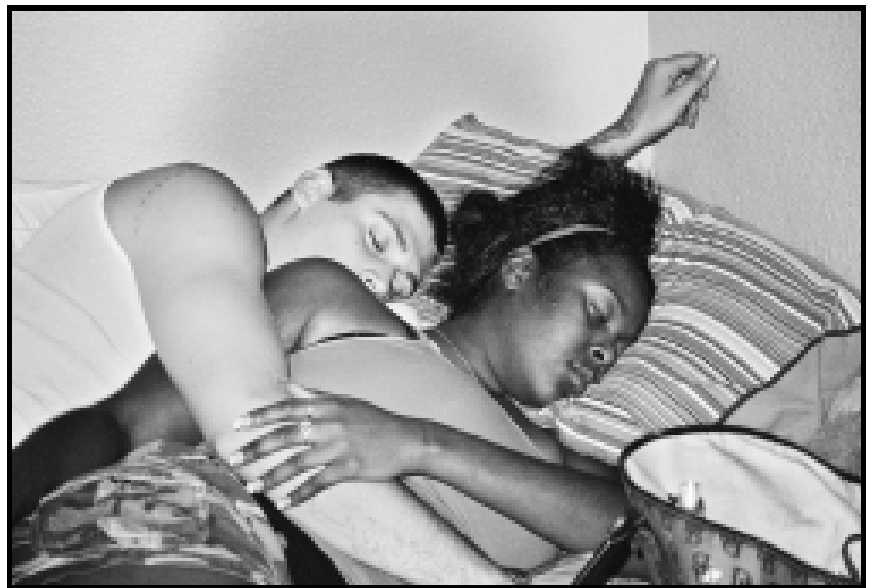

Figure 54: We grind. Warmth, comfort, speed naps, companionship. 
Rogue took two photographs; one of her husband and one of herself hugging him (figure 55). She stated, "This is a picture of my husband. And he's a need. I need to have him to feel whole. And it would kill me if I lost him."

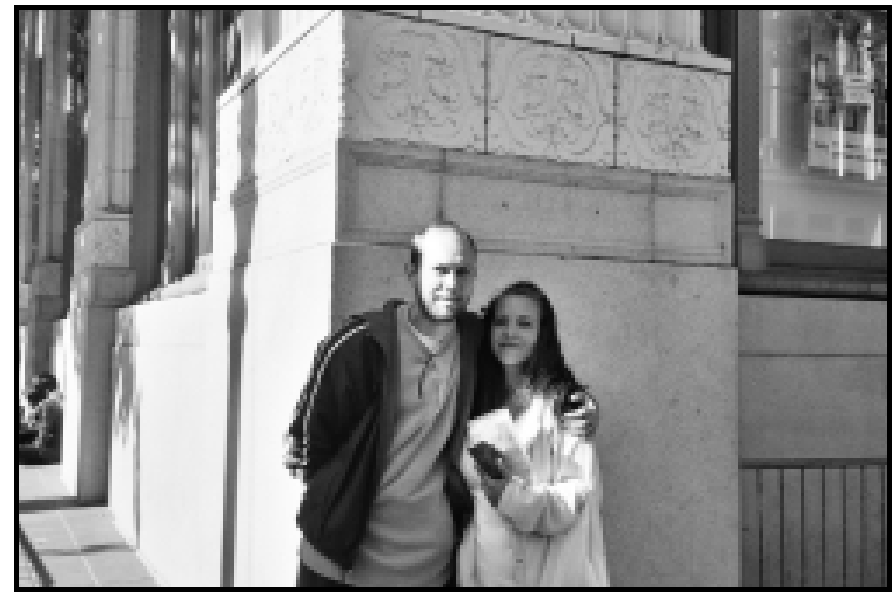

Figure 55: Untitled.

\section{Community}

Many of the artists relayed their need and/or aspiration for community and depicted this through art, poetry, body parts and performance. Crystal expressed the need for community support during hard times and photographed a mural to emphasize her point(figure 56).

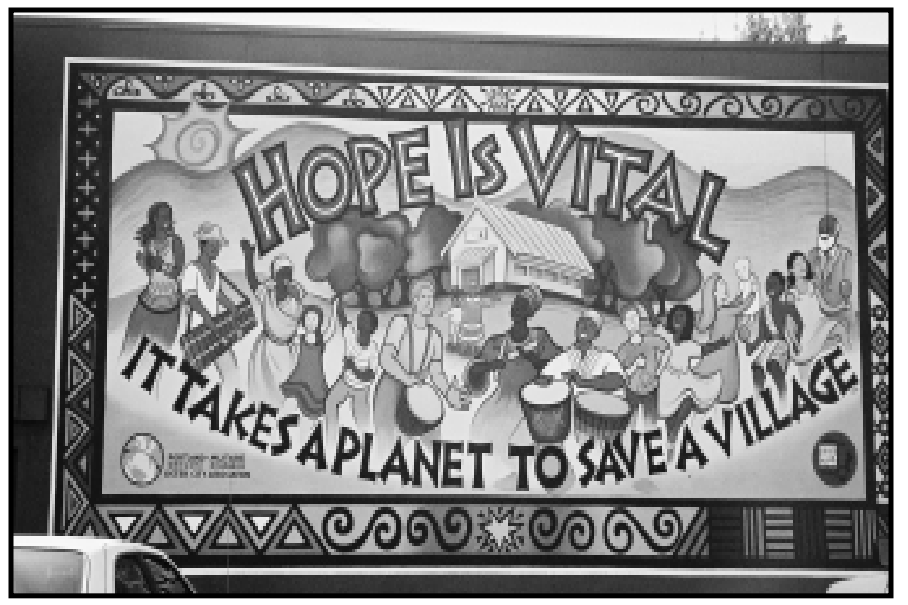

Figure 56: Hope for our community. 
She said, "This one says Hope is Vital which I believe is absolutely necessary. And it says, It Takes a Planet to Save a Village. And sometimes I feel that way. When you're really having a hard time it takes other people to help you. You can't do it by yourself."

Merry Mag highlighted her personal and communal need to foster women specific communities by photographing a woman's feet (figure 57).

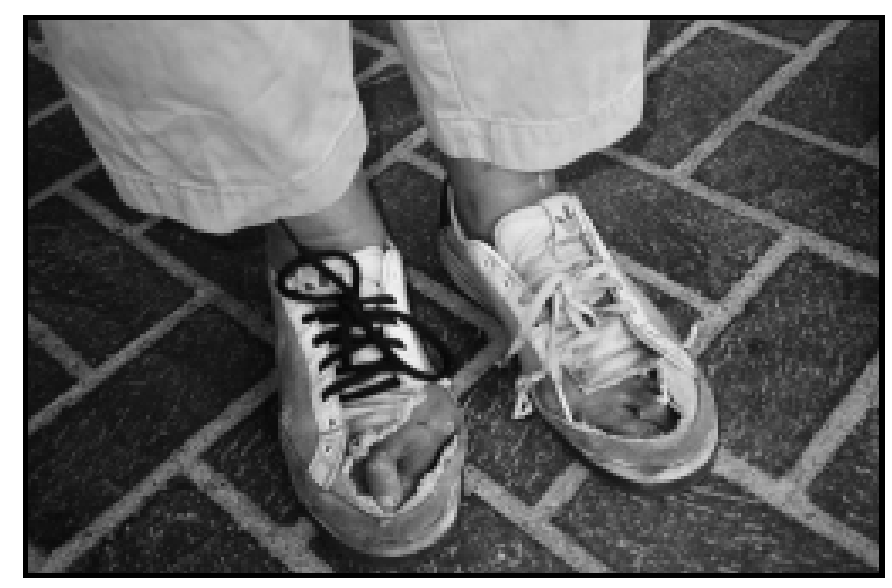

Figure 57: I can only hope my feet are matched and weathered as much as these beautiful feet from walking and doing outreach to others in poverty.

I'm really drawn to this woman I met...she's an older woman probably in her 80 s and I can see by her feet that she's traveled and that she's not one of these prissy foot women that has had a man taking care of her. She's trudged a road, probably the same path that I have; a road of destiny and has not bought into the system...She's probably been a prostitute most of her life and she's getting up there in age and she's very, very smart... we carried on a very good, intelligent conversation between each other. She allowed me to take a picture of her feet which I find very beautiful. When I'm her age I'll still be carrying my basket and have feet that are worn like that and not buy into the whole Max Factor industry or the whole male industry that says you have to look a certain way or be a certain way... the sisterhood I experience with street sex workers is incomparable.

Another artist who emphasized her desire for solidarity among sex workers was

Grahm. She photographed her friend typing in front of a computer to illustrate her personal and communal need for on-line communities of sex workers (figure 58). Grahm 
discussed the opportunity to communicate and connect with different people through the internet communities while having a choice to remain anonymous.

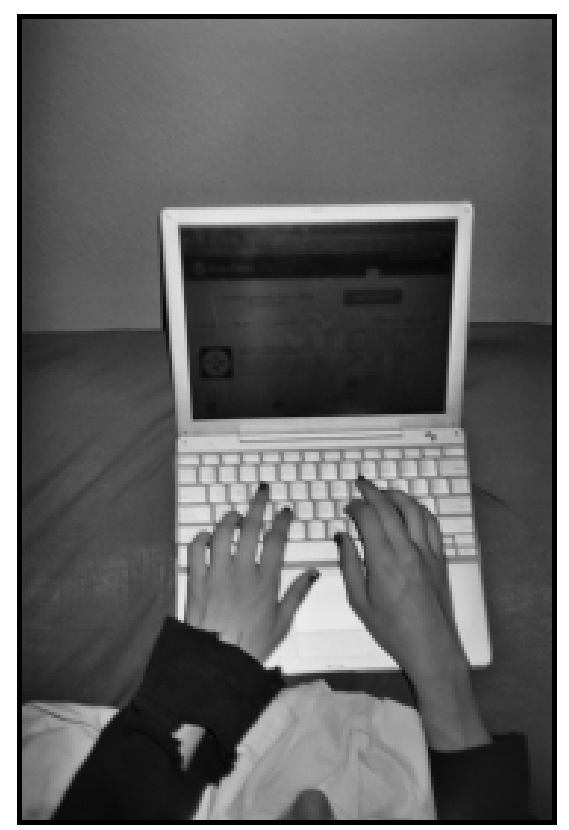

Figure 58: Untitled.

\section{Pet companionship.}

Dogs played a major role in the participants' lives. Many of the women framed their need or aspiration to have pets in their lives because of their loyalty, acceptance, unconditional love and support. Eight of the artists photographed their dogs in various poses (playing, sleeping, sitting, laying, and nursing) to represent their love for their pet. Lady Purfection took a picture of her dog, Cowboy (figure 59). She emphasized, "I know he loves me no matter what. No matter what I do, he's gonna love me. Even if I throw him in the bath and give him a bath he's gonna love me. He's gonna love me no matter what. And he's gonna respect me even if I'm a dancer or not." 


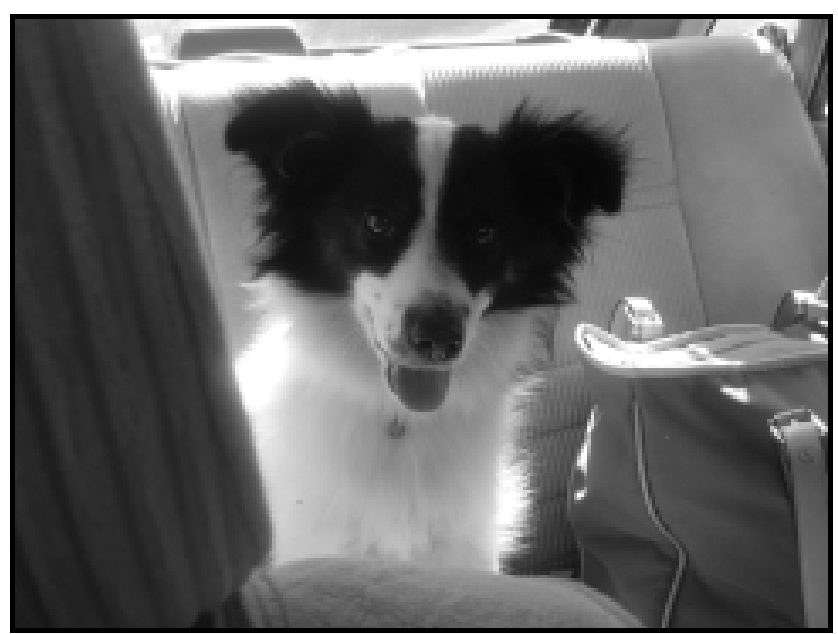

Figure 59: Cowboy: sporadic...fun, inspiration, love...never judges me for my profession.

Bee also photographed her dog.

Animals- they don't take drugs, they don't drink, they remember everything. I love the animals because they are better than people. I really do; they don't have ulterior motives. They have needs and they give. Dogs are so forgiving. Boy, they are the most forgiving animals, I swear to God...that's one of the reasons why I love animals. Since I was little I wanted to be veterinarian.

She shared the character traits she loved in dogs and her personal aspiration to always be around dogs. Similarly, Rizzo expressed love and adoration for Dumpster, her friend's dog (figure 60). She talked about Dumpster's key role among her group of friends as always being around for love and companionship. Rizzo also shared her aspiration to always be around dogs, to have their love, and to hold their attention. 


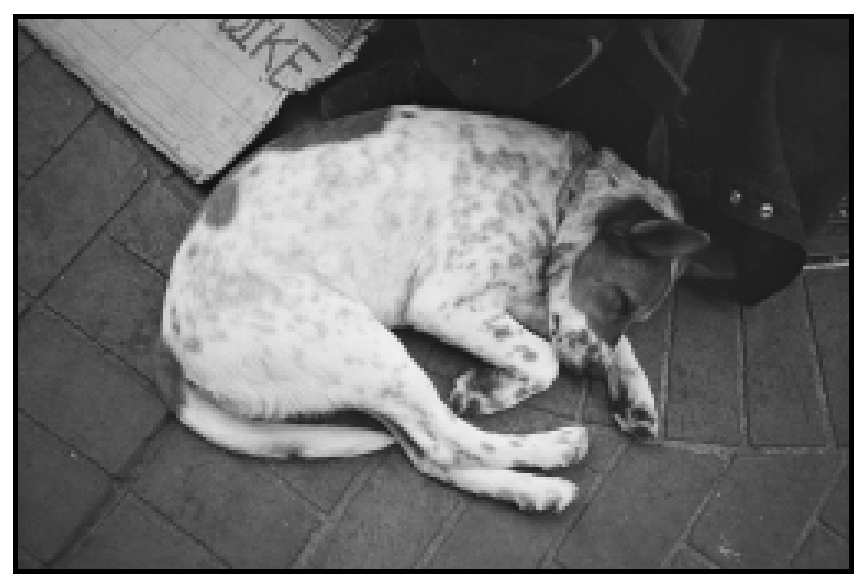

Figure 60: Untitled.

Mouse shared a similar appreciation for the unconditional love she has received from dogs and held them up as a model for how she wanted to be in life. Mouse's photograph was one of many that she took of dogs in different states of play and rest (figure 61).

Her name is Jet... the picture, on one hand, is basically about the fact that I want dogs in my life. I need dogs in my life. Having a dog around- it's the best reminder I can get for what I want my attitude about life to be. It is a great reflection of what my ideal outcome of my life would be because everything is new to dogs all the time... and they are always so excited and I want to be that excited about life all the time and they don't hold grudges.

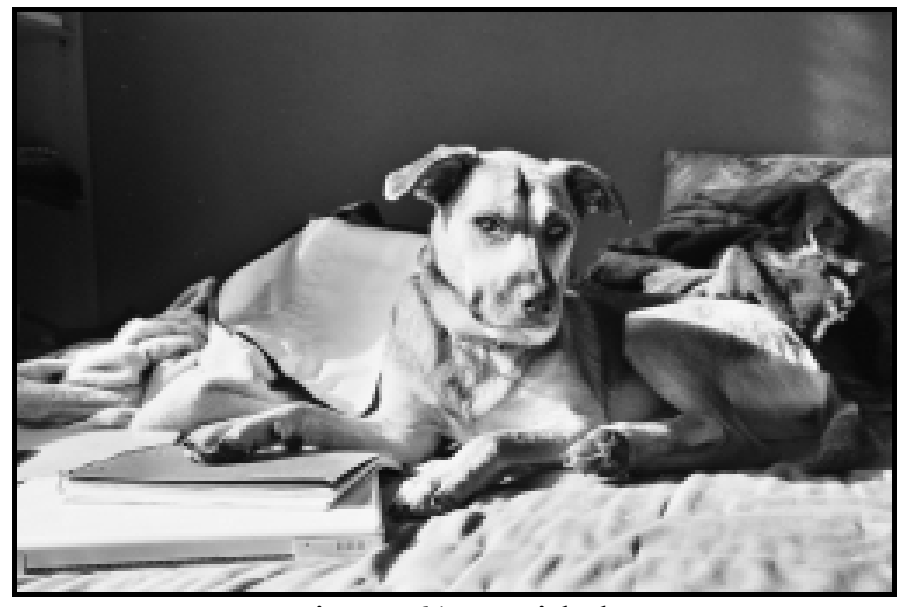

Figure 61: Untitled. 
Sarah also shared this perspective and took multiple photos of her two dogs. In reference to one of the pictures (figure 62), she shared:

My dog gives me much, much comfort. My little dog, Quincy, he knows- dogs are strange- they know when you're sick, they know when you're feeling bad, they know just what to do- especially this one...there's my other dog...he's not as cuddly and sweet as Quincy, but he's a good boy. He's 14 and he's been there with me through thick and thin.

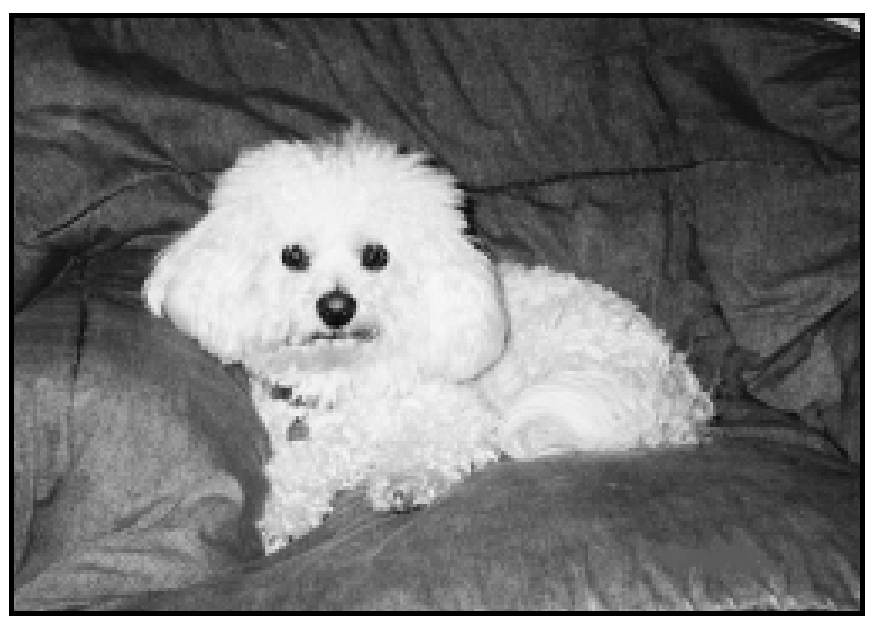

Figure 62: Untitled.

The women who photographed their dogs shared their love for them and their own personal and emotional connections with their pets.

\section{Meditations on death.}

The personal need to address the pain associated with the death of loved ones emerged as an important theme in the women's lives. Some of the artists who were currently living on the streets at the time of the study shared their loss of good friends. For these women, creating art through photography was an opportunity to address feelings related to death and loss. The act of photographing and sharing their stories of pain provided a space for healing. The different photographs taken included an image of a skull, a series of photographs at the scene of a murder, a memorial, Dead End road signs, tombstones, and self portraits recreating emotions of loss, pain and mourning. 
Two of the women took multiple photographs related to their experience of pain, sadness and suffering when their good friends were murdered by a serial killer in 1999 . Their photographs highlighted their need to remember these women, as well as the personal and communal need to stay safe. Merry Mag presented a series of self-portraits where she positioned herself in front of a newspaper depicting her hand-written words “tortured and murdered ho's" (figure 63).

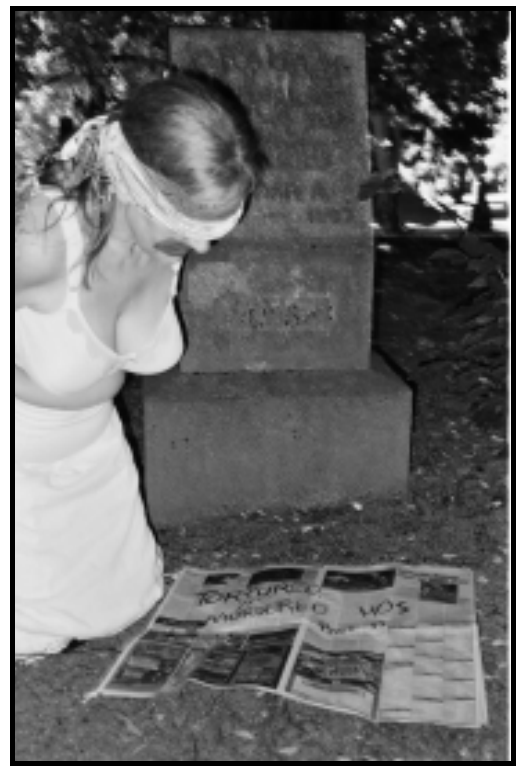

Figure 63: See you in Ho Heaven Tomorrow.

To accompany her series of images taken at a cemetery, Merry Mag said:

These pictures represent to me a lot of heartache. So much heartache that its really hard from me right now because I'm clean for one thing, and feeling all these feelings, its like a delayed reaction. I think about these women all the time. How they were tortured and murdered and how beautiful they were and how many men loved them...there was a murderer out on the streets that had been killing prostitutes. And there wasn't much written about us... in the papers, you know. What was happening- it was all hush-hush. It wasn't mainstream media news because we were just ho's. This is a tribute to them in honor of their memory and of my pain. When I look as this image of this tape over my mouths it's like I couldn't talk about it. I mean, I had to just go out there and turn tricks after finding out that my friends had just died in order to stop the pain or to stop myself from committing suicide or murdering myself...that's what these pictures are doing- they're speaking for me...that I have survivor's guilt that I'm still alive, and that somehow this project will help new and upcoming prostitutes know that 
you need to say safe. That there are people that care about us and nobody knows why we end up in the industry...I've always had a kinship with women emotionally and have always felt that men were just for, you know...getting money from, so, I hope I'll see them in ho heaven.

In another self portrait, Merry Mag held her head and cried (figure 64). Merry Mag spoke of the stigma she experienced as a sex worker and the lack of attention to the murders in the local media. She created meaning in her photographs by placing herself in a symbolic pose that represented her repressed feelings of pain and loss.

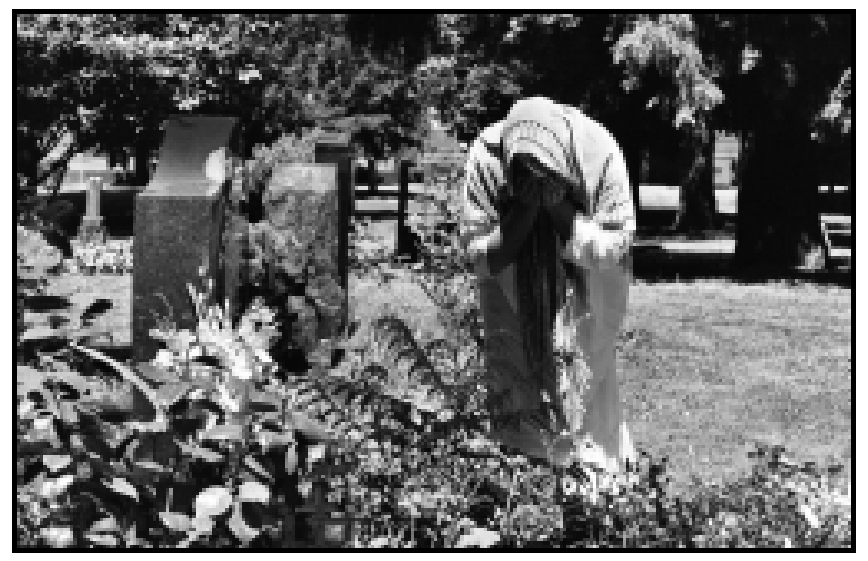

Figure 64: Eileen Wournos - you are my hero.

Sarah expressed similar emotions. She was also working on the streets at that time and experienced the murder of friends by the same serial killer. Sarah paid tribute to her friends through her photographs. Sarah traveled to the scene of the murder and took images of the road that led up the murder, the street and road signs in the surrounding area, the forest where the murdered bodies were found, flowers in a vase (figure 65), and a graveyard (figure 66). 


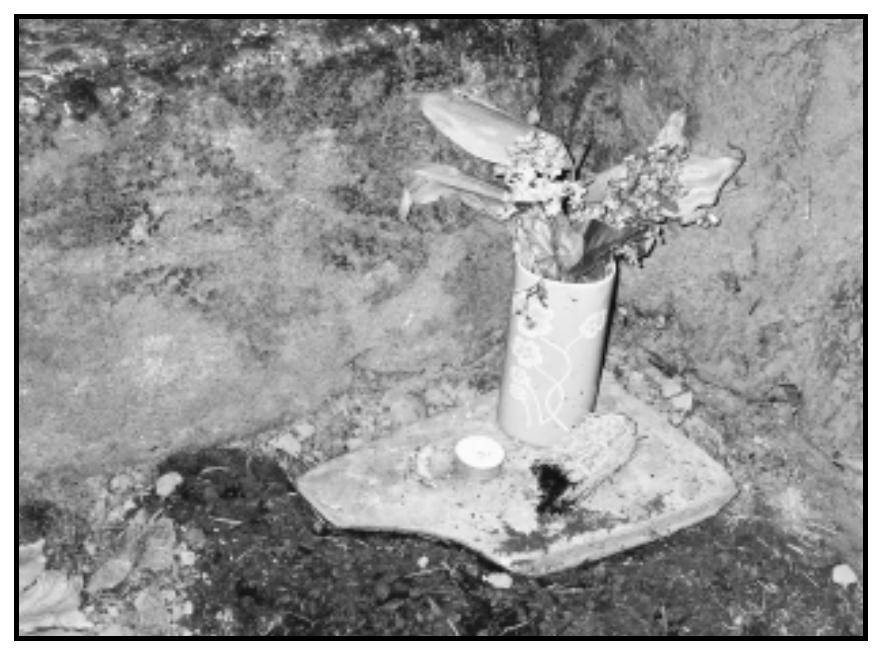

Figure 65: A memorial sound at the trailheads in Forest Park, in remembrance of the three beautiful women violently raped and killed here.

Sarah shared how she lit a candle and said a prayer to remember the women and explained her encounter with the memorial:

I found this memorial with sage, a vase, flowers a crystal, and a candle...I lit the candle...I leaned down on the concrete block next to it and I said a prayer. I think that's very important- I don't EVER want people to forget those women. To the prostitutes- the main public, they're like, "oh, they deserved it! They were asking for it." These women were mothers, children of mothers, daughters, sisters, parents, granddaughters- they deserve some respect and they deserve to be remembered. I know I will never forget them and I will try my hardest to always make sure that they are remembered. There is a need for everybody to understanda need for people to have a sense of compassion for these women that are just trying to survive. The need for law enforcement to put their energy into these predators and not into the women who are simply trying to survive and not hurt anybody... because as women, we represent each other; it could've been me, it could've been any of us.

She also referenced the media and the public's lack of compassion for the street workers who were murdered. Sarah shared her feelings of sisterhood and support for all of the women working on the street. She expressed the importance of having compassion for her murdered friends who were trying to survive in a society that judged them for the work they engaged in. She also explained that her series of photographs represented death and sadness, but that sex work wasn't only about death, sadness and pain. 


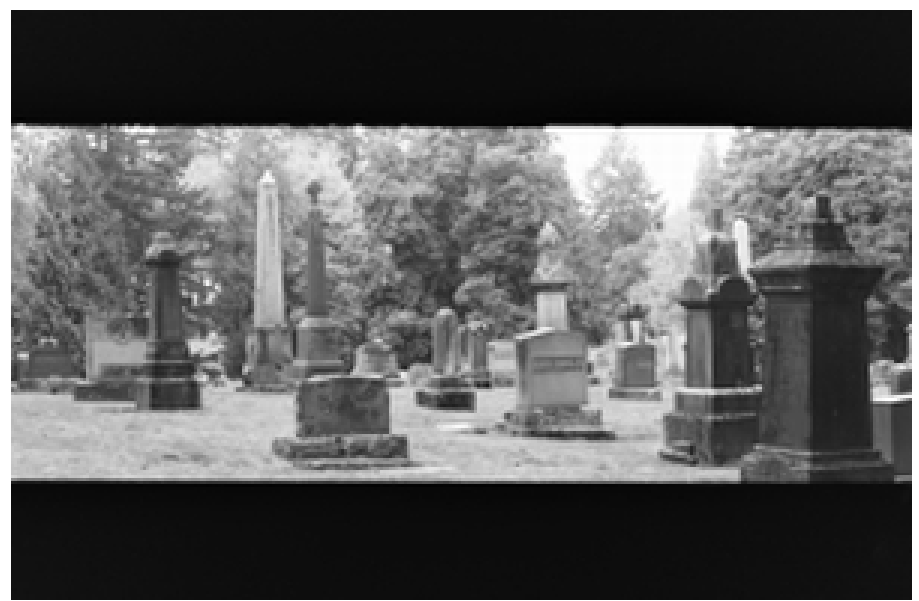

Figure 66: Untitled.

I want to say, its not all- I hate when people think that its all bad, like, I don't feel like a victim, I mean, I've been raped and I've been robbed but that's maybe $.001 \%$ of the time. The rest of the time I've been treated very well and with respect and I felt empowered. So I don't feel like a victim at all, I felt empowered. But these photos represent the sadness of it, you know, that there are the predators out there and we pray, I guess.

Sarah made sure to assert that even though there was potential violence to be experienced when engaging in street work, she did not consider herself a helpless victim, but rather, she felt empowered by her work.

Another participant who addressed her emotions about the recent death of a close friend was Jasmine. She acknowledged her repressed sadness and expressed her need and aspiration to accept death in her photograph of a skull (figure 67).

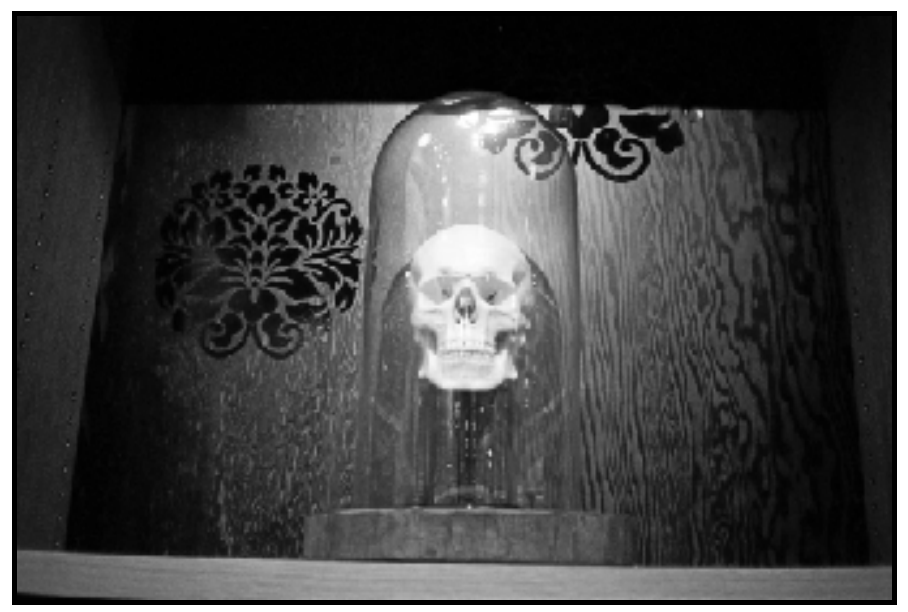


Figure 67: Nordstrom Skull.

Ok, the skull, I love this skull...That would be a future aspiration and the need to accept death. Because there's been a lot of deaths for me in the past year that I've had to deal with and it's been really rough. I'm kinda angry that they're gone and I don't know how to handle this stuff and it's really shitty for me. The skull-the only thing I could think of that represented death- and I don't want to deal with it. Like, it's locked up in a case, so being able to not let it touch me is hard... inwardly especially. I mean outwardly, I've been able to make it with saying, "I'm ok," but a lot of times I'm not. So it just kills me, whenever I think about my friends who died a few months ago...

The artists who discussed their feelings and shared their stories about the death of friends and loved ones identified different stages in their experience of loss and mourning. Each woman had a different manner in which she coped with her emotions related to death and the ways in which she presented this through art.

\section{Fostering of the Mind and Soul}

The theme Fostering of the mind and soul reflects the artists' personal needs and aspirations related to the cultivation of the intellect and spirit. The two sub-themes that surfaced were (1) educational endeavors and (2) faith and spirituality. These two subthemes highlight the intellectual and spiritual pursuits of the artists. The need or aspiration to pursue an education was often related to obtaining a college degree and new knowledge in order to transition out of the sex industry. For others with access to more resources, the need or aspiration for educational pursuits (through reading books) was related to self-enhancement. The personal need or aspiration for faith and spirituality was articulated by various artists as a source of hope and strength in their life.

\section{Educational endeavors.}

Some of the artists expressed a need or an aspiration related to school and education. 
Cultivating one's mind was important and central to their idea of enhancing self and upward mobility. Those women who identified a need or desire for a college education also articulated wanting to transition out of the sex industry and often had an idea of what they wanted to study. Those participants who were most marginalized (i.e. homeless), with the exception of Rogue (who hated having to engage in sex work), did not identify school or education as a need or aspiration. This was identified as important for those artists that had stable living situations.

To represent their desires or need to go back to school, some of the women photographed school buildings, university signs, books and university sweatshirts. Rogue photographed a university sign (figure 68) and expressed her aspiration to go back to school for a business degree to "open up a restaurant and have good business ethics."

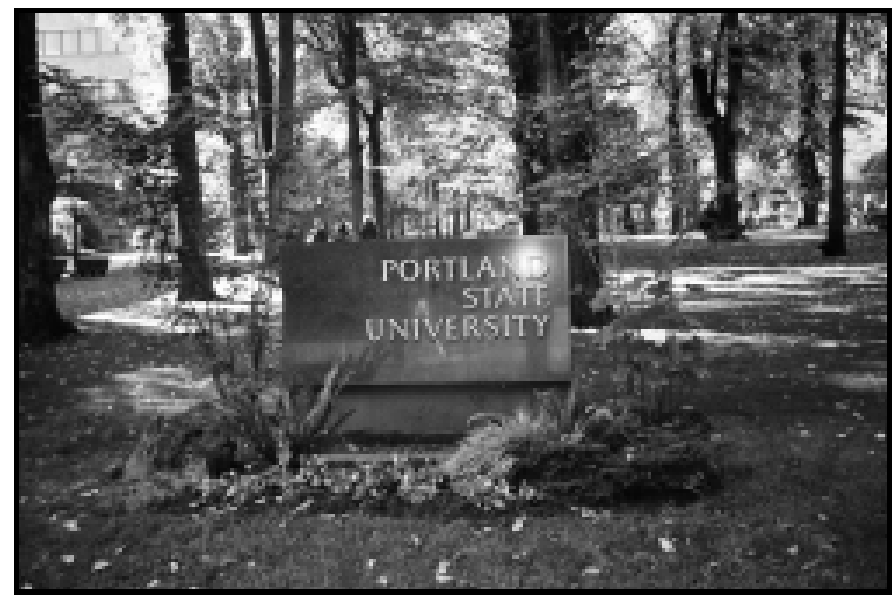

Figure 68: Untitled.

Similarly, Alex photographed a school building (figure 69) and shared her desire to go back to school and study computer graphics, specifically animation. 


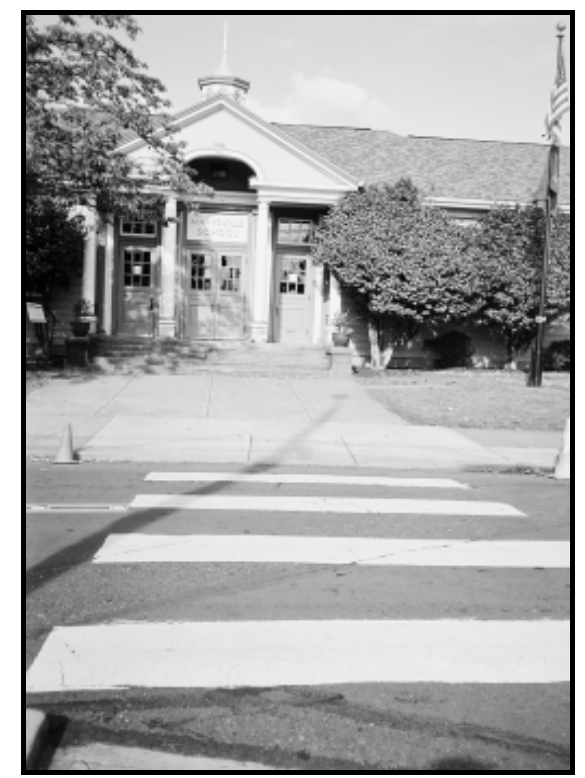

Figure 69: Untitled.

Bee expressed her need to go back to school through a photograph of a university sweatshirt with a $\$ 100$ bill placed on it (figure 70 ). The money represented her desire to go to a "good university" and her need for tuition money. Bee shared how she valued education and stated, "I think all people should further their education because it makes them a more well rounded person even though a lot of people think it is a waste of time."

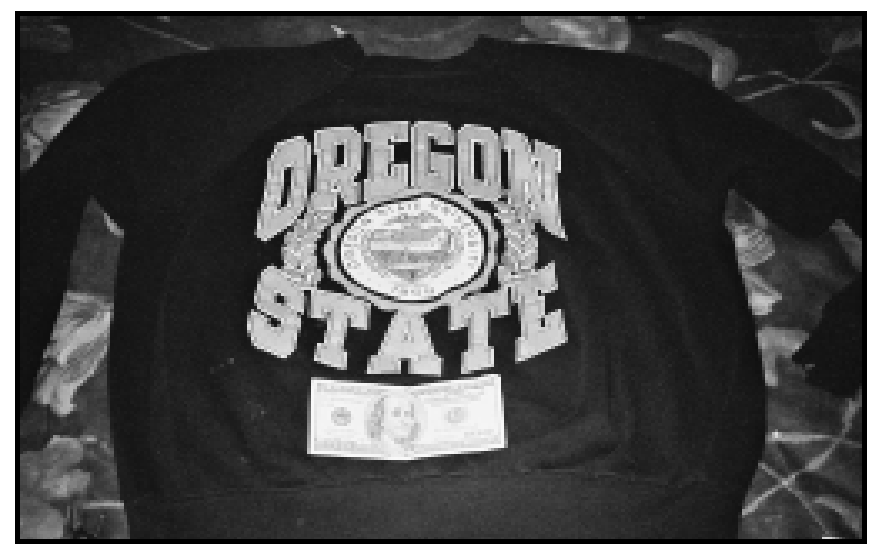

Figure 70: Untitled.

Crystal photographed a bookcase to represent her need and aspiration to continue to educate herself in order to improve her life. Crystal said, "it's always good to get into 
books 'cause the more you know, the more you can apply it to your own life and hopefully get better jobs. Education is very important in order to stay out of crime.”

As a student enrolled at a private university at the time of the study, Mouse also photographed books that she placed on her staircase to represent progress (figure 71). Through her photograph, Mouse represented both her aspiration to finish college and her need for books in her life.

I $d o$ want to finish school someday. I put them [books] on the stairs because I think of stairs as upper progress and someday I'll march forward and finish my degree somewhere. You know, chip away at it and it's gonna get done someday. I need books in my life. College is the aspiration and books are the need. I have never been able to live without books. I started reading when I was two and my mom always joked about how books were like my security blanket.

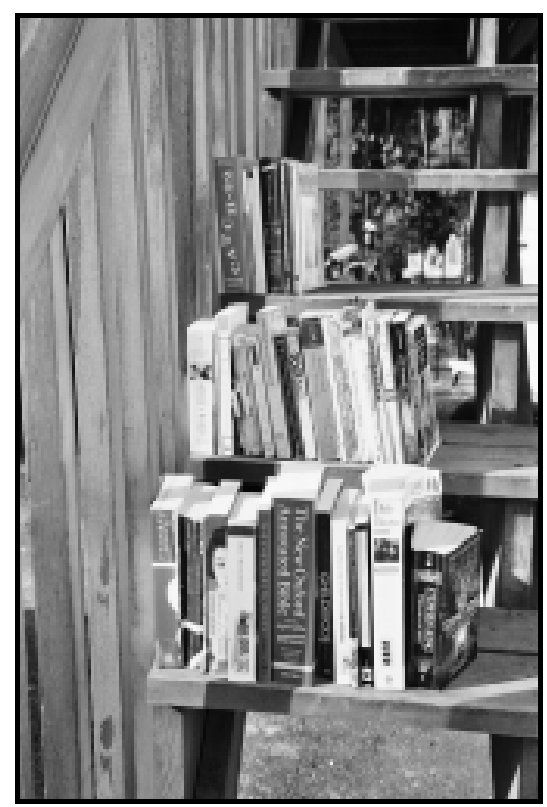

Figure 71: Untitled.

While many of the women articulated a personal need for a college education, Grahm, a college student at the time of the study, expressed a personal, communal and societal need and aspiration for sex education and sexual self knowledge. She photographed her friend reading a book on a bed (figure 72) to represent empowerment 
through knowledge of one's self and body.

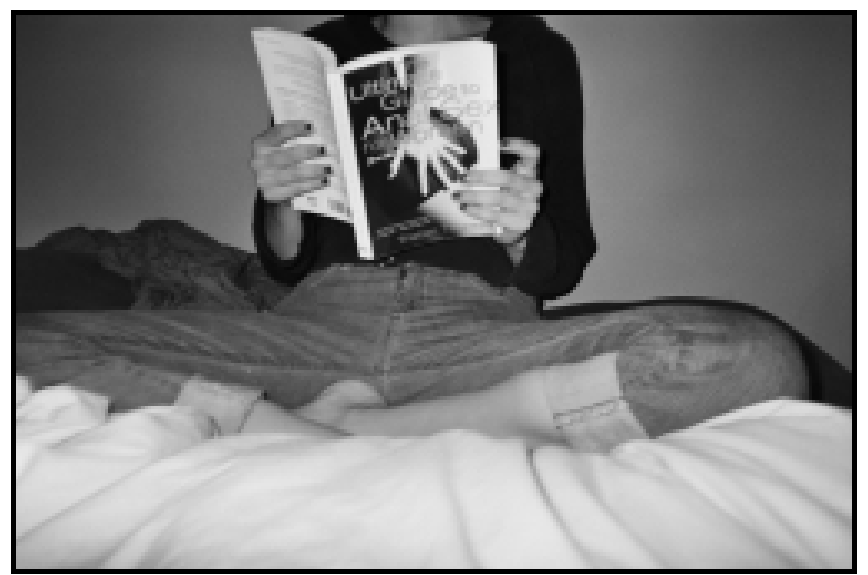

Figure 72: Untitled.

Grahm accompanied her series of photographs with the following explanation:

These are a couple of photos of my friend sitting on a bed and reading The Ultimate Guide to Anal Sex for Women. I took this photo because I wanted to have an opportunity to mention a lot of sex workers' literature. Tristan Taormino wrote that book and she's an interesting pornographer, like, a sort of "empowering, learn about sex, take your health into your own hands" sort of culture that I think is, in a lot of ways, related to sex work, even if you go way back to Nina Hartley's instructional videos. They are instructional porn and the beginnings of feminist porn that are related to teaching people about their bodies.

For Grahm, knowing about one's own body was a source of empowerment and books represented a way to share skills and knowledge to improve one's life and the lives of others. She went on to share her belief in the power of information sharing:

Talking about sex is skill-sharing in this context- it's not that talking about sex is inherently liberating or whatever, but I do believe that openness is valuable as a way of learning how to communicate about things that are difficult. In talking about things explicitly we begin to get comfortable articulating our own boundaries, protecting ourselves and learning to have the type of sex- with clients or lovers or whoever or with ourselves- that we want to have.

\section{Faith and spirituality.}

Belief in a higher power, faith and spirituality were identified as important to the women's lives. Over half of the participants expressed their need or aspiration for faith 
and shared the importance of spirituality in their lives by depicting photographs of crosses, churches, statues of Jesus, Islamic prayer rugs, and other faith-based symbols. Faith was a source of empowerment, contradiction and inspiration for the artists.

Rogue photographed a church (figure 73) and said, "I grew up Mormon, but I'm not Mormon. I gotta go get back into the church. I gotta rebuild my faith. It's a need.”

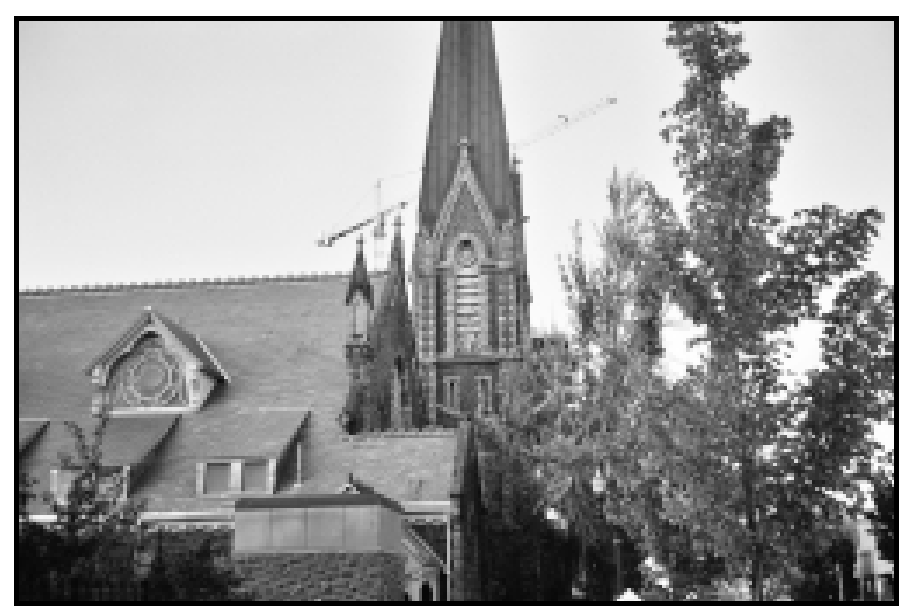

Figure 73: Untitled.

A similar reference to the need for faith was made by Crystal, who photographed a statue of Jesus on a cross (figure 74).

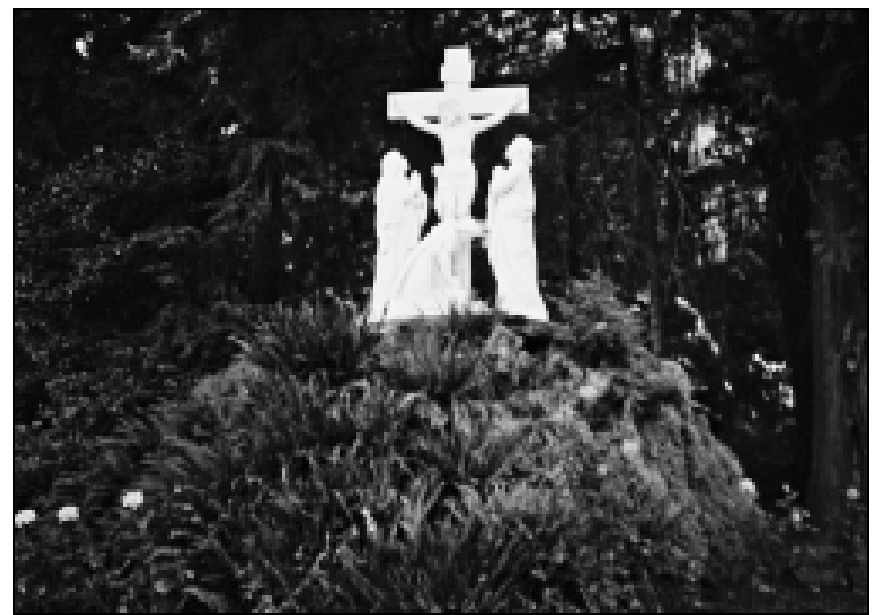

Figure 74: Being spiritual and having a good relationship with God.

She expressed her need to connect with a higher power and said, "You know, Jesus was 
carrying the cross and...it's just very, very peaceful. You know, it kind of gives you hope that there's someone up above watching."

Alex photographed of a statue of Jesus (figure 75) and stated, "This is the need to have Jesus in my life." She also expressed her aspiration to be close to God in another photograph that she took of a church.

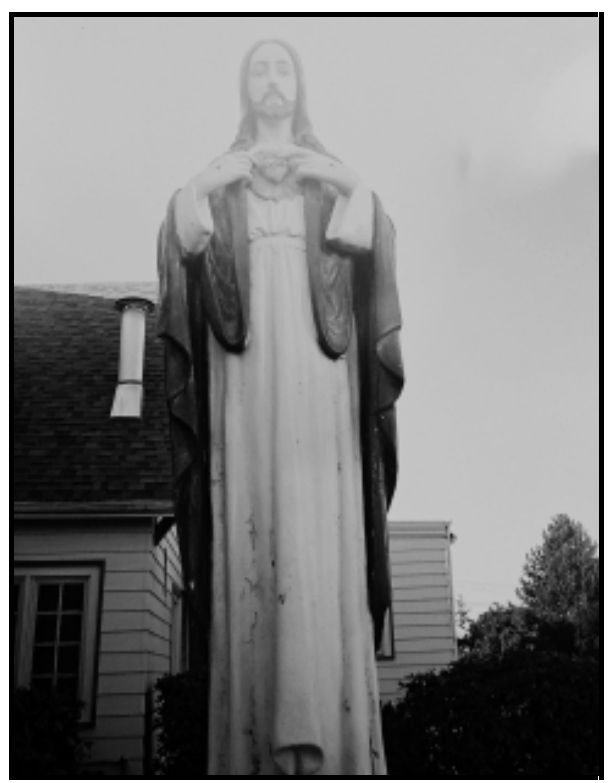

Figure 75: My Best Friend.

While some artists photographed religious symbols, others artists photographed them-selves next to sacred objects of spiritual value, as well as loved ones. For example, Lady Purfection photographed her fiancé in the car with a cross in front of him to represent her aspiration to keep having faith, which brings hope in their lives (figure 76). 


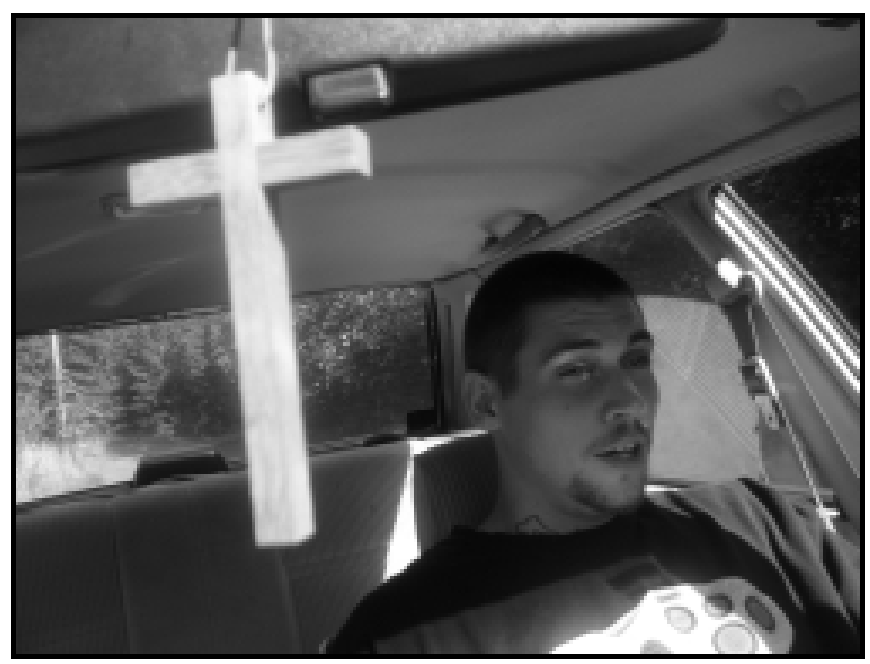

Figure 76: God Bless.

Merry Mag photographed an image hanging on the walls of her bedroom that represented her faith (figure 77) and also photographed her prayer rug (figure 78).

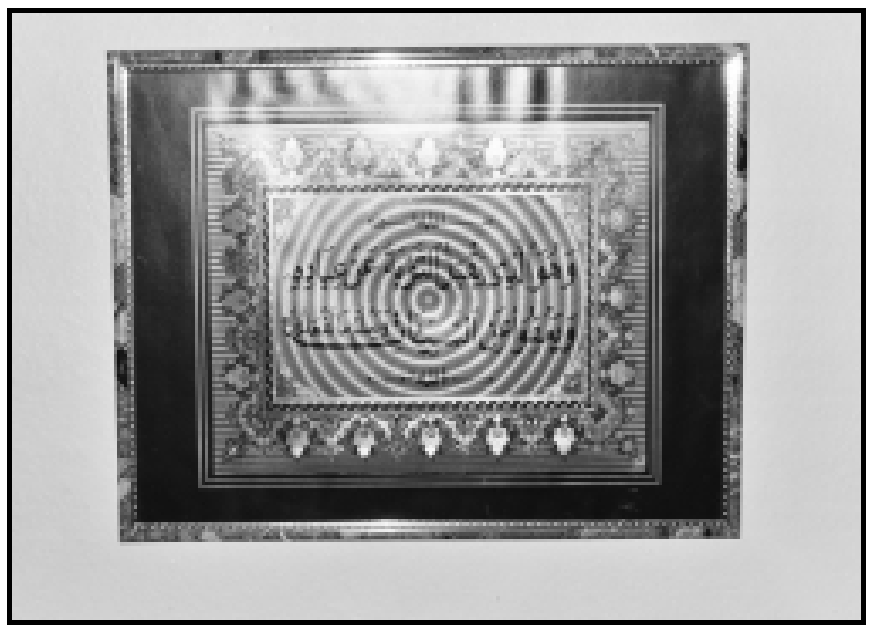

Figure 77: Untitled.

She shared the internal conflict she had with her spiritual beliefs and her work in the sex industry. Merry Mag expressed, "I believe my whole life is a spiritual experience; even turning tricks is very spiritual to me because it is very intimate." She identified her conflicted self when she continued, "I have this prayer to Allah...am I bringing too much attention to myself? Because in Islam we're supposed to be very humble, but I feel like, as an artist, as a creative person, that I am the art." 


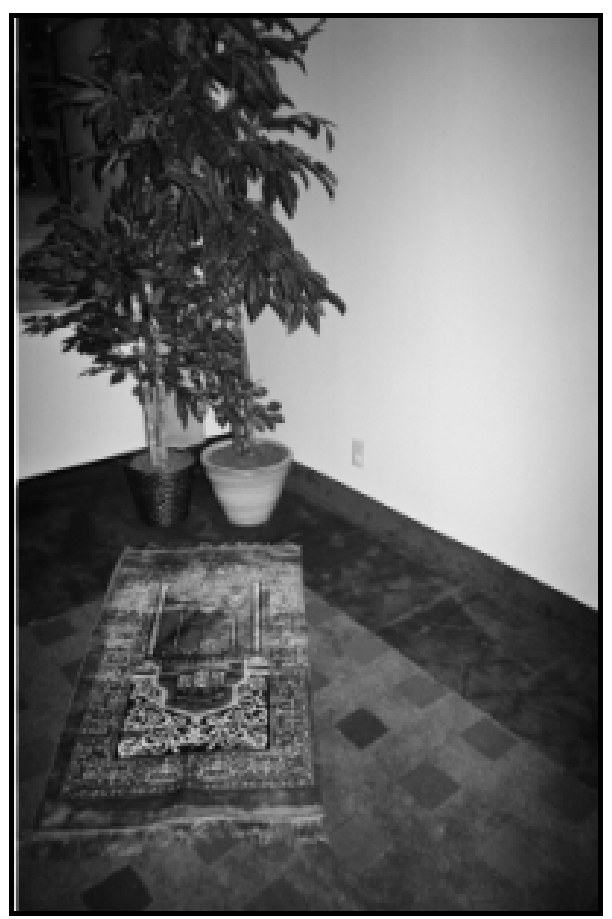

Figure 78: Untitled.

To represent her need for faith and spirituality in her life, Sarah placed a baby photograph on top of a Holy Bible (figure 79).

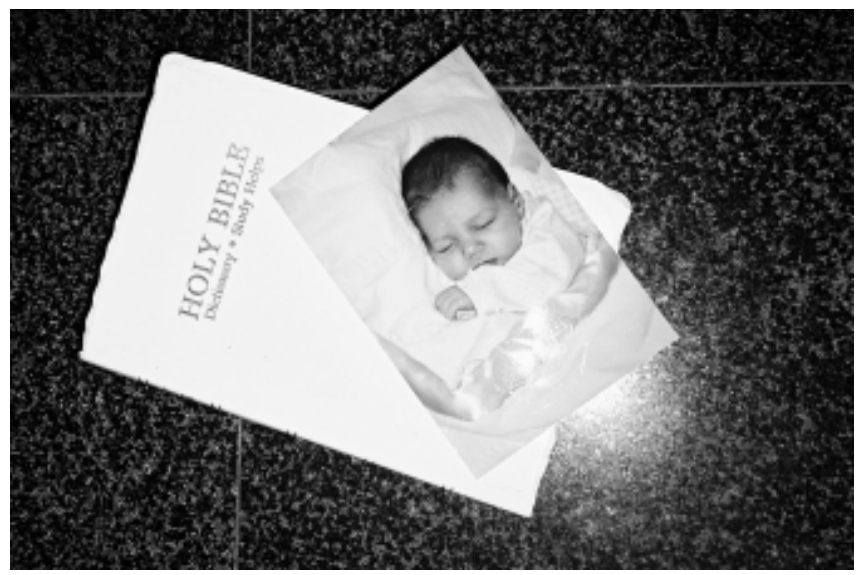

Figure 79: Untitled.

The picture of the Holy Bible and the baby- that's my niece and it's a representation of my faith, which has brought me through all the hard times of working and addiction, and what not. And my niece kinda represents the same thing, you know, she represents- she is the reason why I am working so hard to improve my life. I took a picture of the Bible, not necessarily for Christianity but the need for spirituality- without it, I am sure, I know, I wouldn't be around. 
Social Justice and Activism

Social justice and activism represents the political agency of the women and their activist efforts to speak out against the criminalization of sex workers, work-related stigma, and other injustices. The three sub-themes that emerged include: (1) sex workers' rights; (2) judgment, stigma and stereotypes; and (3) poverty and racism. The artists expressed their advocacy for sex workers' rights through the communal need to address the criminalization of sex work and radical feminist discourse on sex work. The artists expressed personal and communal needs to not be judged, stigmatized or stereotyped differently. Some participants shared their personal needs to not feel judged for the work they did in the sex industry or because of their homelessness. The need to end stigma and stereotypes associated with sex work was expressed as a communal need by those artists with the most privilege. The artists also called attention to the stereotypical victimization of women in the sex industry and the notion that sex workers needed to be saved. Many of the women also articulated the need to address poverty and racism within their communities. These photographs centered on communities of street workers and homeless individuals. The artists who illustrated issues of poverty also shared their own experiences of stigma related to homelessness and street work.

Sex workers' rights.

The artists were vocal about their needs to defend the rights of sex workers. Many of the artists expressed personal, communal, and societal needs for activism in support of the rights of sex workers through representations of collages incorporating activist material, through humor relaying an activist message, and by performance portraying an activist idea. Regardless of the type of sex work the women engaged or their access to 
resources, the participants highlighted their rights and institutional injustices against them.

Sarah photographed three condoms (figure 80) to highlight the unreasonable laws criminalizing women, specifically street workers.

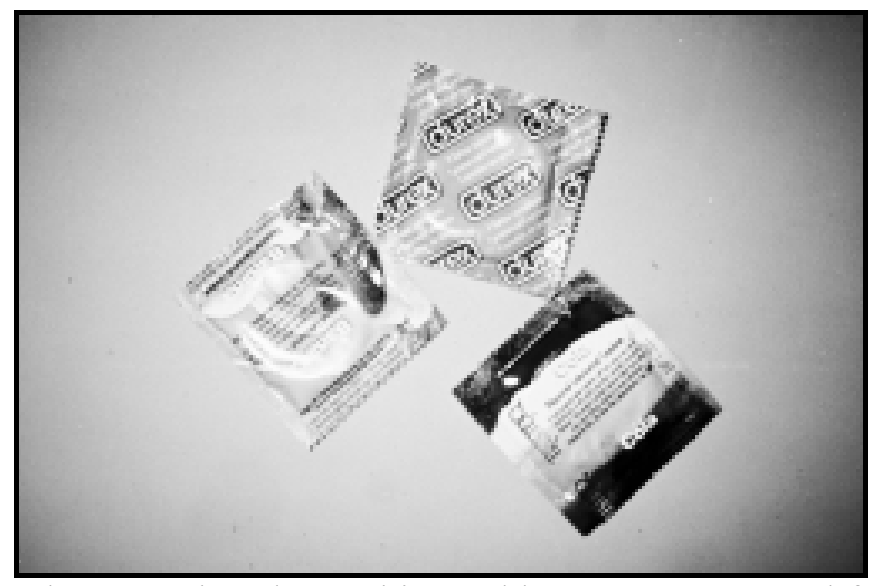

Figure 80: The three condom law: This could get YOU arrested for prostitution!

Three or more condoms can get you arrested for prostitution. And that's really important to me. I HATE that law. It makes me SSSSICK. Here women are trying to protect themselves and others against AIDS and Hepatitis and other diseases, and they're gonna arrest them for it?! That needs to be changed.

In a photograph of her cat (figure 81), Sarah used humor to highlight the unjust criminalization of sex workers.

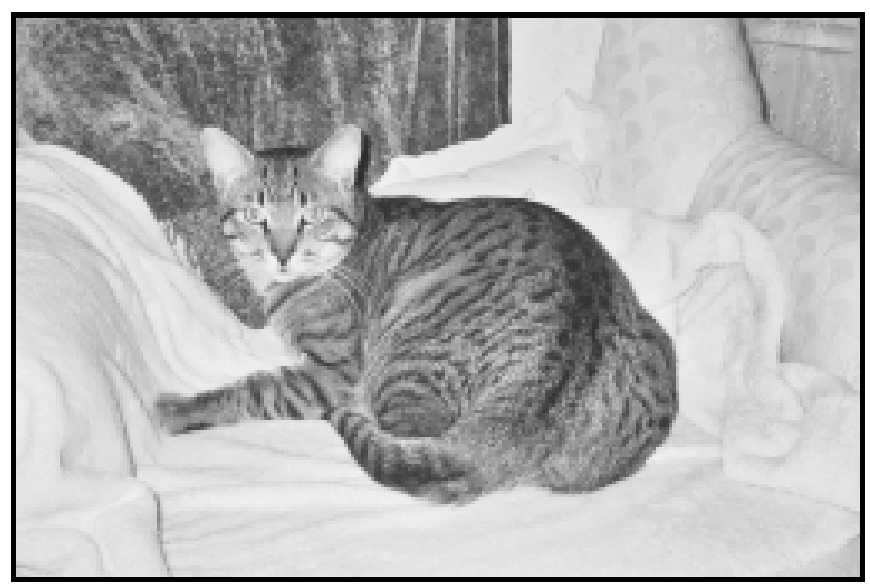

Figure 81: The last legal pussy.

She explained, "This is my favorite one (laugh). I want, underneath it, something like, 
“the only legal pussy" or "the only pussy that's legal" (laughter)... That's exactly what this is about- legalization... It's a huge passion of mine." Similarly, Jasmine expressed the societal need for legalization of prostitution.

My opinion, to really help sex workers would be to make it safe for them to carry out what they do. I don't think there is anything wrong with selling your body if it's safe and it's clean and it's regulated like in Amsterdam...they have a whole system for them [sex workers]. They take care of them. The government takes care of their health...that's why I think that this government [Bush

Administration] is suppressive...they don't want us happy and safe. They want us repressed under parental laws and they want to own our bodies, literally. It's horrible. I mean, by making prostitution illegal they're not helping people; they are making our lives worse. I, I-ugh! I, I really, I hate it! They don't care about us women, they just treat us like garbage, they think of most of us as garbage...

Merry Mag shared her anger towards privileged policy makers and the

unreasonable laws used to punish sex workers. She stated her preference for the

decriminalization of sex work and created a collage of images to include activist buttons, signs, stickers, money, make-up, and undergarments (figure 82).

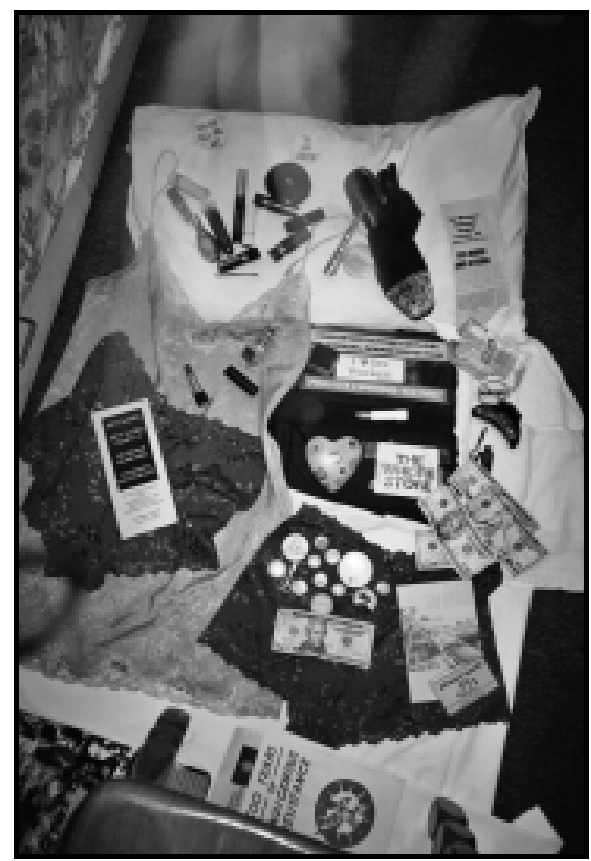

Figure 82: There is no shame in consensual sex work. There is shame in a society that would criminalize us for trying to support and protect ourselves. 
It's hypocritical. Yeah, you know, white men making the laws. Because they don't like that women are making money for it [sex work] and they don't like it that they are being tricked out of their money. You know, they don't want women having the upper hand and they're pissed off that women have all the pussy. They feel like they should be able to get it for free, when and however they want. But it's one way I feel like where women have the power is in our pussy but we're not taught that's what it is, that we can use it as a way to get money. So I think it's very hypocritical. I'd rather it be just solely blunt fuck honest -I'll give you head the way you like it, and you give me money so I can pay my bills or do whatever the hell I want with it. But that's illegal and that's stupid.

Grahm focused on her personal and communal aspiration to build a stronger

activist community around stripping. She photographed a resource and information box

located in the dressing room of the exotic dance club where she worked (figure 83).

It's a box that is from the mid to late 90 s, that some women who were involved in a non-profit and activist organization, Danzine, had this...it was just this really cool, grassroots, activist effort. I wish that there was something like that going on right now, and that people were engaged in the same sort of projects, which I guess I could take the time to do if I wasn't really involved with school... but that's definitely an aspiration of mine- to build a stronger activist community around stripping specifically, sex work generally... So this is a little free box and it says "use me but don't abuse me" on the side. We just have random little things like razors, condoms and PWCL flyers in it...

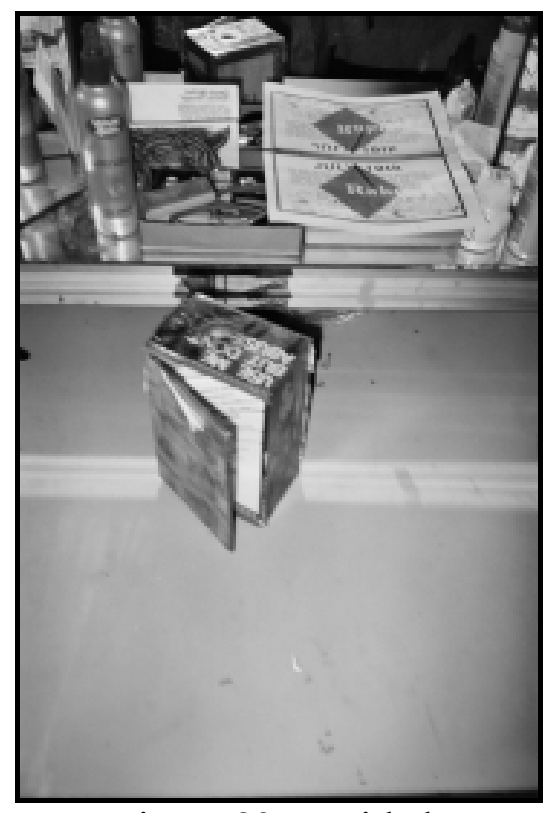

Figure 83: Untitled. 
Grahm also took a series of photographs to challenge assumptions and ideas about sex workers as a homogenous group (figure 84).

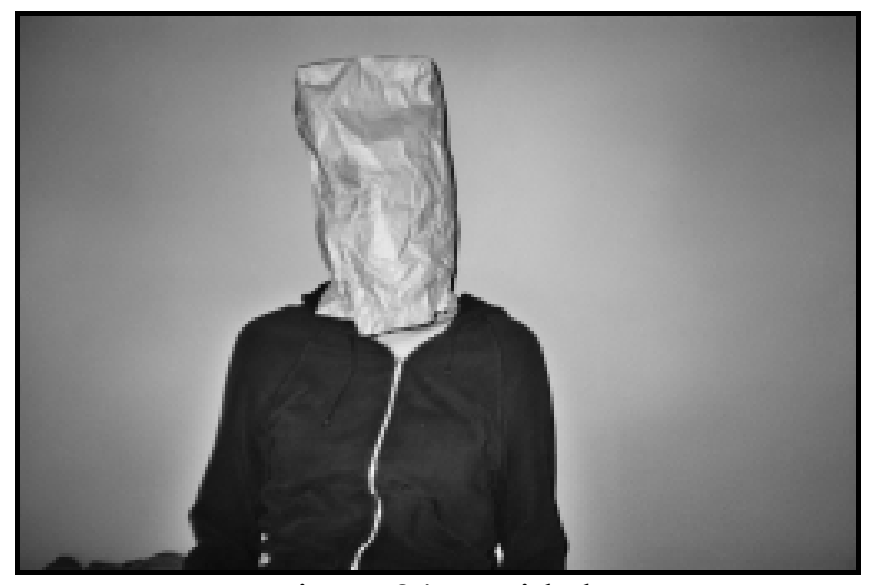

Figure 84: Untitled.

I had my friend wear a paper bag on her head for a few reasons. Generally, to express how sex workers are talked about as a subject group, and not given a face, and talked about historically as a social problem and a thing that happens- not as something that people are engaged in- an abstract phenomenon that has nothing to do with the people that actually do the work.

Grahm used her intellect and knowledge of history to express personal, communal and societal needs to challenge radical feminist discourse on the sex industry. She re-created a historically symbolic image related to the sex worker's rights movement and added:

Also, it's a reference to "Scarlot the Harlot," who is an old-timer sex worker/activist... So Scarlet the Harlot wore a paper bag on her head...to a "take back the night" protest to sort of get people to think about the ways they were excluding real people from their cause. I think that radical feminist discourse talks about prostitution in a way that is really abstract and not addressing the fact that there are people that do this work that come to this work from a lot of different places. She [Scarlot] used to do this work for a lot of different reasons, so that was a little bit of a thing about Scarlet and old school prostitution activism.

Judgment, stigma, and stereotypes.

While the issue of stigma was raised in multiple stories, there were some women who specifically photographed and addressed personal and societal need to challenge stigma, stereotypes, and assumptions about sex workers. The experience of stigma as a 
sex worker was discussed in the context of theories imposed by academics, media stereotypes, assumed gender roles, and economic marginalization. Stigma was expressed differently by the artists depending on their work environment, access to resources and identities.

At the club where she worked, Grahm took a series of photographs depicting money and drinks on a dressing room table (figures $85 \& 86$ ) to critique social stereotypes of strippers.

So I took some photos of some piles of cash because there's this idea that strippers make helluv' bank, and it's not always true and it's not always predictable, but sometimes it is. ...there is this weird cultural obsession with stripper imagery...that strippers are obsessed with cash, or like, bad with their cash and that it's difficult to manage your money when you have this constant flow of cash...money is sexualized and having cash in your hand becomes a thing that is very sexy. But really, people value cash in intensely different ways.
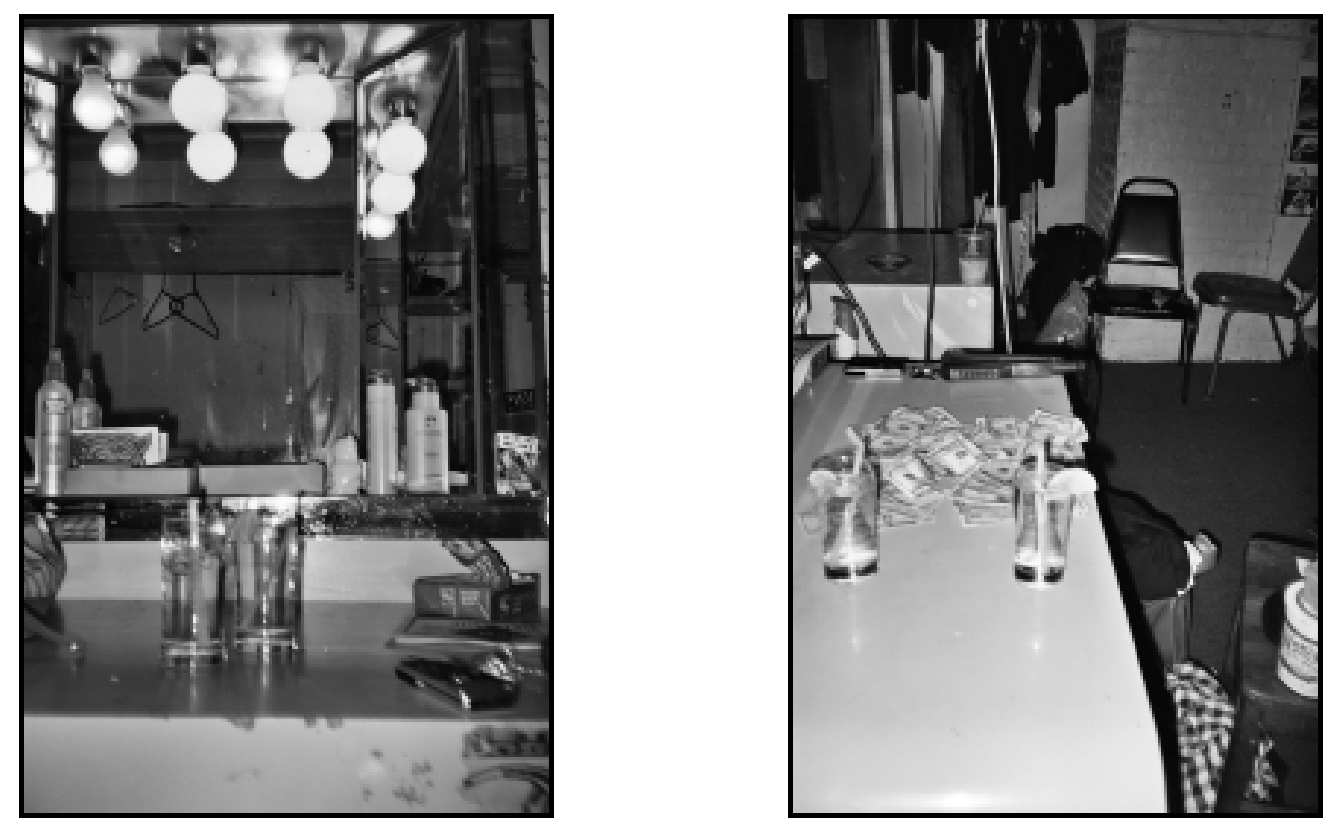

Figures 85 \& 86: Collecting drinks in the dressing room.

Grahm expressed her frustration with the stereotyping of strippers as irresponsible with the cash they earned, while Mouse expressed her anger with being objectified as a 
stripper. She used a self-portrait of her body (figure 91), with her breasts covered by pieces of chicken, to represent how she felt judged, like a piece of meat.

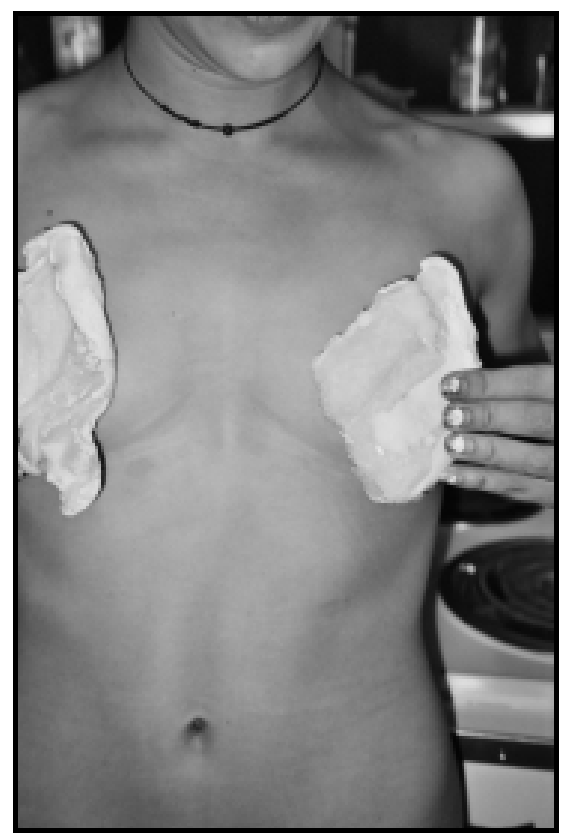

Figure 87: Untitled.

Also using the idea of a woman's body in parts, Grahm also took a series of photographs

(figures $88,89 \& 90$ ) and wrote the following caption to accompany this series of images:

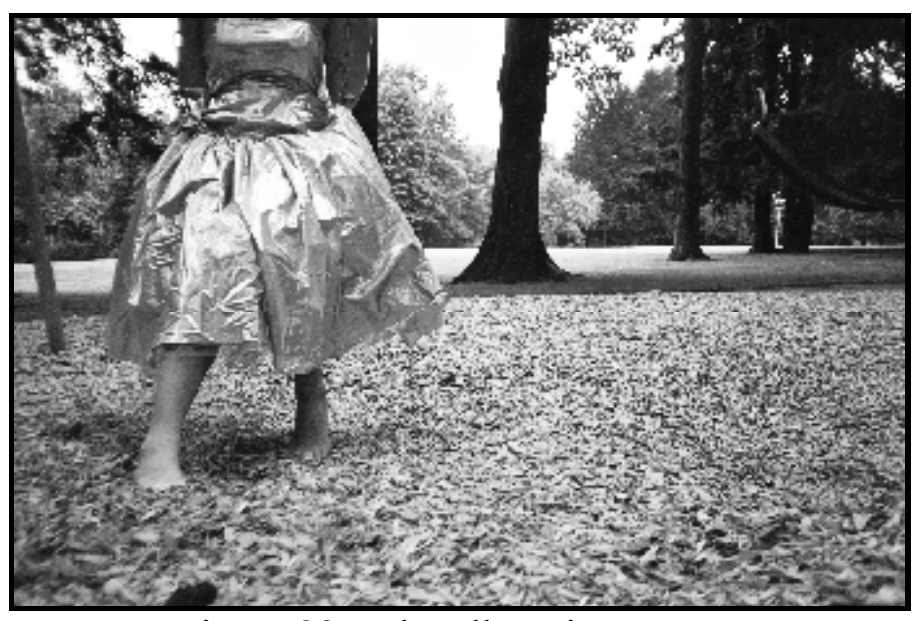

Figure 88: Who all are innocent I. 


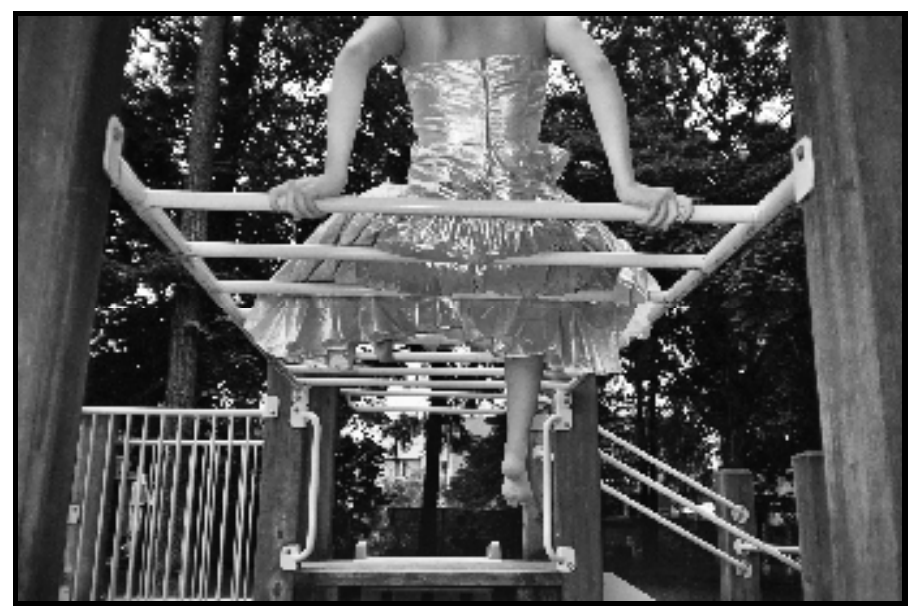

Figure 89: Who all are innocent II.

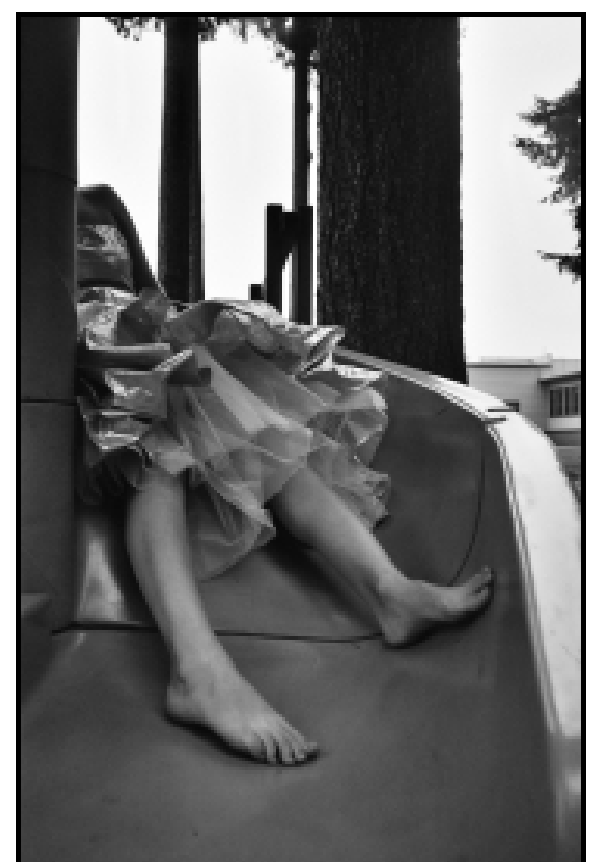

Figure 90: Who all are innocent III.

I want to call attention to the sexualization of victimhood, to voyeurism, to the objectification of sex workers in discourses about them. Always gendered female. Out of her mind in one way or another. I want to encourage people to question the impulse to help, to save, to define what's "really" going on. The woman in the photographs dressed up today. She is a caricature of herself. She is the object of her own sales pitch. You can't see her face but she sees you staring.

She went on to say:

This sort of little girl playground thing is about the stereotype of sex workers as wounded, hurt, and vulnerable, or the idea of helplessness. But a lot of the shots 
are also from underneath her and underneath her skirt that are pretty voyeuristic. I did that because I think that while there's this idea of how sex workers are in a really vulnerable position, they are victims. I think there's also a really intense aspect of that voyeurism that sexualizes that vulnerability, that victimization... the way that women's bodies are talked about in that discourse is really objectifying in and of itself and robs people of agency. So that is where the kind of creepy Lolita gaze comes in, looking up her skirt from underneath the monkey bars, and her head and face absent from every shot.

Through her images and access to feminist sex work discourse, she challenges the stereotypical portrayal of sex workers as vulnerable victims.

Alex photographed a wooden fence to express her need to not feel fenced in and stereotyped because of her work (figure 91). Her work in the sex industry presented complexities in her romantic relationships.

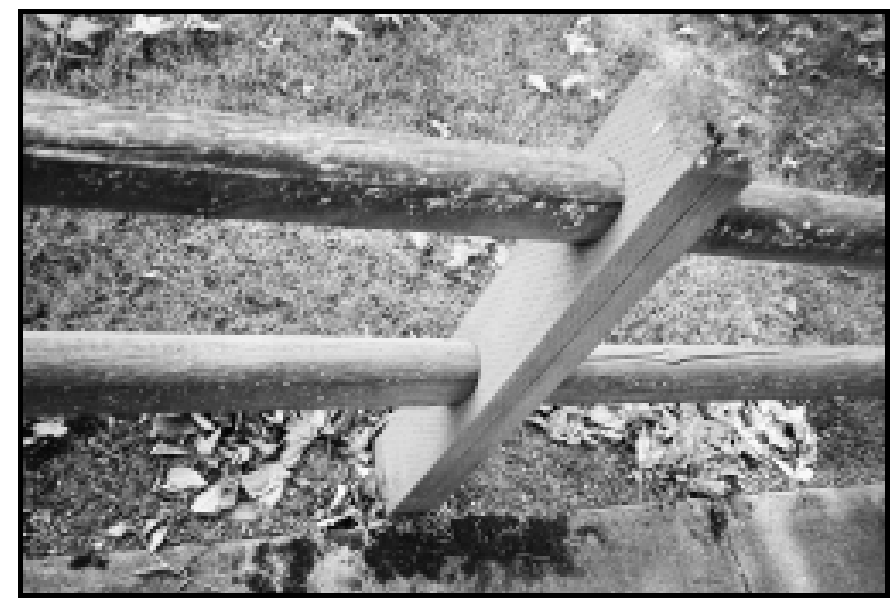

Figure 91: On both sides of the fence.

It's like, sometimes working in this industry you feel fenced in. Because there's a certain stereotype, there's certain things- inherent problems that resurface personally. The one thing that people love you and like you for is the one thing people inevitably throw in your face and, and despise you for. If a guy takes an interest in you, and then all of a sudden you think, oh, its very complimentary but then he's like, "oh, why don't you just go suck up to some guy and get your money the way you--" or they call you "big whore," so you know, you feel fenced-in in that way- there's no way around it or out of it.

Other women also discussed feeling judged and stereotyped because of their work in the sex industry. Rogue expressed her personal need for people not to judge and 
stereotype her. She used a portrait of herself standing up against a concrete wall (figure 92) to explain how she has been discriminated against as a homeless street worker and not allowed in restrooms or public buildings.

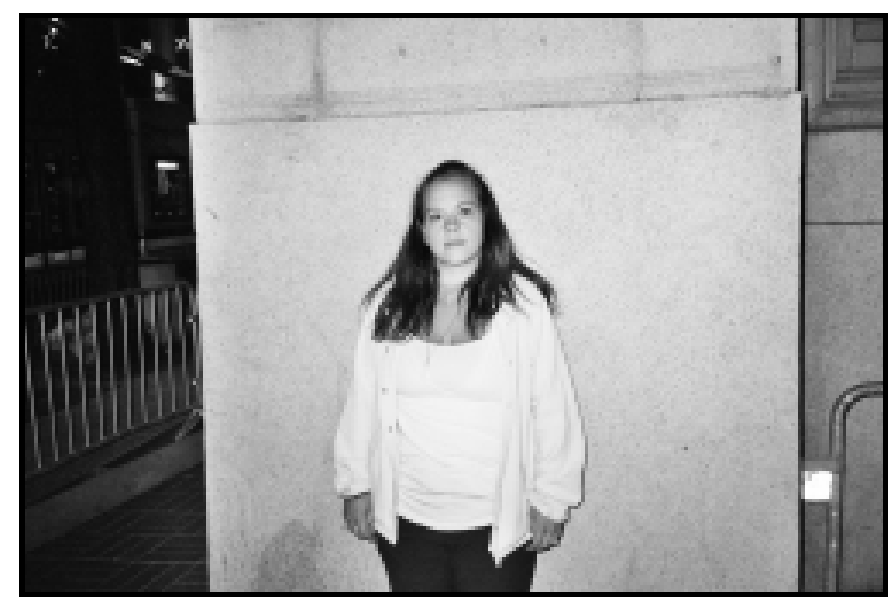

Figure 92: Untitled.

Stereotyped- judged by the book, by the cover of the book, instead of having them open it and take a look. Finding out for themselves what it's really about. When you look homeless, they don't want you in there- they look at your fingernails. I've seen them do it. I've seen them do it to me. If you've got dirt in your fingernails, whether it's a lot or not, they look for that. They want to see if you're clean. They look at your hair. That is why I always attempt to have a brush on me. I try not to dress, you know, too homeless.

Photographs related to stigma manifested differently for each artist depending on the type of sex work she was involved in as well as other factors related to one's diverse status.

\section{Poverty and racism.}

The artists presented poverty and racism as communal and societal need. They presented the intersections of race, class and gender on international, national and local levels. Some participants shared stories of their own struggles with poverty and expressed compassion for those less privileged. Those who lived on the streets at the time of the study or had experienced homelessness in the past photographed images of street people whom they knew. The artists also photographed collages, educational posters, ethnic 
symbols and the juxtaposition of body parts. Their photographs represented the injustice experienced and observed in their communities related to exploitation, stigma, and racism.

Merry Mag photographed money on top of a newspaper (figure 93) and explained the need to be aware of (Western) male privilege and poverty as it related to sex work.

I see this picture of these young girls in Cambodia and it reminded me of how they get paid pennies, pennies for what they're doing and the white men, rich men, go to Cambodia 'cause they know that can get sex from these young girls and do absolutely anything with their bodies. And the people that are running these organizations are vile and they don't give a rip about them. And their families let them go because they can't support and feed their children and they say they're gonna give them a job but what it is, is a sex job. So I feel a real affinity to these young girls, all over the world, I do...

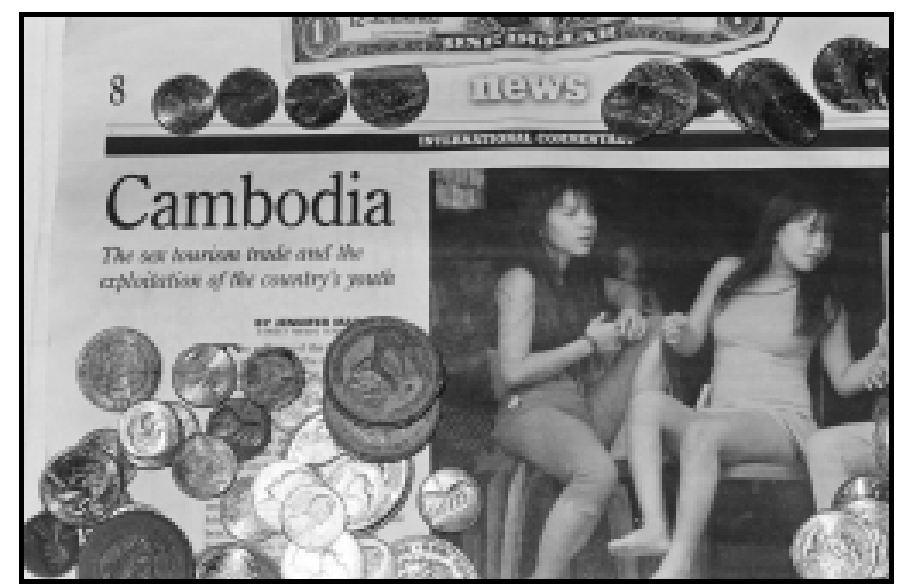

Figure 93: It's a rich white-man's world- How many childhoods are lost? I started in sex work at the tender age of 12 in the USA.

Merry Mag also took multiple photographs of her friends living on the streets to

highlight her sense of sisterhood connection with the homeless community (figure 94).

She explained her activist role and her own ability to see herself in others.

That one woman, she's always getting' picked up. The police harass her almost all the time. We're working now on this sit lie ordinance because you can't sit or lie. She's a native woman; she's a prostitute, a sister. I help her with a few dollars when I can afford it...I really love her and worry about her and I talk to her pretty much everyday.... she likes it that I love her-like street community-and that I'm not an enemy. I'm not looking down on her. 
Even though Merry Mag was living in low income housing at the time of this study she maintained friendships with those less fortunate and continued activism on their behalf.

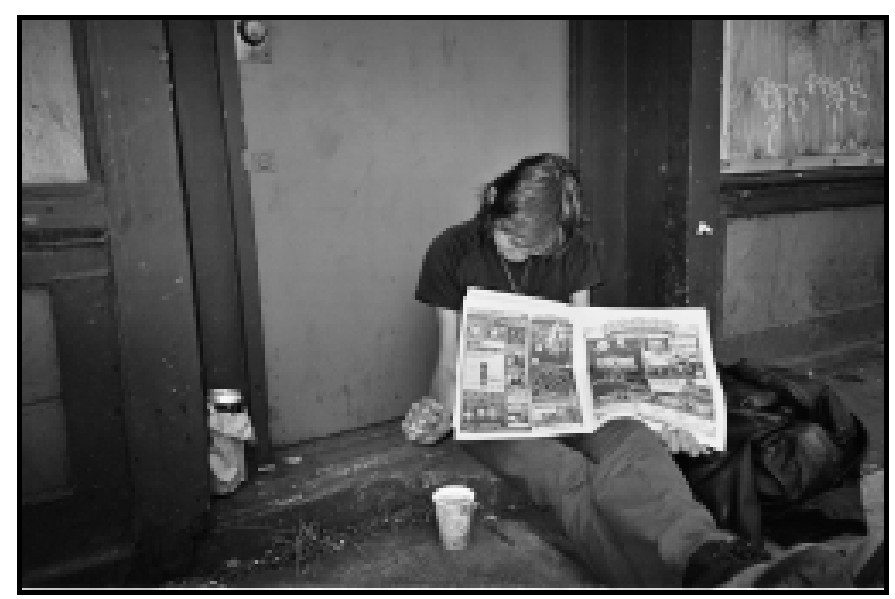

Figure 94: Untitled.

Jasmine also brought attention to poverty and injustice with her photograph of a homeless veteran (figure 95). She expressed anger with society and the government.

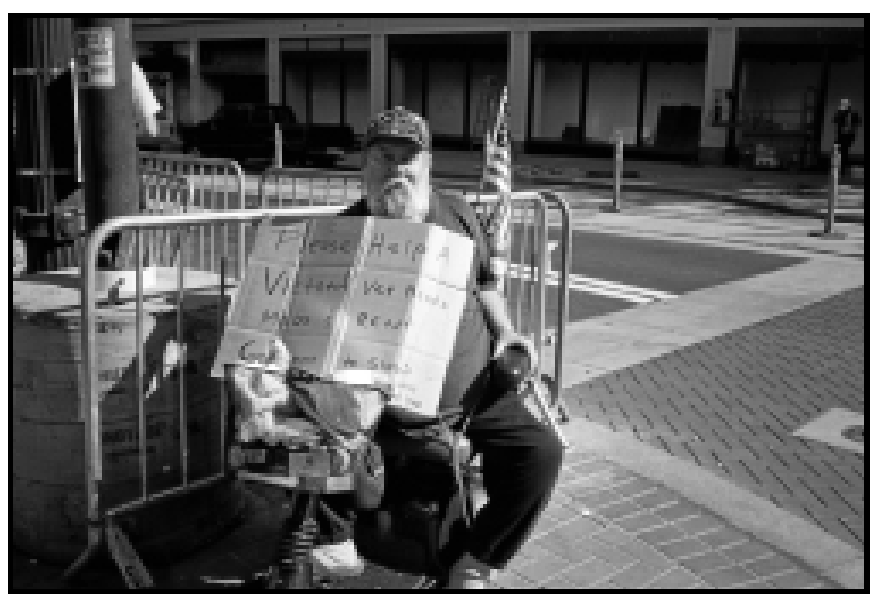

Figure 95: Untitled.

This is a friend of mine...He was poisoned with Agent Orange in Vietnam. He has a lot of health problems; he has COPD [chronic obstructive pulmonary disease] and emphysema, but he is a really nice old man. He feeds me whenever he comes down and sees me. He gives me money if he gets extra for the day and one of my future aspirations is to get involved in doing something to help out old veterans. It's a fucking God-damn crying shame how they treat these veterans in this country, just like fucking cows, expendable fucking garbage! These people fucking risked their lives for a fucking war that we had no business being in to begin with and then they treat them like this. He has to come out and beg on the 
fucking streets to help supplement his income. It makes me really angry but that's why I took a picture of him.

Merry Mag highlighted the communal and societal need for awareness of racism, slavery, poverty, and injustice in her photograph below (figure 96). She linked her perspectives on institutional racism and poverty with her own story of living and working on the streets.

This is a sleeping bag with a pillow on a bench with an empty beer by it...We gave the Native Americans beer and alcohol and they couldn't handle their alcohol. They liked it- they called it firewater... alcohol influenced the 2 million people that we have in our industrialized nation in prison...they also market beer to young Black males and females...so to me it's just a way to enslave them using the legal drug, alcohol. It also represents to me, being out on the streets sleeping, you know, how dirty it was and how I had to try and keep myself clean...if I could get a trick to get a room, then I could take a shower or have a bathroom to go into to clean up so that I could be presentable enough to make some money.

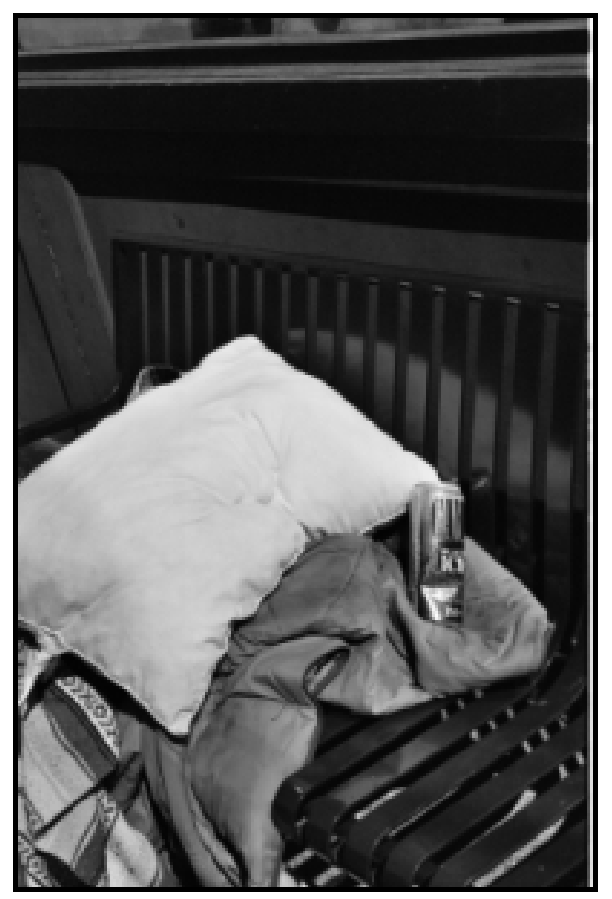

Figure 96: Untitled.

Jasmine expressed anger and pain because of the way she was treated and stigmatized in society as a homeless street worker (figure 97).

It's hard to spend each day with people looking down on you and people looking at you in disgust and people treating you like you don't exist. It's hard to exist 
like that, even if you've got as tough of a skin as I do. Sometimes I just break down and cry because I feel so bad. I mean, that is why it's so important to have friends and people that are there, and especially people that are going through the same thing that you are. It helps.

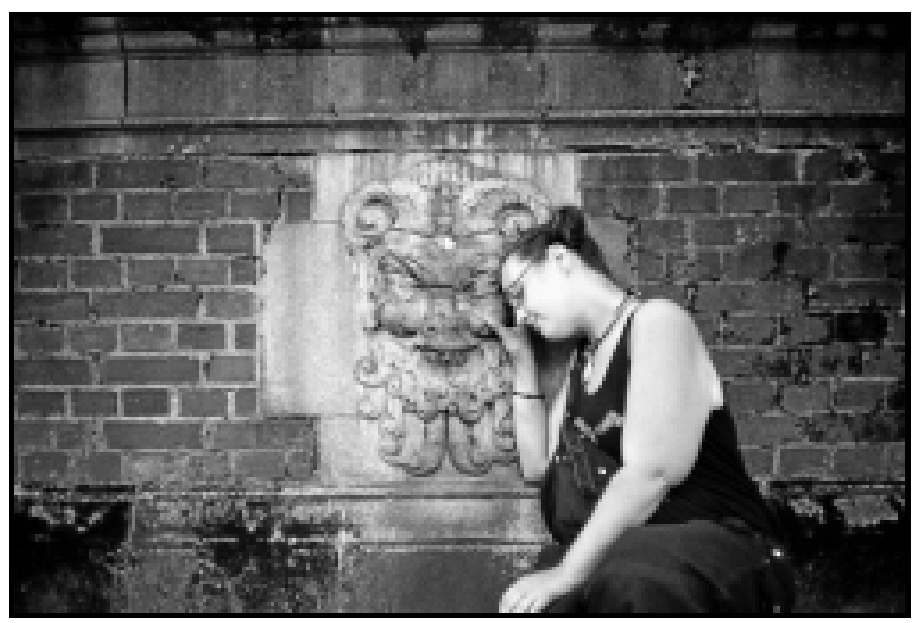

Figure 97: Untitled.

Sarah addressed her experience of stigma and the societal need to end racism and stereotyping. She shared her story of interracial dating through a photograph of her hands clasped with the hands of her ex-boyfriend (a former trick) (figure 98).

I took this picture of my ex-boyfriend and I holding hands because he's Black and I'm white. Of course, a lot of Black guys get a lot of raw deal. He got a bad rap, that pimping rap, and the police called my mom when we were together and told her that he was my pimp, which is so ridiculous. He never once told me to go out there and make money... I've see a lot of racism by the police. It makes me sick!

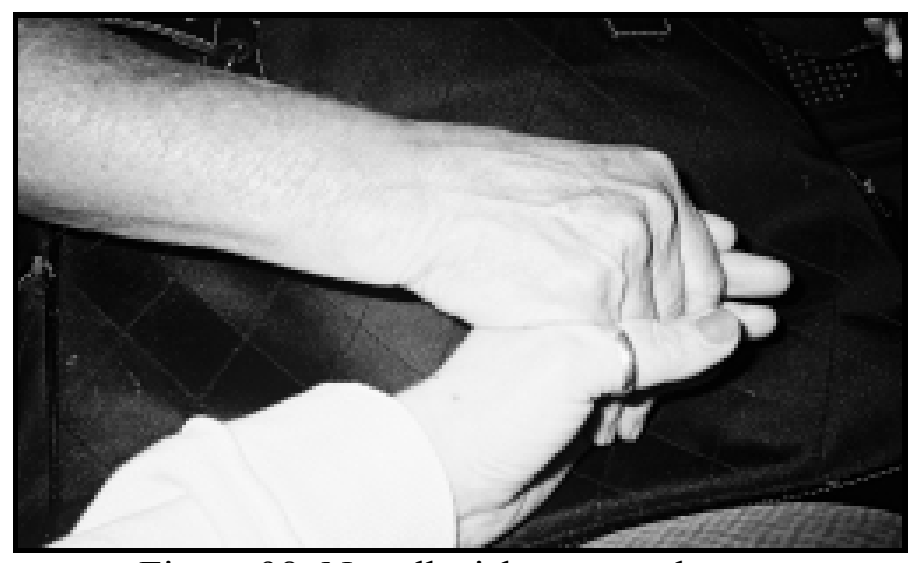

Figure 98: Not all tricks are predatory. 


\section{Dreams and Desires}

Dreams and desires emerged as a theme related to photographs depicting personal passions, interests, and dreams. Bee captured the essence of this theme when she photographed a dream catcher hanging from the walls of her room and stated, "This is about dreams. How important they are. You need to have dreams. You do. Otherwise, why live?" The four sub-themes that reflect the artists' personal dreams and desires include: (1) play, fun, and happiness; (2) rest and relaxation; (3) interests and hobbies; and (4) motherhood. Those women with access to resources and not having to worry about daily survival, photographed and conceptualized the theme of Playing, having fun, and being happy as a need and aspiration. The women expressed the sub-theme rest and relaxation as a need or aspiration for tranquility and inner peace. The artists presented diverse interests and hobbies and framed them as personal needs or aspirations, including the pursuit of a hobby, the desire to travel, and the contemplation of other career options. Here, the artists shared their talents, skills and passions. The sub-theme of motherhood involved the artists' desire to be mothers and their personal needs as mothers. The unifying factors connecting these sub-themes include objects, ideas, visions and experiences which brought the women pleasure, possibilities and inspiration.

\section{Play, fun and happiness.}

The artists who weren't struggling to survive expressed a desire to have fun, be happy and play. The participants photographed various places and things that symbolized their pursuit of play, fun, and happiness, and its importance in their lives. They expressed difficulty envisioning what this would look like, due to over-working and not taking the time to have fun and pursue their own happiness. Some artists analyzed the sexual 
meaning of the word "play" and discussed their desire for a more innocent understanding and experience of play.

Bee photographed a playground (figure 99) to represent her personal need to have fun and spend more time having fun. She also expressed the need to know how to have fun, since it was something she was not used to doing because of working too much. Bee shared a story from a time in her life when she was homeless and living in a truck. Where she may have considered a pastime like camping fun at one point in her life, after her experience with homelessness camping was no longer enjoyable.

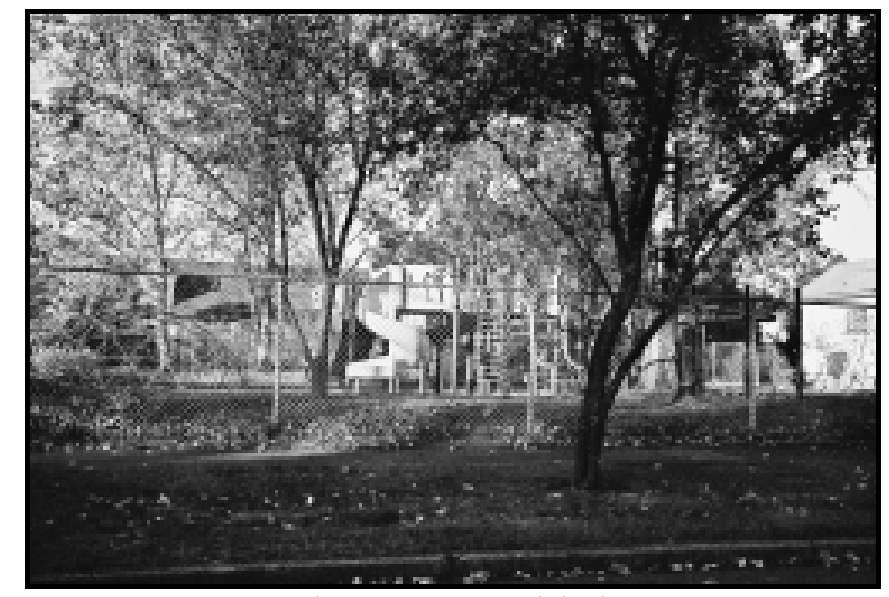

Figure 99: Untitled.

Alex expressed similar uncertainty about what made her happy. She photographed a tree, with a smiling face on it, and shared her aspiration to be happy (figure 100). When asked what happiness would look like for her, she responded, 'I'm not sure. I used to know. Sometimes it comes in different ways. I mean, whatever it is- that's what I want to be." Further conversation around what made her happy in life led her to share, "taking photos. And actually, I hadn't taken photos in a really long time." Alex shared that she had worked as a photographer years ago and said the photovoice project offered her the opportunity to be creative again. 


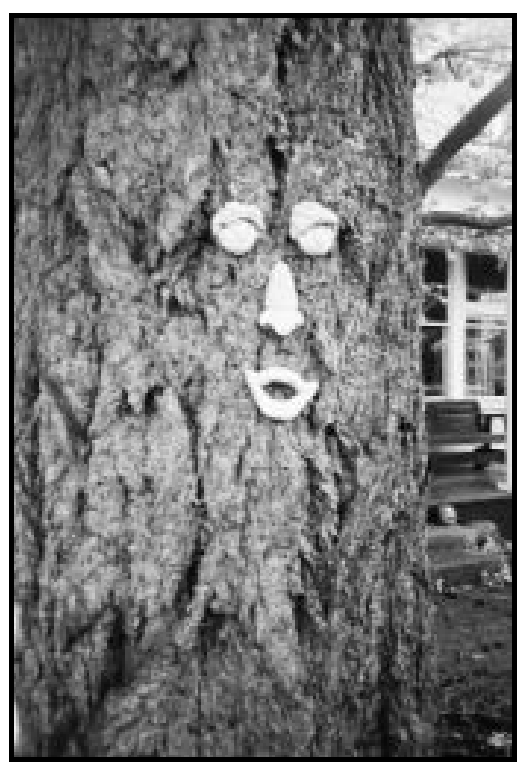

Figure 100: To be happy.

Mouse, who photographed her stripper clothes on a seesaw in the park (refer back to figure 34), shared:

I want to see friends of mine and just run up and start playing with them...but, also, how the phrase "play" itself goes through kind of a transformation when you get older because it's so... play is so tied, when you are an adult, to sexual activity... at some point that word goes through a sort of loss of innocence.

For Mouse, the innocent association with the word, "play," was important to her but no longer something she felt could revert back to.

\section{Rest and relaxation.}

The artists expressed personal needs or aspirations for rest and relaxation. They associated rest and relaxation with the body, the mind, solitude, privacy, warmth, peace, and stability. Those women who expressed this need and aspiration often had stable living situations and worked as exotic dancers. Rest and relaxation was often associated with water and its calming presence. This was expressed by the women through photographs of their own bodies submersed in water and large bodies of water, like the river and the ocean. 
Bee photographed a parked boat (figure 101) and shared her love for the beach.

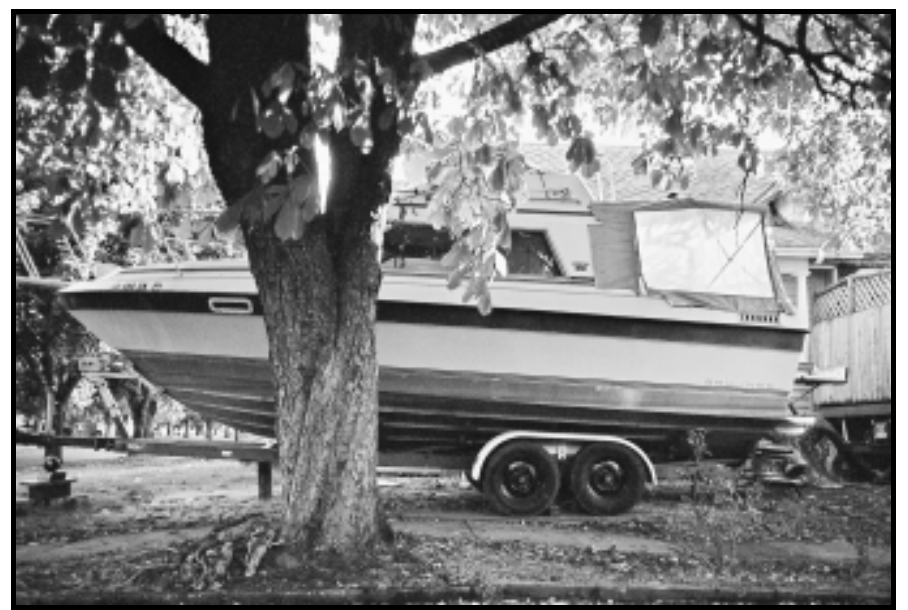

Figure 101: Untitled.

I used to sleep on the beach when I was younger... because nobody was bothering me, nobody was asking for anything, nobody was calling me, nobody was bugging me, and I could sleep good. Oh, I loved it! And there was this spot where the surfers used to go and that was really calm, quiet...

Lady Purfection photographed the Willamette River to represent their aspiration for calm and peace (figure 102). She explained:

For me it's not just a picture of the river or the buildings or the freeway - it's my inspiration. I love the water. When I'm stressed out or confused or my mind is boggled I can go to the river and it will calm me.

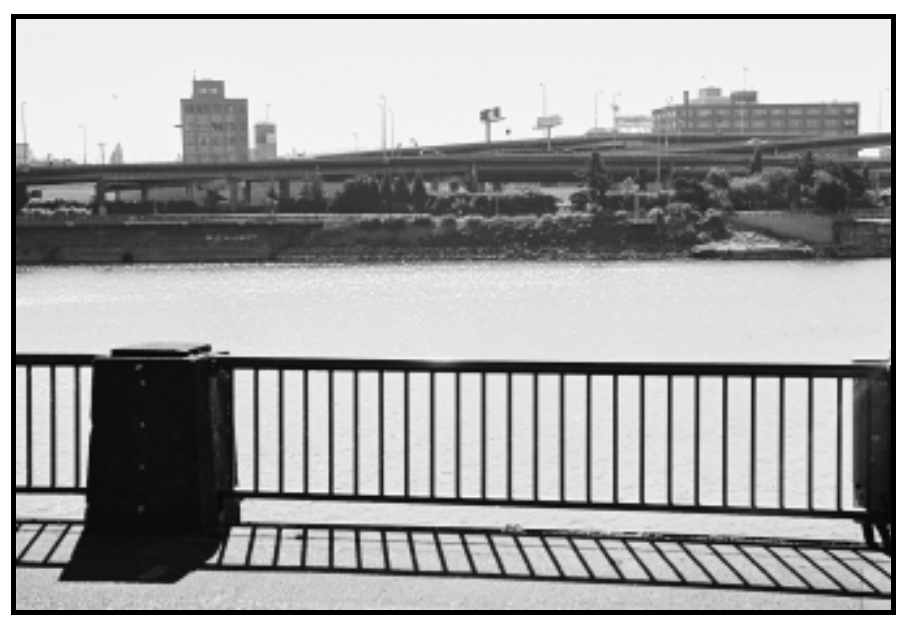

Figure 102: Life with hope is freedom to believe in your future 
Rizzo expressed her desire to be able to relax and have more stability. She photographed the river to represent her personal aspiration to have life flow smoothly (figure 103).

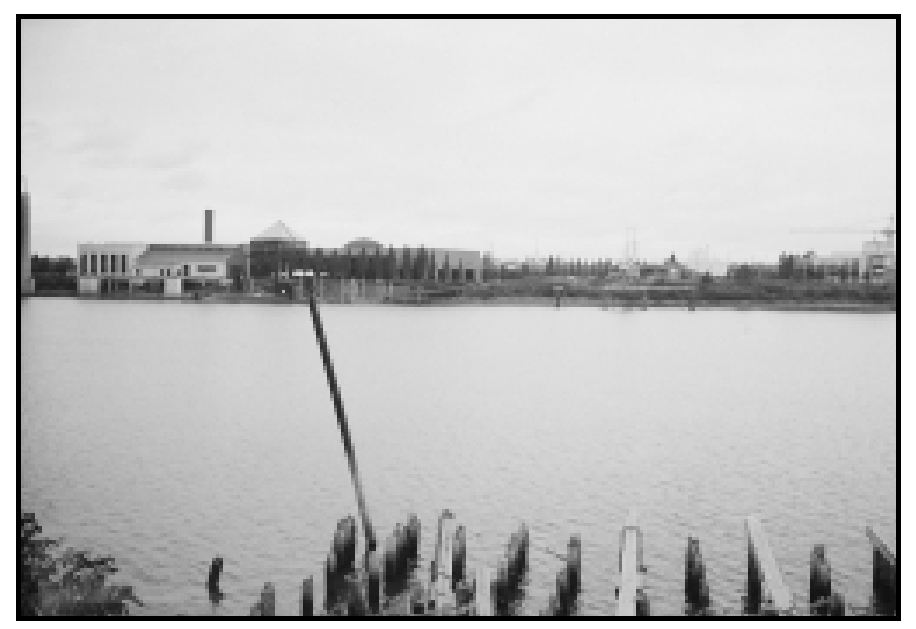

Figure 103: Untitled.

I want my life to flow easy, you know, like the river. 'cause right now its rapids and waterfalls and I definitely don't know where I'm gonna sleep every night and I don't know what I'm gonna do everyday. I don't know for sure if I'm gonna see a client or not and it sucks... I always have to worry about getting enough money to support my habit and I don't wanna have to worry about that.

Jasmine echoes this desire in her photograph of the trees from the camp where she slept (figure 104).

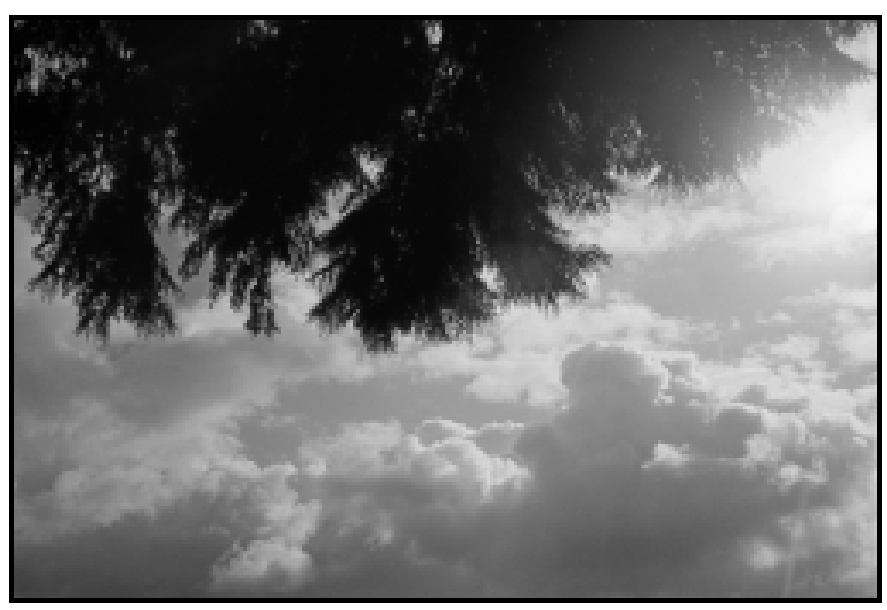

Figure 104: Awakening Vision.

Mouse took a photograph while sitting in her bathtub. She immersed herself in a 
bathtub full of water and took a photograph of her feet (figure 105) and expressed a need to relax while situating herself in a place where she couldn't relax.

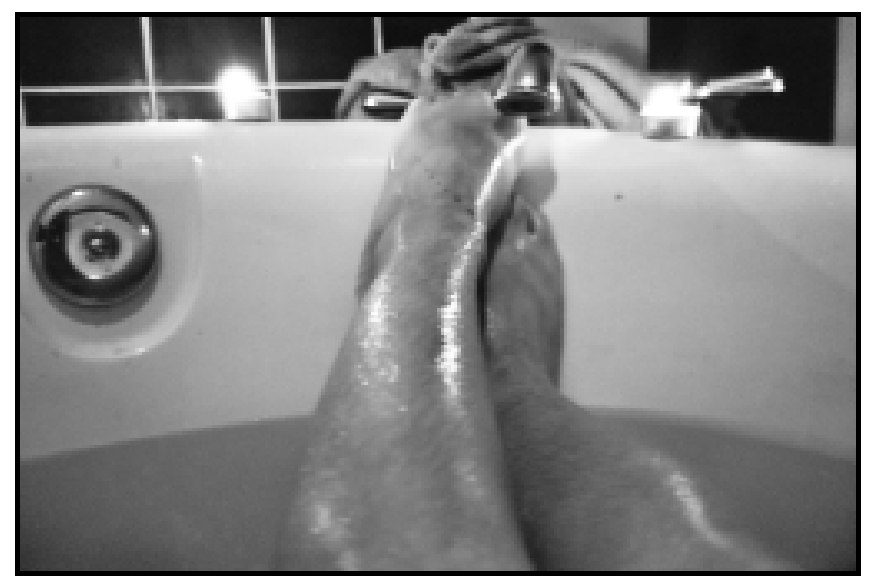

Figure 105: Untitled.

My feet were surprisingly tense when I took the shot. I would like to feel more relaxed but...in a sense baths aren't as relaxing for me as for other people. I think part of that is the reason that being naked doesn't feel as private to me, as it does for other people. Because when some people go in to take a bath, it's like, "ok I'm naked" and automatically that makes one feel sort of private and they are finally in a space where they are safe enough that they can take all their clothes off. That does nothing for me. I need to be able unwind a little more and find some other sort of outlet that I can use to relax.

For Crystal, relaxation was associated with tanning beds and warmth. She photographed the inside of a tanning bed (figure 106).

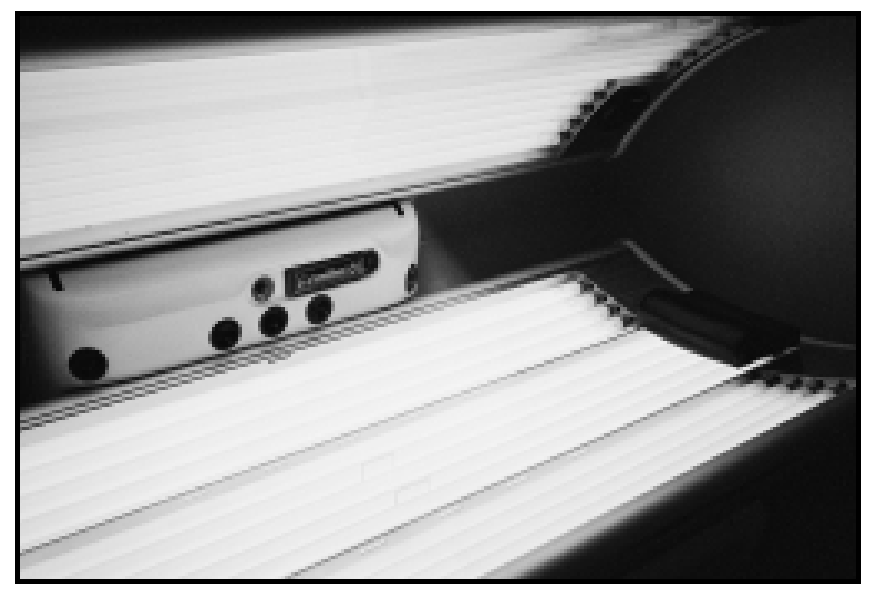

Figure 106: Untitled. 
Crystal explained, "This is a place I've spent a little time; you know once or twice a week. So I can sit there and just relax and just let my mind go away.”

\section{Hobbies and interests.}

The artists expressed personal aspirations and needs to pursue hobbies and interests including art, music, sports, travel, and other types of work. The women photographed their hobbies, often things they hadn't pursued in a while. This project served to remind them of the pastimes that made them happy and the creative talents they possessed. The aspiration to travel was shared by a few of the women who also identified with the gutter-punk sub-culture. The participants who photographed career aspirations were either exotic dancers transitioning out of the sex industry or younger women with visions of different possibilities in their lives.

\section{$\underline{\text { Art }}$}

Bee photographed two jean jackets she decorated with beads, patches, and other artwork to express her need to spend more time being creative (figure 107).

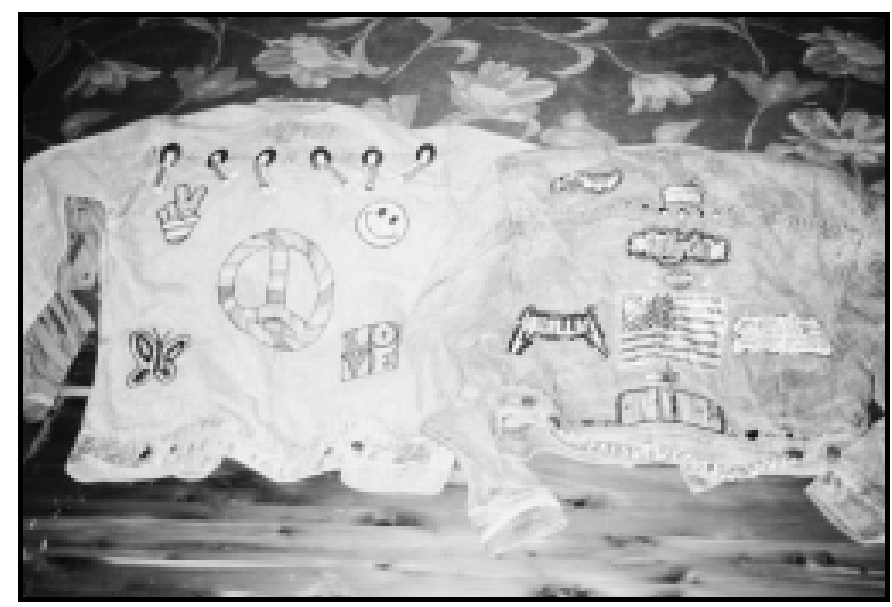

Figure 107: Untitled.

She described, "It's the need to spend more time doing creative things because it relaxes 
me. And I'm usually alone. Nobody is bothering me. I get so little peace..." Bee found peace, solitude, and relaxation when creating art.

Crystal photographed graffiti to represent her appreciation for public art (figure 108). She explained, "A lot of people think it's dirty, but I like it because it's a form of artwork. It's a place where someone can really express themselves and as long as it's not harming anyone, or harming their business or whatever, I think it's great that people can be so colorful and do it..." Crystal articulated how graffiti, as a form of artistic expression, was an inspiration to her.

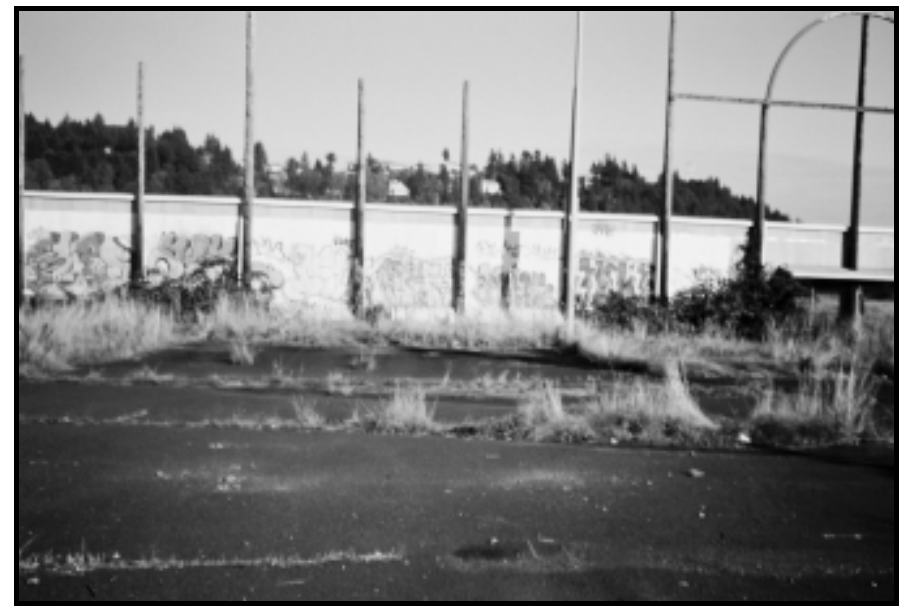

Figure 108: Untitled.

\section{$\underline{\text { Sports }}$}

Bee photographed ice skates and golf shoes (figure 109) to represent a need and aspiration to pursue two hobbies that made her happy: ice skating and golf.

I used to skate a lot and play golf... It's sooo fun... That is another thing that has to do with the fun I don't get to do any more. That's an aspiration to do again. It's also a need. It's a need to do these kinds of things that feed your soul. 


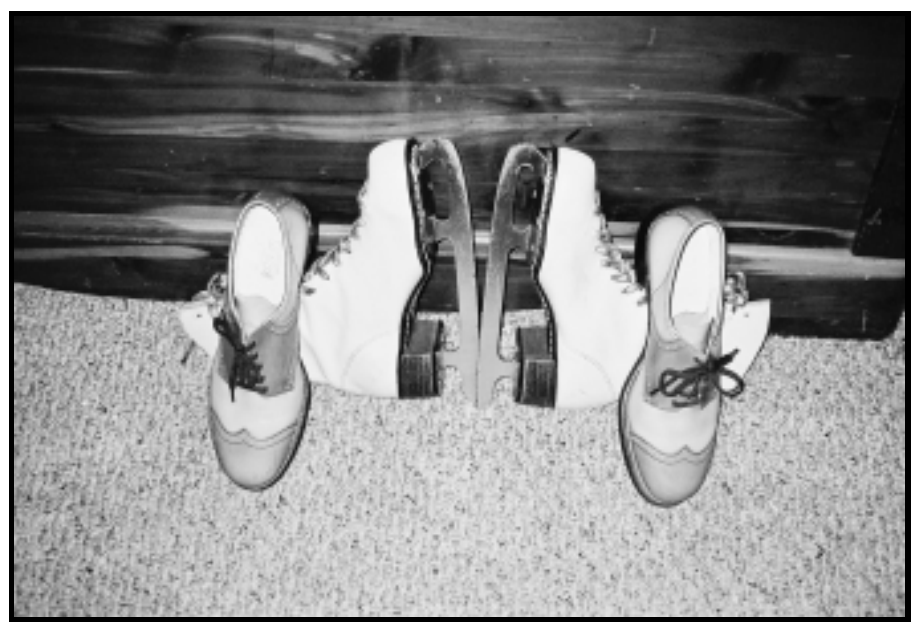

Figure 109: Untitled.

Rogue also expressed interest in sports and shared an aspiration to attend a live football game. She photographed a football stadium (figure 110) and went on to envision herself with her husband at the stadium cheering on the teams.

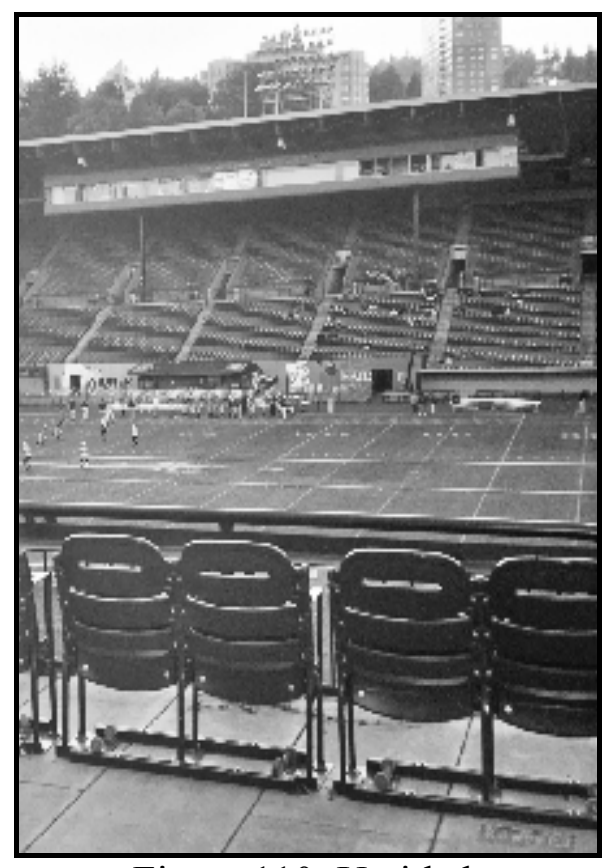

Figure 110: Untitled.

$\underline{\text { Music }}$

Music was presented as an important need and aspiration. Mouse presented a selfportrait to represent her passion for playing music (figure 111). 


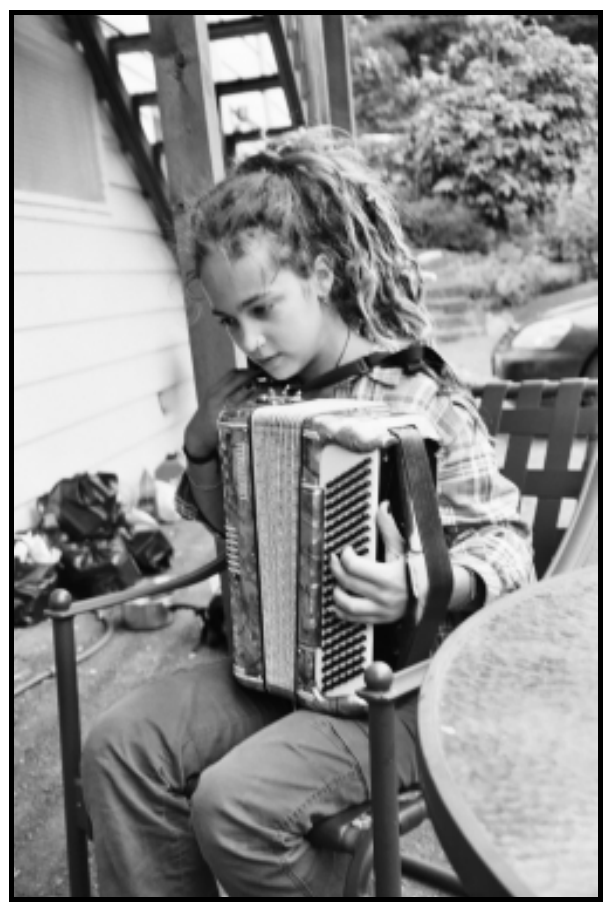

Figure 111: Gypsy Eyes.

That's one of the nice things about aspiring to be better at art -it's an endless pursuit. I mean, there's no limitation of yourself. You are only measuring your skill and art against yourself and against your own standards and your own perception of ability. So I really like that, but I can always be getting better. I love playing accordion. I play accordion and trumpet-those are two of my great loves.

Rogue also shared a love for music and photographed a piano (figure 112) to represent an aspiration to have one to play.

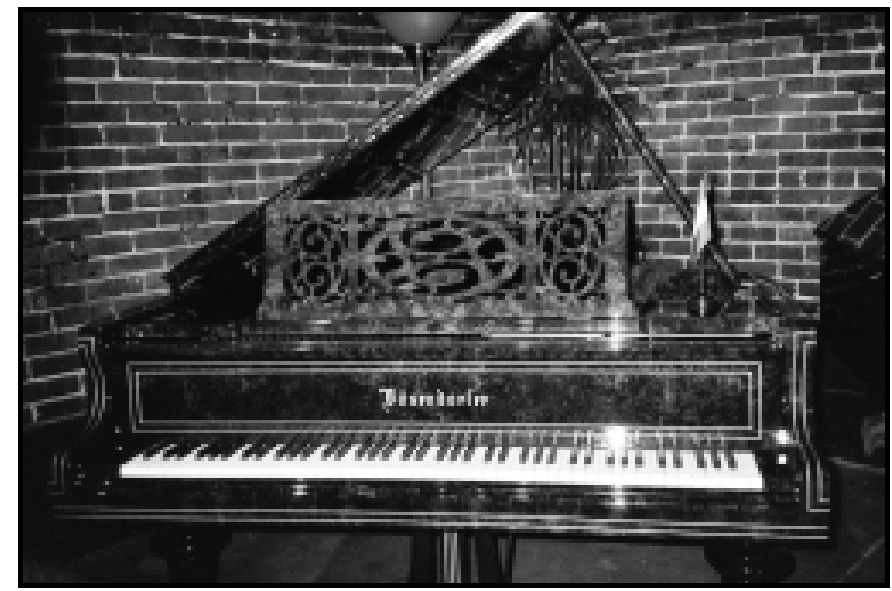

Figure 112: Untitled. 
She stated, "Ever since I was a little girl I've always wanted a piano. And I will have a piano. It might not be this piano, but I will have one. I don't care if I'm 90 years old, I will have a piano. I played piano for a year. I played the violin and the cello. But I like the piano more."

\section{$\underline{\text { Travel }}$}

The artists communicated the aspiration to travel via photographs of destination signs, travel signs, trains, and a globe. Rogue's image of a globe (figure 113) represented her personal aspiration to travel the world. She expressed a fascination with different cultures and a dream to climb the pyramids in Egypt.

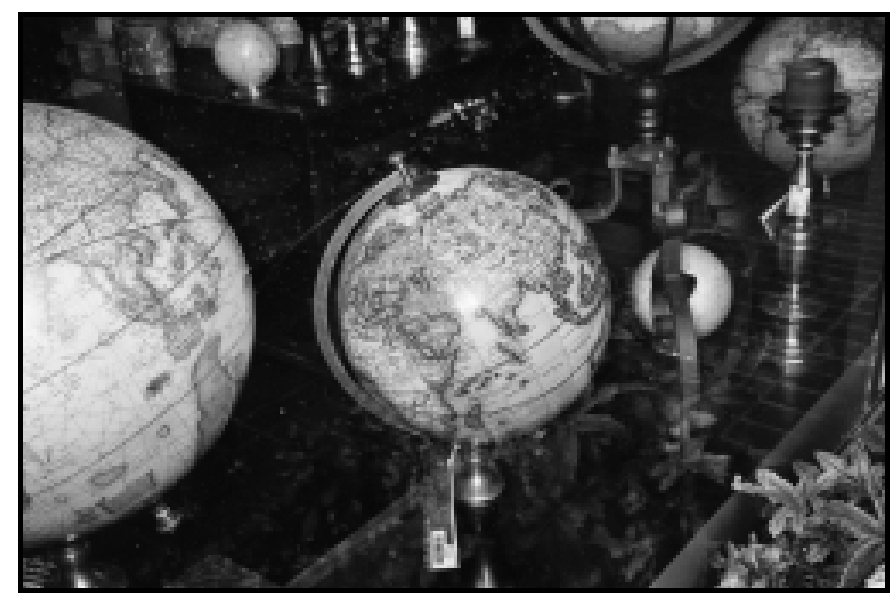

Figure 113: Untitled.

Rizzo took multiples photos of travel signs to represent a desire to travel and hop trains (figure 114).

It's an aspiration 'cause I wanna travel and I want to do more of that. So that's my aspiration to get clean and get on my feet just a little bit to be able to travel. Because even hopping trains and stuff, I can't do that with a habit, so I would have to get clean to be able to travel in that way. It would be nice to go to, like, New York or something and not have to worry about being dope sick. 


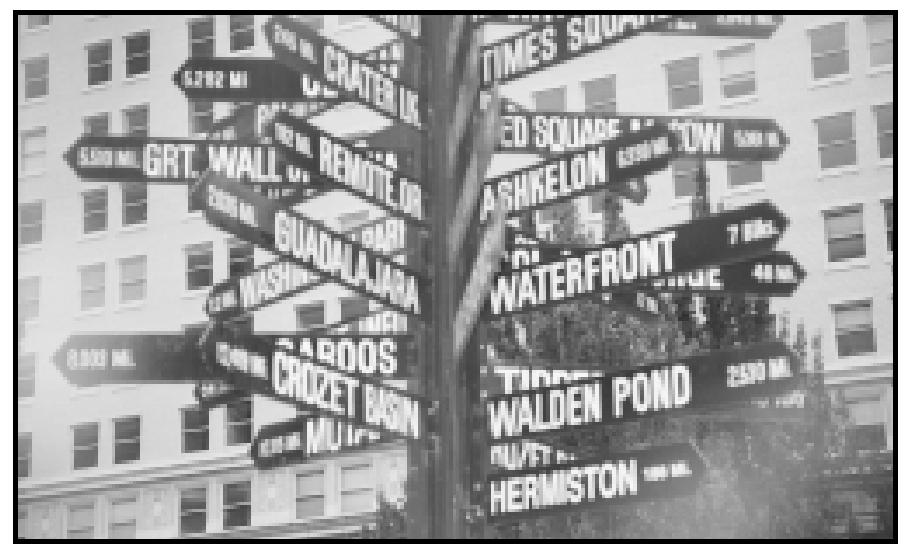

Figure 114: Untitled.

Similarly, Rogue took a photograph of train tracks (figure 115) and shared:

I've never traveled by train. Well, unless you consider the MAX but that doesn't count- this is a train...You'd see all the different sceneries by train that you wouldn't see on a plane or on a bus.

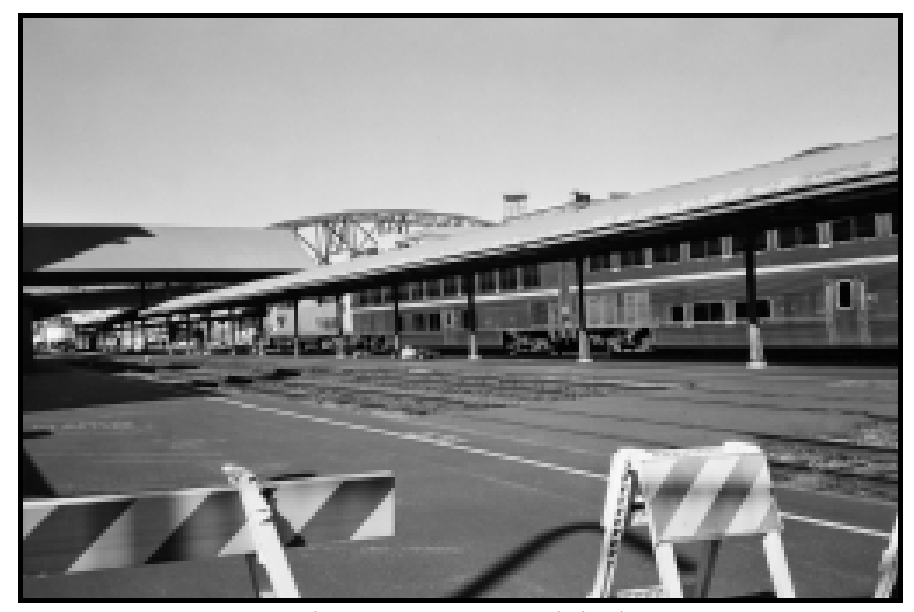

Figure 115: Untitled.

\section{$\underline{\text { Career Interests }}$}

Some of the participants photographed symbols they associated with a career they aspired to pursue. Jasmine took a series of photographs of flowers, plants in nature, buildings (figure 116), and statues in the city to express her dream of becoming a photographer. She wanted to "capture beauty and places and things like this ceiling and like that gargoyle that not everyone would stop to take the time to notice and look at." 


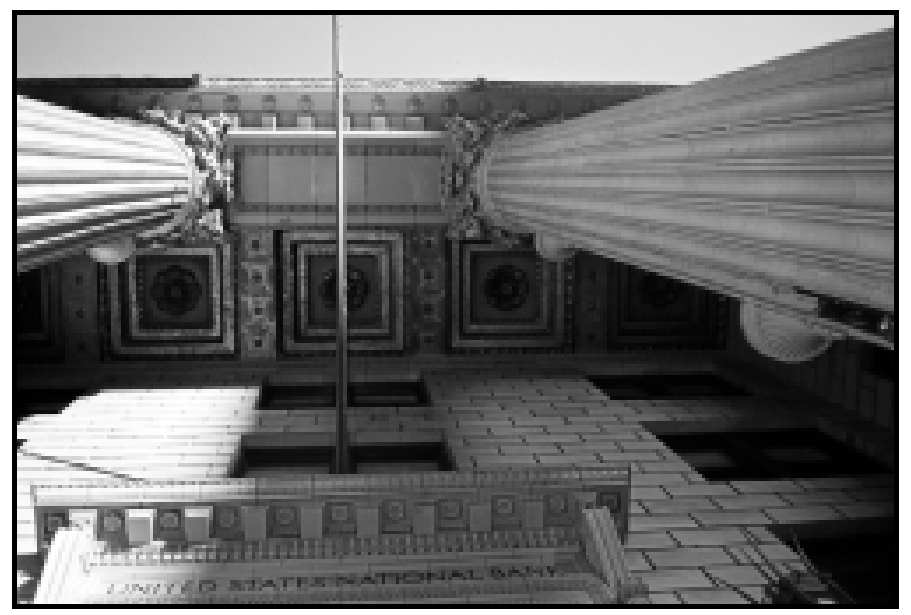

Figure 116: Untitled.

Bee shared a need to open her own business. She photographed a window of an office building (figure 117).

Since I was little I wanted to be veterinarian.... I'm bored with the [sex industry] business I'm in anyway. I can't go any higher than where I am right now. I've done it all, the only thing I haven't done is own my own business...I would be so happy working for myself because I've made a lot of people rich in the restaurant business helping them. Be my self's boss...I am so confused; there are so many things I want to do. I also want to work with animals. I thought about doing mobile grooming one time.

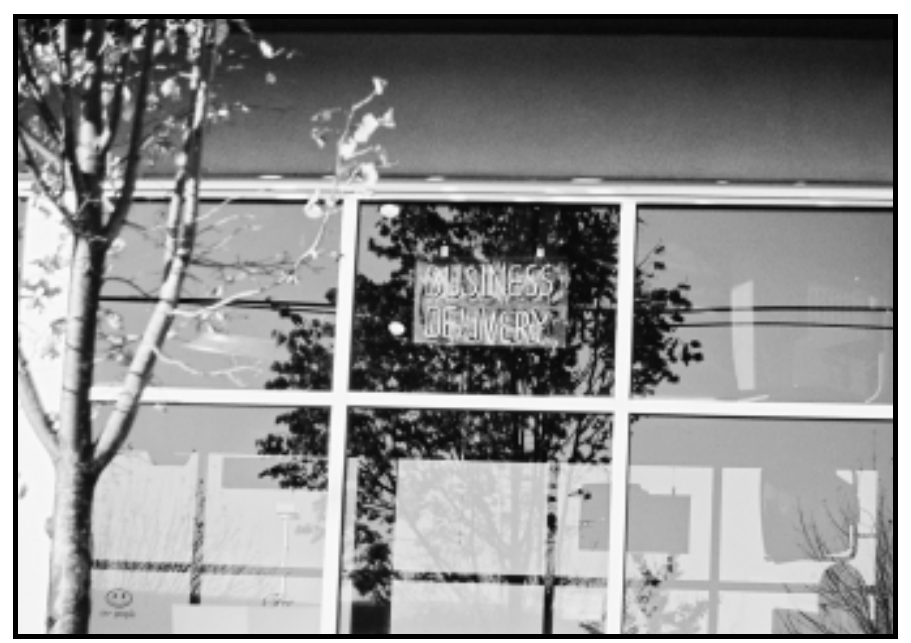

Figure 117: Wishful sign of dreams \& goals

Bee expressed her need to pursue a different line of work since she wasn't able to move up as a stripper and bartender where she worked at the time of the study. She displayed 
confidence in knowing how to assist others with making money and displayed selfassurance of success.

A similar assuredness was presented by Rogue who shared a similar idea of wanting to open up her own business: a karaoke restaurant for kids. She took a photograph of a sign for cooking school (figure 118) and explained her aspiration. "I actually want to be a chef. I want to open up my own restaurant. Actually, a karaoke restaurant so kids could come. Not a bar, but an actual karaoke restaurant that kids can actually go in and sing karaoke." Rizzo shared the same aspiration to be a chef. She photographed a sign for culinary school and a sign that read Serious Cooks. She said, "It's an aspiration to be one of the serious cooks that are serving, to be able to buy a cute little French whisk and actually know what to do with it (laughs)."

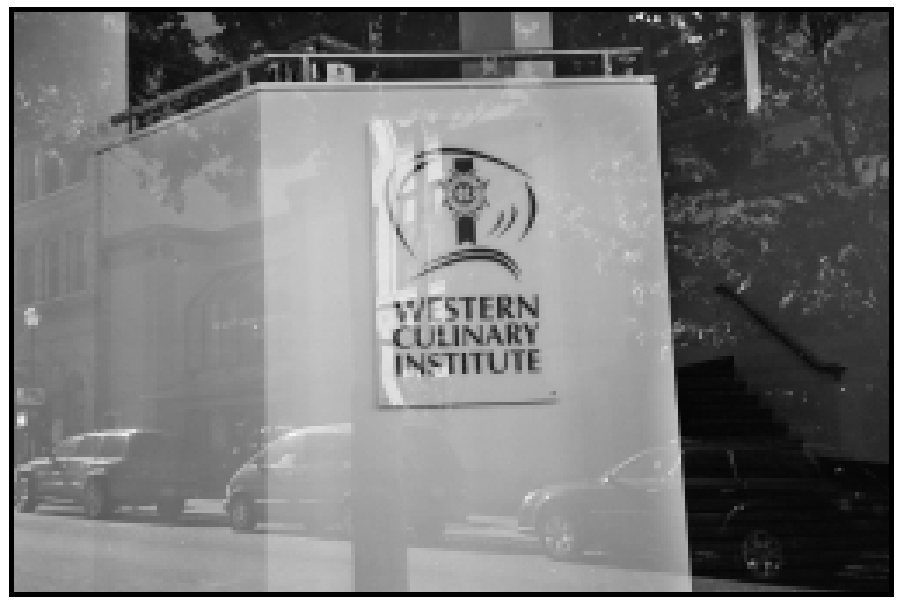

Figure 118: Untitled.

Rizzo, the youngest of the artists, had a series of photographs related to career aspirations that she represented through photographing signs around the city. She also photographed a sign that read Stylist Available, for walk-in appointments (figure 119) and explained, 'that was another aspiration 'cause if I wasn't gonna be a cook I'd want do 
stuff with cutting hair or doing makeup and stuff. So I'd be cool if I was one of those stylists available."

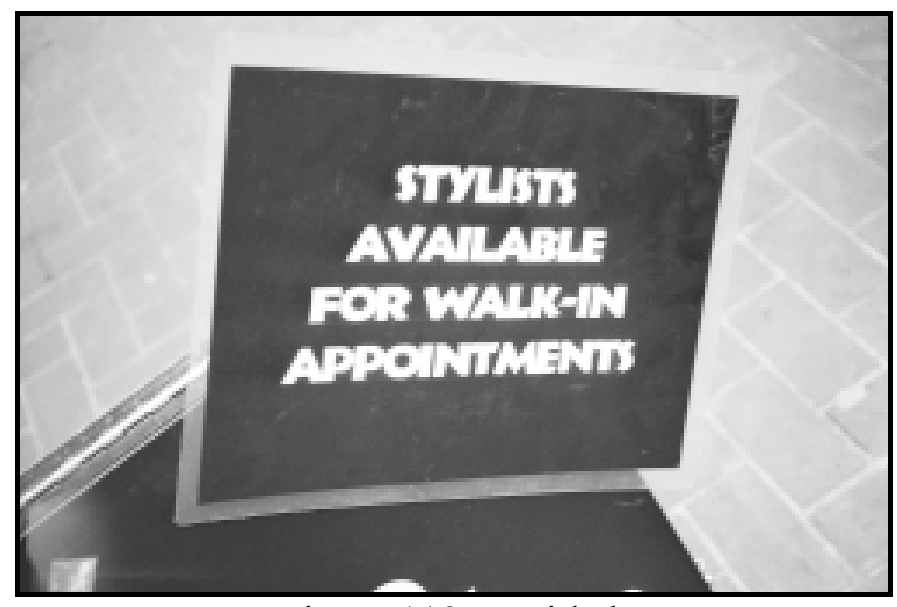

Figure 119: Untitled.

Crystal also expressed interest in pursuing a career in cosmetology. She photographed the Portland Beauty School and shared, "that would be a dream to go to. It looks like a really nice beauty school...It's just in really high demand these days to look great (laughter). I'd like to do like spa stuff, like deep conditioning. Everybody just gets so busy with their life that they need to take time out and get pampered."

\section{Motherhood.}

A few of the artists depicted various aspects of motherhood. Some of the artists expressed the aspiration to have kids and someone to care for, others discussed their relationship with their children, or lack of a relationship, often in the context of their experience with domestic violence. For some of the women who worked as exotic dancers, motherhood was central to some of their aspirations. For those women who lacked resources and experienced homelessness and addiction, motherhood was secondary to the need for drug and alcohol treatment. 
Bee discussed a desire to have another child despite an inability to have anymore children.

I had cancer and had to remove everything...I had already had it for three years....I was working with cancer. You know, I was bleeding and I was working with baby diapers. I wanted to have one more child, but I am done now. Yeah, it sucks, right? But you know what? You live. Live and learn.

She described her photograph of a teddy bear sitting on her bed (figure 120).

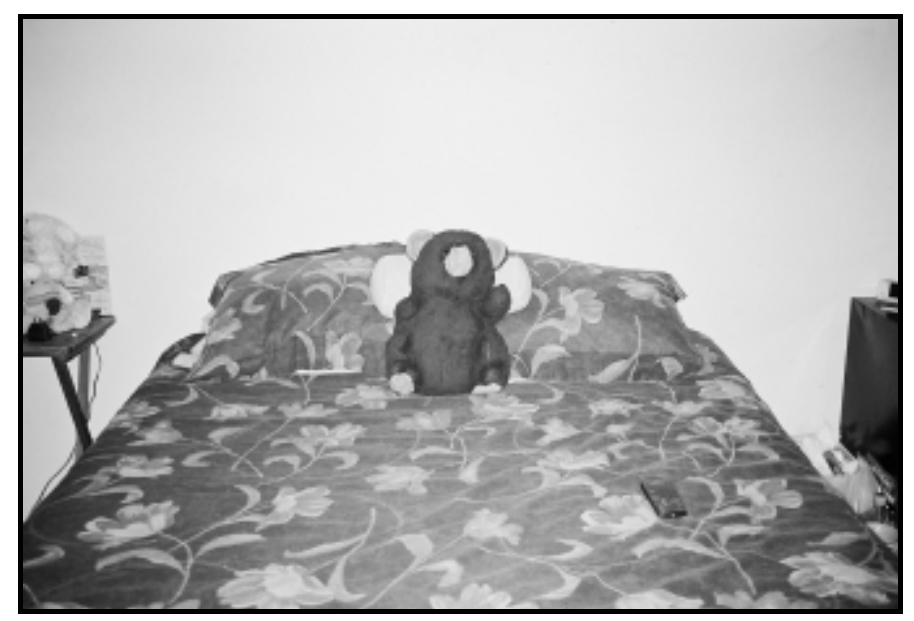

Figure 120: Untitled.

So the teddy bear represents my son. It was brand new when I got it... and now I use it for a headrest (laughter). When I am laying in bed, he makes a great headrest, and I just can't let go of it. I just can't...I was a single mom so me and my son- we're pretty close. It doesn't seem like it when people meet us but we are- we're really close. Because it was him and I against the world a lot. My son has seen me get beat up. He was too little to do anything- but the youngest boy pulled my ex off of me. He was on top of me with his knee in my neck.

Like Bee, Crystal shared her experience with domestic violence and expressed an aspiration to be reunited with her four children who were in foster care at the time of the study. She said, "I went through a really long relationship that included a lot of domestic violence. For eight years I went through that and now that I'm free from him, I am able to get a better life for me and someday for my children." Jasmine and Rogue were living on the streets at the time of the study and dealing with addiction. Their children were living 
in the care of family members. Like Crystal, they expressed the desire to be reunited with their children.

The artists who did not have children shared aspirations of motherhood. Rizzo photographed a book titled, What to Expect When You're Expecting, and said, "Its an aspiration. I was in the bookstore and maybe someday I'll buy that book if I get pregnant. But to do that I would have to get clean. But someday I'd like to have a least one kid, preferably a girl.”

Alex echoed the aspiration to have a child and used humor and symbolism in her photograph of a building sign that read $A-B O Y$ (figure 121). She shared, "the next one is A-Boy building which I think is a warehouse store; that is my desire to have my child, which is a boy." When asked why she preferred a boy, Alex responded, "I think it comes from my fear of not wanting to be my mother... and my mom didn't want to be like her mom, so if I had a child, if I had a boy, I wouldn't have to worry about him not wanting to be like me (laughter). Because inevitably, you will become what you fear."

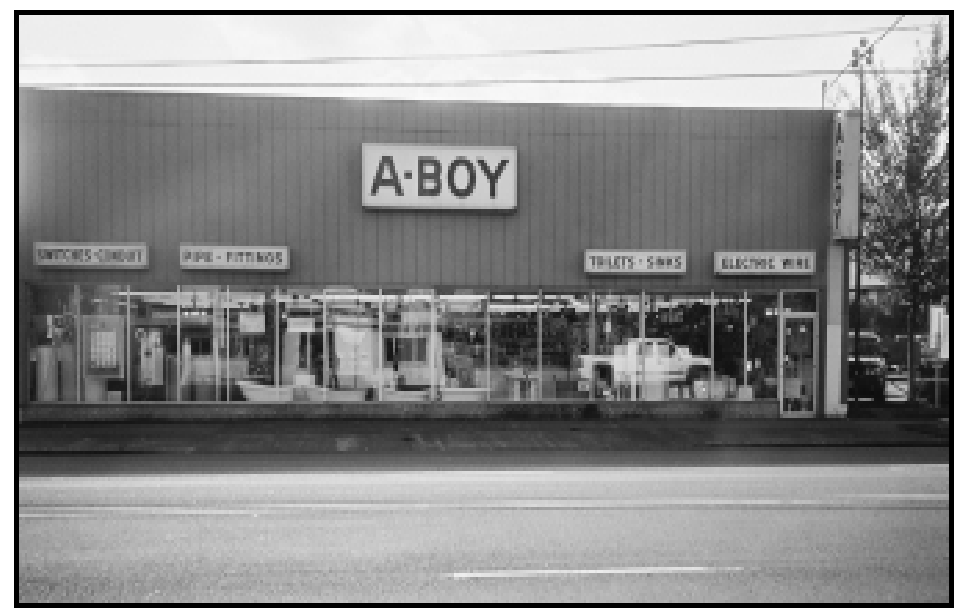

Figure 121: Untitled.

In contrast, Mouse photographed a dog feeding her puppies (figure 122). She shared that she didn't want to give birth to her own kids but eventually wanted to adopt. 


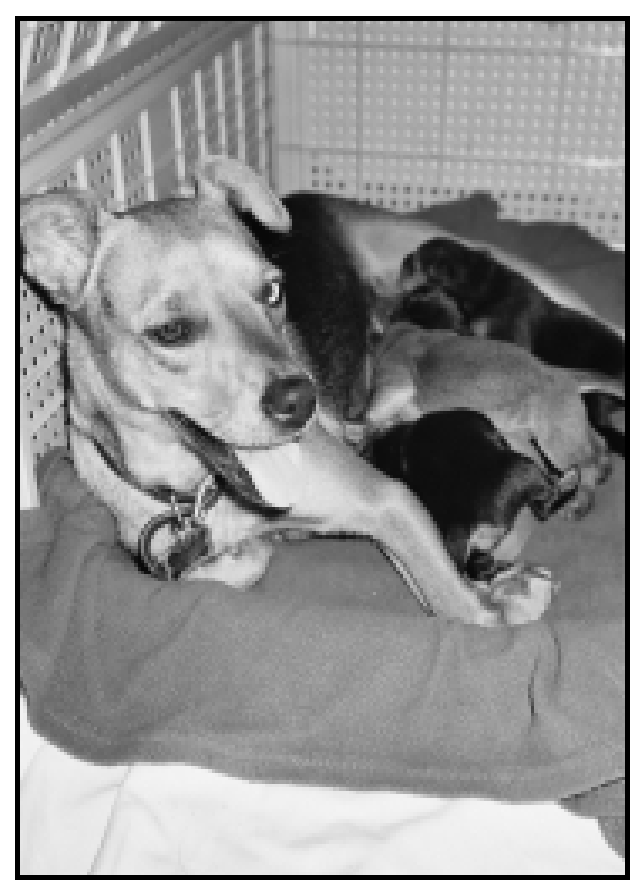

Figure 122: Untitled.

Its funny looking at this... because I don't actually want to have kids myself but it was such a miracle, in a way, watching the puppies be born... she just instinctively knew what to do...it was just intuition and seeing the bond that she had with them almost made me aspire to want to have kids, but more than anything I think it made me-because I don't want to have kids but I do want to adopt kids at some point-so, it made me think about the bond that I someday wanted it to have with something that I was responsible for and could take care of.

\section{Self-empowerment and Identity}

Self-empowerment and identity surfaced as a result of the multiple self-portraits and references to identity, personal strengths and abilities. This theme illuminates the women's agency, power and creative self-representation. The five sub-themes related to the artists' empowerment and identity include: (1) inner strength and personal growth, (2) relationship with work, (3) identity and existence, (4) self-confidence, and (5) respect and recognition. The sub-theme inner strength and personal growth includes photographs that relay the artists' personal aspirations for enhancing themselves through internal 
growth, seizing life opportunities, and building on existing strengths. The artists also shared their personal relationships with work by including their personal needs associated with their type of sex work, maintaining a good appearance for clients, and having a supplementary income. Viewing sex work as art was an aspiration for some, while one artist expressed her hatred for street work.

The artists also discussed racial and ethnic identity in the context of their work. Identity and existence emerged as a sub-theme from those artists who identified the need to maintain certain identities that empowered them and allowed for self-expression. The need to differentiate one's identity from the character roles one played while working was common. The personal need or aspiration to exist related to how one chose to live, be, and belong to society. The women illustrated Self-confidence as a personal need and aspiration related to actions and perceptions of self. The artists working as exotic dancers emphasized their need for respect and recognition related to their work and their danceridentity compared to street workers who expressed aspirations for respect and recognition within society.

\section{Inner strength and personal growth.}

Many of the artists took photographs representing their inner strengths, their desires for growth, and their aspirations for seizing new opportunities. The women photographed their bodies, nature, animals, and symbols of opportunity to express their needs, desires, and experiences related to inner strength and growth. The artists photographed their feet, doors, signs, and animals to represent their aspirations for pursuing various possibilities and life opportunities.

Mouse photographed herself in her garden holding a watering can over her head 
(figure 123) to represent her personal need and aspiration for growth.

I took that thinking about the things that I need in my life, like plants, like in a very organic sense. Like just needing water and sunlight which is kind of hard in Portland and aspiring for growth...in a very organic sense. And tranquility because plants don't- as far as I know- plants don't think about growing.

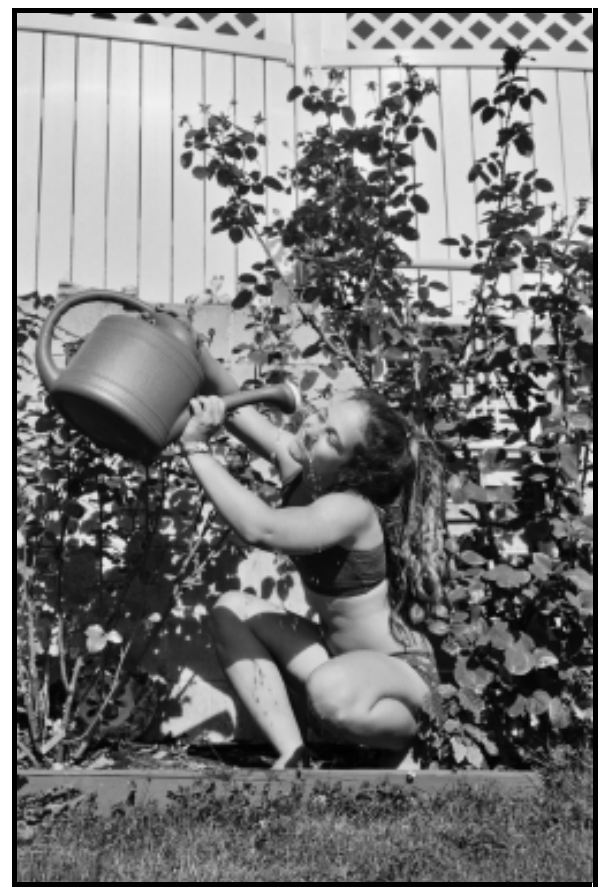

Figure 123: Untitled.

Similarly, Rizzo photographed a flower to represent her aspiration for internal change and growth. She also paralleled the blossoming of a flower to her own internal growth associated with her youthful age. Rizzo also photographed a book that read Now Discover Your Strengths to express her self confidence and her aspiration to discover more of her personal assets and abilities.

I mean sure, I'm a good prostitute (laughing), but I'm sure I can do other things, too. So it's just an aspiration for me to discover my strengths and things that I can do besides the stuff that I do now... and become a stronger person.

For Crystal, a change in her life involved being able to visualize her self in positions where she was utilizing her strengths and interests. 
I can actually see things changing, you know. I can actually see myself volunteering at places and doors opening. I can see that now. A few years ago, I was like, is this [domestic violence] ever gonna end? I just kinda got feeling stuck in a rut and got really kinda scared, but I'm to the point where I don't care. I'm gonna be out of my comfort zone. And I'm gonna be scared. I'm just not gonna let anyone know it (laughter)

Crystal reflected on the opportunities available to her when she leaves her comfort zone and the possibilities for change in her life.

Jasmine expressed her need to pursue new opportunities through a photograph of doors (figure 124). She expressed feeling overwhelmed with the unknown and the obstacles ahead while simultaneously feeling excited and hopeful with the possibilities.

I laid down to do that one actually. The door, to me it represented all of the doors that are shut to me... the need to open certain doors I haven't been through yet. They are big and they're immense... like these big bronze doors that are kind of scary and it's almost like the need to overcome obstacles...right now I have the need to break down those doors.

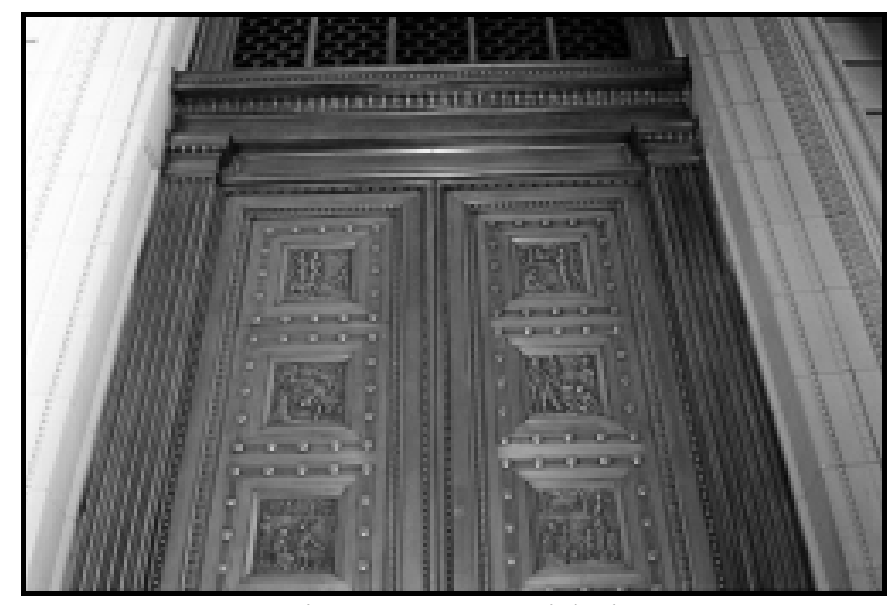

Figure 124: Untitled.

Jasmine also took a picture of her feet and said, "my feet standing up on this beautiful path is like a future aspiration of me being able to stand on my own two feet and put myself on the path that I want to be on." A similar aspiration to walk on a chosen path in life was expressed by Rizzo. She also photographed her feet to symbolize a new start, her 
resilience in life and her aspiration to keep going (figure 125).

I feel like I've walked millions of miles in my life and been through a lotta stuff so it's an aspiration. I'm gonna keep going and keep walking through all different parts of my life and different changes in my life. For me, these are new shoes so it's like a new walk of life, a new trip for those shoes; a new route for those shoes to go on.

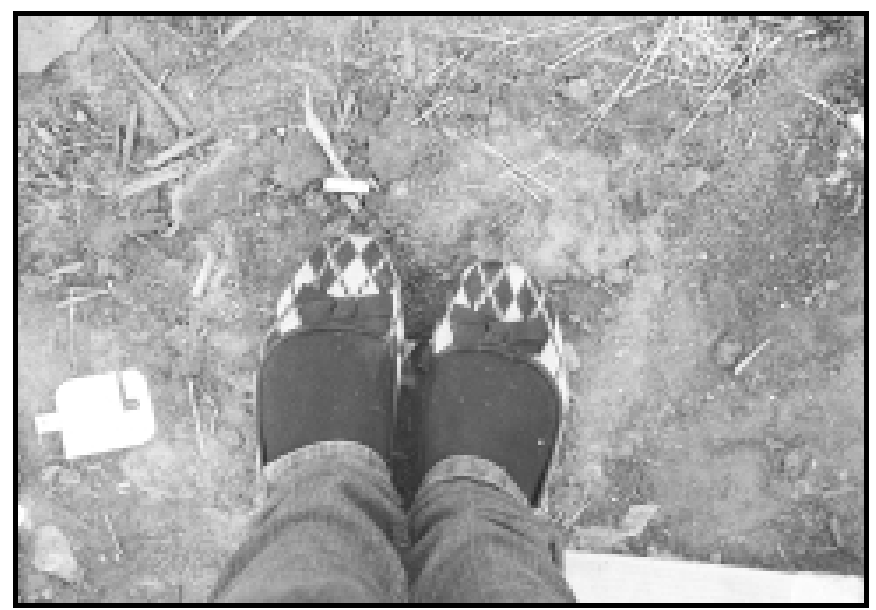

Figure 125: Untitled.

Mouse presented a photograph of herself on the top of the roof (figure 126) to symbolize her aspiration to be more spontaneous.

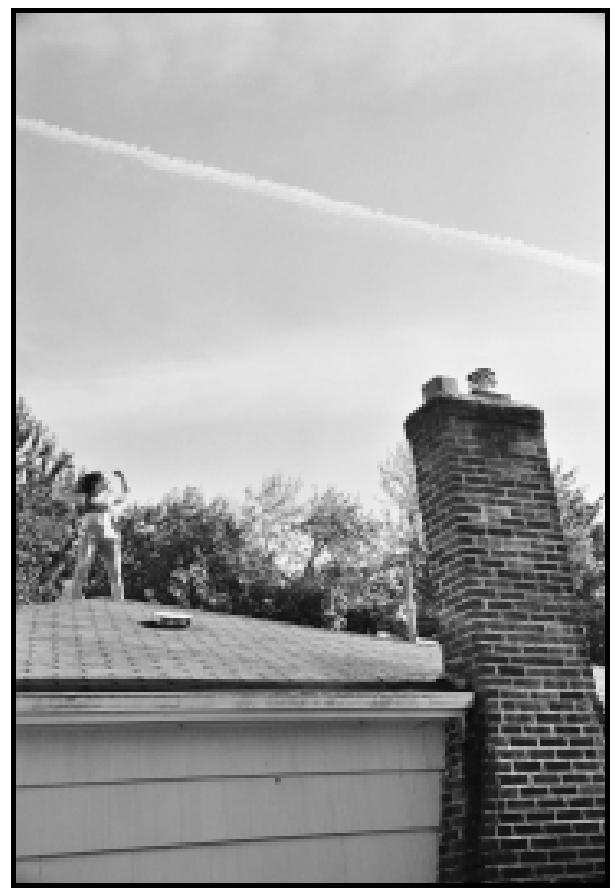

Figure 126: Untitled.

265 
It was the first time I climbed up on top of my house (laughter). I did it because I had never done it before and I thought it would be a good opportunity to take a photo of this because I want to do that more often in my life. I want to just think of spontaneous seemingly impossible things that I've never done before and just do them. And the airplane trail and having me so small in the corner really emphasizes how large that I felt the possibilities were at that moment. So, I mean, to use the cliché, the sky is the limit. That's really how I felt standing on the apex of the roof right there.

\section{Relationship with work.}

The artists took various images related to their work environment, type of work, personal boundaries, and the challenges and benefits of sex work. They represented these needs and aspirations through self portraits and photographs associated with their work environment (e.g. signs, lockers, work accessories). The women discussed their work environment and level of satisfaction (or dissatisfaction) with sex work. For those women who worked as exotic dancers, they described the importance of their relationship with club management. Clear communication and boundaries with management, as well as job perks (free food, tanning, etc.), helped to promote a positive working environment. The artists expressed different levels of fulfillment through their work. The women who experienced satisfaction from their job presented self-portraits to represent their sex work as art. Work satisfaction (or dissatisfaction) was often related to the participants' level of dependency on sex work for their livelihoods. However, dependency on sex work did not correlate with a lack of resources since some women who were homeless at the time of the study had other avenues for making money.

The artists discussed their work in the context of their identities. Racial identity was significant to one's experiences while working and related to a desire for respect. Work accessories seemed to represent an extension of the women's identities. While not 
all participants specifically photographed concepts related to their job, they articulated their personal relationship to their work in the sex industry.

\section{Work environment and satisfaction}

Lady Purfection photographed the signs and messages hanging from the walls of the dressing room at the exotic dance club where she worked (figure 127). She expressed a personal and communal need to communicate with strip club management.

You see these types of signs in a lot of strip clubs you go to, hanging in the dressing room. So the signs---it's good communication. It's a need for me. It's a need to feel like I can communicate with the clubs that I'm working at. For them, it's a need to communicate with the entertainment...

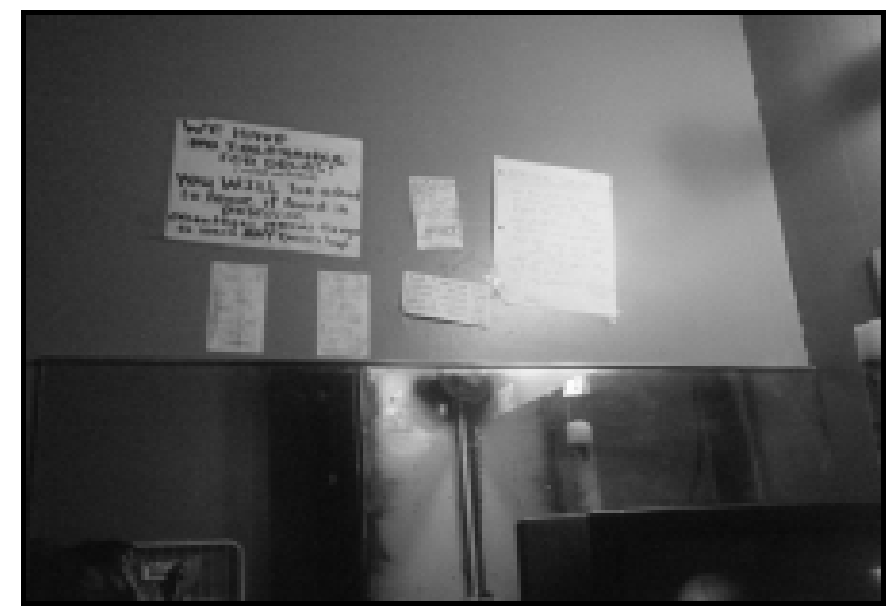

Figure 127: Untitled.

Lady Purfection also took two photographs of lockers in the dressing room of the exotic dance club. They symbolized her aspiration to have her own space at the club and represented stability, privacy, prestige and a sense of belonging.

Lockers are just significant in the entertainment world just 'cause they [club management] don't have a key; they don't have your combo so they can't just go in and start rummaging for your stuff. I think that's part of what my problem is now. I don't have my space...I tried to go back to $[\mathrm{XXX}]$ and [XYZ] but it's not gonna happen. And I'm just trying to find my place. 
Jasmine explained her relationship with street work and clarified that her work in

the sex industry was not her main source of income.

The first time I ever sold my ass (laughing) was when I was 21 ...I didn't have a bad experience...I've done everything from picking up johns on the corner to escort work....me and my friend-we put ads on Craigslist-but only when I'm really hurting for money. But usually, I prefer to just panhandle, its [sex work] not something I want to get into doing...I've seen what happens when you do something like that as a primary form of income- it ages you very quickly, I know girls who have been doing it for years...

In contrast, Crystal spoke about how her only form of income has been through

sex work. She expressed fear that she would not have any other work experience if she chose to discontinue this type of work when she was older.

We need to think about our future...we need to try to get a resume so we can get better jobs and try to get out before it's too late...before you're stuck in your 50's. Not that I'm making judgments but just that it's scary to think about the future without a whole lot that I could put on my résumé... Some days can be okay-real good and other days just aren't and you just never know. It can be difficult at times; not always consistent. It's a lot of work, to try to please the world, to try to please men, to make yourself look good -it takes a lot of time and energy to make yourself look great and to be healthy and it doesn't last forever...

Crystal speaks to the unstable income from stripping and escort work and the energy it takes to look good. She photographed a sign outside of a strip club (figure 128) and discussed the benefits of working there even though business decreased.

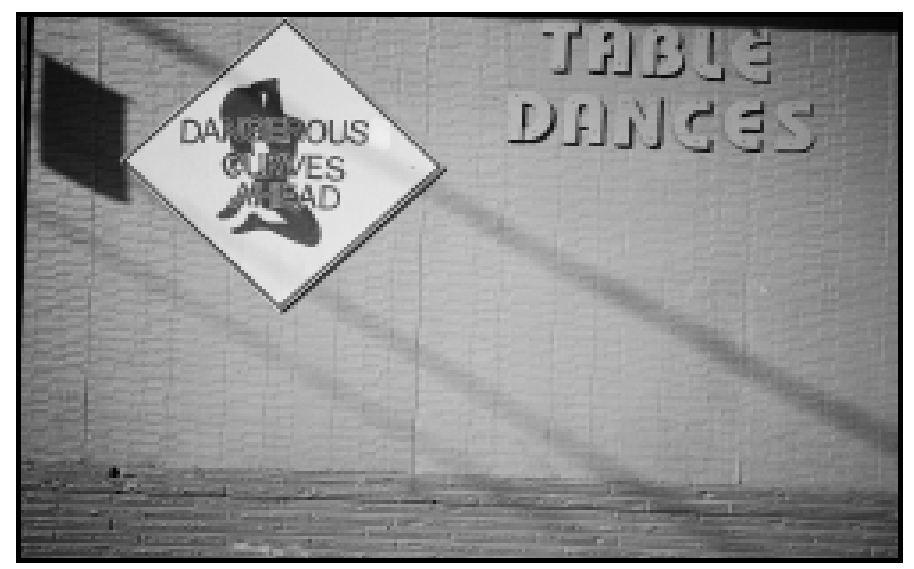

Figure 128: Untitled. 
The special thing about this place here is that you get your own free lunch or breakfast, your choice. Inside the dressing rooms they have a tanning bed so if you want you can go tanning in there for free. I feel like it's fair- they've expanded it and remodeled it and made it cleaner, it's a cleaner environment but it's gotten a lot less busy, so money-wise, it's just ok, it doesn't get super busy so that's probably why they do that for the dancers there...

Mouse also expressed satisfaction with the club she worked at and shared, "it's just like a really nice homey kind of environment, and the management is really, really wonderful people... it's just a really nice place to work and I like that there is no drama...people don't steal stuff from each other." Job satisfaction was also expressed by Grahm, who expressed content with her co-workers and the management. She said, "I've been really happy working there. I think that it's a way more supportive place than a lot of other places I've been to before."

In contrast, Rogue expressed discontent with her need to engage in street work in order to survive. Her husband was unaware of her involvement with street work. She presented a portrait of herself panhandling (figure 129) and shared an aspiration to no longer hold a sign while waiting for a client.

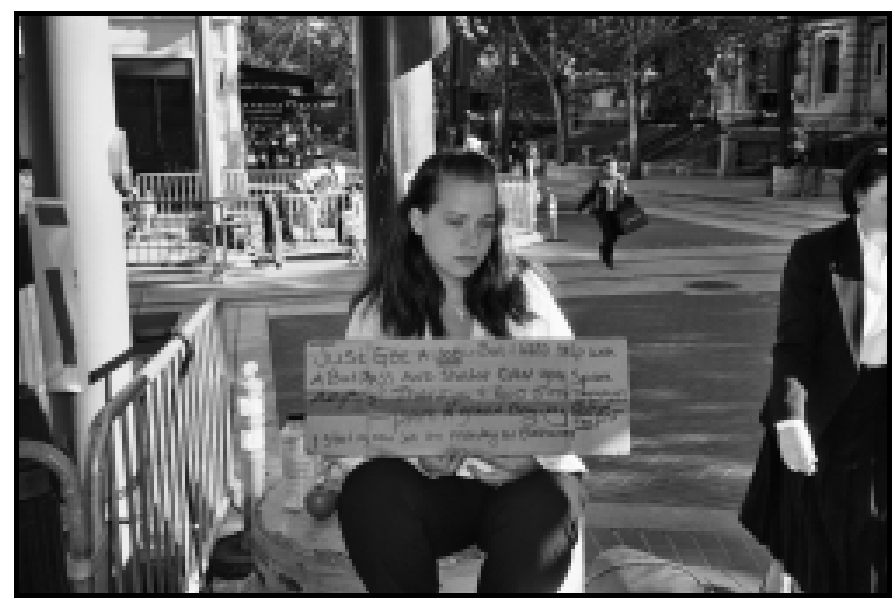

Figure 129: Untitled.

She also took a photograph of a tree (figure 130) and explained the symbolism behind her 
image. She said, "This one is more of a need and an aspiration. Just to stand tall and strong like the tree does. It's hardest to stand tall and strong when I have to lie to my husband. I hate what I'm doing. I absolutely hate it."

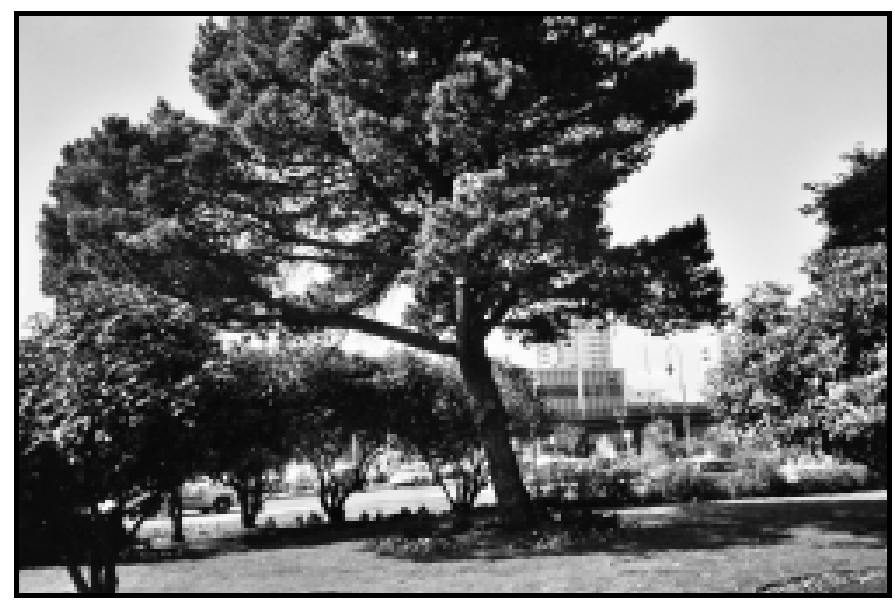

Figure 130: Untitled.

\section{$\underline{\text { Sex work as art }}$}

A few participants expressed the notion of sex work as art through self portraits.

Lady Purfection, Mouse, and Bee expressed feelings of empowerment and photographed the pride they took in their work in the sex industry. Mouse used a self-portrait (figure 131) to represent her stripping as an art form.

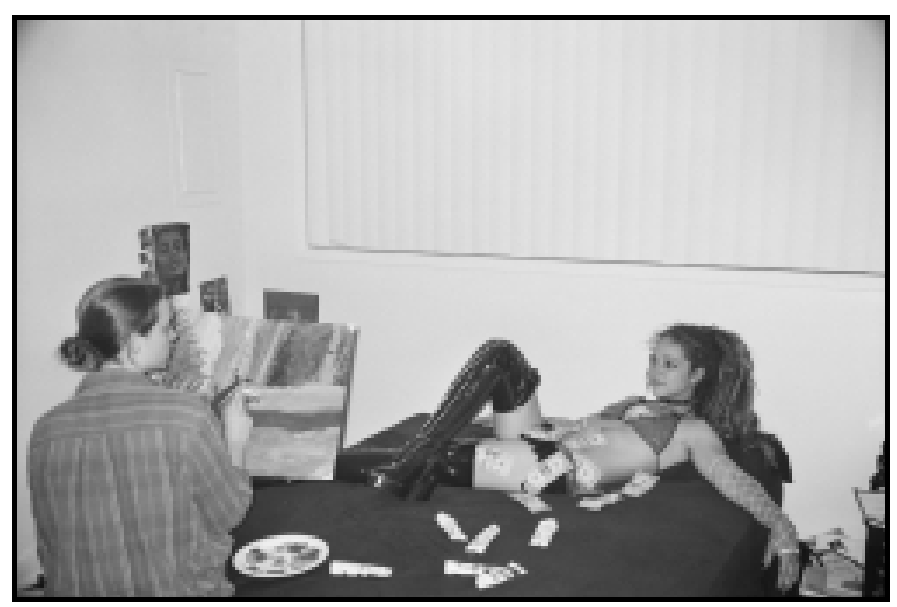

Figure 131: Rich Landscape. 
I put these photos together because no matter what kind of sex work you do, it is a kind of art. When I think of stripping, I really do try to treat it like an art. I mean, everything from the movements that you do while you are dancing, to the image that you project when you are interacting with other people.

Mouse further explained how she composed the scene of herself being painted by her

friend as a landscape to challenge typical ideas of beauty.

I told my friend that I wanted her to paint me... I told her, you know, just act like you are painting me, but have the landscape visible, because this is a beautiful painting. And I thought that it was an interesting idea that she was obviously painting me in the picture but it translates to just something beautiful. And the fact that she could be looking at someone dressed up in super trashy stripper clothes covered in cash and just be that sort of beauty. So, I think of stripping as an art and every so often it would be nice to have it be appreciated as such and to have people to notice the kind of things that these people don't notice.

Lady Purfection also presented the idea of her work in the sex industry as art. She

photographed a piece of found art depicting a female silhouette (figure 132).

Basically, I'm in the sex industry because it's fun. It's an experience you won't ever get anywhere else unless you partake in it. I love what I do, I love art and it's a form of art to me, entertaining. One day I hope to be famous for my art, not just for my sex work... This picture of a dancer on the wall... it's just drawn with a sharpie... this picture symbolizes that women are sexy...it represents compassion because of the way that she's angled and the way that it's drawn.

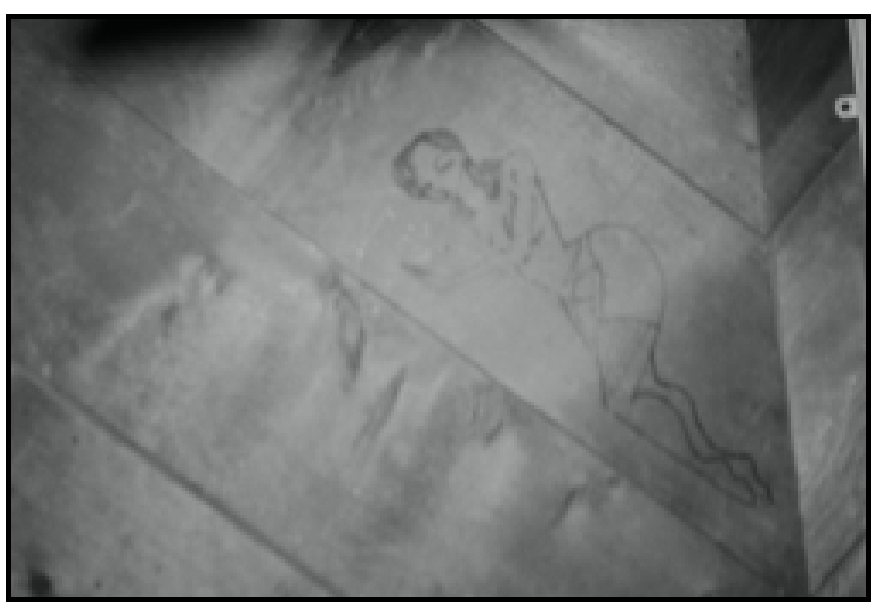

Figure 132: Untitled.

She paralleled her experiences as an exotic dancer with what she saw represented in the 
found artwork. Like Mouse, Lady Purfection presented a series of photographs of herself dancing on stage (figure 133) to express the perspective of sex work as art. In the individual dialogue session she said:

So, these other pictures that I have here of me dancing at [XXX] I actually had a customer take these pictures because I really wanted to get this picture of this pole trick that I do because I love it so much. I mean, I don't get an hourly wage no matter where I dance at so everything is all based on tips. For me, I just like to express myself and let everyone know look, I'm attractive but there's more than what you see. And I think sometimes when I'm dancing I show that because people ask me all the time, "what do you do outside of work? I'm interested to know." And I just say "well, I take pictures, I write, I'm trying to go back to school. I do a lot." And so that all ties in with my compassion for my work.

During this project, Lady Purfection wrote several poems to accompany her photographs.

She also talked about her frustration with how she is sometimes perceived racially and ethnically at work.

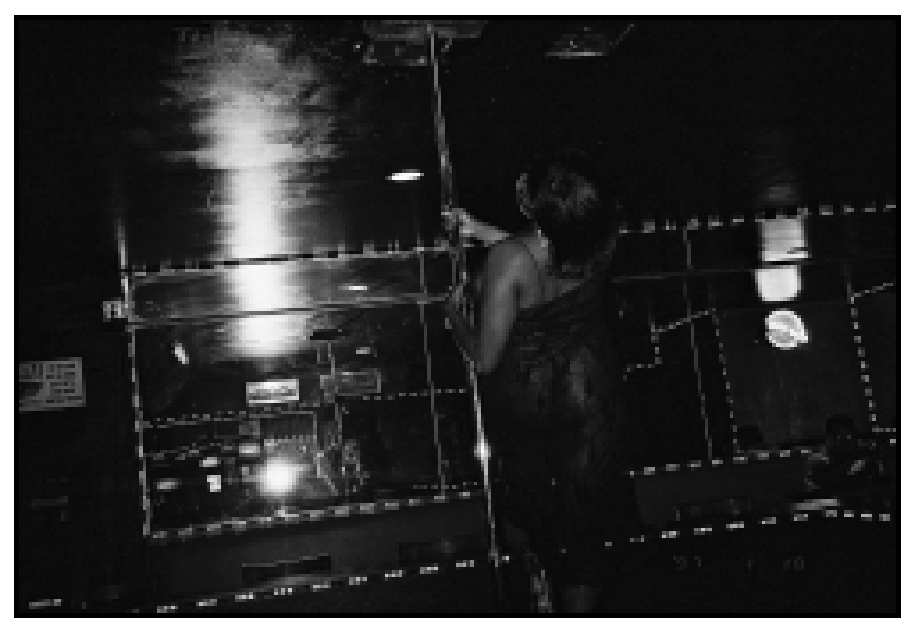

Figure 133: Seductive Tales: self-expressive, watch closely, but not too deeply.

I mean it's not hard, or it's not easy being Creole Blackfoot Native mix which is considered Black. And some people can tell that I'm mixed and some people can tell I'm not straight up Black. I mean what is straight up Black? African? Jamaican? What? I have people come up to me speaking Swahili and fuckin' Spanish when they're from the Caribbean, like Cuban. So, for me it's not so easy... of everything I go through, dancing is- it's my decision. I put up with a lot and I chose not to put up with a lot. I don't think that I disrespect myself. I don't think that I disrespect my body. It's self-expression. There's so much art and there's so many different venues for art and some people don't understand and 
they think “oh, they're just selling their self, they're just being pimps, they're just this and that" and it's not like that... When you're close-minded, you don't really get a good grasp of life.

\section{$\underline{\text { Work accessories }}$}

Some participants photographed the different bags they carry in different situations (i.e. work, travel, going out). Bee photographed three bags of all different sizes (figure 134) and explained, "Bags of my life. I live out of bags. I should have put my purse in there, because I live out of my purse, too. I cannot carry a small purse. This is my life. They are all needs. I need to have this, I need to have this, I need these things, I need these bags to do my job and live." She described the different things she carried in her bags; all symbolizing her relationship to different types of clothing she needed for work or for her personal life.

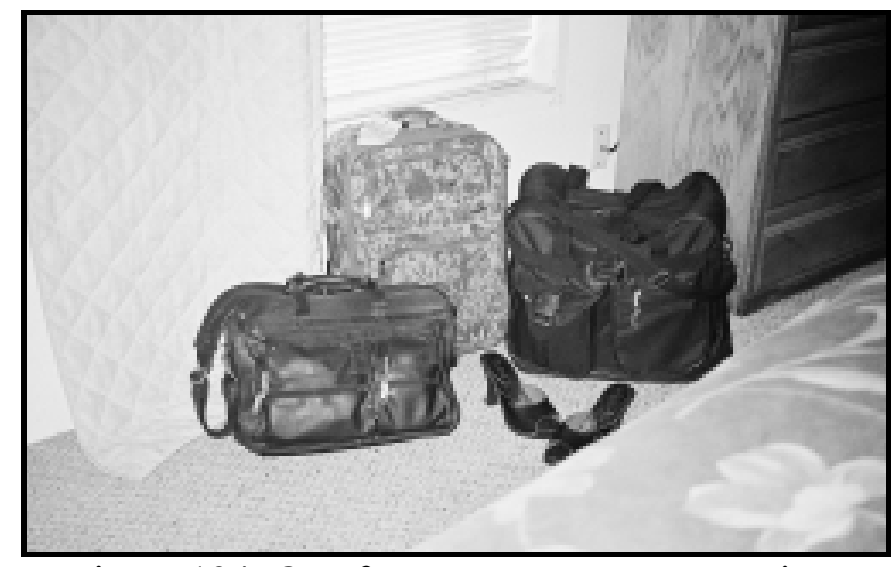

Figure 134: One for every necessary occasion.

Mouse also photographed the bags she carried in life (figure 135).

This picture was interesting because I was thinking about the containers for my life, because that one, that tiny little purse right there, is the bag that I carry when I'm stripping. Because it's small enough that it's not huge and bulky, but it's large enough that it holds my cigarettes, my lighter, my cash and my makeup. And that's all I need... but then I was thinking, there is my school back pack and that holds everything that I need when I'm going to classes; it holds all my notebooks, my books, all my writing utensils, my coffee mug and it's the perfect size for that. And then, this pack is what I have when I am traveling and that holds, you know, 
my camping stove, a number of books, many layers of clothing, my sleeping bag, the pillow on the side there...I was thinking about how my life has progressively become more compact...I was thinking that I want there to be more synthesis in my life of all those different parts of it, instead of everything being self-contained inside containers. I just want everything to be more fluid. I don't want to have to compartmentalize so much. It was also interesting thinking about the different sizes of my life at different stages.

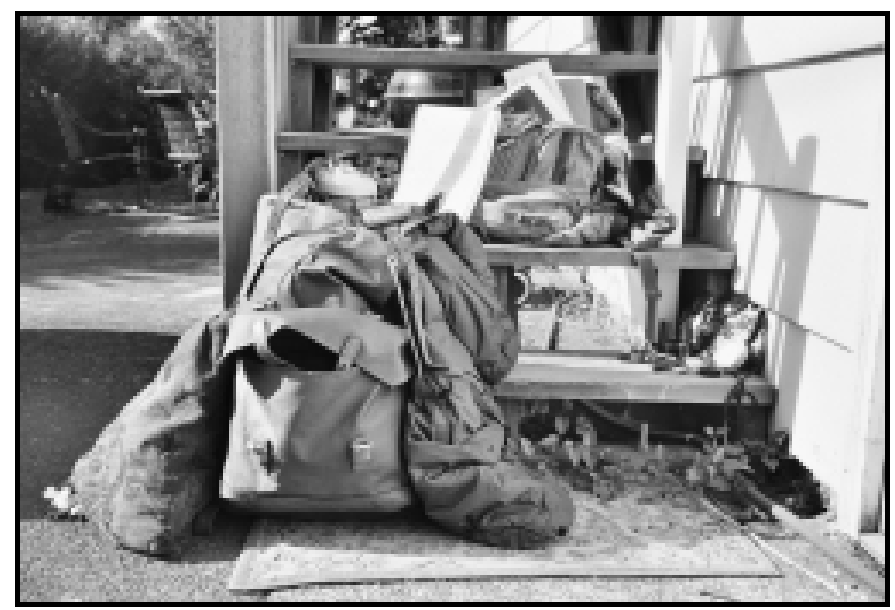

Figure 135: Untitled.

\section{Identity and existence.}

The artists took various photographs of themselves or objects to symbolize extensions of themselves, such as a basket, shoes, particular landscapes, trains and signs. It was important for the artists to present their identities and as a way to be perceived and understood as more than just a sex worker. For some women, it was a way to differentiate their sex worker identity with their other identities. The women presented clothing, shoes, and other objects to define themselves as unique beings. For those women who were homeless at the time of the study, self-portraits served to validate their existence.

Merry Mag took a self portrait with a basket on her head (figure 136) to symbolize her activist identity. 


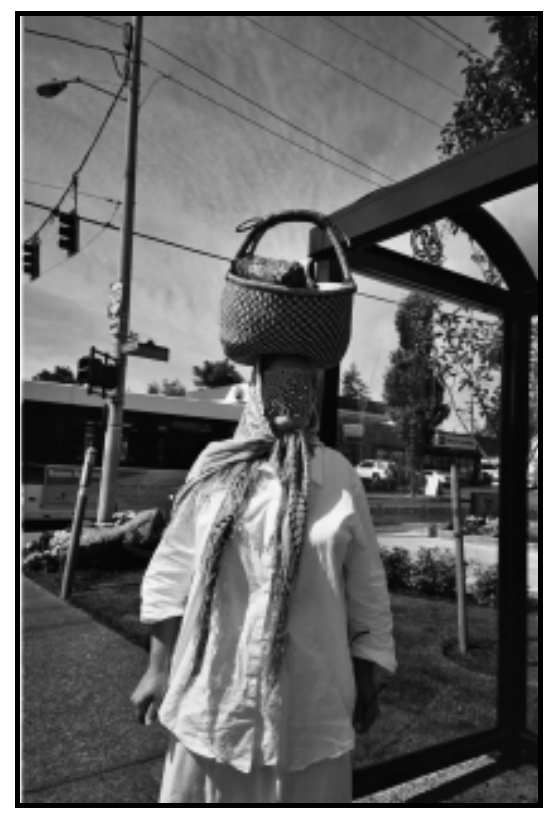

Figure 136: Untitled.

Thru my ability to learn to balance it [basket], I feel an affinity with millions of women from all over the world. I carry hygiene items, condoms, syringes in there... band aids, clean fresh socks, makeup for women...a lot of us women [street workers] would get together on the corner and get ready for the day... I just always thought that women that wore a basket were beautiful and I thought, that's all I need- whatever I could carry in my basket and I knew that the police could not search my basket without a search warrant. I wear it today as an aspiration...

Her basket was a source of resistance and empowerment and a way in which she could represent her values and interact with her community. Merry Mag also photographed her basket alone (figure 137), seen as an extension of herself.

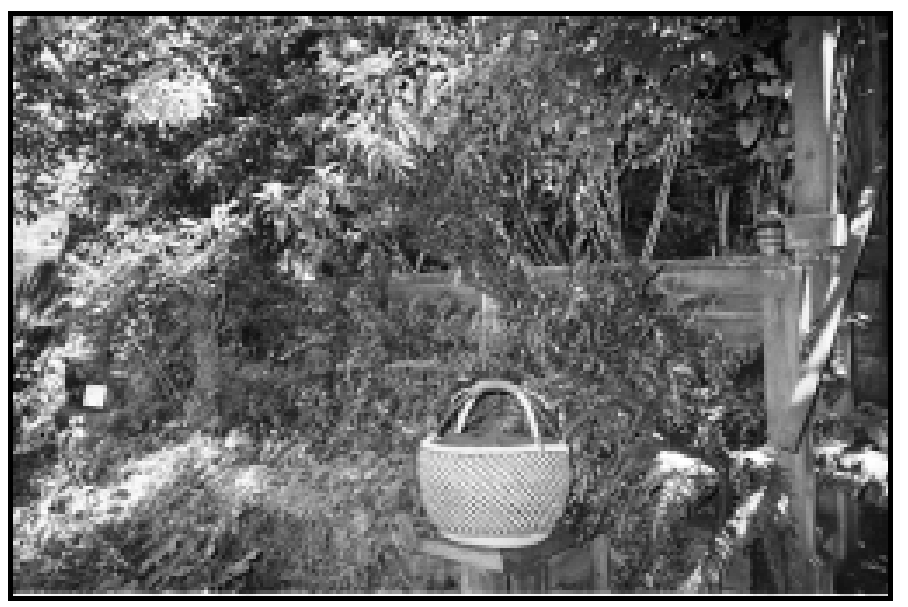

Figure 137: Untitled. 
Mouse presented a portrait of herself in front of the mirror to represent a need to keep her identity separate from her stripper character (figure 138).

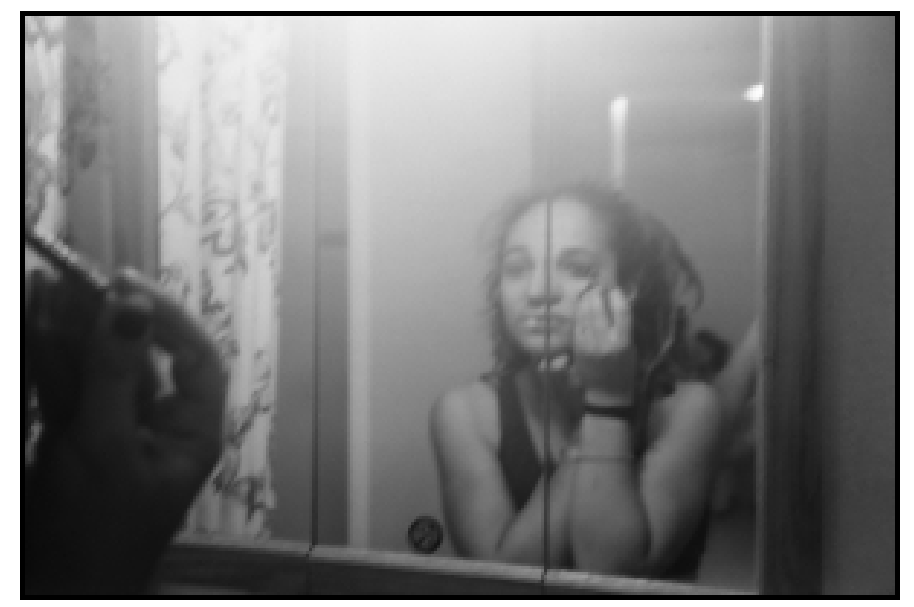

Figure 138: Untitled.

You can see me making my face up in the mirror...that side of my face I had make up on, and that side of my face I didn't...I wanted it to show that there were two sides; that there was the ghost side, the apparition side, the character that I play, and then there is the real side of me...I think of them as being divided. I sometimes flip and change back and forth from one to the other but I never think of them of being as cohesive and as a single being. I don't think I really would want to embody who I am when I am stripping in my everyday life...I don't want to think of myself necessarily as the kind of person who shamelessly flirts with fifty year old strange men I have never seen before in my life and gets naked in front of them and teases them and I just don't want to think of that as who I am. It's my job, its how I make money, but it's not who I am...that is not my personality... It's a character that I play to make money and it's like theater.

Mouse also photographed two different pairs of shoes side by side (figure 139) as a

symbol to represent a need to feel comfortable with who she is as a person.

Shoes are very defining for who you are...these are the boots that I am wearing right now. These are the boots that I wear every single day. That is my foot wear. That it's the foot wear embodiment of who I am, and those [heels] are my character shoes... what shoes you're wearing have a huge effect on your comfort level...I feel comfortable in these shoes. Those shoes [heels] make me feel like shit (laughter). They make you hurt all over when you are wearing them. For the entirety of the eight hour shift, oh my God, they hurt. So, in terms of the way that different shoes make you feel, I want to feel like who I feel like I am. And I want to feel comfortable. 


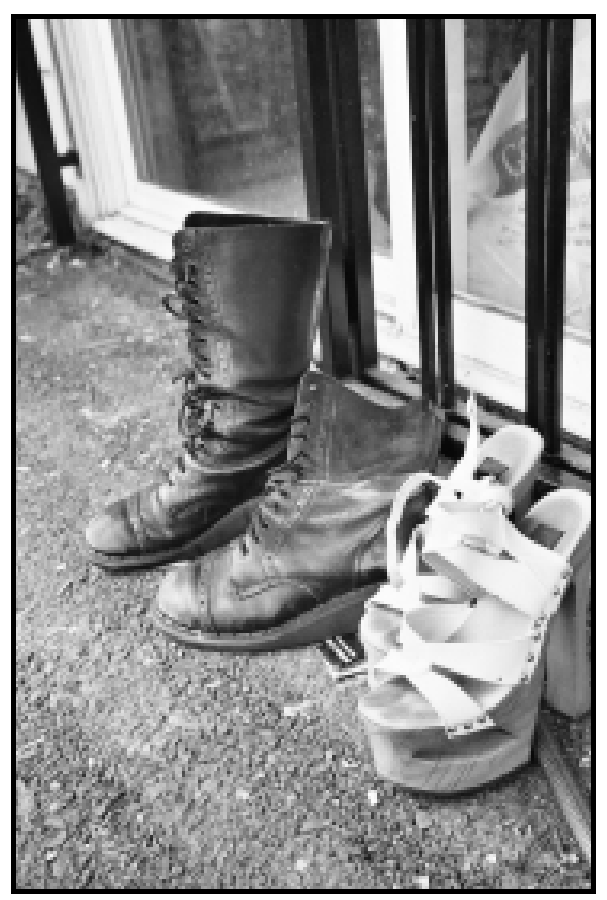

Figure 139: Untitled.

While Mouse reflected on a desire to keep her true self separate from her sex work character, Jasmine expressed a need to stay connected to her past and her identity as a train rider and gutter-punk in her photograph of a sign and train tracks (figure 140).

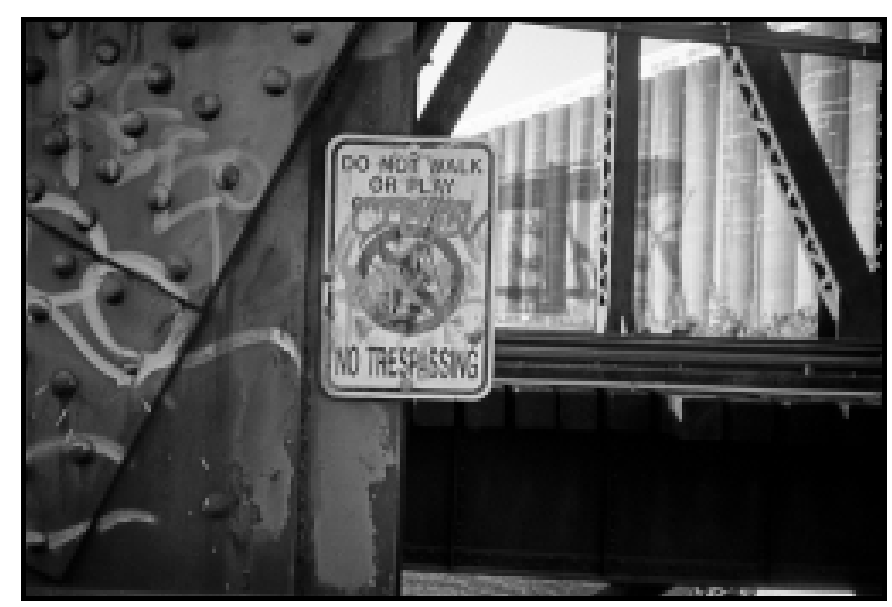

Figure 140: No Trespassing.

The "no trespassing" sign has a meaning- from constantly being shut out of places for who I am and what I am. It also represents me as a train rider, a gutter-punk. That is my need to stay connected with my past and who I am, because that is part of who I am, the whole train rider thing and Union Pacific... I hopped my first train when I was $21,22 \ldots$ I've hung around at places like this almost my whole 
life...part of it is a need to, you know, be able to go places that others can't, and a need to not be constantly shut out of everything. It's always, "No trespassing" "Can't stay here, move on!" "Move along! Get out!" "Nobody wants you here because of who you are, because you're poor!" you know, "Nobody wants you around!" Like I'm just supposed to roll over and die and disappear because it's inconvenient for society to have me around.

Jasmine described the discrimination she faced because of her identity as a homeless train rider and as someone who identified as a gutter-punk. She also photographed her shadow on a wall that displayed her graffiti (figure 141) to represent her need to exist. "That's my tag Midwest Drunk Punks. It's my shadow, see, I wanted one of my shadow in there. That's my need to exist, you know, to exist and be recognized...that I am part of a subculture, part of something, I always have been or I have been for quite some time."

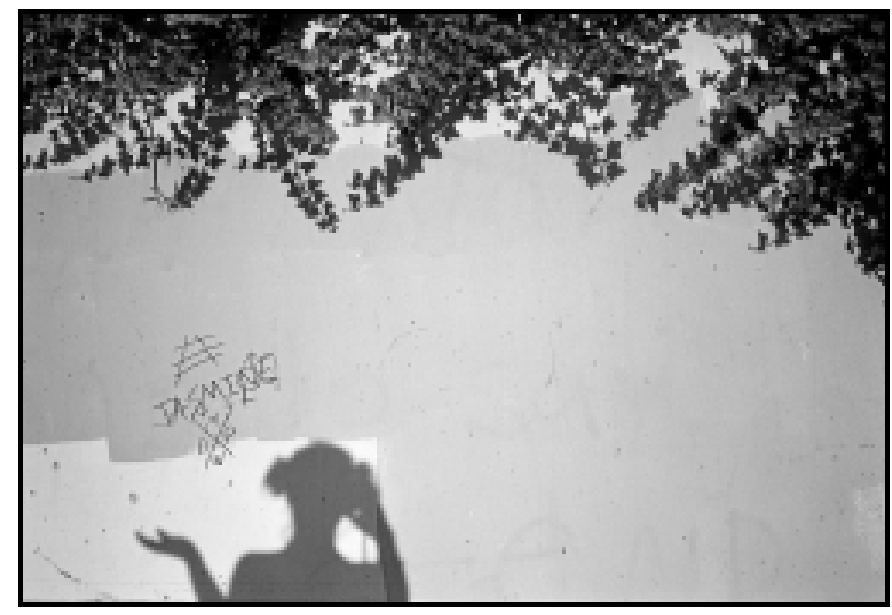

Figure 141: Shadow Tag.

\section{Self-confidence.}

Self-confidence was an important theme represented as an aspiration and expressed through self-portraits of self-assurance. Feeling secure and confident allowed the women to resist stigma, and love and accept themselves. The artists presented their confidence; by hiding parts of themselves (behind sunglasses) and by exposing themselves (through nudity). 
Lady Purfection photographed herself in the passenger seat of a car (figure 142)

to express a personal aspiration to always be confident.

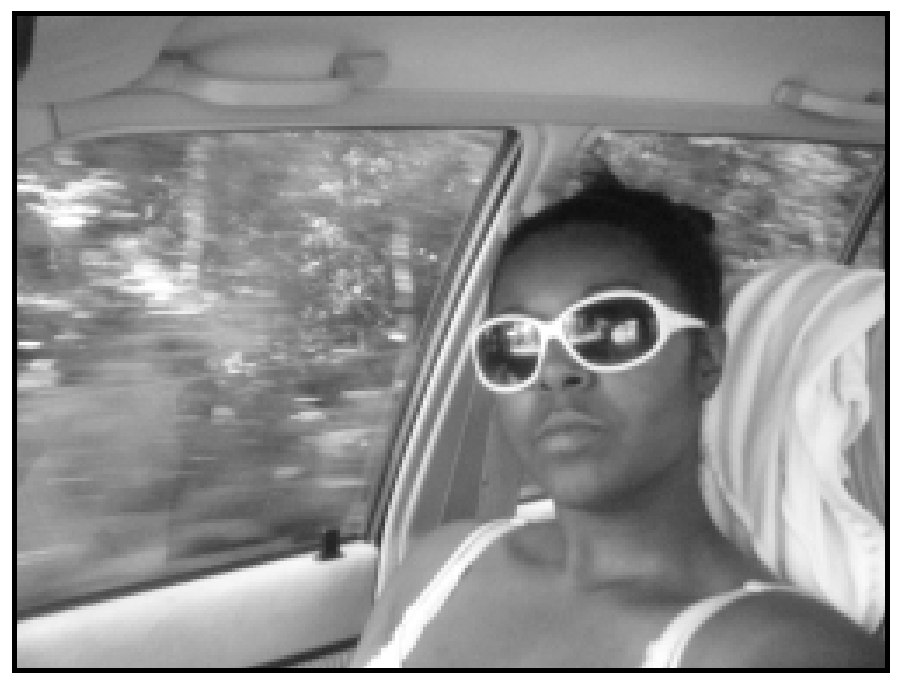

Figure 142: Can't see me... but I can see you.

I wear stunners-I call them sucker reflectors 'cause I just like to think that people can't see me. When I take pictures of myself- it's inspiration for myself because I can look at myself and say, this is what I'm doing, this is how I'm living my life and if they don't like it, oh well.

Lady Purfection's sunglasses represent her resilience and self-protection from society's

judgments. In her self portrait (refer to figure 136) Merry Mag also shared the importance of having confidence and not worrying about being judged for working in the sex industry.

Jasmine photographed herself physically exposed (figure 143) to express her aspiration to be comfortable with her own body.

I just wanted to be like a primal naked self, you know, like this is me, and I am confronting you with myself, there's no armor, nothing. That's like an aspiration to able to show myself without shame... I'm very self-conscious of people seeing me naked...so maybe it's a future aspiration to be able to be comfortable with my own body for once. 


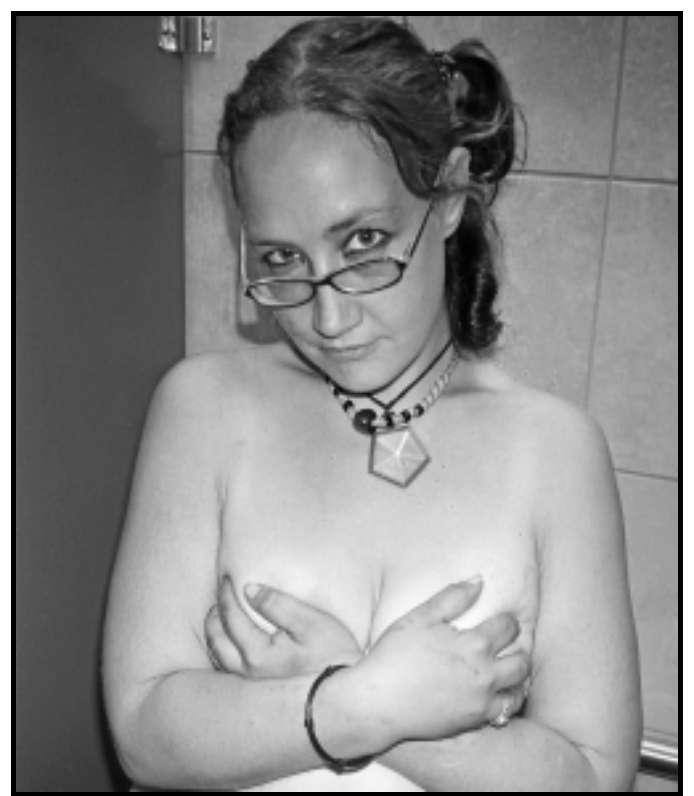

Figure 143: Me, Myself \& I.

Like Lady Purfection, Jasmine wanted to confront her audience with herself and be accepted for who she is. While Jasmine articulated an insecurity and represented confidence in her self-portrait of exposure, Lady Purfection represented her confidence by remaining hidden behind sunglasses.

\section{Respect and recognition.}

The artists took photographs that centered the personal and communal needs for respect, recognition, appreciation, and belonging, in the context of work and life. Images included self-portraits, cityscapes, and indoor scenes constructed to tell particular stories. The artists placed value on wanting to be seen as a human being.

Mouse juxtaposed two photographs to represent her need to be acknowledged, respected and admired while working. One image captured her feelings of vulnerability, exposure and rejection when customers ignored her while stripping (figure 144). Another image represented what she wanted to feel while stripping on stage (figure 145). 


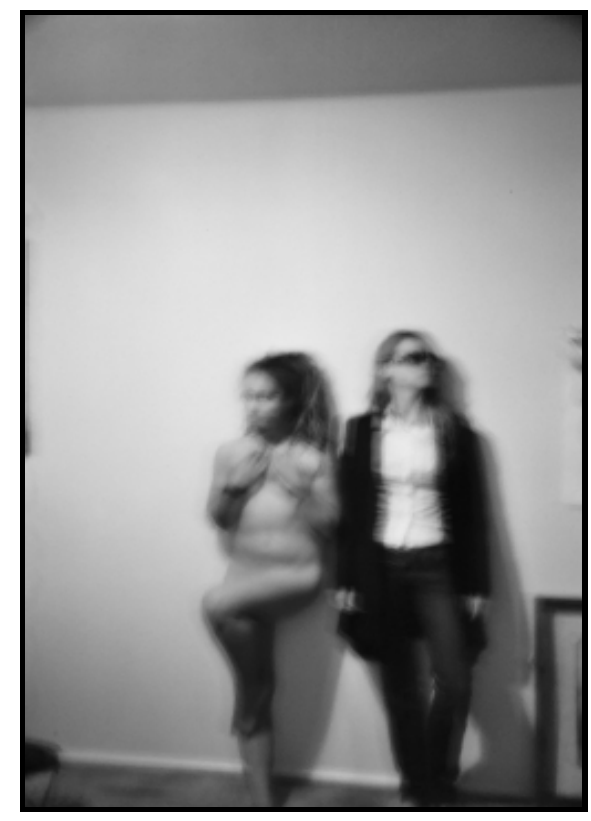

Figure 144: Untitled.

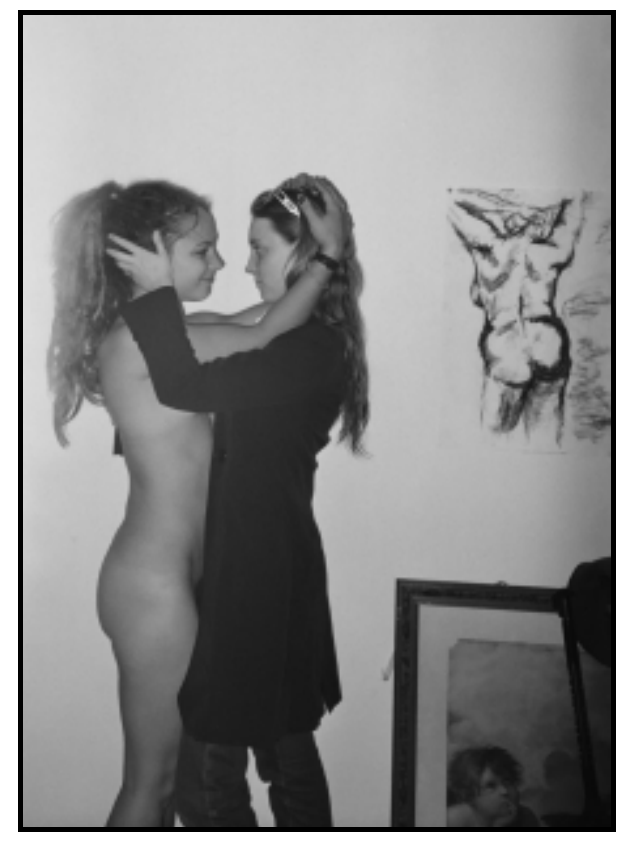

Figure 145: Untitled.

I thought that it [photo on the left] reflected the worse manifestation of how I feel when I am working. In that I am putting myself out there to people, I'm completely naked; it feels very vulnerable to be like that and to just have the people who are clothed around me just not even paying attention. I mean, just not caring and when you're stripping and you're really trying- I mean, you put so much effort into trying to look beautiful for other people in this very conventionalized way... and they ignore you. It just makes you feel like shit. So, I took those two first because I thought that was an important feeling to capture, but then I went back and thought, I am trying to make this about needs and aspirations and these indirectly reflect a need that I need to not feel like this. But then I thought I needed to go back and take these other pictures because this is what I need from people when we are in that kind of position.

Mouse created her own performance story to illustrate her experiences as well as her vision of being accepted while working and embraced for her hard work.

Mouse took another series of photographs- self-portraits- of her performing mundane tasks and activities inside and outside of her house in her stripper clothes. These photographs of her (i.e. smoking, drinking milk) represent a personal need to be recognized as a human being (figure 146). 


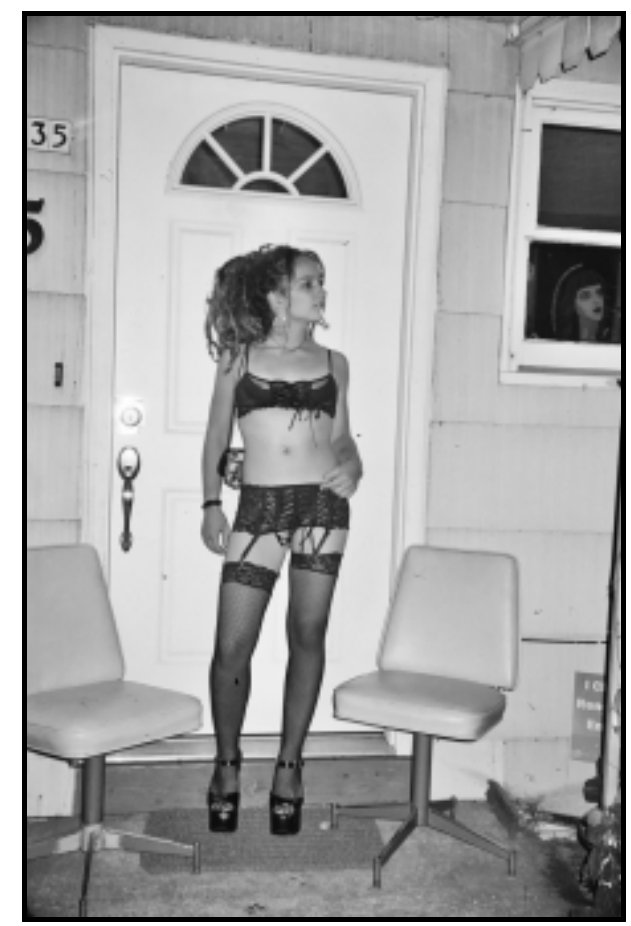

Figure 146: Smoke Break.

To accompany the photograph of herself smoking outside she stated:

Clients don't want to hear about your actual life, that you drink milk out of the fridge and that you smoke too many cigarettes out on your porch too late at night. Or, you know, what you actually aspire to do with your life. They want to hear that you have naked pillow fights, sprayed with cream all over each other... (laughter). They would much rather have you facilitate those fantasies that they already have running. So, I took these pictures because I really wish that it wasn't the case, that even if it is my job to be that role for those men and occasionally women that come there, that...I do wish sometimes that I could still be acknowledged or at least recognized more as a human being with a normal life.

Jasmine photographed a bridge to represent her aspiration for recognition and belonging to society (figure 147). This symbol represented her potential for becoming a part of society, instead of an observer from below or above the bridge.

My aspiration is becoming a part of society, a part of this city, you know, doing something cool in this city, this part of the country; actually making a name for myself, eventually... so this is a bridge I've walked across many times. I used to sleep under it. I used to walk across that bridge every morning after I got up, coming back over to downtown. I've always liked the view from it, and I've stood there watching the ships come in... 


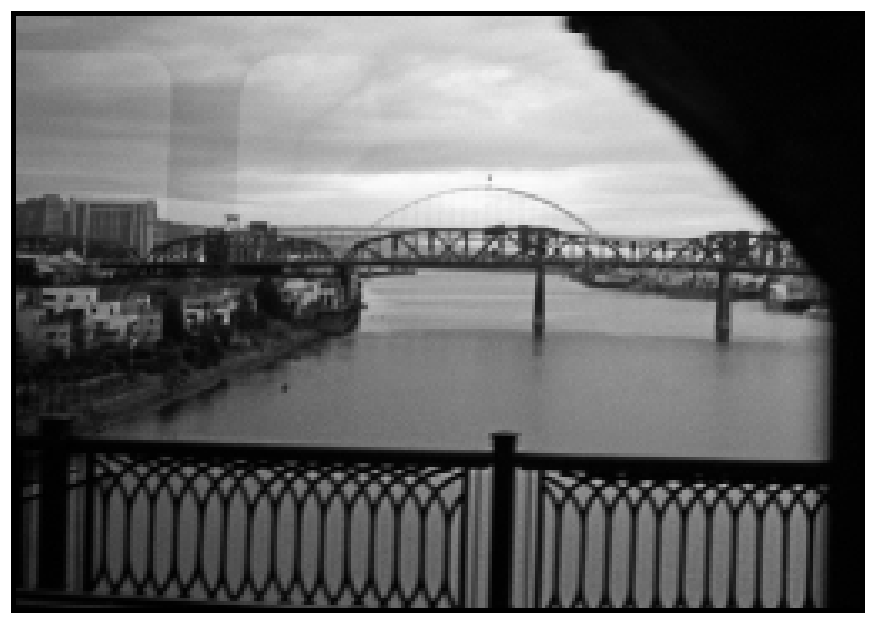

Figure 147: Untitled.

While the photographs taken by Lady Purfection addressed her need for respect,

she explained that she wasn't able to specifically photograph that key concept.

How do you take a picture of respect? The need for respect from people on the outside looking in. I don't disrespect anyone, period. I don't. Just because I'm an entertainer doesn't mean I don't deserve respect or I don't deserve the right to live my life how I want to as long as I'm not damaging anyone else's lives or putting anyone else at harm. I don't think that the government, or the police, or whoever, has the right to just disrespect people. Respect to me is- it's my ability to be able to live my life without the people on the outside looking in and judging me.

Lady Purfection's sentiments about the personal, communal and societal needs for respect were echoed by all of the artists who participated in this study in different ways and through various stories and images. Regardless of the type of work the artists were engaged in or their level or privilege, all of the women expressed the need to be respected as workers and as human beings. 


\title{
CHAPTER 7
}

\section{DISCUSSION}

\author{
Introduction
}

The women's photographs capture the multi-layered and multi-dimensional nature of their lives, as well as the depth, beauty and complexity of each artist. The images also capture their humanity and desire to be viewed and treated with respect. While their photographs and stories do not always give a prime focus to needs and aspirations related to sex work itself, they are linked to other areas of their lives, including domestic life, homelessness, hobbies, motherhood, politics, activism, grief, love and happiness. This speaks to the ability of photovoice to capture the richness of people's intricate lives and the opportunity for sex workers to present various parts of their selves. These photographs serve to challenge the stereotypes of sex workers usually presented in the media, which uphold essential unidimensional representations of sex workers. The artists' needs and aspirations are shaped by their pasts, attitudes, beliefs and actions in the present, as well as desires for the future. Using the photovoice method to weave together their visions and voices allows for individual experiences and diverse realities to be seen.

From the perspective of an arts-based researcher interested in the "visual voice" of sex workers who are often spoken about and for in research, I highlight in this chapter the following three concepts that emerged from a synthesis of the findings: (1) intersectionality and how it informs the women's diverse experiences (i.e. there is no universal sex worker experience); (2) the shared experience of stigma; and (3) the power of art in research. These themes will be discussed and presented in the context of the 
photovoice method and its focus on the photographic self-representations of participants' selves, lives and experiences. This chapter presents how the intersections of the artists' multiple identities and social locations shape the diversity of their experiences. These factors also form the varied ways in which each chooses to express her needs and aspirations through photography. The artists' self perceptions are presented to challenge radical feminists' assumptions of their realities. The findings also highlight a common experience shared among the artists: the stigma attached to working in the sex industry. While stigma is experienced and expressed differently among the artists, the women resist the externalized stigma through agency as photographers and in the creation of their art. Finally, the power of art as a research tool is discussed as it impacts the artists as study participants and me, as the researcher.

\section{Intersectionality}

The term intersectionality was initially coined by Kimberlé Crenshaw in 1989 to highlight the merging and mingling of multiple markers of difference (Ludvig, 2006). In this discussion, intersectionality refers to the idea that an individual's experiences are influenced by a multitude of identities (such as race, gender, sexuality, ethnicity, class, ability, etc.) that interact and intersect. Social locations are created by the intersections of multiple identities (Murphy, Hunt, Zajicek, Norris \& Hamilton, 2009). The findings of this study suggest that the unique self-representations of needs and aspirations for each artist are informed by the intersections of their multiple identities and social locations. Educational levels, sub-culture, age, lifestyle, personality, and roles in life (mother, grandmother, wife, student, etc.) inform the artists' diverse identities and influence their 
experiences and expressions of needs and aspirations. Some of the life circumstances relevant to the artists in this study include working conditions, family situation, living and working in Portland, involvement in school, child welfare, or in the criminal justice system, and homelessness. If I were to do this study all over again, considering the prominence and relevance of intersectionality in these women's lives, I would adopt intersectionality theory as one of my guiding theories.

This study challenges the findings of other social science research studies that find commonalities among sex workers based on their type of work; either as strippers or street workers. For example, Weitzer (2005) asserts that "the diverse experiences are patterned in such a way that the prostitution market is segmented between indoor and street sectors" (p. 215). However, the diversity of the artists and their multiple realities transcend different types of sex work in this study. In the following sections, I weave together the artists' experiences based on specific shared identities and social locations, while highlighting the diversity of their needs and aspirations. I also present the artists' self-perceptions and the ways in which they construct their images to express their different needs and aspirations.

Diversity of Needs and Aspirations

The intersections of the artists' multiple identities and social locations resulted in unique and sometimes overlapping needs and aspirations. Participants who shared similar identities and social locations experienced the purpose of this study differently, including a space for personal exploration, an opportunity for healing, and a space for community activism. The lived experiences of the women and the ways in which they manifested visually through photographs included different experiences of (but not limited to) the 
following: work and working conditions, violence, stigma, drug use and abuse, homelessness, love, romantic relationships, future career aspirations, experiences of domestic violence, and motherhood.

One might assume that Mouse and Grahm share similar experiences of working in the sex industry, as well as similar needs or aspirations. They are the same age; they work as exotic dancers, identify as Caucasian, attend the same private university, and come from similar socio-economic backgrounds. However, the ways in which they represent their needs and aspirations vary greatly, as well as what they identify as important. Grahm's photographs mostly depict communal needs and aspirations as she intellectualized the sex industry and brought attention to the harmful radical feminist discourse on sex work. Grahm does not reveal many things about her personal life, aside from her involvement in sex work activism. On the other hand, Mouse's photographs are very personal in nature, consisting mostly of self-portraits. She does not identify any communal or societal needs or aspirations and uses this project as a personal way to reevaluate her life and think deeply about issues related to love, identity and being in the world. She shares how her identification with the gutter-punk sub-culture shaped her life aspirations. Despite a shared type of sex work, Mouse and Grahm had different experiences as strippers. Grahm works at a hip, women-run nude dance club whose clientele consists of white, educated men in their early $20 \mathrm{~s}$ and 30 s. Mouse works at a family-owned strip club whose clientele consists of mostly Latino men and older gentlemen interested in playing video poker. Both women work in other aspects of the sex industry. Mouse engages in nude modeling and Grahm works as a dominatrix.

Based on the assumption that individuals who share similar traits also have 
similar experiences, one might never assume Mouse to have much in common with Merry Mag, aside from heroin use. However, their photos and the ways in which they took them (e.g. constructing their own scenes where they performed for the camera) are very similar. Merry Mag, a 52-year-old street worker, "street educated," and homeless for most of her life photographed very personal needs and aspirations. She uses this project as a forum to heal from past grief. Like Mouse, she also reflects on issues of love and identity. On the other hand, Merry Mag shares Grahm's activist identity and passion for activism.

In this study, there are other artists who share similar lifestyles, common identities and social locations, but express very different needs and aspirations. Merry Mag and Sarah both share past experiences of homelessness and the death of mutual friends. They work on the streets, identify as Caucasian, and struggle with drug dependency. Sarah's needs and aspirations center on resources for street workers, struggles with addiction, spirituality, and her experience of stigma. Sarah and Merry Mag shared similar experiences of stigma (from society, clients and the police), encountered violence while working, and faced discrimination as homeless women. However, Merry Mag's roles (as a mother, grandmother and activist) coupled with a stable living situation at the time of the study shape her expression of needs and aspirations. Merry Mag expresses the need for awareness of poverty, violence and sex worker's rights. She expresses aspirations for romantic love, more time with her grandbaby, and acceptance in society. Sarah does not have children or a stable place to live and identifies different dreams and desires related to survival.

Contrary to Farley and Kelly's (2000) claim that physical and sexual violence and 
drug abuse are intrinsic to prostitution, this was not the experience for all of the women in the study. For example, Jasmine and Rogue are both in their 30s with young children in the care of family members. They work off of Craigslist, engage in street work, and struggle with heroin abuse and homelessness. Neither photographed a need or aspiration related to the experience of violence. This does not necessarily imply that violence is not ever experienced, but rather, that perhaps the occurrence and type of violence in their lives does not require immediate attention or priority over other needs and aspirations as suggested in some research.

Both Jasmine and Rogue present self-portraits of themselves panhandling to document their preferred method of income-generation and their need to survive. While Rogue hates sex work (the only participant who expresses discontent with sex work), Jasmine does not mind it and sets clear boundaries for what services she is willing to provide. Rogue's aspirations revolve around living a middle class lifestyle with her husband, getting off the streets, and addressing her heroin addiction. Jasmine's photographs are influenced by her identification with the gutter-punk sub-culture and her alternative ways of viewing the world and its beauty. Her needs and aspirations reflect the years of stigma she experienced as a result of this identity, her status as a homeless sex worker, and addiction.

Rizzo, who is 18 years old, shares similar identities and social locations as Jasmine and Rogue, in that she is homeless, identifies with the gutter-punk sub-culture, engages in street work, works off of Craigslist, identifies as Caucasian, and struggles with addiction. Most of her photographs reflect her need for resources and include innovative ideas of how those needs can be met. She also identifies her various skills, which she 
aspires to enhance, and sees her work in the sex industry as temporary. Her youthful age is reflected in her photographs depicting the multitude of future possibilities.

Photographs of career aspirations were also taken by Alex, Bee and Crystal. All three of these artists articulate their desire to transition out of the sex industry. While these women share common identities and similar social locations, one cannot assume their needs and aspirations to be similar. They are all single and worked as strippers for ten years. All three expressed how they were getting older and "couldn't move up" in sex work. Crystal and Bee experienced domestic violence in the past. This resulted in the loss of custody of Crystal's four children. Bee did not lose custody of her son and shares how their experiences of homelessness and domestic violence brought them closer together. Bee's aspirations center on wanting to do more for her self (i.e. pursue another line of work and focus on her hobbies) now that her son is an adult. Crystal's photographs express her desire for better self-care and independence so that she can reunite with her children. Jasmine and Rogue also discuss their children who are in the care of others. While Crystal's children are in the custody of the state, her needs are centered on improving her finances and transitioning out of the sex industry so that she can be reunited with her children. This is not the case for Jasmine and Rogue, whose children are in the care of family members. Their photographs center on needs related to survival and addressing heroin addiction in order to have more stability in life.

While none of the artists explicitly discuss their racial or ethnic identities and their influence on their experiences in the sex industry, Crystal shares how her Latina background and Catholic upbringing play a role in her spiritual beliefs- giving her hope in life. Lady Purfection also expresses the importance of her faith and feeling empowered 
from within. She presents various photographs that emphasize her choice to work in the sex industry and her need to be respected. In a self-portrait of herself dancing on stage, Lady Purfection mentions that it isn't easy being Creole Blackfoot Native mix, but she does not elaborate on how her racial identity impacts her experience working in the sex industry. Her fiancé supports her work as an escort and stripper, unlike Alex, who feels that the men in her life are judgmental towards her because of her work. Lady Purfection, Merry Mag, Bee, and Mouse all communicate their view of sex work as a form of art and symbolize this idea in photographs of themselves and their surroundings.

\section{Self Perceptions}

It is important to highlight that contrary to some perceptions and representations of sex workers as vulnerable victims (Farley \& Kelly, 2000; Farley \& Barkan, 1998) none of the women in this study see themselves as victims, even if they experienced emotional, physical, and sexual violence, poverty, or drug addiction. All but one of the artists present mixed feelings about sex work in regard to personal power, agency, freedom and choice. All of the artists emphasize that working in the sex industry was their choice. This is contrary to some radical feminist beliefs that "few women would choose prostitution" (Young, Boyd, Hubbell, 2000, p. 797). As previously mentioned, Rogue was the only participant who expressed negative experiences from her work in the sex industry. She expresses feeling ashamed by engaging in prostitution and wanted to stop but felt compelled to trade sex for money out of financial desperation and to support her drug habit.

\section{Construction of Needs and Aspirations}

The artists constructed their needs and aspirations in their photographs by 
representing parts of their complex selves, locations, and identities.

In the process of performing in front of the camera, as well as explicitly creating images (of ourselves or of other subjects) and telling stories (including those around images, for ourselves and for others), we enact ourselves, individually and collectively. (Van House, 2009, p.1084)

Each artist's expression of her needs and aspirations reflects how she internally defined and "framed" her reality, herself, and other people; how her thoughts, feelings, memories, attitudes, and beliefs were stored inside her and manifested visually.

Some of the participants constructed performative photographs by dressing up for the camera and constructing their own scenes to relay a particular experience. I was intrigued with the idea of sex workers creating self-portraits as a vehicle for promoting their self-exploration, reflection and personal discovery of their needs and aspirations. Martin and Spence (1985) highlight that a self-portrait "represents a range of possibilities, or subject positions, which are not forever fixed in silver...these can be examined, played with, questioned, accepted or discarded" (p. 67). Mouse, Lady Purfection, Merry Mag, Jasmine and Rogue used their self in their photographs. Mouse took a series of self-portraits in various stages of dress, in different types of clothing, and in different locations. She represented herself as a musician playing the accordion, a spontaneous woman daring to climb on top of the roof, an individual desiring growth, a character working as a stripper, as a piece of art in her stripper clothes, and so on. Similarly, Merry Mag experimented with self-representation and took a number of photographs that depicted herself as an activist, a grandmother, and a street worker mourning the loss of her sisters. Jasmine's self-portraits included images of her gutterpunk identity in the form of graffiti, her situation as a homeless woman while 
panhandling, and an image of her "primal naked self."

A few of the women used their bodies or photographed the body parts of others to represent their own needs and aspirations. The bodies that the artists photographed represent sites of struggle, power, strength, independence, choice and vulnerability. Grahm took a series of photographs of body parts to represent the need to challenge the representations of sex workers and the assumptions made about their lack of selfdetermination. Grahm's choice of images and ideas around challenging radical feminist theoretical constructs reflect her socio-economic location and status as a college student. Mouse presents her own body as a site of objectification and judgment, as well as a location of power and vulnerability. This symbolism is also illustrated in her other photographs and descriptions of the contradictions she experienced while working in the sex industry. Tidwell, Heston and Fitzgerald (2009) believe that "even when people use objects as stand-ins or signifiers for their bodies, they are linking, extending or representing their corporeal existence and identity" (p. 129).

Some of the artists represent their emotions in photographs to symbolize a particular need or aspiration. For example, Merry Mag, Sarah, and Jasmine represent their emotions around the deaths of their close friends. Through their images they express needs to address feelings of pain, guilt, anger and sadness associated with death. Gauntlett (2007) explains that "making artistic work gives a person the opportunity to externalize, and therefore, diffuse their personal pain" (p.11). The artists' photographs and the opportunity to share their stories appeared to facilitate healing. One of the artists, Alex, infuses many of her photographs with humor to express various needs and aspirations. According to Van House (2009), humor can be seen as a form of self- 
representation. Under certain circumstances, use of humor has been a powerful tool for resistance and a means of coping with difficult situations (Gouin, 2006). Alex uses humor to contest assumptions and stereotypes. Sarah also uses humor in her photograph of a cat to express the communal need to not be criminalized for street work.

Many of the artists use their imagination to express their needs and aspirations. In particular, the artists wrote poetry to accompany their images. Leavy (2007) explains that "poetry relies on emotional evocation as part of meaning-making while simultaneously exposing fluidity and multiplicity of meaning" (p. 5). Poetry is used to provide an additional layer of meaning and self-expression of the artwork. Both Alex and Lady Purfection identify as poets and felt their artwork to be complete once their photographs were accompanied by poetry. The artists also use storytelling as a way to create meaning of their images representing needs and aspirations. The stories shared by the artists consist of their past experiences and provide a perspective of their social locations and circumstances in life. Cole and Knowles (2001) state:

The stories we remember and tell about our lives reflect who we are, how we see ourselves and perhaps, how we wish to be seen. In other words, when participants are revealing elements of their lives they are revealing elements of their identities. (p.119)

As story tellers, the artists hold the power of sharing their experience and representing themselves in any way they chose. They also hold the freedom to re-invent themselves.

\section{Stigma}

While the intersections of one's multiple identities produced distinctive experiences and varied needs and aspirations, there were meaningful similarities. Based 
on their shared sex worker identity, the artists expressed experiences with stigma. This study supports the findings of other sex work research that highlight the stigma experienced by sex workers. Vanwesenbeeck (2001) addresses the stigma faced by female sex workers and the additional efforts they put into managing their identities. Sloan and Wahab (2000) speak to the burden of stigma and the barriers faced by sex workers as a result of discrimination.

While the experience of stigma is prevalent in all artists' photographs and stories, the ways in which stigma is experienced and expressed differs across them. Vanwesenbeeck (2005) also asserts that stigma does not affect all sex workers to the same extent. In this study, variation was found in the amount and type of stigma-related experiences and negative social reactions encountered. It was common for women to experience additional layers of stigma related to their drug addiction, homelessness, and mental health issues. Phelan, Link, Moore and Stueve (1997) discuss the stigma faced by individuals who are homeless and experience mental health issues and the perpetuation of their discrimination in society.

For the participants in this study, stigma took various forms. Based on their sex worker identity, the artists described stigma as verbal and physical insults by clients, law enforcement, and lovers; for example, being called a "slut," "whore," "diseased," and "AIDS-infested." One participant was told to "go suck-up someone else" by her partner. Stigma was also felt by feeling "judged," "disrespected," "worthless," and being treated like "garbage." Some women talked about being a homeless sex worker and feeling like they "didn't exist," "invisible," "excluded," and "shut out from everything." The artists who experienced stigma related to mental health issues felt like "people were looking 
down in disgust" and expressed feeling like they were "contagious." While stigma was experienced differently depending on one's social location, identity, and working conditions, the need to not be stigmatized and stereotyped was infused in many of the discussions and photographs. The following section describes the stigma experienced by the artists and the ways in which it was resisted through the creation of art.

\section{Resistance to Stigma}

Many of the artists used their photographs as a strategy to challenge fixed ideologies about sex workers and sex work, to deconstruct old dichotomies, and to define themselves. Jasmine, Rogue, and Merry Mag discuss the stigma they felt as homeless women and as sex workers. Rogue presents a self-portrait of herself facing the camera (figure 93) and challenges the viewer to really get to know her instead of just "judging the book by its cover." As someone who was homeless and involved in street work Rogue feels stigmatized and judged based on her appearance. Jasmine adds that her gutter-punk identity, in addition to being homeless, contributes to feeling stigmatized and excluded from certain public places. The symbol of graffiti that she photographed (figure 141) represents her place within a sub-culture. She shows her resistance to hide her identity as a gutter-punk as she "tagged" her existence. Merry Mag presents an image of a homeless woman's feet (figure 58). In her description of the woman's feet as beautiful, she re-defines common notions of beauty and resists the stigmatization and judgment of homeless individuals.

Grahm discusses the communal need to address stigma. She also expresses her own personal desire and need for anonymity due to the stigma associated with working in the sex industry. While she does not explicitly report feeling stigmatized, she expresses 
her fear of "coming out" as a sex worker because of the social stigma. Alex photographs a fence (figure 92) to depict the stigma she feels from men who hate her for the same thing that they love her for (working in the sex industry). Her image of a fence and description of not wanting to feel "fenced in" represents a resistance to the stigma imposed on her by potential romantic partners.

Merry Mag and Sarah worked on the streets for many years. They both experienced substance abuse, homelessness and violence. For both women, stigma is intertwined with experiences of violence from clients and the police. Merry Mag shares a story of her experience of physical violence from a client who beat her and called her a "whore." Her accompanying photograph of the stitches (figure 27) and the caption that includes "Not all People Hate Us" represents her resistance to the stigma of sex workers. Sarah also shares her experience of feeling stigmatized by police and recalls their hurtful insults towards her. As she shares her story, she talks about her own resistance to being arrested by the police in that moment when they accuse her of prostituting without any evidence. They call her a "fucking bitch," a "nasty whore," and accuse her of having "AIDS-infested tears." Sarah also expresses being treated unfairly at a motel (figure 18) where she is discriminated against and kicked out because of her involvement in street work. She shares how she stood up for herself and the other women who were with her to resist the unjust discrimination.

Merry Mag carries the weight of the social stigma attached to sex work and feels that she isn't worthy of romantic love as she expresses in her photograph of E.T. (figure 48). She also talks about the stigma she feels because of her mental health issues and the discrimination she experiences from her own children. Merry Mag shares her experience 
of being treated as if she is contagious and incapable of watching over her granddaughter because of her schizophrenia. She feels stigmatized by her children as a result of her mental health issues and photographs her resistance to their stigma in a self-portrait of herself holding her grandbaby with pride (figure 49). In other photographs, Merry Mag presents her opposition to outsider-imposed stigma through her collage of activist images (figure 83) and her critique of criminalizing laws against sex workers. Sarah also depicts her resistance to the stigma associated with working in the sex industry in her photograph representing the "3 condom law" (figure 81 ). She wants to highlight that anyone carrying 3 condoms or more is susceptible to being punished under this law, not just sex workers.

The artists exercise power, agency, and control as they presented their realities, varied experiences, and multiple identities in the forms of needs and aspirations. The use of a camera provides the means of giving the artists authoritative voice (Bloustien \& Baker, 2003). They use their creative control and freedom to set the agenda for what was depicted and discussed. The artists are agents exploring their subjectivities. By presenting their needs and aspirations and choosing to reveal or withhold information, they shaped the stories that evolved. The artists actively resisted the stigma in their lives through the creative representations of their multiple realities and complex selves. These acts of resistance through art can be seen as a strategy for taking action. The opportunity to represent themselves, their needs and desires allows for the redefinition and reconceptualization of stereotypes and assumptions.

\section{Power of Art}

For the Artists 


\section{Transformation}

The use of art in this study had a powerful and meaningful impact on the artists. Many of the women reflected on the transformative power of art. Under the theme, SelfEmpowerment and Identity, the artists demonstrated how their participation in the process presented new possibilities for living their lives and provided a space for visually documenting their transformation. Photovoice allowed participants to use photographs as an extension of themselves and a space to reenact their visions. For instance, Mouse presents the photograph of herself on the roof top (figure 126) and identifies her aspiration to do "more spontaneous, seemingly-impossible things in her life." She identified her aspiration, acted upon her desire, and photographed herself in action. This was also evidenced in one of Jasmine's self-portraits. She presents herself topless (figure 143 ) and shares her aspiration to be able to show her naked self without shame. Like Mouse, she identified her aspiration, took action to achieve her goal, and photographed her accomplishment. Rizzo also articulates her aspiration to save money. During her participation in the project, she bought a new coin purse and devised a strategy to save her money by placing the coin purse at the bottom of her backpack. The opportunity for sex workers to use photography to document their needs and aspirations elevates the importance of their creative abilities and their personal strengths, thus supporting the potential for transformation.

\section{Empowerment}

The participants whose photographs were related to the theme Social Justice and Activism felt empowered through the opportunity to use art as a form of activism. For 
Sarah, her participation in the study gave her the opportunity to explore her creativity in support of the rights of street workers. She shares:

I was SO skeptical about getting into this project because of my health issues and I just felt like I couldn't take on anything extra because I couldn't commit to it but I am SO glad I did because it's given me a purpose. I've always had a purpose to help the girls and to stand up for our rights and to fight against police brutality and what not, and so this has given me a great opportunity to pursue my mission, and so I'm so happy... it's also created an urge, a desire to experiment more with photography. I loved taking the photographs...I can't wait for the art show.

For Grahm, whose photographs also centered on the theme of Social Justice and Activism this study presented excitement and possibility. She said, "It is exciting and new to think about how your ideas are coming across when you are taking a photo and how you can't control how it's perceived or whatever. That is exciting-like thinking about the places where these images can go in people's heads..." Using photography provided the artists with the chance to reach and engage the public.

Some of the women felt empowered by the ways in which photography provided them with an opportunity to think about what was important in life. For Mouse the process of creating art and talking about her needs and aspirations was empowering. She expressed:

It was amazing. I really liked how much it forced me to think about these things in relation to being a sex worker, or in general, I haven't thought about what my needs and my life were in a really long time... especially now, that I am going through a tumultuous time. There is a lot upheaval in my life right now and I am redefining what my goals are in a lot of ways. Thinking about a lot of these aspirations made me feel a lot more positive. The fact that photography was involved was really wonderful because every time I would come up with something I would take a picture. Now I have that record of what I was aspiring to. This is probably the most important roll of pictures I have ever taken because there was so much thought put into each one of those and they are all so personal. Each picture reflects something that I think of as being very, very important.

Mouse's participation offered the opportunity to identify, redefine, and document her 
needs and aspirations during a crucial time in her life.

Agency and Voice

Participation in this photovoice study was a way for the artists to assert their agency and voice. After sharing all of her photographs in the individual dialogue session, Lady Purfection talked about her experience in the study. She said, "I just wanted to say that I'm glad I partook in this study. It just makes me feel good that my voice is being heard. I'm just really happy I got a chance to share my part.” Through their visions, voices, and the opportunity for self-representation, the artists assert their agency and subjectivity. Considering the participants as agents capable of investigating their own situations empowers them and can make a project more useful to them (Feen-Calligan, Washington, \& Moxley, 2009). Through this photovoice project, Merry Mag found use in the healing power of art. She expressed, "the process has been wonderful healing for me, especially relative to the women that I personally knew that died...And you know, I could have said a million words but until I went to that graveyard and had my friend take those pictures of me, I couldn't tap into the pain that I had buried so deep with my friends that had been murdered..."

\section{$\underline{\text { Visibility and Existence }}$}

For those most marginalized in the study, based on their lack of resources for survival and type of sex work, the project provided visibility and a sense of existence. Hammond (2004) states, “a photographic presence may serve as an important political statement of existence and significance" (p. 137). A few women identified the need for existence and some women photographed events in their lives as a way to prove things happened. For instance, Sarah photographed Motel Cabana (figure 18) as a way to 
document the injustice she experienced and to share feelings of discrimination. Rogue and Jasmine took various self-portraits, photographs of their loved ones and of their lives on the streets. They talk about being stigmatized and treated as if they didn't exist in society. Photographing themselves and their surroundings communicates their presence in this world and reinforces the importance of their existence.

Friedrich Nietzsche suggested that human beings, since ancient times, have felt the need to make marks to represent their lives and experiences, not simply as a reflection of private dreams, or to communicate instrumental facts about survival, but as a kind of necessary celebration of existence: an impulse which calls art into being, as the complement and consummation of existence, seducing one to a continuation of life [1872] (Gauntlett, 2007, p. 26).

This quote reinforces the power of the artists' photographs, which went beyond the expression of their needs and aspirations, to illustrate the human essence of being.

\section{For the Researcher}

This study gave me the opportunity to hear the rich stories and experiences of a marginalized group of women I might not have otherwise connected with. It challenged my own biases, fears, and assumptions. At the same time, this study stimulated, inspired and transformed me. I did not know what to expect from the artists and assumed their photographs would fit into neat categories of needs and aspirations, either based on type of work, race, class, or age. I did not take into account intersectionality and the complexity of human existence, past and present, and the various forces shaping visions for the future. I had not even considered the different sub-cultures existing within the sex industry. I assumed that sex workers embodied more or less, one stereotypical "type." I was inspired by the diversity of images, their emotional impact, and the creative ways in which the women depicted themselves and their experiences. I did not expect the 
participants to go to such great lengths to create their own scenes and infuse self-portraits to relay a particular idea. I assumed that the photographs would mostly consist of documentary style images. I also did not expect the women to identify their dogs as crucial to their needs and aspirations in life. This spoke to their desire to feel support, acceptance and unconditional love.

I cherish my unique relationships with each of the artists. There were three women with whom, under different circumstances, I could have easily been good friends. One artist invited me to her place of work, sharing another part of her life with me. Another participant invited me into her home and shared her hospitality. Two of the women exposed me to a humbling experience related to their state of homelessness. During one of my encounters with them, I sat down next to them on a downtown street to collect their film and check in about their progress. I happened to sit behind their street sign created for panhandling and was offered a sandwich by a stranger walking down the street who thought I was also homeless. This experience gave me a sense of empathy and a deeper feeling of awareness.

I value how the artists shared personal images of their streets, homes, pets, friends and family, and those things close to their hearts. I was invited to understand their lives, dreams and desires, and to celebrate their artistic creations. I carried their memorable images around with me in my mind. I felt compassion for the artists as they described the stigma they experienced and other difficulties they encountered day to day or in their past. At the same time, I felt a unique connection and closeness with having the privilege to hear about and see their dreams and aspirations, some of which I also shared. Seeing the photographs related to the women's aspiration of travel mirrored my own love for 
travel and experience of other cultures. Seeing photographs depicting musical instruments echoed my own love for playing the piano and my dream to learn how to play the accordion. I also shared similar aspirations with the artists, related to finishing school, for example, the fear that this dissertation would not be completed.

I gained a greater appreciation for the complexity of their lives and some of the inherent contradictions of working in the sex industry. I attribute these contradictions to the multiple and often contested identities of the artists. I also acknowledge that contradictions exist within each and every one of us. There were times when I felt sadness about the women's experiences of violence, as well as outrage at the injustices and unfair policies aimed at criminalizing those engaged in sex work. We experienced a range of emotions together in the individual dialogue sessions, we cried, we laughed. I admired how the artists stretched their boundaries of personal expression and told powerful stories of strength, empowerment, and resilience. Art allowed us to step both deeper and outside of ourselves and our experiences (Cahnmann, 2006).

This arts-based study also fostered my relationships with members of the community who shared similar values, interests, and appreciation for art. Collaboration with my community partner provided support, guidance, and personal growth. Our many months of working together inspired different ways of understanding the research process through our sharing and exchange of ideas. We spent countless hours debriefing, brainstorming, and pooling our limited resources together to provide compensation for the artists. We combined our skills and visions to bring together the artists, social service providers, and members of the community at different points during the study and to the 
art exhibits. The following chapter details the power of art for social work practice, policy and research. 


\section{CHAPTER 8}

\section{CONCLUSION}

\section{Implications for Social Work}

The images and voices of sex workers in this study hold several implications for social work practice, policy and research. The social work profession has a history of not taking into account the voices of sex workers when creating programs to meet their needs. From a practice perspective, the use of photography allows sex workers to identify and creatively represent their needs and aspirations, thus informing social service design and delivery. The photovoice methodology provides an opportunity to bring together individuals and empower communities to work for long-term social change. Visual images can serve to educate and influence social workers, activists, academics and other influential community advocates working on sex work policy issues. Alternative methods of data collection and representation in social work research allow for a new ways of knowing and understanding the nuanced experiences of sex workers.

\section{Practice}

Social workers who engage in practice with sex workers can explore the usefulness of creative art forms, such as photography, as another way of knowing that can be used to inform practice wisdom. This study brings forth the significance of: (1) valuing diverse and creative ways of knowing and expression, (2) cultivating professional awareness of sex workers' needs and aspirations for improved service design and delivery, and (3) taking steps to move beyond just social service delivery and toward working for social change. 


\section{Valuing knowledge through art}

Fusing art with social work enhances the multiple possibilities of knowing, seeing and understanding differently. Kaminsky (1985) parallels art with social work and articulates:

Art, like social work, provides catharsis and insight, self-awareness and awareness of the contradictory nature of society and our experiences of it. Social work, like art, validates the experiences of groups of people who have been rendered voiceless by official culture. (p. 22)

Social work can learn many things from the arts with regards to the multi-layered, multidimensional nature of people's lives. The creation of art in social work serves to illustrate the multiple realities of individuals working in the sex industry from their own perspectives and manners of representation. Photovoice method provides "a vehicle for stimulating the 'authentic voice' of participants, enabling them to communicate their own experiences" and emphasize aspects of their work in the sex industry that is often inaccessible to the public (Feen-Calligan, Washington \& Moxley, 2009, p. 426).

An appreciation for different ways of knowing and self-expression is congruent with social work values of valuing the dignity and worth of each person (NASW, 1999). By turning the photographic lens on themselves and their life experiences, the artists in this study engaged in diverse ways of critical self-reflection and creative selfrepresentation. Photovoice reinforces the belief that each woman is an expert of her own life, while maintaining the power in her ability to shape her subjectivity according to the narratives and images she wishes to share. Incorporating art into social work practice with sex workers can encourage dialogue, which is critical to promoting the understanding of their lived experiences. 
The photographs in this study rendered empathic understanding of the sex workers' needs and aspirations and how they defined them. Artistic forms of representation facilitate compassion by connecting people on emotional and intuitive levels, which is a necessary precondition for challenging harmful stereotypes (Leavy, 2009). Social workers need to disregard negative stereotypes and judgmental attitudes about sex workers and place them at the center of service provision (Wahab, 2004) instead of treating them as vulnerable victims that need to be saved. By valuing the creative and diverse images and voices of sex workers as artists, social workers can attempt to abandon stereotypes and assumptions about individuals working in the sex industry. They can begin to operationalize the social work values of self-determination and acceptance. Social workers can start to work from an expanded understanding of sex work as a complex form of work. From a social work standpoint, Allen Irving (1999) asserts that we must embark on alternative journeys where sacred, stable meanings slide into the space of scattered meanings, fluid subjectivity and multiple realities. Resonating with this dissertation, Irving asks us to see ourselves not as social workers seeking universal truths, but as "connoisseurs of ambiguity" (p. 6). This suggests we embrace multiple realities, different ways of knowing, and various mediums of expression and representation as valuable for understanding the complexity of human experience.

\section{Service design and delivery}

Photovoice has various implications for service design and delivery. Individuals working in the sex industry should have a central role in the design and delivery of social services. Photovoice supports participant-driven identification and determination of appropriate social service needs. The participatory aspects of photovoice provide social 
workers with collaborative tools to include sex workers perspectives. Sex workers' perspectives "may lead to culturally appropriate solutions because participants are involved in the collection, interpretation and dissemination of the findings" (Valera, Gallin, Schuk \& Davis, 2009, p. 312). Photographs provide visual data from the homes, streets, workplaces, and communities where sex workers spend their time. This lends itself to a more culturally appropriate understanding of social service needs and potentially more innovative service design to meet and deliver those needs. Photographs also form visual evidence to facilitate the prioritization of issues identified by sex workers and to support their advocacy endeavors. For example, in this study, Jasmine photographed her sleeping bag at the camp where she stayed every night to express the immediate need for shelter. Rogue photographed herself panhandling on the streets to highlight the lack of resources for survival. Rizzo photographed clean needles to emphasize the need for more needle exchange services.

This study suggests several recommendations for resources associated with improving service design and delivery to sex workers. Many of the basic needs for survival expressed by the sex workers in this study are similar to those articulated in a needs assessment study of street workers by Weiner (1996). The artists in this study who were homeless identify needs related to survival and sustaining their everyday existence such as needs for food, water, clothing, shelter, and services like drug rehabilitation and health care. These women also highlight the need for drop-in centers with available meals, showers, and mailboxes. All of the artists express the need for social inclusion and acceptance, as opposed to stigmatization and judgment. 
Photovoice method can also be used to explore which existing services need to be altered or changed to meet the needs of sex workers. Through images of their experiences, individuals working in the sex industry can share evidence and thoughts on social services and programs that are not having their intended effect (Molloy, 2007). The women in this study provide several recommendations for improving existing social services to meet their needs. For example, Rizzo photographed food to relay the need for take-away lunches instead of sit- down meal services at a shelter due to unpredictable working hours of street work and escorting. Rogue, Rizzo and Lady Purfection photographed restrooms and water fountains to advocate for 24-hour access. Sarah and Lady Purfection, who lived in different motels, spoke to the need for a drop-in center that was not contingent upon, or connected to drug and alcohol treatment services. A drop-in center could serve as a safe space for sex workers to go to after work shifts. The participants emphasized the lack of services available in Portland for sex workers who are not involved in drug and alcohol rehabilitation or the criminal justice system. Others expressed the need for voluntary drug rehabilitation services not connected to the criminal justice system. Social services must be acceptable and accessible for individuals working in various aspects of the sex industry, delivered in a safe environment, and in a respectful manner (NASW, 2005). The different realities and circumstances of the women in this study illustrate the importance of including sex workers' voices in the development of different types of services to ensure their appropriateness.

The unique aspect of this study was that the artists' photographs highlight their needs while simultaneously visually depicting and providing insight into their experiences and the conditions of their lives. Visual art, such as photography, adds an 
additional layer of perception and understanding of sex workers' needs. The use of photographs is valuable for highlighting current living situations, documenting the lack of resources, and revealing the deeply nuanced, highly complex relationship among individuals and their environment. For example, living in a state of homelessness can mean and look like many different things, but using the camera as a tool to illustrate one's living situation may engender empathy and urgency to create positive change.

Illuminating the aspirations of sex workers is congruent with social work strength-based practices that focus on individual talents, competencies, visions, and hopes. The opportunity to photograph their aspirations supported these sex workers' agency and self-determination. The visual documentation of possibilities and the identification of talents and strengths in one's life can assist sex workers with building upon those strengths to improve conditions in their life, if desired. The arts can convey messages of hope and opportunity. While alternative occupations and lifestyles may be limited for some women, it is still important to recognize that there are possibilities and choices available to sex workers, even within limited options (Wahab, 2004). An aspiration for several of the artists in this study was to obtain an education to learn and enhance various skills (e.g. managerial, culinary, veterinary, computer, artistic skills). Educational opportunities and job assistance services for sex workers should be available for those who want them. Education can serve to broaden employment opportunities, and job training can serve as a way to explore other occupations. The opportunity to photograph one's aspirations can provide a starting point for identifying strengths, interests, and new directions in life. For those sex workers who are content with their lives and their choices, visual documentation of their experiences can be reaffirming and 
empowering. Photography can be an opportunity for sex workers to advocate for rights, display their talents and strengths, and share their visions and voices.

Photovoice method provides the opportunity for participants and social work researchers and practitioners to reflect together and stimulate discussion, awareness, and action plans for addressing social justice. Visual representations of the lives and experiences of sex workers have the power to provide individuals with a new consciousness of what actions to take and how to proceed. Exhibits in the community featuring art by sex workers serve to educate the public, taking research out of academia and to diverse groups of people and different communities. Photographic representations of sex workers' diverse lives and multiple realities can serve to challenge stigma and work towards addressing their rights.

\section{Working towards social change}

Photovoice has the potential to improve service design and delivery to sex workers by taking into account their own visual voices of what is needed in their communities to meet their needs. However, while social services provide support to those sex workers who are struggling to survive, this does not address the underlying structural inequalities that serve to marginalize and stigmatize sex workers on various economic, social and political levels. Beyond providing visual evidence for innovative and relevant social service design and delivery, photovoice supports a social change agenda for working toward long-term equality and structural change.

According to Paul Kivel (2006) when social workers place all of their focus on social service design and delivery, this serves as a disadvantage to long-term social change. Using a hierarchical, economic pyramid to present the unequal distribution of 
wealth and resources in the U.S., Kivel (2006) explains the role of social service agencies in maintaining established wealth and existing poverty through the system of "helping" others instead of developing ways to create community power for change. He advocates for placing our energy into mobilizing communities to battle against exclusion, marginalization, decriminalization and violence, while "simultaneously engaging in a long-term struggle for redistribution of wealth and power" (Kivel, 2006, p. 23).

Kivel's framework for social change supports the intent and purposes of the photovoice method with regards to bringing people together to connect and identify common goals, and empowering people to work for social change. Photovoice is one such strategy for uniting sex workers so that they see they are not alone, their problems not unique and their needs and aspirations interrelated. This study was successful in bringing individuals together through photography to identify their needs, aspirations, common struggles, and experiences. Through various art exhibits, the women in this study continue to present their visions and voices to different communities to bring awareness of the stigma, discrimination, and inequalities they encounter based on their various identities and work in the sex industry. Photovoice is congruent with Kivel's emphasis on creating situations where individuals can take action by coming together for increased consciousness, resource sharing and empowerment. I agree with Kivel's argument that it is not enough to focus on social service delivery, but rather, to go further to support the grassroots leadership, organization, and empowerment of individuals and communities; one way to do this is through art created by sex workers. Policy

Incorporating art as social activism within social work has the potential to impact 
county, state and NASW policy related to sex workers. Photovoice art exhibits provide a forum for influencing local policies, such as the PFZs, that criminalize sex workers. Artistic representations of sex workers' needs and aspirations support advocacy for social services and long term structural change instead of a criminal justice response to sex work. A few of the artists address the need for decriminalization or legalization of sex work in their photographs and expressed the importance of changing current state policy on sex work. They articulate the importance of being able to carry out their work safely and without fear of arrest. Photographs created by sex workers can serve to visually depict the harmful effects of criminalization on their lives.

Social workers who are informed of the significance of decriminalization can advocate for the rights of individuals working in the sex industry, together with sex workers themselves, and adapt a decriminalization agenda within their agencies. Social workers can also support the NASW policy statement on commercial sex work that supports self-determination, addresses the issues faced by sex workers and advocates for their rights. It is important for sex workers to be acknowledged by social workers as experts, leaders, and advocates of their own lives and profession. Participation in a photovoice study where their visions and voices are shared with various communities can open up opportunities for sex workers to engage in activism and action for social change. Research

Photovoice is a useful means for uncovering voice, meaning, visions and the lived experiences of sex workers. It contributes to new ways of knowing and understanding the world through the eyes of the artists using an interdisciplinary approach to research. While the fields of education, community health, and nursing have embraced arts-based 
research, social work has yet to significantly incorporate the arts into research. This dissertation provides an example for how to use art within research to facilitate a richer, more complex understanding of sex workers' experiences and realities.

The images and processes of artistic creation are always at least one step ahead of the reflecting mind. If we continue to follow the standard behavioral science methods of establishing what we plan before we do it, we undermine the power of our discipline to offer something distinctively new and useful to research. (McNiff, 1998, p. 27)

This speaks to the potential for arts-based research approaches to contribute to new knowledge about the perspectives and multiple realities of sex workers.

Arts-based research in social work counters the dominant forms of representation produced within the social sciences and supports the use of art to deepen meaning, expand awareness, and enlarge understanding. Creative forms of data representation promise to increase the variety of questions that we ask about the phenomenon we study since they present new ways of seeing and new settings for their display. Creative forms allow the researcher and the participants to utilize their individual skills and abilities. As an artist and a researcher, I had the opportunity to creatively express my experiences of the research process. The artists had the opportunity to use their photographic talents to illustrate their needs and aspirations. Using art within research is a way to utilize greater varieties of human intelligence, talent, and imagination.

Arts-based research in social work can foster social action and advocacy around the needs and issues of sex workers through creative means that are shared beyond academia and with the broader community. This is congruent with the profession's ethical responsibilities of social and political action within the broader society (NASW, 
1999). This study responds to the unmet need for combining creativity and scholarship with social action for the purpose of educating communities, challenging stereotypes, and inspiring action for change with regards to sex workers.

\section{Challenges Encountered}

While the benefits of arts-based research far outweigh the challenges encountered, the difficulties of carrying out a photovoice study are important to discuss. A major challenge of this study was participant recruitment. Even though Portland has a large sex industry, and despite the fact that I collaborated with a community partner for assistance with recruitment, it was difficult to find women who were interested or able to dedicate so much time to the photovoice study. Sex workers are a difficult to population to reach. The illegality and stigma associated with their work inhibits sex workers from openly identifying themselves to others for fear of legal ramifications or judgment from others.

Difficulties in recruitment may also be related to the nature of the research and motivations to participate in the study. The task of creating art through photography may be daunting, frightening or too demanding for some individuals. In addition, the $\$ 50$ in compensation, coupled with the camera and photographs, may have paled in comparison to what some of the women could make working. Some of the women's motives for participation include passion about the issues, activism around sex workers' rights, and a stated desire to help other female sex workers. There were three women who contacted me about participating in the study after hearing about the art exhibit in the media. However, by this time, all phases of the research were completed. 
Another challenge included maintaining contact with the participants over a long period of time. Several of the women experienced homelessness throughout the duration of this study and were difficult to reach. Drug dependency, health, school, legal troubles, work schedules, and "life" in general got in the way of the women's ability to take time to finish their roll of film. Some participants took a week to finish their roll of film while others took months. Those participants invited to participate toward the end of the recruitment process reported needing more time to finish their photographs and one participant reported feeling rushed to finish. Participation in this study was timeconsuming for participants because contact was maintained with all of the women for six months (from the start of recruitment until the first art exhibit opening). The participatory features and my dedication to using art as activism required many hours of work on my end and costly to implement. Two community fundraisers were held to cover the compensation costs for the artists, in addition to the costs of the black and white film, printing, framing, and food catering for the group dialogue sessions and art shows.

There were no immediate policy changes associated with this study, and as previously mentioned, policy makers did not attend any of the community art exhibits. However, influential community advocates, family, friends, and members of the community attended the exhibits and supported the artists by purchasing their art. Through this photovoice study there was little time to develop action steps for change with the participants, such as creating a concrete plan to present their visions and voices at a Portland Town Hall meeting or another venue with access to policy makers. There was a strong desire from the artists to come together in the group dialogue sessions. However, these meetings seemed to be more productive for sharing images and planning 
for the art exhibit than for the generation of ideas for gathering material needed to influence policy change.

The findings of this photovoice dissertation are still subject to dilemmas of interpretation and representation (Denzin \& Lincoln, 2005). While the participants agreed that visually depicting their needs and aspirations was important to them, I was the one who ultimately chose the focus of representing "needs" and "aspirations." The artists decided which photographs could and could not be included and which photographs should be blurred, and they interpreted their own photographs and assigned meaning. However, this still does not address the complexity of power in the research relationship. Ultimately, I was the one who chose how these images and voices would be (re)presented to an academic audience. Even though the artists were the creators and interpreters of their own images, I chose which final images to share and what parts of their quotes to include. While I tried my best to faithfully represent the themes identified by the artists, I still held the power of representation within this dissertation.

It is not the intent of this study to generalize these findings to all sex workers and it is important to highlight that these images and voices reflect the creativity, experiences and multiple realities of 11 women working in various aspects of the sex industry in Portland, Oregon at the time of this study. It is important to note that this study did not capture the needs and aspirations of those women who are engaged in sex work but who may not see or think of themselves as a sex worker. This study must be considered in its social, historical, and geographical moment as the lives of sex workers are not static. Although this study captured one moment in time, these individual moments of self- 
expression through photography portray the richness and complexity of the artists' lives, inspiring further exploration and understanding.

\section{Suggestions for Further Research}

Additional understanding is needed about the needs and aspirations of a wider sample of women working in various aspects of the sex industry, including the experiences of male and transgender sex workers. While the 11 women in this study did not specifically discuss how race, class, or ethnicity specifically informed their needs or aspirations, further exploration would provide valuable insight for feminist standpoint theories. In addition, many of the artists in this study referenced their identification with a sub-culture. Further research might use art to explore the connections between subcultures and experiences in the sex industry, as well as diverse sexual sub-cultures within commercial sex.

I found it interesting to see how many of the artists used their bodies and selfportraits to confront social pressures and Western definitions of physical attractiveness. Future research may consider using photovoice method to explore sex workers' concerns of beauty, the pressure to stay young and physically fit. Future research projects may use photovoice to explore love, family, friends, and pet companionship as sources of support for sex workers. Friendships were also central to the women's lives, particularly for those who were homeless, dealing with substance abuse issues, and involved in street work or escort work off of Craigslist. It was surprising to see how many participants photographed their dogs and voiced the importance of having a pet as a companion and a source of love, emotional support and acceptance. 
Deeper understanding is needed about the role of motherhood (or fatherhood) in the lives of individuals working in the sex industry, including custody issues. Another area that deserves further attention is the role of the internet and new technologies on one's experience of working in the sex industry. The internet can be a site of client recruitment, a space for sharing, learning, connecting and engaging in activism, as well as a place for love-making. Additional research projects can include understanding the crucial role that the internet plays in the sex industry and in the lives of sex workers and their clients.

It is crucial that future research with sex workers continue to use the arts-based method of photovoice to explore and understand the multi-layered, multi-dimensional and complex realities of individuals working in the sex industry. We should continue to advocate for research that challenges stereotypes and stigma. We support methods that include the creative participation of sex workers and the opportunities for selfrepresentation and self-definition. As social workers who strive to understand the human condition, photovoice can offer a kaleidoscopic perspective of the "Rich Landscape" (Mouse) that individuals inhabit, as well as our own.

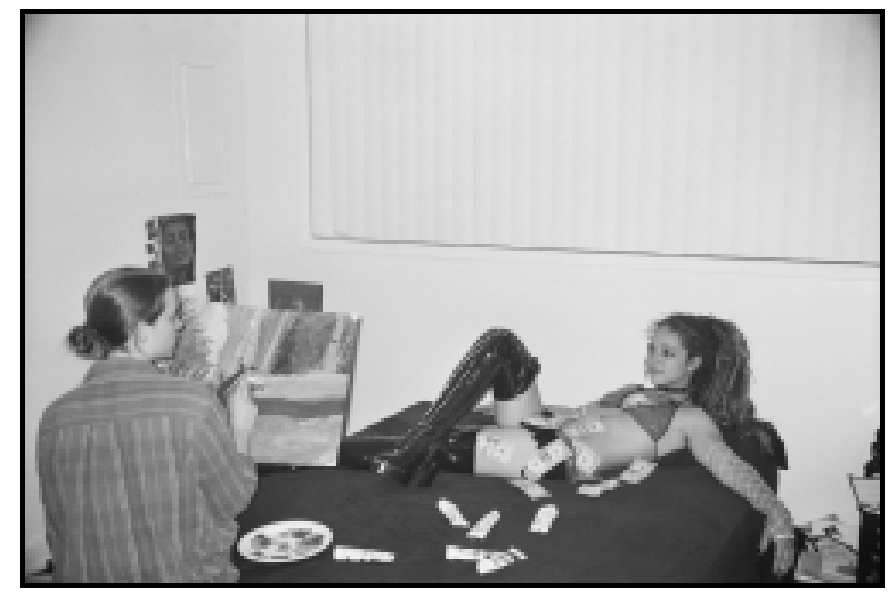

Figure 148: Rich Landscape. 


\section{REFERENCES}

Abrams, L. S. (2000). Guardians of virtue: The social reformers and the "girl problem," 1890-1920. Social Service Review, (September).

Abrams, L. S. \& Curran, L. (2000). Wayward girls and virtuous women: Social workers and female juvenile delinquency in the Progressive Era. Affilia, 15(49), 49-64.

Ada, A. \& Beutel, C.M. (1993). Participatory research as a dialogue for social action. San Francisco, CA: University of San Francisco Press.

Agustin, L. (2002). Challenging 'Place': Leaving Home for Sex. Development, 45(1), $110-117$.

Agustin, L. (2005). New Research Directions: The cultural study of commercial sex. Sexualities, 8(5), 618-631.

Alcoff, L. \& Potter, E. (1993). Introduction: When feminisms intersect epistemology, In L. Alcoff, L. \& E. Potter (Eds.), Feminist Epistemologies, (pp.1-14). New York: Routledge.

Alexander, P. (1987). Introduction: Why this book? In F. Delacoste \& P. Alexander (Eds.) Sex work: Writings by women in the sex industry. Pittsburg, PA: Cleis Press.

Alexander, P. (1987). Prostitution: A difficult issue for feminists, In F. Delacoste \& P. Alexander (Eds.), Sex work: Writings by women in the sex industry. Pittsburgh, PA: Cleis Press.

Anderson, M. L. (1997). Thinking about women: Sociological perspectives in sex and gender. Needham Heights, MA: Allyn \& Bacon. 
Baseman, J., Ross, M., \& Williams, M. (1999). Sale of sex for drugs and drugs for sex: An economic context of sexual risk behavior for STDs. Sexually Transmitted Diseases, 2(6), 444-449.

Barlett, K. (1993). Gender and law: Theory, doctrine, commentary. Boston: Little, Brown \& Company.

Barone, T. (2000). Aesthetics, politics, and educational inquiry: Essays and examples. Washington, D.C.: Peter Lang.

Barone, T. \& Eisner, E. (1997). Arts-based educational research in complementary methods for research education. (Ed.) Richard Jaeger. Washington, D.C.: American Education Research Association.

Barry, K. (1979). Female sexual slavery. Englewood Cliffs, NJ: Prentice-Hall.

Barry, K. (1995). The prostitution of sexuality. New York: New York University Press.

Barthes, R. (1981). Camera Lucida: Reflections on photography. New York: Noonday.

Barton, B. (2002). Dancing on the mobius strip: Challenging the sex war Paradigm. Gender \& Society, 16(5).

Baseman, J., Ross, M., \& Williams, M. (1999). Sale of sex for drugs and drugs for sex: An economic context of sexual risk behavior for STDs. Sexually Transmitted Diseases, 2(6), 444-449.

Bell, L. (1987). Good girls/Bad girls: Feminists and sex trade workers, face to face. Seattle, WA: Seal Press.

Bell, S. (1994). Reading, writing and rewriting the prostitute body. Bloomington: Indiana University Press.

Block, J. (2004). Sex Trafficking: Why the faith trade is interested in the sex trade. 
Conscience, (Summer/Autumn).

Bloustien, G. \& Baker, S. (2003). On not talking to strangers: Researching the micro worlds of girls through visual auto-ethnographic practices. Social Analysis, 47(3), 64-79.

Benoit, C. \& Shaver, F. (2006). Critical issues and new directions in sex work research, The Canadian Review of Sociology and Anthropology, Special Issue 43(3), 243252.

Bindman, J. (1998). An international perspective on slavery in the sex industry, In K. Kempadoo \& J. Doezema (Eds.), Global sex workers: Rights, resistance, and revolution, (pp. 65-69). New York/ London: Routledge.

Booth, T. \& Booth, W. (2003). In the frame: Photovoice and mothers with learning difficulties. Disability and Society, 18(4), 431-442.

Boyer, P. (1978). Urban masses and moral order in America, 1820-1920. Cambridge: Harvard University Press.

Brooks, A. (2007). Feminist standpoint epistemology, In S. N. Hesse-Biber \& P. L. Leavy, Feminist Research Practice: A Primer, (pp. 53-82). Thousand Oaks, CA: Sage Publications.

Bullough, B. \& Bullough, V. (1987). Women and Prostitution: A Social History. Buffalo, New York: Prometheus Books.

Burnham, J. (1973). The progressive era revolution in American attitudes toward sex. The Journal of American History, 59(4), 885-908.

Butler-Kisber, L. (2008). Collage as inquiry, In G. Knowles \& A. Cole (Eds.) Handbook of the Arts in Qualitative Research: Perspectives, Methodologies, Examples \& 
Issues (pp. 265-276). Los Angeles, CA: Sage Publications.

Califia, P. (1994). Public sex: The culture of radical sex. Pittsburg, PA: Cleis Press.

Cahnmann, M. (2006). Reading, living, and writing bilingual poetry as scholARTistry in the language arts classroom. Language Arts, 83(4), 341-351.

Chancer, L. S. (1993). Prostitution, Feminist Theory, and Ambivalence: Notes from the sociological underground. Social Text, 37.

Chapkis, W. (1997). Live sex acts: Women performing erotic labor. New York: Routledge.

Chapkis, W. (2003). Trafficking, Migration, and the Law: Protecting Innocents, Punishing Immigrants. Gender \& Society, 17(6), 923-937.

Chancer, L. (1998). Reconcilable differences: Confronting beauty, pornography and the future of feminism. Berkeley: University of California Press.

Cho, D. \& Lewis, T. (2005). The persistent life of oppression: The unconscious, power, and subjectivity. Interchange, 36(3), 313-329.

Church, S., Henderson, M., Barnard, M., \& Hart, G. (2001). Violence by clients towards female prostitutes in different work settings: Questionnaire survey. British Medical Journal, 322, 524-525.

Cole, A. \& Knowles, G. (2001). Chapter 6: Making sense of and representing lives in context. In A. Cole \& G. Knowles (Eds.) Lives in Context: The art of life history research. CA: AltaMira Press.

Cole, A. \& Knowles, G. (2008). Arts-informed research. In G. Knowles \& A. Cole (Eds.) Handbook of the Arts in Qualitative Research: Perspectives, methodologies, examples \& Issues (pp. 55-70). Los Angeles, CA: Sage Publications. 
Collier, J. (1979). Visual Anthropology, In J. Wagner (Ed.). Images of Information (pp.161-169). Beverly Hills, CA: Sage Publications.

Collins, P. H. (1990). Black feminist thought: Knowledge, consciousness, and the politics of empowerment. London: Harper Collins.

Collins, P. H. (1996). Black women and the sex/ gender hierarchy, In S. Jackson and S. Scott (Eds.), Feminism and Sexuality, (pp. 307-313). New York: Columbia University Press.

Collins, P. H. (1997). Comment on Hekman's Truth and method: Feminist standpoint theory revisited: Where's the power. Signs: Journal of Women in Culture \& Society, 22(2), 375-381.

Creswell, J. (1998). Qualitative Inquiry and Research Design: Choosing among five traditions. Thousand Oaks, CA: Sage Publications, Inc.

Cwikel, J. Ilan, K. \& Chudakov, B. (2003). Women brothel workers and occupational health risks. Journal of Epidemiology and Community Health, 57(10), 809-815.

Davis, D. \& Butler-Kisber, L. (1999). Arts-based representation in qualitative research: Collage as a contextualizing analytic strategy, In Annual Meeting of the American Educational Research Association, 19-23 April 1999 (pp. 1-29). Montreal, Quebec, Canada.

Denzin, N. \& Lincoln, Y. (2005). The SAGE Handbook of Qualitative Research, $3^{\text {rd }}$ edition. Los Angeles, CA: Sage Publications.

Delacoste, F. \& Alexander, P. (1987). Sex work: Writings by women in the sex industry. Pittsburg, PA: Cleis Press.

Ditmore, M. (2003). Morality in new policies addressing trafficking and sex work. A 
paper presented at "Women working to make a difference," IWPR's Seventh International Women's Policy Research Conference (June).

Doezema, J. (1998). Forced to choose: Beyond the voluntary v. forced prostitution Dichotomy, In K. Kempadoo \& J. Doezema (Eds.), Global sex workers: Rights, resistance, and revolution, (pp. 34-48), New York/ London: Routledge.

Doherty, M., Garfein, R., Monterroso, E., Brown, D., \& Vlahov, D. (2000). Correlates of HIV infection among young adult short-term injection drug users. AIDS, 14(6), 717-726.

Dworkin, A. (1987). Intercourse. New York: Free Press.

Dworkin, A. (1989). Pornography: Men possessing women. New York: Penguin Group.

Dyches, T., Cichella, E., Olsen, S., \& Mandelco, B. (2004). Snapshots of life: Perspectives of school-aged individuals with developmental disabilities. Research \& Practice for Persons with Severe Disabilities, 29(3), 172-182.

Edwards, J., Halpern, C. \& Wechsberg, W. (2006). Correlates of exchanging sex for drugs or money among women who use crack cocaine. AIDS Education and Prevention, 18(5), 420-429.

Eisner, E. (1997). The promise and perils of alternative forms of data representation. Educational Reader, 26(6), 4-10.

Eisner, E. (2008). Art and knowledge. In G. Knowles \& A. Cole (Eds.) Handbook of the Arts in Qualitative Research: Perspectives, methodologies, examples \& issues (pp. 3-12). Los Angeles, CA: Sage Publications.

El Bassel, N., Witte, S., Wada, T., Gilbert, L., Wallace, J. (2001). Correlates of partner violence among female street-based sex workers: substance abuse, history of 
childhood abuse, and HIV risks. AIDS Patient Care STDS, 15, 41-51.

Ewald, W. (1985). Portraits of Dreams: Photographs and stories by children of the Appalachians. New York: Writers and Readers.

Ewald, W. (1996). I dreamed I had a girl in my pocket: the story of an Indian village. New York: Double Take Books.

Farley, M. (2004). Bad for the body, bad for the heart: Prostitution harms women even if legalized or decriminalized. Violence Against Women, 10, 1087-1125.

Farley, M., Baral, I., Kiremire, M. \& Sezgin, U. (1998). Prostitution in five countries: Violence and posttraumatic stress disorder. Feminism and Psychology, 8, 405426.

Farley, M. \& Barkan, H. (1998). Prostitution, violence, and posttraumatic stress disorder. Women and Health, 27(3), 37-49.

Farley, M. \& Kelly, V. (2000). Prostitution: A critical review of the medical and social sciences literature. Women \& Criminal Justice, 11(4), 29-64.

Feen-Calligan, H., Washington, O. \& Moxley, D. (2009). Homelessness among older African-American women: Interpreting a serious issue through the arts in community-based participatory action research. New Solutions, 19(4), 423-448.

Ferguson, A. (1984). Sex war: The debate between radical and libertarian feminists, Signs, 10(1), 106-112.

Finley, S. (2003). Arts-based inquiry in $Q I$ : Seven years from crisis to guerilla warfare. Qualitative Inquiry, 9(2), 281-296.

Finley, S. (2008). Arts-based research, In G. Knowles \& A. Cole (Eds.) Handbook of the Arts in Qualitative Research: Perspectives, methodologies, examples \& issues 
(pp. 71-82). Los Angeles, CA: Sage Publications.

Finley, S. \& Finley, M. (1999). Sp'ange: A research story. Qualitative Inquiry, 5(3), 313 337.

Franz, J. (2005). Arts-based research in design education, In Proceedings AQR Conference, Melbourne.

Freire, P. (1970). Pedagogy of the oppressed. New York: Continuum.

Freire, P. (1973). Education for critical consciousness. New York: Seabury Press.

Freire, P. (1976). Education: The practice of freedom. London: Writers and Readers Cooperative.

Freire, P. (1985). The politics of education: Culture, power and liberation. Hadley, MA: Bergin \& Garvey.

Frohmann, L. (2005). The Framing Safety Project: Photographs and narratives by battered women. Violence Against Women, 11(11), 396-1419.

Garoian, C. (1999). Performing pedagogy. Albany: State University of New York Press. Gauntlett, D. (2007). Creative explorations: New approaches to identities and audiences. New York, NY: Routledge.

Gibson, R. (1999). Paulo Freire and pedagogy for social justice. Theory and Research in Education, 27(2), 129-159.

Gilfoyle, T. (1999). Prostitutes in History: From Parables of Pornography to Metaphors of Modernity. The American Historical Review, 104(1), 117-141.

Giobbe, E., Harrigan, M., Ryan, J, \& Gamache, D. (1990). Prostitution: A matter of violence against women. Minneapolis, MN: Whisper Press.

Gold, S. (2004). Using photography in studies of immigrant communities. American 
Behavioral Scientist, 47(12), 1551-1572.

Goldstein, P. (1985). Prostitution and Drugs. Lexington, MA: Lexington Books.

Gouin, R. (2006). What's so funny?: Humor in women's accounts of their involvement in social action. Qualitative Research, 4(25), 25-44.

Grittner, F. K. (1990). White slavery: Myth, Ideology \& American Law. New York \& London: Garland Publishers.

Hammond, J. (2004). Photography and ambivalence. Visual Studies, 19(2), 135-144.

Haraway, D. (1988). Situated knowledges: The science in feminism and the privileges of partial perspective. Feminist Studies, 14, 575-599.

Haraway, D. (1991). Simians, cyborgs, women: The reinvention of nature. New York: Routledge.

Haraway, D. (1997). Modest_Witness@Second_Millennium.FemaleMan_Meets_ OncoMouse: feminism and technoscience. (pp. 24-32). New York: Routledge.

Hardesty, L. \& Greif, G. (1994). Common themes in a group for female IV drug users who are HIV positive. Journal of Psychoactive Drugs, 26(3), 289-293.

Harding, S. (1987). Conclusion: Epistemological questions. In S. Harding (Ed.), Feminism and methodology: Social science issues (pp.181-190). Bloomington: Indiana University Press.

Harding, S. (1991). Whose science? Whose knowledge? Thinking from women's lives. Ithica, NY: Cornell University Press.

Harding, S. (1993). Rethinking standpoint epistemology: “What is strong objectivity?” In L. Alcoff \& E. Potter (Eds.), Feminist Epistemologies. New York: Routledge. Harding, S. (2004). The feminist standpoint theory reader: Intellectual and political 
conversations. New York: Routledge.

Hartsock, N. (1983). The feminist standpoint: Towards a specifically feminist historical Materialism, In S. Harding \& M. Hintikka, Discovering reality. Dordrecht, Holland: D. Reidel.

Hawkesworth, M. (1989). Knowers, knowing, known: Feminist theory and claims of truth. In M. Malson, J. O’Barr, S. Westphal Wihl \& M. Wyer (Eds.), Feminist theory in practice and process, (pp. 327-351). Chicago: University of Chicago Press.

Haymes, S. (2002). Race, pedagogy, and Paulo Freire. Philosophy of Education Yearbook 2002.

Hekman, S. (2004). Truth and method: Feminist standpoint theory revisited, In S. Harding (Ed.), The feminist standpoint theory reader: Intellectual and political controversies (pp. 225-241). New York: Routledge.

Herbison, S. \& Lokanc-Diluzio, W. (2006). The novella approach to inform women living on low income about elderly breast cancer detection. Health Promotion Practice, 10(10), 1-11.

Hirschmann, N. (1997). Feminist standpoint as postmodern strategy, In S. Kenney \& H. Kinsella (Eds.), Politics and feminist standpoint theories (pp. 73-92). New York: Haworth Press.

Hobson, B. M. (1987). Uneasy Virtue: The politics of prostitution and the American reform tradition. New York: Basic Books, Inc., Publishers.

hooks, b. (2004). Choosing the margin as a space of radical openness, In S. Harding (Ed.), The feminist standpoint theory reader: Political and intellectual 
controversies (pp. 153-159). New York: Routledge.

Hubbard, J. (1991). Shooting back: A photographic view of life by homeless children. San Francisco Chronicle.

Hubbard, J. (1994). Shooting back: A photographic view of life by Native Americans. New York: The New York Press.

Huff, D. (1998). Every picture tells a story. Social Work, 43, 6, November, 576-583.

Hundleby, C. (1997). Where standpoint stands now. Women \& Politics, 18(3), 25-43.

Hunt, A. (1999). Governing morals: A social history of moral regulation. Cambridge, UK: Cambridge University Press.

Hussey, W. (2006). Slivers of the journey: The use of photovoice and storytelling to examine female to male transsexuals' experience of health care access. Journal of homosexuality, 15(1), 129-158.

Hutton, H. E., Treisman, G. J., Hunt, W. R., Fishman, M., Kendig, N., Swetz, A., \& Lyketsos, C. G. (2001). HIV risk behaviors and their relationship to posttraumatic stress disorder among women prisoners. Psychiatric Services, 52(4), 508-513.

Inciardi, J., Lockwood, D. \& Pottieger, A. (1993). Women and crack-cocaine. New York: Macmillian.

Irving, A. (1999). Waiting for Foucault: Social Work and the Multitudinous Truth(s) of life. In A.S. Chambon, A. Irving, \& L. Epstein (Eds.), Reading Foucault for Social Work (pp. 27-50). New York: Columbia University Press.

Israel, B. A., Eng, E., Schulz, A.J., \& Parker, E.A. (2005). Introduction to methods in community-based participatory research for health. In B.A. Israel, E. Eng, A.J. Schulz, \& E.A, Parker (Eds.), Methods in community-based participatory 
research for health (pp.3-26). San Francisco, CA: Jossey-Bass.

Jagger, A. (1983). Feminist politics and human nature. Sussex, Great Britain: Harvester.

Jagar, A. (1997). Love and knowledge: Emotion in feminist epistemology, In S. Kemp \& J. Squires (Eds.), Feminisms (pp. 188-193). Oxford, UK: Oxford University Press.

Jeffrey, L. A. \& MacDonald, G. (2006). Sex workers in the Maritimes talk back. Vancouver, B.C.: UCB Press.

Jeffreys, S. (1997). The idea of prostitution. North Melbourne, Australia: Spinifex.

Jenness, V. (1990). From sex as sin to sex as work: COYOTE and the reorganization of prostitution as a social problem. Social Problems, 37, 403-420.

Jenness, V. (1993). Making it work: The prostitutes' rights movement in perspective. Hawthorne, NY: Aldine de Gruyter.

Joldersma, C. (2001). The tension between justice and freedom in Paulo Freire's epistemology. Journal of Educational Thought, 35(2), 129-148.

Jolin, A. (1994). On the backs of working prostitutes: Feminist theory and prostitution policy. Crime Delinquency, 40, 69-83.

Jusza, J. \& Baker, S. (2004). Protection and participation: An interactive programme introducing the female condom to migrant sex workers in Cambodia. AIDS Care, 16(4), 507-518.

Kaminsky, M. (1985). Daily Bread: Or, the Marriage of Art and Social Work. Social Work with Groups, 8(1), 17-23.

Kemmis, S. \& McTaggart, R. (2005). Participatory action research: Communication action in the public sphere. In N. Denzin \& Y. Lincoln (Eds.), The sage handbook of qualitative research. New York: Thousand Oaks. 
Kempadoo, K. (2001). Freelancers, temporary wives, and beach-boys: Researching sex work in the Caribbean. Feminist Review, 67, 39-62.

Kempadoo, K. \& Doezema, J. (1998), Global sex workers: Rights, resistance, and revolution, New York/ London: Routledge.

Kesler, K. (2002). 'Is a feminist stance in support of prostitution possible? An exploration of current trends,' Sexualities, 2, 219-235.

Killian, C. (2001). Understanding cultural aspects of health through photography. Nursing Outlook, 49, 50-54.

Killion, C. \& Wang, C. (2000). Linking African American mothers across life stages and station through photovoice. Journal of Health Care for the Poor and Underserved, 11(3), 310-325.

King, D. (1990). Prostitutes as pariah in the age of AIDS: A content analysis of coverage of women prostitutes in the New York Times and the Washington Post, September 1985 to April 1988. Women and Health, 16,155-176.

Kivel, P. (2006). Social service or social change? Retrieved April 5, 2010, from http://www.paulkivel.com/

Kral, A., Lorvick, J. \& Edlin, B. (2000). Sex- and drug- related risk among populations of younger and older injection drug users in adjacent neighborhoods in San Francisco. Journal of Acquired Immune Deficiency Syndrome, 24(2), 162-167.

Kramarae, C. \& Spencer, D. (Eds.) (1992). The knowledge explosion: Generations of feminist scholarship. New York: Teacher's College Press.

Kunzel, R. G. (1993). Fallen women, problem girls: Unmarried mothers and the professionalization of social work 1890-1945. New Haven: Yale University Press. 
Kurtz, S., Surrat, H., Inciardi, J., \& Kiley, M. (2004). Sex work and “Date” violence. Violence against women, 10, 357-385.

Langer, S. (1957). Problems of art: Ten philosophical lectures. New York: Scribner.

Latkin, C., Hua, W., \& Forman, V. (2003). The relationship between social network characteristics and exchanging sex for drugs or money among drug users in Baltimore, MD, USA. International Journal of STD and AIDS, 14, 770-775.

La Jevic, L. \& Spinggay, S. (2008). A/r/tography as an ethics of embodiment. Qualitative Inquiry, 14(1), 67-89.

Leavy, P. (2007). Merging feminist principles and arts-based methodologies. Paper presented at the annual meeting of the American Sociological Association, TBA, New York, New York City, Aug 11, 2007. Retrieved December 21, 2009, from http://www.allacademic.com/meta/p175345 index.html

Leavy, P. (2009). Method Meets Art: Arts-Based Research Practice. New York: The Guilford Press.

Leigh, C. (2000). Unrepentant Whore: The collected works of Scarlot Harlot. San Francisco: Last Gap.

Lemert, C. (1992). Subjectivity's limit: The unsolved riddle of the standpoint. Sociological Theory, 10(1), 63-72.

Lever, J. \& Dolnick, D. (2000). 'Clients and call girls: Seeking sex and intimacy,' In Weitzer, R. (Ed.), Sex for sale: Prostitution, pornography and the sex industry, (pp. 85-100). New York: Routledge.

Lincoln, Y. (1995). Emerging criteria for quality in qualitative and interpretive research. Qualitative Inquiry, 1(3), 275-289. 
Logan, T., Cole, J., \& Leukefeld, C. (2003). Gender differences in the context of sex exchange among individuals with a history of crack use. AIDS Education and Prevention, 15, 448-464.

Logan, T., \& Leukefeld, C. (2000). Sexual and drug use behaviors among female crack users: A multi-site sample. Drug and Alcohol Dependence, 58, 237-245.

Longino, H. (1993). Subjects, power and knowledge: Description and prescription in feminist philosophies of science, In L.Alcoff \& E. Potter (Eds.), Feminist epistemologies. New York: Routledge.

Longino, H. (1999). Feminist epistemology, In J. Grecco \& E. Sosa (Eds.), The Blackwell guide to epistemology (pp. 327-353). Malden, MA: Blackwell.

Lopez-Jones, N. (1999). Some mother's daughter: The hidden movement of prostitute women against violence. London: Crossroads Books (International Prostitute Collective).

Ludvig, A. (2006). Difference between women? Intersecting voices in a female narrative. European Journal of Women's Studies, 13(3), 245-258.

Martin, R. \& Spence, J. (1985). New portraits for old: The use of the camera in therapy. Feminist Review, 19, 66-92.

MacKinnon, C. (1987). Feminism unmodified: Discourses on life and law. Cambridge, MA: Harvard University Press.

MacKinnon, C. (1989). Toward a feminist theory of the state. Cambridge, MA: Harvard University Press.

May, R. (1994). The courage to create. New York: Norton.

Melzer, E. (2005). Trafficking in politics: Bush's strong rhetoric on sex slavery masks 
policy failures, In These Times, Retrieved March 14, 2007 from

http://www.inthesetimes.com/site/main/article/2007/

Millett, K. (1970). Sexual politics. Garden City, NY: Doubleday \& Company.

Millet, K. (1975). The prostitution papers. St. Albans: Paladin.

Miller, J. (1993). Your life is on the line every night you're on the streets: Victimization and the resistance among street prostitutes. Humanity \& Society, 17, 442-446.

Miller, E. M., Romenesko, K., Wondolkowski, L., (1993). The United States, In Prostitution: An international handbook, on trends, problems, and policies. Davis, N.J. (Ed.) Westport, Connecticut: Greenwood Press.

Miller, J. \& Schwartz, M. (1995). Rape myths against street prostitutes. Deviant Behavior, 16(1), 1-23.

Minkler, M. (1978). Ethical issues in community organization. Health Educational Monographs, 6, 198.

Mitchell, C. \& Allnutt, S. (2008). Visual Art: Photographs and/as social documentary, In G. Knowles \& A. Cole (Eds.), Handbook of the Arts in Qualitative Research (pp. 251-263). Los Angeles: Sage Publications. .

Morrell, J. (2007). Voices from the Street: Truths about homelessness from Sisters of the Road. Portland, OR: Gray Sunshine Publishing.

Morison, L., Weiss, H., Buve, A., Carael, M., Abega, S., Kaona, F., Kanhonou, L., Chege, J. \& Hayes, R. (2001). Commercial sex and the spread of HIV in four cities in Sub-Saharan Africa. AIDS, 15(no. supplement 4), S61-S69.

Morisky, D., Ang, A., \& Sneed, C. (2002). Validating the effects of social desirability on self-reported condom use behavior among commercial sex workers. AIDS 
Education and Prevention, 14(5), 351-360.

Murphy, A. (2003). The dialectical gaze exploring the Subject-Object tension in the performances of women who Strip. Journal of Contemporary Ethnography, 32(3), $305-335$

Murphy, A. \& Venkatesh, S. (2006). Vice Careers: The changing contours of sex work in New York City. Qualitative Social Work, 29, 129-154.

Murphy, Y., Hunt, V., Zajicek, A., Norris, A., \& Hamilton, L. (2009). Incorporating Intersectionality in Social Work Practice, Research, Policy and Education. Washington, D.C.: NASW Press.

McGlish, G., \& Bacon, J. (2003). Chapter 34: Standpoint theory. Instructor's manual for E. Griffin, A First Look at Communication Theory, $5^{\text {th }}$ edition, New York: McGraw-Hill, Inc.

McKeganey, N. and Barnard, M. (1990). Sex Work, In H. Miller, C. Turner, \& L. Moses (Eds) AIDS: The second decade. Washington, D.C.: National Academy Press. McNiff, S. (1998). Arts-based research. London: Jessica Kingsley.

McNiff, S. (2008). Art-based research, In G. Knowles \& A. Cole (Eds.) Handbook of the Arts in Qualitative Research: Perspectives, methodologies, examples \& issues (pp. 29-40). Los Angeles, CA: Sage Publications.

Nagle, J. (Ed.) (1997). Whores and other feminists. New York: Routledge.

Narayan, U. (1989). The project of feminist epistemology: Perspectives from a nonwestern feminist. In A. Jagger \& S. Bordo (Eds). Gender/Body/Knowledge: Feminist reconstructions of being and knowing. New Brunswick: Rutgers University Press. 
Narayan, U. (2004).The project of feminist epistemology: Perspectives from a nonWestern feminist. In S. Harding (Ed.), The feminist standpoint theory reader: Political and intellectual controversies (pp. 213-224). New York: Routledge. National Association of Social Workers (NASW) (1999). Code of ethics. Retrieved February 3, 2008 from http://www.socialworkers.org/pubs/code/code.asp National Association of Social Workers (NASW) (2005). Commercial Sex Workers and Social Work Practice: NASW Policy Statements Abstracts. Social Work Speaks, $7^{\text {th }}$ Ed. Retrieved January 22, 2010 from http://www.socialworkers.org/resources/abstracts/abstracts/comSex.asp.

Nemoto, T., Iwamoto, M., Wong, S., Le, M., \& Operario, D. (2004). Social factors related to risk for violence and sexually transmitted infections/ HIV among Asian massage parlor workers in San Francisco. AIDS and Behavior, 8(4), 474-483.

Newbury, J. \& Hoskins, M. (2008). A meaningful method: Research with adolescent girls who use crystal methamphetamine. Child Youth Care Forum, 37, 227-240.

Nielsen, J. M. (1990). Introduction. In J. M. Nielsen (Ed.), Feminist research methods (pp. 1-37). Boulder, CO: Westview Press.

Nightingale, D. \& Cromby, J. (Eds) (1999). Social constructionist psychology. Buckingham: Open University Press. Retrieved October 20, 2009 from http://www.psy.dmu.ac.uk/michael/qual_reflexivity.htm

Nixon, K., Tutty, L., Downe, P., Gorkoff, K., \& Ursel, J. (2002). The everyday occurrence: Violence in the lives of girls exploited through prostitution. Violence Against Women, 8(9), 1016-1043.

Norris, J. (2000). Drama as research: Realizing the potential of drama in education as a 
research methodology. Youth Theatre Journal, 14, 40-51.

O’Neil, J., Orchard, T., Swarankar, R., Blanchard, J., Gurav, K. \& Moses, S. (2004).

Dhandha, Dharma \& Disease: Traditional sex work and HIV/AIDS in rural India. Social Science \& Medicine, 59(4), 851-860.

O'Neill, M. (2002). Renewed methodologies for social research: ethno-mimesis as performative praxis. Sociological Review 50(1), 75-88.

Outshoorn, J. (2005). The political debates on prostitution and trafficking of women. Social Politics, 12(1), 141-155.

Overall, C. (1992). What's wrong with prostitution? Evaluating sex work. Signs: Journal of Women in Culture and Society, 17(4), 705-724.

Paglia, C. (1992). Sex, art and American culture. New York: Vintage.

Park, P. (1989). What is participatory research? A theoretical and methodological perspective. University of Massachusetts? Amherst. Center for Community Education and Action, Inc. Northampton, MA.

Pauw, I. \& Brener, L. (2003). "You are just whores- you can't be raped”: Barriers to safer sex practices among women street workers in Cape Town. Cultural, Health \& Sexuality, 5, 465-481.

Phelan, J., Link, B., Moore, R., and Stueve, A. (1997). The stigma of homelessness: The impact of the label "homeless" on attitudes toward poor persons. Social Psychology Quarterly, 60(4), 323-337.

Pheterson, G. (1989). A vindication of the rights of whores. Seattle, WA: Seal Press. Porter, J. \& Bonilla, L. (2000). Drug Use, HIV, and the ecology of street prostitution, In Weitzer, R. (Ed.), Sex for sale: Prostitution, pornography and the sex industry, 
(pp. 103-121) New York: Routledge.

Pyett, P. \& Warr, D. (1999). Women at risk in sex work: Strategies for survival. Journal of Sociology, 35(2), 183-197.

Ramazanoglu, C. (1989). Improving on sociology: The problems of taking a feminist standpoint. Sociology, 23(3), 427-442.

Reinharz, S. (1992). The principles of feminist research: A matter of debate, In C. Kramarae, \& D. Spender (Eds.), The knowledge explosion: Generations of feminist scholarship. New York: Teacher's College Press.

Rhodes, S., Hergenrather, K., Wilkin, A., \& Jolly, A. (2007). Visions and voices: Indigent persons living with HIV in the southern United States use photovoice to create knowledge, develop partnerships, and take action. Health Promotions Practice, 0, 1-11.

Rieman, D. J. (1998). The essential structure of a caring interaction: Doing phenomenology, In J.W. Creswell (Ed.), Qualitative Inquiry and Research Design: Choosing Among the Five Traditions. Thousand Oaks, CA: Sage Publications, Inc.

Riono, P. \& Jazant, S. (2004). The current situation of the HIV/AIDS epidemic in Indonesia. AIDS Education and Prevention, 16(no. supplement A), 78-90.

Roberts, P. (1999). A dilemma for critical educators? Journal of Moral Education, 28(1), 19-30.

Rollins, J. H. (2007). Visual culture archaeology: A Criti/Politi/cal methodology of image and identity. Cultural Studies-Critical Methodologies, 7(1), 3-25.

Romans, S., Potter, K., Martin, J., \& Herbison, P. (2001). The mental and physical 
health of female sex workers: a comparative study. Australian and New Zealand Journal of Psychiatry, 35(1), 75-80.

Romero-Daza, N., Weeks, M., \& Singer, M. (1999). Much more than HIV! The reality of life on the streets for drug-using sex-workers in inner city Hartford. International Quarterly of Community Health Education, 18, 107-119.

Romero-Daza, N., Weeks, M., \& Singer, M. (2003). "Nobody gives a damn if I live or Die": Violence, drugs, and street-level prostitution in inner-city Hartford, Connecticut. Medical Anthropology, 22, 233-259.

Rosler, M. (1989). Around and afterthoughts (on documentary photography), In R. Bolton (Ed.), The contest of meaning. Cambridge: MIT Press.

Ross, M., Hwang, L., Zack, C., Bull, L., \& Williams, M. (2002). Sexual risk behaviors and STIs in drug abuse treatment populations whose drug of choice is crack cocaine. International Journal of STD AIDS, 13(11), 769-774.

Rothman, S. M. (1978). Woman's proper place: A history of changing ideals and practices 1970 to the present. New York: Basic Books.

Rubin, G. (1984). Thinking sex: Notes for a radical theory on the politics of sexuality, In C. Vance (Ed.), Pleasure and danger: Exploring female sexuality (pp. 267-319). London: Routledge Kegan Paul.

Sarasema, T. (2003). Bereavement and the healing power of arts and writing. Qualitative Inquiry, 9(4), 603-621.

Saulnier, C.F. (1996). Feminist theories and social work: Approaches and applications. New York: Haworth Press.

Saunders, P. (2005). Traffic Violations: Determining the meaning of violence in sexual 
trafficking versus sex work, Journal of Interpersonal Violence, 20(3), 343-360.

Saunders, P. \& Soderlund, G. (2003). Traveling threats: Sexuality, gender and the ebb and flow of trafficking as discourse. Canadian Woman Studies, 22, 35-46.

Sclater, D. (2003). The arts and narrative research. Qualitative Inquiry, 9(4), 621-625.

Scoular, J. (2004). 'Criminalizing "Punters": Evaluating the Swedish Position on Prostitution', Journal of Social Welfare and Family Law, 26,195-210.

Shah, S. (2004). Prostitution, sex work and violence: Discursive and political contexts for five texts on paid sex, 1987-2001, Gender and History, 16(3), 794-812.

Sherman, S., German, D., Cheng, Y., Marks, M., \& Bailey-Kloche, M. (2006). The evaluation of the JEWEL project: An innovative economic enhancement and HIV prevention intervention study targeting drug using women involved in prostitution. AIDS Care, 18(1), 1-11.

Shrage (1994). Moral dilemma of feminism: Prostitution, adultery and abortion. New York: Routledge.

Shrage, J. (2004). Moral dilemma of feminism: Prostitution, adultery and abortion. New York: Routledge.

Silbert, M. \& Pines, A. (1982).Victimization of street prostitutes. Victimology, 7(1-4), 122-133.

Simons, H. \& McCormack, B. (2007). Integrating arts-based inquiry in evaluation methodology: Opportunities and challenges. Qualitative Inquiry, 13(2), 292-311.

Sinding, C., Gray, R., \& Nisker, J. (2008). Ethical Issues and Issues of Ethics, In G. Knowles \& A. Cole (Eds.) Handbook of the Arts in Qualitative Research: Perspectives, methodologies, examples \& issues (pp. 459-168). Los Angeles, CA: 
Sage Publications.

Sinner, A., Leggo, C., Irwin, R., Gouzouasis, P., \& Grauer, K. (2006). Arts-based educational research dissertations: Reviewing the practices of new scholars. Canadian Journal of Education, 29(4), 1223-1270.

Sloan, L. \& Wahab, S. (2000). Feminist voices on sex work: Implications for social work, Affilia, 15(4), 457-479.

Sloan, L. \& Wahab, S. (2004). Four categories of women who work as topless dancers. Sexuality \& Culture, $8(1), 18-43$.

Smith, D. (1990). Women's perspective as a radical critique of sociology. In S. Harding (Ed.), Feminism and methodology (pp. 84-96). Bloomington: Indiana University Press.

Smith, B. (1998). The truth that never hurts: Writings on race, gender and freedom. New Brunswick, NJ: Rutgers University Press.

Smith \& Osborn (2008). Chapter 4: Interpretive phenomenological analysis. In J. Smith (Ed.), Qualitative psychology: A practical guide to research methods, $2^{\text {nd }}$ edition, (pp. 53-80). Los Angeles, CA: SAGE Publications.

Spence, J. (1995). Cultural sniping: The art of transgression. London: Routledge.

Stanley, L. \& Wise, S. (1993). Breaking out again: Feminist ontology and epistemology. London: Routledge.

Sterk, C. (1999). Fast lives: Women who use crack cocaine. Philadelphia: Temple University Press.

Stokrocki, M. (1994). Through Navajo Children's Eyes: Cultural Influences on the Representational Abilities. Ó in Visual Anthropology, 7, 27-67. 
Strack, R., Magill, C. \& McDonagh, K. (2004). Engaging youth through photovoice. Health Promotion Practice, 5,(1), 49-58.

Streng, J., Rhodes, S., Ayala, G., Eng, E., Arceo, R., \& Phipps, S. (2004). Realidad Latina: Latino adolescents, their school, and a university use photovoice to examine and address the influence of immigration. Journal of Interprofessional Care, 18(4), 403-415.

Stout, K.D. \& McPhail, B. (1998). Confronting sexism and violence against women: A challenge for Social Work. New York: Longman.

Sullivan, G. (2005). Art practice as research: Inquiry in the visual arts. Thousand Oaks, CA: Sage Publications.

Surratt, H. L., Kurtz, S.P., Weaver, J. C., \& Inciardi, J. A. (2005). The connections of mental health problems, violent life experiences, and the social milieu of the "stroll" with the HIV risk behaviors of female street sex workers. Contemporary Research on Sex Work/ Journal of Psychology \& Human Sexuality, 17(1/2), 2344.

Sutherland, K. (2004). Work, sex, and sex work: Competing feminist discourses on the international sex trade, Osgoode Hall Law Journal, 42(1), 1-28.

Swigonski, M.E. (1994). The logic of feminist standpoint theory for social work research. Social Work, 39(4), 387-393.

Taylor, P. (1993). The texts of Paulo Freire. Buckingham: Open University Press.

Truong, T., Do, T., West, G., Durant, T. Jenkins, R., Pham, T. \& Valdiserri, R. (2004). Sex workers in Vietnam: How many, how risky? AIDS Education and Prevention, 16(5), 389-404. 
Valera, P., Gallin, J., Schuk, D., \& Davis, N. (2009). "Trying to eat healthy": A photovoice study about women's access to healthy food in New York City. Affilia, 24(3), 300-314.

Valera, R., Sawyer, R., \& Schiraldi, G. (2001). Perceived health needs of inner-city street prostitutes. American Journal of Health Behavior, 25, 50-59.

Van House, N. (2009). Collocated photo sharing, story-telling, and the performance of self. International Journal of Human-Computer Studies, 67, 1073-1086.

Vanwesenbeeck, I. (2001). 'Another decade of social scientific work on prostitution.' Annual review of sex research, 12, 242-289.

Vanwesenbeeck, I. (2005). Burnout among female indoor sex workers. Archives of Behavior, 34(6), 627-639.

Vaughan, K. (2005). Pieced together: Collage as an artist's method for interdisciplinary research. International Journal of Qualitative Methods, 4(1), 2-21.

Wahab, S. (1997). Let's talk about sex work: Feminisms, social work and the sex industry. Doctoral Dissertation. University of Washington, School of Social Work. Seattle, WA.

Wahab, S. (2002). For their own good?: sex work, social control and social work, a historical perspective. Journal of Sociology and Social Welfare, 24(4).

Wahab, (2004). Tricks of the Trade: What Social Workers Can Learn about Female Sex Workers through Dialogue. Qualitative Social Work, 3(2), 139-160.

Wahab, S. (2005). Navigating mixed theory projects: Lessons from a qualitative evaluation of Salt Lake City’s Prostitution Diversion Project. Affilia, 20(2), 203221. 
Walkowitz, D. J. (1999). Working with class: Social workers and the politics of middle class identity. Raleigh: University of Northern Carolina Press.

Wallace J, Weiner A, Steinberg A, Hoffmann B., \& Fielding C. (1992). Intravenous drug use, inconsistent condom use, and fellatio in relationship to crack smoking are risky behaviors for acquiring AIDS in streetwalkers. International Conference on AIDS. Jul 19-24.

Wallerstein, N. \& Bernstein, E. (1988). Empowerment Education: Freire's ideas adapted to health education. Health Education Quarterly, 15(4), 379-394.

Wang, C. (1999). Photovoice: A participatory action research strategy applied to women's health. Journal of Women's Health, 8(2), 185-192.

Wang, C. \& Burris, M. A. (1994). Empowerment through photo novella: Portraits of participation. Health Education Quarterly, 21(2), 171-186.

Wang, C. \& Burris, M. A. (1997). Photovoice: Concept. Methodology, and use for participatory needs assessment. Health Education \& Behavior, 24(3), 369-387.

Wang, C. \& Burris, M. A., \& Ping, X. Y. (1996). Chinese village women as visual anthropologists: A participatory approach to reaching policymakers. Social Science Medicine, 42(10), 1391-1400.

Wang, C., Cash, J., Powers, L. (2000). Who knows the streets as well as the homeless? Promoting personal and community action through photovoice. Health Promotion Practice, 1(1), 81-89.

Wang, C. \& Pies, C. (2004). Family, maternal, and child health through photovoice. Maternal and Child Health Journal, 8(2), 95-102.

Wang, C., \& Redwood-Jones, Y. (2001). Photovoice Ethics: Perspectives from Flint 
Photovoice. Health Education and Behavior, 28(5), 560-572.

Wang, C., Yi, W.K., Tao, Z.W., \& Carovano, K. (1998). Photovoice as a participatory health promotion strategy. Health Promotion International, 13(1), 75-86.

Watrin, R. (1999). Art as research. Canadian review of art education, 26(2), 92-100.

Wattsjohnson, Y. (2005). Articulating knowledge for transformation In F. Bodone (Ed.), What Difference does research make and for whom? New York: Peter Lang Publishing, Inc., 191-201.

Weber, S. (2008). Visual images in research. In G. Knowles \& A. Cole (Eds.) Handbook of the Arts in Qualitative Research: Perspectives, methodologies, examples \& issues (pp. 41-54). Los Angeles, CA: Sage Publications.

Weber, S. \& Mitchell, C. (2004). Chapter 10: Visual Artistic modes of representation for self-study. In J. Loughran, M. Hamilton, V. LaBoskey, \& T. Russell (Eds.), International handbook of self-study of teaching and teacher education practices. New York: Springer.

Weber, S. \& Mitchell, C. (2004). Art for accessibility: Art as activism; Art for reflexivity. Arts-Informed, 3(2), 17-19.

Weeks, M., Grier, M., Romero-Daza, N., Puglisi-Vasquez, M., \& Singer, M. (1998). Streets, drugs, and the economy of sex in the age of AIDS. Women and Health, 27, 205-229.

Weeks, M, Abbott, M., Liao, S., Yu, W., He, B., Zhou, Y., Wei, L., \& Jiang, J. (2007). Opportunities for women-initiated HIV prevention methods among female sex workers in Southern China. Journal of Sex Research, 44(2), 190-201.

Weiler, K. (1991). Freire and a feminist pedagogy of difference. Harvard Educational 
Review, 61(4), 449-474.

Weiler, K. (2003). Paulo Freire: On hope. Radical Teacher, 67, 32-35.

Weinberg, M. S., Shaver, F.M., \& Williams, C.J. (1999). Gendered sex work in the San Francisco Tenderloin. Archives of Sexual Behavior, 28, 503-521.

Weiner, A. (1996). Understanding the social needs of streetwalking prostitutes. Social Work, 41(1), 97-105.

Weitzer, R. (1991). "Prostitutes' Rights in the United States: The failure of a movement." Sociological Quarterly, 32(1), 23-41.

Weitzer, R. (2000). The politics of prostitution in America, In R. Weitzer (Ed.), Sex for sale: Prostitution, pornography, and the sex industry, New York: Routledge, 159180.

Weitzer, R. (2005). Flawed theory and method in studies of prostitution. Violence Against Women, 11(7), 934-949.

Weitzer, R. (2005). New directions in research on prostitution. Crime, Law \& Social Change, 43, 211-235.

Weitzer, R. (2006) The social construction of sex trafficking: A new moral crusade. Paper presented at the annual meeting of the American Sociological Association, Montreal Convention Center, Montreal, Quebec, Canada (August) Online $<$ PDF $>$ Retrieved October 10, 2006, from http://www.allacademic.com/meta/p103577 index.html

Williamson, C. \& Folaron, G. (2001). Violence, risk, and survival strategies of street prostitution. Western Journal of nursing research, 23(5), 463-475.

Wood, J. (1982). Communication and relational culture: Bases for the study of human 
relationships. Communication Quarterly, 30, 75-82.

Wood, E. (2000). Working in the Fantasy Factory: The attention hypothesis and enacting of masculine power in strip clubs. Journal of Contemporary Ethnography, 29(1), $5-31$.

Worth, S., \& Adair, J. (1972). Through Navajo Eyes: An Exploration in Film Communication and Anthropology. Bloomington, IN: Indiana University Press.

Wyatt, D., Bloom, F., \& Solmai, A. (2000). Dilemmas in Conducting Qualitative Sex Research in Applied Field Settings. Health Education \& Behavior, 27(1), 10-23.

Young, A., Boyd, C., \& Hubbell, A. (2000). Prostitution, drug use, and coping with psychological distress. Journal of drug issues, 30(4), 789-800.

Zatz, N. (1997). Sex work/ sex act: Law, labor and desire in constructions of prostitution. Signs, 22, 277-308. 


\section{Attention Sex Workers in Portland, OR: We are looking for your images and voices!!!}

Are you:

- Female

- 18 years or older

- Currently working in the sex industry for the past six months (including working on the streets, at an escort agency, as a dancer, a dominatrix, an erotic masseuse, or a model in a private booth)

- Engaged in sex work (defined as the exchange of sex or sexual stimulation for money or other forms of payment)

This research study:

- This is an Arts-Based Photovoice Research Study with Sex Workers!!!

- Photovoice is where we give YOU cameras to document your needs and aspirations

- This study will result in an art-exhibit of photographs and stories

The goals of Photovoice are:

* to enable people to record and reflect their community's strengths and concerns

* to promote critical dialogue and knowledge about important community issues through large and small group discussions of photographs

* to reach influential community advocates and people who can be mobilized for change

- We are interested in ART AS ACTIVISM!!!

Your participation will involve:

- Attending a 1-1 $1 / 2$ hour photovoice training session

- Taking a roll of 36 photographs of what is important to you

- Participating in a 1 1 $\frac{1}{2}-2$ hour individual dialogue session about your photos

\section{* You will be paid $\$ 50$ for your time and the $35 \mathrm{~mm}$ camera is yours to keep!}

\section{If you are interested in learning more about this study, please contact: Moshoula (503-725-5028) or Crystal (503-957-9556)}

(If we do not answer, please leave your name, a telephone number, and a time when we can call you back) 


\section{Appendix B: Social Service Agency Recruitment Letter}

Today's Date

To whom it may concern:

I am a graduate student at Portland State University (PSU) and a Principal Investigator conducting research with sex workers in Portland, Oregon. I would like to tell you a little about my study so that you can refer any potential participants and post the enclosed flyers about the study at your agency.

The purpose of this study is to understand the needs and aspirations of sex workers, using the arts-based research method called photovoice. According to Caroline Wang and Mary Ann Burris, photovoice is a process by which people can identify, represent, and enhance their community through photography. Photovoice entrusts cameras to the hands of the people to enable them to act as recorders, and potential catalysts for change in their own communities. It uses the immediacy of the visual image and accompanying stories to provide a voice and to promote an effective, participatory means of sharing individuals' experience and expertise.

The use of photovoice in this study is to enable female sex workers in Portland to photograph their lives as a way of documenting their perspectives, strengths, and struggles. The goal is to promote critical dialogue about the issues of concern to sex workers through discussions of their photographs, and to reach influential community advocates and the broader public about their concerns and aspirations through an art exhibit of their photographs.

Those individuals who are eligible for our study are:

- Female and 18 years or older

- Currently working in the sex industry for the past six months (including working on the streets, at an escort agency, as a dancer, a dominatrix, an erotic masseuse, or as a model in a private booth)

- Engaged in sex work (defined as the exchange of sex or sexual stimulation for material goods like money, drugs, food, transportation, or rent)

All participants will be compensated for their time. The Human Subjects Committee of PSU has strict guidelines that I will follow to protect the confidentiality and the rights of the women who participate in this study. If you have any questions about these procedures or want more details about the study, please do not hesitate to call me, Moshoula, at 503-725-5028, or my community advisor in this study, Crystal, at (503-9579556). Thank you for your time and consideration.

Sincerely, Moshoula Capous Desyllas, PSU School of Social Work Crystal Tenty, PSU Conflict Resolution Program 


\section{Appendix C: Telephone Recruitment and Screening Script}

*Making a call in response to a message left by a potential study participant

If not available:

Investigator: Hello, may I please speak to ?

Response: No, she is not in right now. Can I take a message?

Investigator: Sure, could you tell her Moshoula returned her phone call. I can be reached at 503-725-5028. Thank you!

If available:

Investigator: Hello, may I please speak to ?

Response: $\quad$ This is she.

Investigator: This is Moshoula and I am calling you back regarding the research study. You left a message for me yesterday about being interested in hearing more about this study. Is this a good time to talk?

If no, not a good time to talk:

Response: No, actually, it isn't a good time to talk.

Investigator: When would be a better time to call you back?

Response: (Day) and (Time) will work better.

Investigator: Okay, I will call you back on (Day) at (Time).

If no, not interested at all anymore:

Response: I changed my mind; I don't want to be in the study.

Response: Oh, okay. Thank you for your time. Good-bye.

If, yes, a good time to speak:

Response: Yes, actually this is a good time to talk.

Investigator: Okay. I am a graduate student at Portland State University and I am looking for female sex workers to participate in my doctoral research study. The purpose of this study is to understand the needs and aspirations of sex workers in Portland by giving women a camera so that they can photograph what is important to them and other sex workers. This study using an arts-based research method called photovoice. The goals of photovoice are to enable people to record and reflect their personal and 
community's strengths and concerns through taking photographs, to promote critical dialogue and knowledge about important issues through discussion of their photographs, and to reach policy makers and influential community advocates who can influence positive social change through public forums and showing of their photographs. Does this sound like something you might be interested in?

If no, not interested at all anymore:

Response: Actually, this study isn't really something I am interested in.

Response: Oh, okay. Thank you for your time. Good-bye.

If, yes, still interested:

Response: Yes, this sounds interesting. Go on...

Investigator: Great. I wanted to ask you a few questions to make sure that you are eligible for this study. Would you be willing to answer a few questions related to your age, gender, and your involvement in the sex industry, so that I can determine if you are eligible to participate in the study? Please know that you are free to say no, and not answer any questions you do not wish to answer.

If she does not want to answer any questions:

Investigator: It's okay; I understand your desire not to answer my question. Would you prefer I continue to describe the research project or do you prefer not to answer any questions at all?

$\rightarrow$ If she would rather not answer any questions at all, I will thank her for her time.

$\rightarrow$ If she wants me to continue discussing study, I will provide more information, and then return to the this part where I asker her permission to ask her the eligibility questions.

If she is willing to answer the questions:

Response: Sure, I don't mind answering your questions.

Investigator: Thank you. I am going to review the criteria for women to be in the study. After I go over them, please tell me if they are all true for you. If one or more of the criteria are not true for you, just answer no. Feel free to ask questions. Does this sound okay to you?

Response: Yes. I am ready.

Investigator: The first criteria is a woman needs to be eighteen years or older. The second criteria is a woman's gender since birth is female. The last criteria is a woman has been involved in sex work in the past six months in 
Portland. In this study, sex work is defined as the exchange of sex or sexual stimulation for money or other forms of payment. Please say "yes" if all of these criteria fit you or "no" if one or more of them does not fit you.

If she does not meet the eligibility criteria:

Investigator: Thank you. Unfortunately, this study is not a good fit since I am looking for women who can meet a specific set of criteria. Thank you for taking the time to talk to me today. I appreciate your interest in this study and your willingness to help me.

If she meets the eligibility criteria:

Investigator: Thank you. Based on your answer to these three questions, you fit the eligibility criteria for this study if this is something you are interested in. I wanted to talk to you a little bit more about this study and what your participation would entail. If you have any questions throughout, please feel free to ask them anytime. If you agree to participate in this study, you will attend a 1-1 $1 \frac{2}{2}$ hour long training workshop on the photovoice method and the ethics behind taking pictures in your communities. Then, you will be a given a $35 \mathrm{~mm}$, automatic camera and a roll of 36 -exposure, black \& white film to photograph objects, places, things, and people that are important to you with regards to your needs and aspirations. I will meet with you to pick up the camera for developing. Once the photographs are developed, we schedule a date for an individual dialogues session. You will decide on a private, comfortable place (either at my home, your home, or anywhere else that is convenient for you) where we can hold a $1-1 \frac{1}{2}$ hour long dialogue session where you will talk about the stories behind the 8-10 photographs of your choice. We will also discuss what description you would like to accompany the photographs. You will be given one set of prints to keep and you will receive the negatives to keep once this study is over. For your participation in these activities, you will be compensated you $\$ 50$ in cash in appreciation for your time and efforts. You will also get to keep the camera. Also, I will invite you to participate in an optional brief follow-up meeting with me to clarify anything you said during the individual dialogue session; this to make sure that I accurately portray your experiences in my analysis for this study. Your participation in this study will last over a period of 2 to 3 months. Do you have any questions so far?

Investigator: In addition, if are interested, after our individual dialogue session you will also be invited to participate in an optional 11/2-2 hour group dialogue session where all of the participants in the study will be invited to discuss the themes that emerged from the photos and the ways in which to present everyone's photos in an art exhibit in order to reach influential community advocates and policy makers. You will also be invited to this art exhibit of 
all of the participants' photographs from this study. You could choose whether to have your photos in the art exhibit.

I also want to add that you are free to contact me throughout this study at any time. You are also free to withdraw from the study at any time. It's possible you could feel some discomfort or embarrassment participating in the dialogue sessions because the stories behind your photographs may be very personal. However, you do not have to share anything you wish not to share. Those things we speak about in the individual dialogue session will be kept confidential. I will not use your real name in this study, but rather, at the start of the photovoice training workshop you will be asked to choose a pseudonym or make up a name for yourself. Again, I want to emphasize that your participation in this study is voluntary and you may stop participating at any time. Do you have any questions?

Investigator: Does this study sound like something you would like to participate in?

If, no, not interested after hearing about the study:

Investigator: Thank you for your time. I appreciate your taking the time to listen. Goodbye.

If, yes, interested after hearing about the study:

Investigator: Could you meet with me 15 minutes prior to the workshop training session to be held at (community location) on (date) at (time) so that we can go over the study consent form in person and so that you can sign it if you still would like to participate in this study?

Response: $\quad$ Sure, I can meet you there at (time) on (date).

Investigator: Great! Do you have any other questions for me? Do you have my phone number so that you can call me if you have any questions? What is the best way to contact you?

Response: (I can be reached at one of these two numbers...)

Investigator: Great! So I will see you on (date) at (time). Thanks again for your time! 


\section{Appendix D: Participant Consent Form}

Images \& Voices: An Arts-based Qualitative Study Using Photovoice to Understand the Needs \& Aspirations of Sex Workers in Portland, Oregon

Principal Investigator

Moshoula Capous Desyllas, Ph.D. student

PSU School of Social Work

PO Box 751

Portland OR 97207

(503) $725-5028$

\section{Community Advisor \& Research Partner}

Crystal Tenty, Masters Student

PSU Conflict Resolution Program

P.O. Box 751

Portland OR 97207

(503) 957-9556

\section{Purpose of the study}

The purpose of this study is to understand the needs and aspirations of sex workers in Portland, Oregon from their own point of view, and to bring forward the knowledge and experiences of their everyday lives. The objective of this study is to use the arts-based method of photovoice to promote discussion about the issues of concern to sex workers. Following the study, an art-exhibit of photographs will be presented to reach influential community advocates and the broader public about these concerns and aspirations through an art exhibit of their photographs.

\section{Study Procedures}

If you take part in this project, you will be asked to take photographs of the images that are important to you. You will also be asked to attend a training workshop and an individual dialogue (discussion) session. The training workshop and individual dialogue session will be held in a community location that is private, convenient and acceptable to you.

The training workshop will explain the purpose and procedures of the project; underlying issues about the use of cameras, power, and ethics; potential risks to participants; and how to minimize these risks. You will be given a camera with film and there will be discussion about themes for your photographs. In the event that your camera is lost or broken, we will replace it for you. The training workshop will last approximately $1-1 \frac{1}{2}$ hours.

After you take your photographs, I will meet with you to pick up your film for developing. Then, we will schedule an individual dialogue session to talk about your photographs and the stories that you want to share about them. You will choose which photos to share and this individual meeting will last approximately $1 \frac{1}{2}-2 \mathrm{hrs}$. A few weeks after our meeting, you will also be invited to give feedback on my summary of your comments to be sure I understood what you said. This is optional; you do not have to agree to give me the feedback in order to participate in the study.

You also will be invited to an optional group dialogue session with other participants in the study. At this session, we'll talk about the photographs and plan for an art exhibit to educate the community about sex workers' needs and aspirations. This group meeting will last $1 \frac{1 / 2}{2}-2$ hours and will be held in a community location that is private and convenient for you. Attending this group session is optional; you do not have 
to participate in order to be in the study. If you decide to have any of your photos included in the exhibit, I'll ask you to give permission by signing a separate PSU photo release form. I'll also ask you to present a PSU photo release signed by any person shown in your photograph(s).

With your permission, I will audio-tape record both our individual meeting and the group meeting so that the results are more accurate and better represent your actual words. This study will take place over a period of 2 to 3 months (depending on your choice to participate in the optional activities). At the end of the study, you will be invited to a community art exhibit of the photographs taken.

\section{Risk, Stress and Discomfort}

The use of cameras to photograph your life experiences and issues of concern may have potential risks, such as physical harm and loss of privacy. It is important that others' privacy and rights are respected. You will be advised to always obtain verbal consent before taking any photographs of other people. If you think you may want to use a person's photo in the exhibit, I'll ask you to have them sign a PSU photo release form. Due to the illegal nature of sex work, no photographs possibly showing any illegal or improper behavior will be accepted for discussion in the research project. In addition, you may feel some discomfort or embarrassment from participating in the dialogue sessions because the stories behind your photographs may be very personal. However, you do not have to share or discuss anything you do not wish to talk about and you are free to stop the dialogue at any time. If you experience any stress or discomfort during your participation in this study, you will be provided with referrals to specific agencies that support women working in the sex industry.

\section{Benefits}

The benefits to participating in this study are: (1) you will receive $\$ 50$ in cash after completing the individual dialogue session and you will get to keep the camera and one set of photographs, (2) you will receive a $\$ 5$ Fred Meyer gift card if you participate in the optional group dialogue session, (3) you will have the opportunity to voice your concerns through your photographs to influential community advocates, and (4) your participation will contribute to the understanding of sex workers' needs and aspirations in Portland, Oregon.

\section{Costs}

The training workshop and dialogue sessions will be conducted at no cost to you. The camera, film and development of the film will all be provided for you.

\section{Confidentiality}

All information that you provide in this study will be kept strictly confidential. If you show me photographs of people, I will not ask any identifying information about them (e.g. name, address, etc). All participants will choose a pseudonym (made up name) in order to be anonymous. Only the researcher will have your real name, and this will be kept private and separate from the research data. While all participants in the group dialogue session will be asked to keep what is said in the group discussion private, we 
cannot guarantee that others in the group will not share what is said or shown.

Your name and consent form will be kept separate from the photographs and dialogue transcripts and data to ensure that you cannot be identified. If you agree to participate, all identifying information will be removed from the audio-tape transcripts so that your responses remain confidential. In other words, the transcripts will not include any identifying information and the audio tapes will be destroyed once they are transcribed.

The information gathered, including audio-tapes, photographs, and transcripts will be kept in a locked storage cabinet or password protected computer at the office of the researcher in the School of Social Work. The researcher will be the only person who has the key for this locked storage cabinet or password for the computer. The exceptions of confidentiality are if you share information with me about the abuse of a child, which by law, has to be reported to the appropriate agency.

Some of your comments may be included in the reports written to summarize what has been learned from this study, however, the summary will not include any identifying information about you. Neither your name nor your identity will be used for any publication or publicity purposes without your written permission.

\section{Voluntary Participation/Withdrawal from the Study}

Your decision to participate in this study is strictly voluntary. You may refuse to participate or you may withdraw from the study at any time without any penalty or consequence.

\section{$\underline{\text { Statement of Consent }}$}

The study described above has been explained to me. The risks and benefits have been explained to me. I understand that the information regarding my personal identity will be kept confidential. I agree to not share information that I hear from others in the optional group dialogue session. I understand that I will be given a copy of this consent form after signing it. I understand that my decision to release my photographs for publication or use in public forums is voluntary and that I may choose to withdraw my permission at any time. I freely agree to release my photographs or only certain specified photographs for use in this research study.

I have read this consent form and I have had the opportunity to discuss this study with the researcher. I have had my questions answered in a language I understand. If I have questions later on about the research I can ask one of the Principal Investigators, Moshoula Capous Desyllas, or Crystal Tenty, who are listed on this consent form or I can contact the Human Subjects Research Review Committee, Office of Research and Sponsored Projects, 600 Unitus Bldg., PSU, 503-725-4288.

Signature of Participant

Printed Name of Participant
Date

Witness 


\section{Appendix E: Project Summary Handout}

\section{Purpose and Background}

The Principal Investigator, Moshoula Capous Desyllas, a Ph.D. student in the School of Social Work at Portland State University and the co-facilitator, Crystal Tenty, a Master's student in the Conflict Resolution Program at Portland State University, are doing a study on the needs and aspirations of sex workers in Portland, Oregon using the arts-based, qualitative research method of photovoice.

\section{What is an arts-based research?}

Arts-based research makes use of the diverse ways of knowing and experiencing in the world. It aims to reach a broad audience, beyond the university. Arts-based research has the potential for offering ways of re-visioning issues that are simply not possible through descriptive language. Three main goals of arts-based research are:

(1) Social activism by giving voice to the powerless and silenced

(2) Making connections between research and lived experience

(3) Making meaning through multiple senses and medium

\section{What is photovoice?}

According to Caroline Wang and Mary Ann Burris, photovoice is a process by which people can identify, represent, and enhance their community through photography.

Photovoice entrusts cameras to the hands of the people to enable them to act as recorders, and potential catalysts for change in their communities. It uses the immediacy of the visual image and accompanying stories to provide a voice and to promote an effective, participatory means of sharing individuals' experience and expertise.

The use of photovoice in this study is to enable female sex workers in Portland to photograph their life as a way of documenting their perspectives, strengths, and struggles. The goal is to promote critical dialogue about the issues of concern to sex workers through discussions about their photographs, and to reach influential community advocates and the broader public about their concerns and aspirations through an art exhibit of their photographs. 


\section{Appendix F: Training Workshop Session Curriculum}

(Duration: 1-11/2 hours; Location: Convenient community location chosen by participants)

The individual dialogue session will include an overview of the goals and purpose of photovoice and the procedures of the project; underlying issues about the use of cameras, power, and ethics; potential risks to participants; and how to minimize these risks. Participants will be given a camera with film and will be given camera tips to keep in mind while taking photographs. There will be discussion about themes to focus the photographs on. The training workshop will last approximately $1-1 \frac{1}{2}$ hours.

Prior to Beginning:

- Consent forms will be reviewed with participants 15 minutes prior to start of training workshop.

- Key elements will be highlighted with participants (i.e. project rationale, study procedures, timeline, risk, safeguards, voluntary nature of the study and rights to withdrawal without penalty)

- Individual questions will answered and then those individuals interesting in participating will sign the consent form prior to beginning Training Workshop Session.

Introduction \& Purpose of the Project:

- Introductions of Principal Investigator and Co-facilitator

- Project Summary Handout (Appendix E)

- Emphasis on the shared power that the community advisor/co-facilitator and I have participants. This shared power will entail a joint ownership of the research project, a collaborative, participant-based analysis of the photographs, group efforts for organizing an art exhibit of their photographs, and a collective orientation toward community action

- Ice breaker activity: Sex workers making a difference-perhaps ask them if they think they are making a difference- why, how, why not...

\section{Dialogue and Discussion:}

- Establish group ground rules for discussion

- Ask group what is photography, what does it mean to them- conveys information, captures point in time, etc.

- Brief background of photography as a mechanism for social change

- Power, authority and responsibility that one has with holding a camera

- Importance of respecting the rights and privacy of others

- Always obtaining verbal approval from an individual before taking their photograph

- Asking permission to sign PSU photo release for their photo to be exhibited

- Ways to approach someone with a camera (Wang \& Burris,1997) 
(a) What is an acceptable way to approach someone to take his or her picture?

(b) Should someone take pictures of other people without their knowledge?

(c) To whom might one wish to give photographs, and what might be the implications? (d) When would one not want to have a picture taken?

- Giving back photos to the community and always obtaining verbal approval from those individuals who may appear in the photographs

Distribute:

- One used $35 \mathrm{~mm}$ film-based camera with a flash feature to each participant

- One roll of 36-exposure black-and-white (C-41 processing) film to each participant

Discuss and Review:

- Mechanical aspects of camera and photographic tips to successfully take pictures (Appendix G)

- Discussion on close-ups and angles, different ways to photograph a group of people, posed and un-posed pictures, and how symbols of the community or culture might be photographed

- Appropriateness of the two themes: needs and aspirations for taking their photographs

(Participants will have the option to refine, substitute, eliminate, add, or redevelop any or

all of the themes posed)

- Reasonable timeline for taking their photographs

- Any final questions? 


\section{Appendix G: Tips for Using a Camera \& Taking Photographs Successfully}

Parts of the camera:

* View finder, lens, shutter release, flash, dial to bring up the next picture

Protecting the camera:

Keep camera away from water, sand, extreme heat/cold

\section{Taking a photograph:}

Keep fingers away from the lens and flash

* Hold steady when pressing the shutter release to take pictures to avoid blurry pictures

* Stand at least 3 feet from your subject, or it will be a blurry picture

* Keep the sun behind you when outside

* When in doubt, use your flash

\section{Use of creativity:}

* Explore different angles

* Alternate different distances from your subject

- Consider both posed and unposed pictures

Think about symbols of the community or culture that might be photographed 


\section{Appendix H: Demographic Data Form}

(Data to be collected during the individual dialogue session)

Date:

Chosen Pseudonym:

Age of participant:

Self-described ethnicity:

Educational Experience:

Years working in the sex industry:

Sector of employment in the sex industry:

Hours of work per week:

Number of children:

Relationship Status:

Anything else you would like to share with me or include in your short biography: 


\section{Appendix I: Individual Dialogue Session Guide}

(Duration: 1 1/2-2 hours; Location: Convenient community location chosen by participants)

The individual dialogue session will be around the participants' photographs. It will last approximately $1 \frac{1 / 2}{2}-2$ hours and will be audio-tape recorded and transcribed.

- Each participant will choose 8-10 photographs to discuss (4-5 photographs related to needs \& 4-5 photographs related to aspirations)

- The questioning acronym PHOTO will be used to contextualize the meaning of each of the participants' chosen photos.

- The acronym PHOTO (Hussey, 2006) asks the following:

6. Describe your Picture?

7. What is Happening in your picture?

8. Why did you take a picture $O$ f this?

9. What does this picture Tell us about your life?

10. How can this picture provide Opportunities for us to improve life (with regard to sex workers' lives in Portland, Oregon)?

i. After discussing each photo in this way, using the PHOTO acronym, participants will be asked:

1. Would you like to say anything else about the photograph that might not have been captured by the five questions?

2. What is missing, if anything, from each photograph? 


\section{Appendix J: PSU Photo Release Form}

I give my permission for my photograph(s), both in printed and electronic form, to be used in publications, community art exhibits, and presentations for educational purposes.

Date:

Printed name:

Signature:

Witness: 


\section{Appendix K: Group Dialogue Session Guide}

(Duration: 1 1/2 -2 hours; Location: Convenient community location chosen by participants)

The optional group dialogue session will provide the opportunity for participants to share their photographs with other sex workers, collaboratively synthesize their themes, and plan for the community art exhibit of their photographs. It will last approximately $1 \frac{1}{2}-2$ hours and will be audio-taped and transcribed.

\section{Prior to Beginning:}

- Key elements will be highlighted with participants (i.e. project rationale, group dialogue procedures, timeline, risk, safeguards, voluntary nature of the study and rights to withdrawal without penalty)

- Individual questions will answered

- Photo Release form will be signed

Dialogue Questions Guide:

The questions that will be asked of participants are as follows:

1. Are there are any photographs and/or themes that you would like to share with the other participants in this study related to community needs and personal aspirations?

2. What have you been thinking about since the individual dialogue session in regards to things you said or new things you would like to talk about?

3. What recommendations do you have to promote social equality for addressing the needs of sex workers in Portland?

4. If you had the undivided attention of politicians, policymakers, educators, social workers, community members, friends and neighbors, what would you say to them about your needs and concerns as a sex worker living in Portland?

5. What would you share with them about your aspirations?

6. What has this process (of using the photovoice method to illustrate and express your experiences) been like for you?

\section{Discussion:}

a. As they discuss their photographs, the group will collectively identify issues, themes, theories that emerge from all of their photographs

b. This process will give participants the chance to voice individual and collective experiences, and to reflect on issues that might not have been addressed in the individual dialogues. 
c. The themes that participants come up with for each research question will be written on a poster board and tacked to the wall.

d. These agreed upon themes will be compared to the investigator's cross-case analysis

\section{Community Art Exhibit Dialogue:}

- Collaborative selection of photographs and stories based on collective themes

- How do participants want to document their stories and which photographs will be displayed for the art exhibit

- Will we have captions and titles next to photographs? Short stories next to photographs?

e. Participants will also have a discussion around how to present photographs and findings in a community art exhibit

f. Discuss art exhibit dates, location, guest list, and advertisement for exhibit

\section{Publication Dialogue:}

g. Discuss participants' interest in and possibilities for writing news paper articles, internet blogs to be placed on SWOC webpage, articles for 'zine, academic journal articles 


\section{Appendix L: Participant Contact Sheet}

(To be kept separate from data)

Name:

Telephone \#:

Best time to call:

Name:

Telephone \#:

Best time to call:

Name:

Telephone \#:

Best time to call:

Name:

Telephone \#:

Best time to call:

Name:

Telephone \#:

Best time to call:

Name:

Telephone \#:

Best time to call:

Name:

Telephone \#:

Best time to call:

Name:

Telephone \#:

Best time to call:

Name:

Telephone \#:

Best time to call:

Name:

Telephone \#:

Best time to call:
Interested in study: yes no

Left message on:

Left message on:

Interested in study: _ yes _ no

Left message on:

Left message on:

Interested in study: __ yes __ no

Left message on:

Left message on:

Interested in study: __ yes __ no

Left message on:

Left message on:

Interested in study: _ _ yes _ no

Left message on:

Left message on:

Interested in study: __ yes __ no

Left message on:

Left message on:

Interested in study: yes no

Left message on:

Left message on:

Interested in study: yes no

Left message on:

Left message on:

Interested in study: __ yes __ no

Left message on:

Left message on:

Interested in study: __ yes _ _ no

Left message on:

Left message on: 
Appendix M: Recruitment Flyer with Graphic

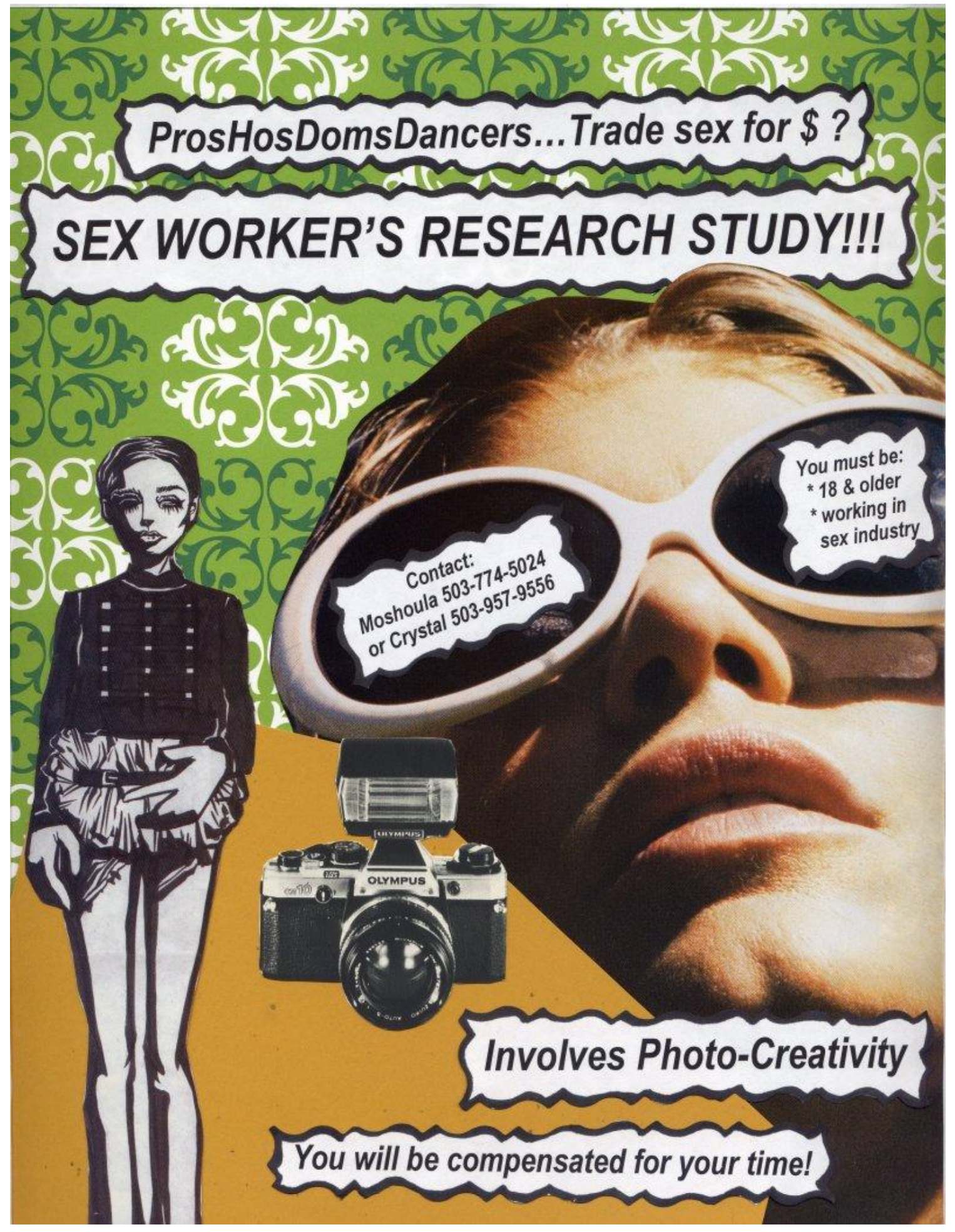


Appendix N: Art Exhibit Flyer

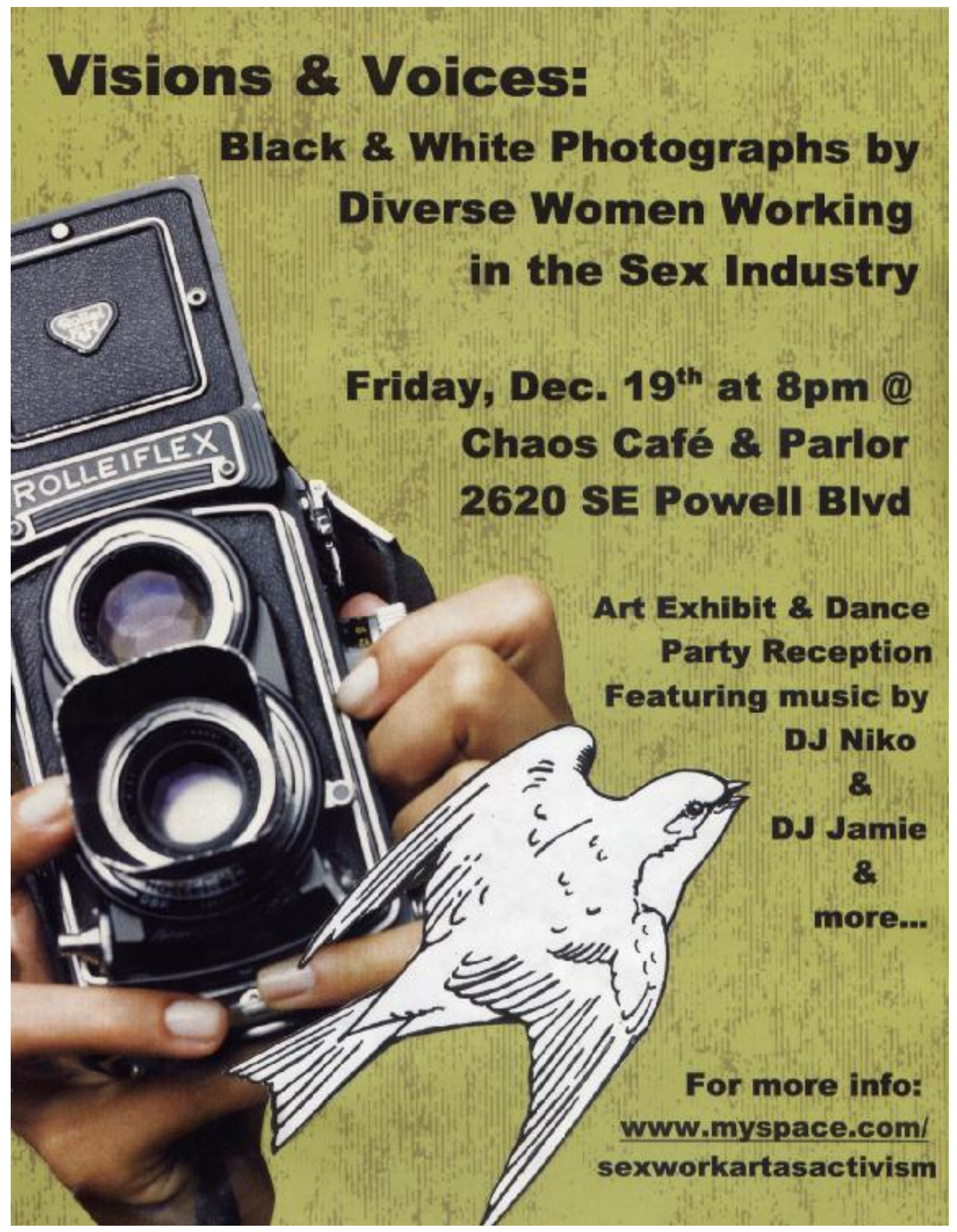

